\title{
AN EXPLORATION OF FACTORS RELATED TO DESIGN IMPLEMENTATION IN THE CANADIAN FEDERAL PUBLIC SERVICE by
}

Samantha Lovelace

A thesis submitted to the Faculty of Graduate and Postdoctoral Affairs in partial fulfillment of the requirements for the degree of

Master of Design

in the

School of Industrial Design

Carleton University

Ottawa, Ontario

(C) 2020, Samantha Lovelace 


\section{Abstract}

When government organizations are able to turn a good design into something that people can use, the potential for benefit is high. But in order to implement that design, change has to happen.

There are theories in change management literature that focus on factors that may determine if the people within an organization, or the organization itself, might be able to make change happen. Given the relationship between design and change, change management theory is likely an important consideration during the design process.

This case study examines formulas proposed to explore an organization's ability to change found in change management literature, uses participant inquiry to improve our understanding of factors that may affect the success of design projects within the Canadian Federal Public Service, and aims to find a formula that could be used during the design process to explore factors related to design project success. 


\section{Acknowledgements}

I would like to extend the greatest amount of thanks and acknowledge the invaluable support of my thesis advisor Chantal Trudel from Carleton's School of Industrial Design and my co-advisor, Dr. Paul Thibaudeau of Carleton's Department of Sociology and Anthropology and colleague at the Government of Canada. Without their tireless encouragement, I would never have completed my thesis. I would also like to thank my Committee, Linda Duxbury from the Sprott School of Business and WonJoon Chung from Carleton's School of Industrial Design, for their feedback and contribution to the evolution of this thesis.

A most gracious thank you is due to all of the participants who very generously offered to take the time to explore and share their stories with me. Without their support, this research would not have been possible. I hope that it can serve to make their jobs easier in the future and give them a tool that might begin to help make their public service design projects successful.

I want to extend a special thank you to all the people who liked, shared and talked about my study and provided encouragement along the way. And a thank you to my colleagues, friends and family who provided feedback on my writing and research, helped me pilot the study and listened as I worked through difficult ideas and challenges.

Finally, I would like to thank Jamie and Eleanor Brown for letting me take time away from other things to satisfy my curiosity and the itch to do something I'd never done before. You've both been along for this crazy ride from very beginning and I'm so happy to be able to share this with you now that we're here. 


\section{Table of Contents}

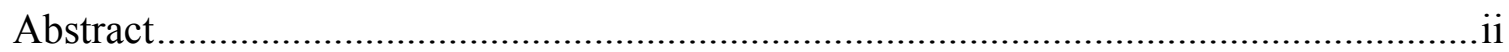

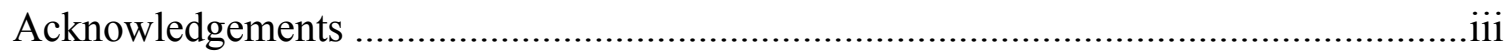

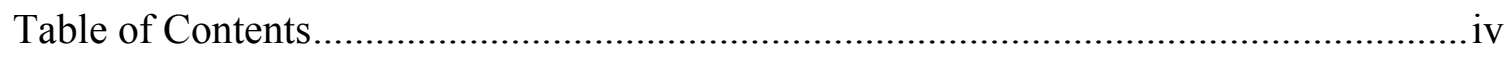

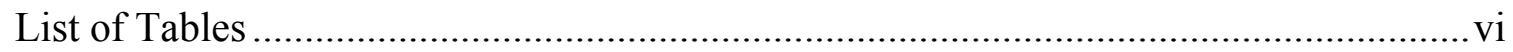

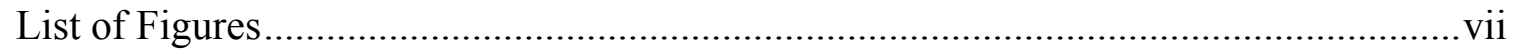

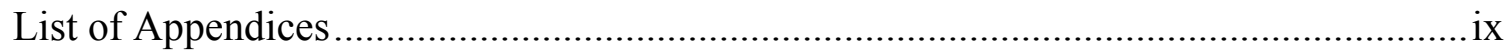

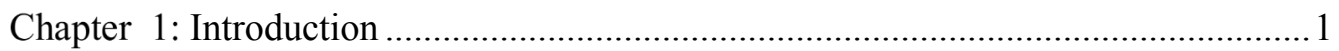

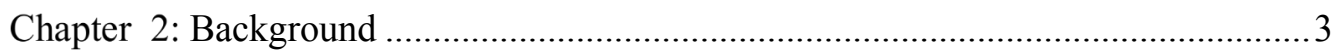

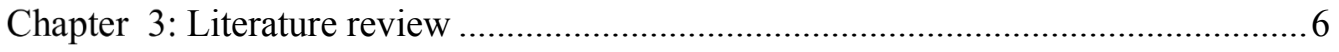

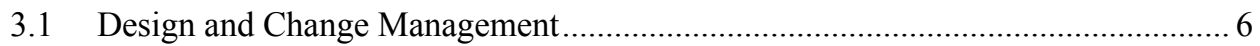

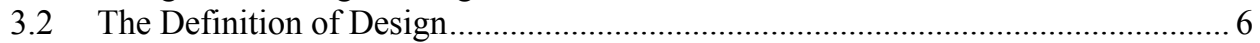

3.3 The Potential for Design in Government ……..................................................... 7

3.4 Realizing the Potential of Design ...................................................................... 10

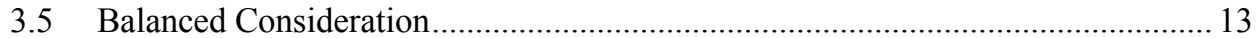

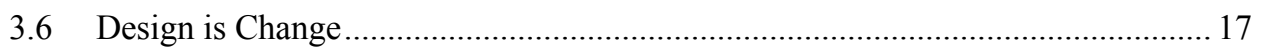

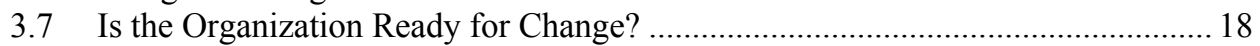

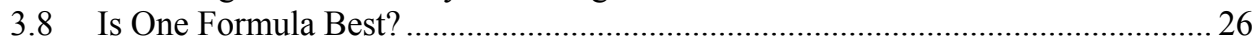

3.9 Method 1: Content Analysis of Formulas in Change Management Literature ....... 30

3.10 Design, The Public Service and Formulas from Change Management Literature. 39

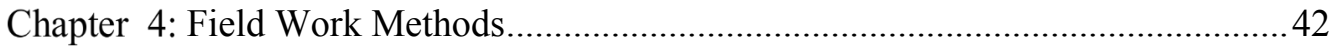

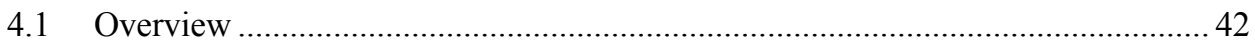

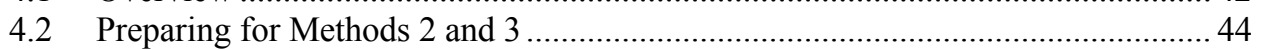

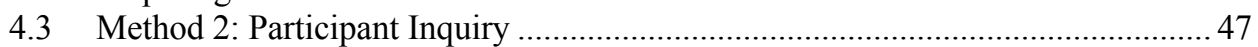

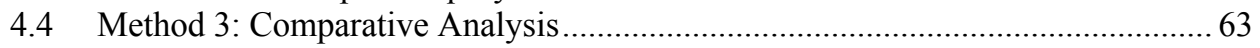

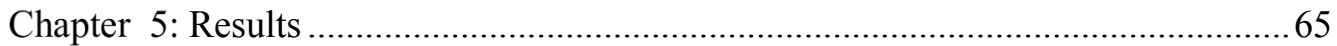

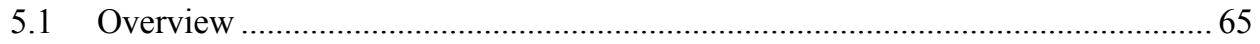

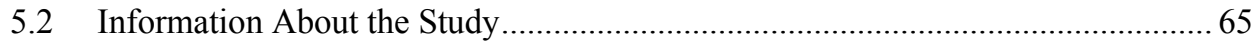

5.3 Preliminary Results Generated from the First and Second Cycles of Coding ....... 68

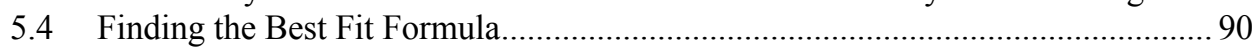

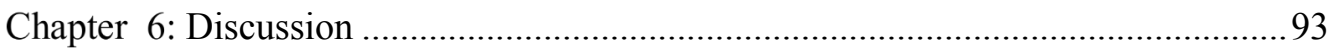

6.1 Factors that May Contribute to Successful Design Implementation in the Canadian

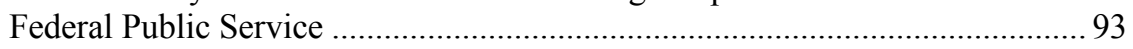


Running Header: AN EXPLORATION OF FACTORS RELATED TO DESIGN

IMPLEMENTATION IN THE CANADIAN FEDERAL PUBLIC SERVICE

6.2 A Formula to Support Design Implementation in the Government of Canada...... 93

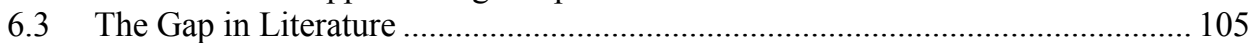

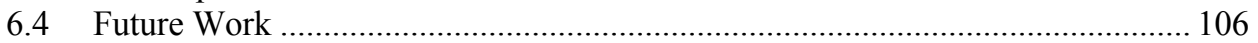

6.5 Limitations and Considerations for Future Studies ............................................ 109

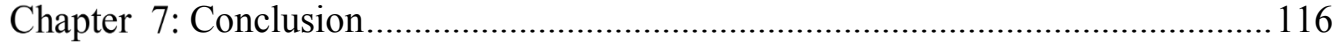

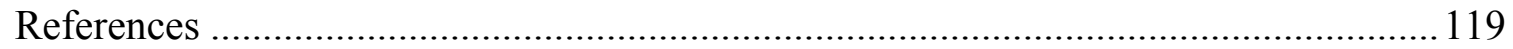

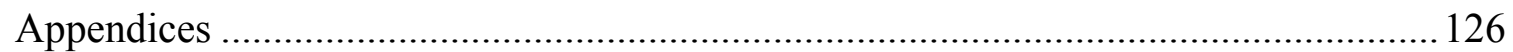




\section{List of Tables}

TABLE 1. THE FIRST 5 FORMULAS FROM LITERATURE THAT WERE INCLUDED IN THE INVENTORY OF 12 FORMULAS FROM CHANGE MANAGEMENT LITERATURE EXPLORED IN THIS THESIS.

TABLE 2. THE NEXT 4 FORMULAS FROM LITERATURE THAT WERE INCLUDED IN THE INVENTORY OF 12 FORMULAS FROM CHANGE MANAGEMENT LITERATURE EXPLORED IN THIS THESIS

TABLE 3. THE LAST 3 FORMULAS FROM LITERATURE THAT WERE INCLUDED IN THE INVENTORY OF 12 FORMULAS FROM CHANGE MANAGEMENT LITERATURE EXPLORED IN THIS THESIS...................2 25

TABLE 4. THE THEMES THAT EMERGED FROM THE CONTENT ANALYSIS, THEIR DESCRIPTIONS AND MAGNITUDE.

TABLE 5. AN EXAMPLE OF GROUPS THREE PATtERn CODES COULD HAVE BEEN ORGANIZED INTO. ....... 62

TABLE 6. A TABLE ILLUSTRATING AN EXAMPLE OF HOW I ANSWERED THE QUESTION OF "WHAT HAS TO

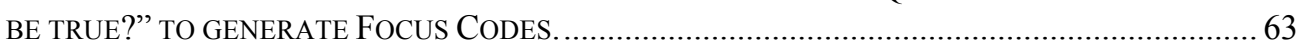

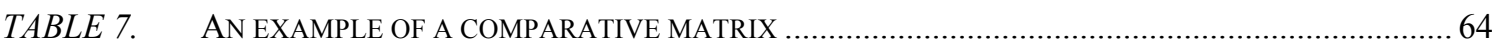

TABLE 8. THE TOP 6 PROVISIONAL CODES FOUND IN PARTICIPANT DATA................................................ 69

TABLE 9. PROVISIONAL CODES THAT ACCOUNTED FOR LESS THAN 1\% OF CODED FACTORS. ................. 70

TABLE 10. WORDS THAT WERE USED IN IN VIVO CODING MOST OFTEN. ................................................. 71

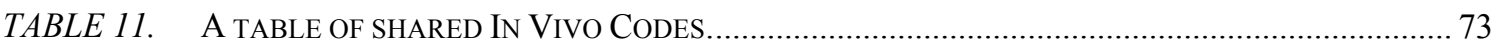

TABLE 12. The top 5 Provisional Codes Simultaneously Coded with In Vivo Codes. ............... 74

TABLE 13. THE TOP 6 PATtern CODES BY AGGREgATEd IN Vivo ReFERENCES..................................... 80

TABLE 14. THE VOLUME OF IN VIVO CODED REFERENCES BY FIRST CYCLE CATEGORY .......................... 80

TABLE 15. THE VOLUME OF IN VIVO CODED REFERENCES WITHIN THE EXPERTISE AND TIME TO DO THE

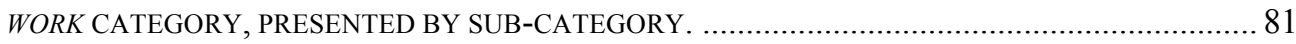

TABLE 16. THE VOLUME OF IN VIVO CODED REFERENCES WITHIN THE LEADERSHIP AND TEAMWORK

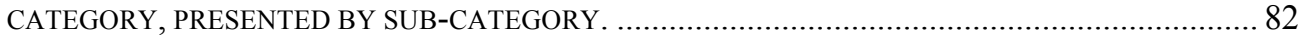

TABLE 17. THE FINAL CATEGORIES UNCOVERED IN RESEARCH AND THEIR MAGNITUDE ............................ 85

TABLE 18. A COMPARATIVE MATRIX EXPLORING THE RELATIONSHIP BETWEEN THE THEMES FOUND IN THE PARTICIPANT DATA AND THE FACTORS PROPOSED IN THE FORMULAS FROM THE LITERATURE. 


\section{List of Figures}

FIGURE 1. A PROPOSED MODEL OF 'GOOD DESIGN' BASED ON CHARACTERISTICS IDENTIFIED IN LITERATURE.

FIGURE 2. AN EXAMPLE OF THE FIRST CYCLE CODING PROCESS USED WHILE EXPLORING FRAMEWORKS FROM LITERATURE USING AN EXCERPT FROM SIRKIN, KEENAN \& JACKSON'S (2005) THE HARD SIDE OF CHANGE MANAGEMENT

FIGURE 3. AN EXAMPLE OF THE SECOND CYCLE CODING PROCESS USED WHILE EXPLORING FRAMEWORKS FROM LITERATURE USING AN EXCERPT FROM SIRKIN, KEENAN \& JACKSON'S (2005) THE HARD SIDE OF CHANGE MANAGEMENT

FIGURE 4. AN EXAMPLE OF THE THIRD CYCLE CODING PROCESS USED WHILE EXPLORING FRAMEWORKS FROM LITERATURE USING AN EXCERPT FROM SIRKIN, KEENAN \& JACKSON'S (2005) THE HARD SIDE OF CHANGE MANAGEMENT

FIGURE 5. A MODEL OF THE CATEGORIES UNCOVERED THROUGH THE CODING OF THE FRAMEWORKS IN LITERATURE AND THE MAGNITUDE OF THE TOP LEVEL CATEGORIES OR THEMES (REPRESENTED BY THE ORANGE BARS BELOW EACH BOX WHICH CONTAINS A THEME)................................... 37

FIGURE 6. A TIMELINE OF RESEARCH ACTIVITIES BETWEEN MAY 2019 AND JANUARY 2020.

FIGURE 7. MAP CONCEPT PROTOTYPES THAT WERE USED TO EXPLORE VARIOUS MODERATED AND UNMODERATED MAPPING METHODS (KABLACH, 2016; MARTIN \& HANINGTON, 2012).

FIGURE 8. PRELIMINARY RESEARCH KIT CONCEPTS INCLUDING CONSENT FORMS, STUDY INFORMATION AND CULTURAL PROBES (WORKBOOKS TO HELP PARTICIPANTS THINK ABOUT SUCCESSFUL AND UNSUCCESSFUL PROJECTS

FIGURE 9. A REFINED PROTOTYPE RESEARCH KIT USED IN THE PILOTING OF THE STUDY TO TEST METHODS IN ADVANCE OF ETHICS APPLICATION.

FIGURE 10. AN IMAGE OF THE FIRST TWO PAGES OF THE OF WORKBOOK FOR A SUCCESSFUL PROJECT. .... 49

FIGURE 11. AN IMAGE OF THE MIND MAPPING TOOL, STICKERS THAT CAME WITH THE TOOL AND SOME ADDITIONAL DESIGN TOOLS FROM THE RESEARCH KIT.

FIGURE 12. A PILOT MIND MAP COMPLETED USING A PROTOTYPED RESEARCH KIT.

FIGURE 13. AN EXAMPLE OF A NOTE THAT IS SIMULTANEOUSLY CODED WITH MULTIPLE PROVISIONAL CODES AND IN VIVO CODES.

FIGURE 14. AN EXAMPLE OF A TREE MAP VIEW OF A HIERARCHY CHART IN NVIVO

FIGURE 15. AN EXAMPLE OF A SUNBURST MAP VIEW OF A HIERARCHY CHART IN NVIVO. 61

FIGURE 16. A WORD ClOUd ILlustrating THE FREQUENCY OF IN Vivo CODES.

FIGURE 17. A HIERARCHY CHART ILLUSTRATING HOW OFTEN A PROVISIONAL CODE WAS USED (THE PROVISIONAL CODE'S MAGNITUDE) DURING THE FIRST CYCLE OF CODING. 
FIGURE 18. A MODEL OF THE CATEGORIES THAT EMERGED FROM THE FIRST CYCLE OF CODING.

FIGURE 19. A TREE MAP OF THE PATTERN CODE HIERARCHY.

FIGURE 20. A TREE MAP OF THE NEW TOP-LEVEL CATEGORIES (THEMES) OF FACTORS THAT MAY CONTRIBUTE TO CHANGE READINESS.

FIGURE 21. A SELECTION OF QUOTES RELATING TO THE CATEGORY PEOPLE CAN MAKE THE CHANGE HAPPEN.

FIGURE 22. A TREE DIAGRAM EXPLORING THE CATEGORY OF PEOPLE CAN MAKE THE CHANGE HAPPEN, FROM SAMPLE IN VIVO CODES TO THE FINAL CATEGORY OR THEME..... 86

FIGURE 23. A SELECTION OF PARTICIPANT QUOTES RELATING TO THE CATEGORY PEOPLE WANT TO DO THE WORK.

FIGURE 24. A SELECTION OF PARTICIPANT QUOTES RELATING TO THE CATEGORY PEOPLE KNOW WHY THE WORK IS BEING DONE.

FIGURE 25. A SELECTION OF PARTICIPANT QUOTES RELATING TO THE CATEGORY THE PROJECT FITS WITHIN THE EXISTING CONTEXT.

FIGURE 26. A SELECTION OF PARTICIPANT QUOTES RELATING TO THE CATEGORY PEOPLE KNOW HOW THE WORK IS BEING DONE.

FIGURE 27. A SELECTION OF PARTICIPANT QUOTES RELATING TO THE CATEGORY THERE IS SHARED UNDERSTANDING ABOUT THE WORK.

FIGURE 28. THE ProsCI ADKAR® MODEL TAKEN FROM WWW.PROSCI.COM. 95

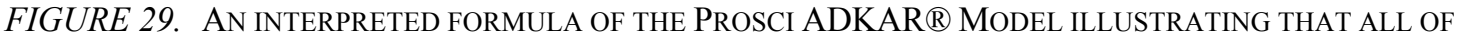
THE FACTORS HAVE TO BE ACHIEVED IN ORDER.

FIGURE 30. A FRAMEWORK TO EXPLORE READINESS TO IMPLEMENT DESIGN WITHIN THE CANADIAN Federal Public Service. 


\section{List of Appendices}

Appendix 1: Formulas from Change Management Literature

A1.1 A Review of the 12 Formulas from Change Management Literature Reviewed for this Thesis

A1.1.1 Formula 1a: The Change Formula …………….......................................... 126

A1.1.2 Formula 1b: Dannemiller's version of the Change Formula .......................... 128

A1.1.3 Formula 1c: Cady et al.'s version of the Change Formula .............................. 129

A1.1.4 Formula 2: The Elephant and the Rider ......................................................... 130

A1.1.5 Formula 3: Pain and Remedy ...................................................................... 132

A1.1.6 Formula 4: The Prosci ADKAR® Model ....................................................... 134

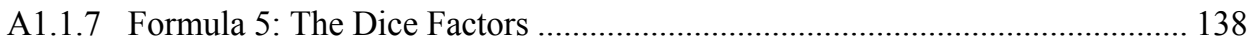

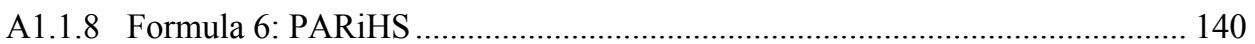

A1.1.9 Formula 7: The Organizational Readiness for Change Instrument (OCR),..... 142

A1.1.10 Formula 8: The Readiness Factors ................................................................. 144

A1.1.11 Formula 9: Multilevel Framework of the Antecedents and Consequences of

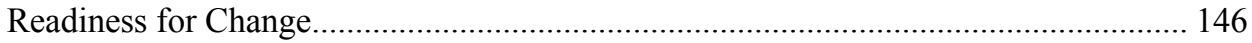

A1.1.12 Formula 10: Organizational Readiness for Change .......................................... 149

Appendix 2: Approach to Coding Participant Data ................................................ 153

A2.1 Information Management and Attribute Coding ….......................................... 153

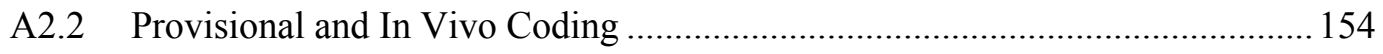

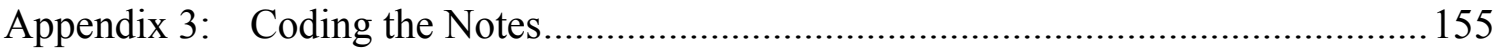

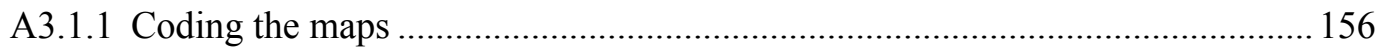

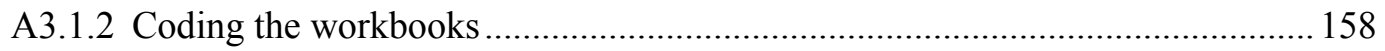

A3.1.3 Record keeping and generating preliminary insights .................................... 159

Appendix 4: Incremental Results...........................................................................163

A4.1 First Cycle Results ................................................................................ 163

A4.1.1 Occurrence of Provisional Codes from literature within the participant data.. 163

A4.1.2 In Vivo Codes generated from participant data ............................................... 165

A4.1.3 Relationships between the Provisional and In Vivo Codes found through

Simultaneous Coding

A4.1.4 Categories generated in the first cycle coding ............................................... 171

A4.2 Results Generated from the Second Cycle of Coding …................................. 176

A4.2.1 The Pattern Codes generated in the second cycle coding ......................... 176

A4.2.2 Relationships between the Pattern Codes and the categories generated in the first cycle of coding.............................................................................................. 179

A4.2.3 Relationships between the Pattern Codes and Provisional Codes .................... 181 


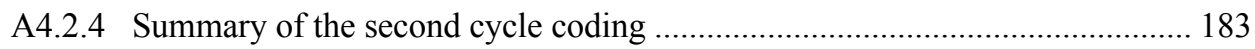

A4.3 Results Generated from the Third Cycle of Coding ....................................... 184

Appendix 5: The Themes Generated from the Third Cycle of Coding ....................... 186

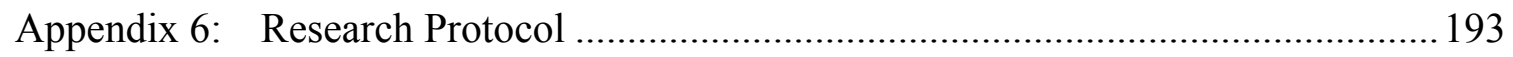




\section{Chapter 1: Introduction}

This case study aims to 1) improve our understanding of organizational factors that may contribute to the success of design implementation within Canadian Federal Public Service and 2) provide a tool designers may be able use to explore organizational factors that may impact the successful implementation of their work for the Canadian Federal Public Service. It is hoped that by contributing to our understanding of organizational factors in public service design work, consideration for the needs of such organizations can be integrated into the early planning stages of design, increase the chance of implementing good design and generate benefit for both the organization and the people it serves.

Specifically, this study aims to improve our understanding of designing within the Canadian Federal Public Service by addressing the following questions:

- What are some of the factors that have been associated with an organization's ability to change or move to a desired state proposed in selected change management frameworks?

- What are some of the factors that could be contributing to the success of design projects within the Canadian Federal Public Service?

- Is there a formula from the change management literature explored in this thesis that could be used in the Canadian Federal Public Service to support the implementation of design?

In the following chapters readers will learn how design is defined within the context of this thesis, why design is important for the Canadian Federal Public Service, about perspectives on how design potential may be realized, and what might be missing 
in one's design process when considering the elements of what makes a 'good design'.

Readers will also learn about a variety of formulas relating to an organization's ability to change found in literature which may contain important factors that could impact an organization's ability to implement a good design successfully, a pre-requisite to realizing benefit from design. Specifically, this part of the literature review looks at organizational factors which have been attributed to an organization's ability to change or move to a future state, which was supported by a qualitative content analysis of the literature conducted in NVivo, a computer-assisted qualitative data analysis software (CAQDAS) product.

The literature review is followed by an overview of my primary research where I explored factors, associated with 'project success' from the experiences of 18 people who have worked on successful and unsuccessful design projects for the Canadian Federal Public Service. This was a multiple-method study that used cultural probes and directed storytelling methods to collect data from participants and then analyzed the content from the study with NVivo. The results from that research were then compared to the results from the content analysis of the literature, which lead to a recommendation of a formula to further explore and assist the design process within the Canadian Federal Public Service. Finally, the thesis concludes with a discussion of these findings in relation to the literature review, opportunities for future research and limitations of the study. 


\section{Chapter 2: Background}

As far back as I can remember I have worked to make things just a little bit better. When I entered the field of User Experience (UX) design in 2008, I worked at a marketing agency that provided end-to-end creative services including strategy, design, development and product management. I was fortunate to be involved at every stage in the creative process - problem identification, research, design and development, release and management. We had dedicated teams that knew what to do and how to do it, working together, side-by-side, delivering solutions that worked for our clients. I knew our work was making things better for our clients, because I was the one reporting on the results.

When I moved into public service consulting a few years later, there was a dramatic shift in the context in which I was working. I was still designing user-centered solutions to achieve a specific organizational goal, but I was no longer involved in every touch point of delivery and had few windows into how everything worked. I was into my $5^{\text {th }}$ year and $20^{\text {th }}$ project as a consultant when, despite a sense that I was applying my design knowledge at an expert level, I realized that little of what I was creating for my clients was seeing the light of day. It did not seem to matter that my clients got that the work was valuable and wanted it, that the designs were appealing and well-tested, the work just wasn't being implemented. It felt like little of the work I was doing was actually making anything better and no amount of client feedback or consultation with my colleagues could shed light on 'why?' So, in 2017, I embarked on a journey into my client's world and became a designer in the Government of Canada. 
I was at the start of a rather large design initiative in the fall of 2018 when I was talking with a change management specialist about my academic pursuit of finding out why it was so hard to get designs made into real things. She pointed me to Beckhard \& Harris' (1977) Change Formula, a 4 factor equation that explored "the cost of change" or what has to be in order for the cost of change to be outweighed by the benefit of the change in order for a change to be successful. This was a way of looking at an organization's 'change readiness' or the "attitudes" of "various systems toward a change" and the "motivation toward implementing change" (p. 24-25).

As a designer, I found this concept interesting for two reasons: I had never taken into consideration whether or not the designs I proposed - designs which were essentially about introducing 'change' to the organization and the public - could actually be made a reality within the context of larger, organizational factors which may be involved in this change. I also love formulas as simple tools to help people make sense of the world around them. As a designer, I find such tools indispensable in not only doing design work, but also in bringing people along when trying to explain complex concepts.

This thesis describes this next part of my journey where I set out to learn more about organizational factors that might impact the implementation of a design in the Canadian Federal Public Service. I explored selected formulas and frameworks from change management literature to get a sense of factors being discussed across these models. I also heard stories from real people working in design for the Canadian Government to develop an understanding of organizational factors that may contribute to the success of design implementation within the Canadian Federal Public Service and 
then compared the factors from the literature to those factors that may contribute to project success in the Canadian Federal Public Service to see if there is a formula that already exists in literature that could be used by designers to explore the organizational context during the design process. 


\section{Chapter 3: Literature review}

\subsection{Design and Change Management}

There's a natural relationship between design and change management. Design is a discipline that generates ideas or plans that can be used to achieve the goals of an organization. It is a practice of envisioning what could be in the future (Heskett, 2002; Peters, 2005; Vizard, 2018). Change management, on the other hand, is a practice of supporting an organization or entity as it moves from its current state to an envisioned future (Conner, 1996; Hiatt, 2006; Kotter, 2012; Sirkin, Keenan \& Jackson 2005).

When design can be realized through change to an organization, it can have an incredible impact on people, organizations, societies and the world overall (Brown, 2009), but it cannot get there without a little help.

\subsection{The Definition of Design}

"Design is to design a design to produce a design"

-Heskett, 2002, p. 3

In Restarting Britain 2, a document written by The Design Commission (2013) which discusses strategic public policy renewal and design, the authors note that design has a "multitude of meanings" (p. 6) which can make it difficult to talk about and explore with others. Heskett (2002) explains that 'design' can be used as a noun to describe a "concept of a field as a whole"; it can be used as a verb reflecting something that people do; and it can also be used as a noun describing the outcome of process or a 
"concept or a proposal" that then leads to a "finished product" (p. 3). It has also been defined as the outcomes of the planned development of a component, product, service, system, concept or context that aims to achieve organizational objectives and achieve a predetermined outcome (Oxford English Dictionary, 2019; Vizard, 2018).

But in an effort to focus on one meaning for the purpose of this thesis, we will focus on 'design' used as a noun to reflect the "concept or a proposal" (Heskett, 2002, p. 3), the result of an open, curious and experimental mindset and a problem-solving process (Brown \& Katz, 2009; Williams, 2015). In this thesis, the 'design' we will be discussing is the plan that could lead to a real-life product or service, will help to define the solution to the original problem and achieve positive outcomes (Peters, 2005; Vizard, 2018).

\subsection{The Potential for Design in Government}

"[Government] involves people creating structures, people making use

of resources, and (at least in a democracy) doing so by following

commonly established and agreed upon processes. Ideally, the execution

of these tasks is geared towards fulfilling the mandate of enhancing

human living; [...] this identifies government as a product of design. If

nobody designed government, then government, or any other

organization for this matter, would not exist".

- Junginger, 2018, p. 24

Design in the public service has an enormous amount of potential. Applying the mindsets, processes and practice found in design research, processes and practice can 
help governments produce operational efficiencies, reducing the need for spending and "costs to the taxpayer" (The Design Commission, 2013; Collins \& Chiaramonte, 2017); support innovation and global competitiveness (Bushore, 2012); "achieve policy goals" (Junginger, 2018); reduce future rework (The Design Commission, 2013) and need for client support; keep government information and services safe (Collins \& Chiaramonte, 2017); and lead to the development of novel solutions to complex problems (Clarke \& Craft, 2018; Dunne, 2018).

Design can add rigor, principles and process to a solution development process so that they are measurable and based on principles (Lewin, 1946; The Design Commission, 2013). Lewin (1946) also explained that design can expand thinking beyond "the boat" (p. 146). Buchanan (1992) points to design as a tool to help craft new, novel solutions to difficult problems. Design thought leaders Josh Brewer (formally of Twitter) and Craig Mackintosh (of Frog Design) both talk about how design can speed up change (Brewer, n.d.; Mackintosh, n.d.).

But just as governments around the world are recognizing the potential design can bring to public service, and as public service mindsets begin to shift focus to clients instead of processes (Treasury Board of Canada Secretariat, 2018), we are faced with the difficult problem of determining if and how the outcomes of this work really helps to solve public service problems. For example, McGann, Blomkamp and Lewis (2018) note that "barely any" of the "public sector innovation (PSI) labs" (p.249) they studied were actually involved in policy design and only a few supported activities of implementation or "scaling" (p. 262). Little evidence has been found linking the work of design labs within the public service context to measurable, positive outcomes that address complex 
issues of policy (McGann et al., 2018; Hum \& Thibaudeau, 2019). According to Lewin (1946), a lack of information about successful or unsuccessful initiatives and factors related to these outcomes, prevents organizations from learning from their past and improving. But in order to understand how successful or unsuccessful an initiative is, it has to be made a reality, which may carry risks if we don't have prior knowledge on similar initiatives.

\subsubsection{The potential for design in the Canadian Federal Public Service}

This need for successful initiatives has never been as strong as it is now for the Canadian Federal Public Service. In a letter to the Prime Minister in March 2019, the Clerk of the Privy Council Office (Michael Wernick) points to some key "shifts" he has noticed over "the last three years". Specifically, he points to changes in "global politics and economics" and Canada's contribution to "support peace around the world". He notes changes within Canada that "demands greater inclusion, civility and engagement" and references how "our world is more open and more digital then ever" $\left(26^{\text {th }}\right.$ Annual Report to the Prime Minister on the Public Service of Canada, 2019).

As the Government of Canada and the Canadian Federal Public Service try to keep up by "Renewing the public Service" (26 ${ }^{\text {th }}$ Annual Report, 2019, p. 21-36) and learning how to manage "uncertainty rather than risk" (Kershaw, Dahl \& Roberts, 2016), the world in which they operate continues to evolve and change. The workforce (and population) is aging and the expectations of public service clients continually pressures the public service for a "push for digitalization" (Junginger, 2018, p. 25). Both externally and internally, it is clear that the problems of the public service in Canada are not getting 
any less complex, the needs of people are not becoming any less important (The Design Commission, 2013) and trust is decreasing (Edelman, 2020). The need for the novel solutions that can be generated through design practice are clearly needed (Clarke \& Craft, 2018; Dunne, 2018).

\subsection{Realizing the Potential of Design}

When considering the potential of design, we need to explore the benefit received from that design. Whether that benefit is realized by the organization, the person being served by the organization or society as a whole, the benefit is generated when someone or something is better off (dmi: design management institute, n.d.; Rae, 2013) or performs better in comparison with something or someone else (Sheppard, Sarrazin, Kouyoumjian \& Dore, 2018).

What this implies is that, in order to understand if the potential was achieved and the benefit delivered, a baseline is needed to measure the relative benefit of the design in question. Whether that baseline is an existing version, a competitive product or service and/or formal design principles, objectives, or best practices, there must be something on which a design can be measured.

For example, Kershaw et al. (2016) propose that, in the public service, benefit is likely found in maintaining the perceived credibility of the Government, the reduction of "uncertainty and risk" (p. 7), cuts to costs, "greater connections between citizens and governments" (p. 7) and getting to "better solutions more quickly" (p. 9). In order to determine the success of projects in the public sector, it is likely that these metrics must 
be explored in order to develop a baseline for design and work towards designs that are likely to benefit both the public service and the people it serves.

Once a baseline is established, the next step in capitalizing on the potential design can deliver to generate benefit through design, involves meeting certain requirements of 'goodness' (Figure 1). The definition of 'good design' is complicated ${ }^{1}$ (Clarke \& Craft, 2018; Heskett, 2002) with, as Hertenstein, Platt and Veryzer (2013) explain it a "rich complex, multi-attribute structure" (p. 8). According to various authors, 'good design' must balance many factors expertly (see Figure 1), including factors of form and function, as well as user experience and organizational impact (Brown \& Katz, 2009; Hertenstein, Platt \& Veryzer, 2013; Junginger, 2018; Wu \& McMullin, 2006; The Design Commission, 2013). It should adhere to principles (Hertenstein, Platt and Veryzer, 2013; Lidwell, Holden \& Butler, 2003; Norman, 2004) and pre-established rules and guidelines for creation. It must be unique to the particular context of design (Hetenstein, Platt and Veryzer, 2013; Young, 2007), focused on achieving specific objectives (Dunne, 2018; Lewin, 1946; Brewer, n.d.) and it has to be something that can be measured (Lewin, 1946).

${ }^{1}$ Although how good a 'good design' is may be subjective and based on a multitude of considerations, all of which are not covered in the scope of this thesis, a summary list of some key indicators of a 'good design' is include here to bring to light first that there are many moving parts that must be considered and also that a design likely does have to meet these requirements in order to benefit the organization and the user. 


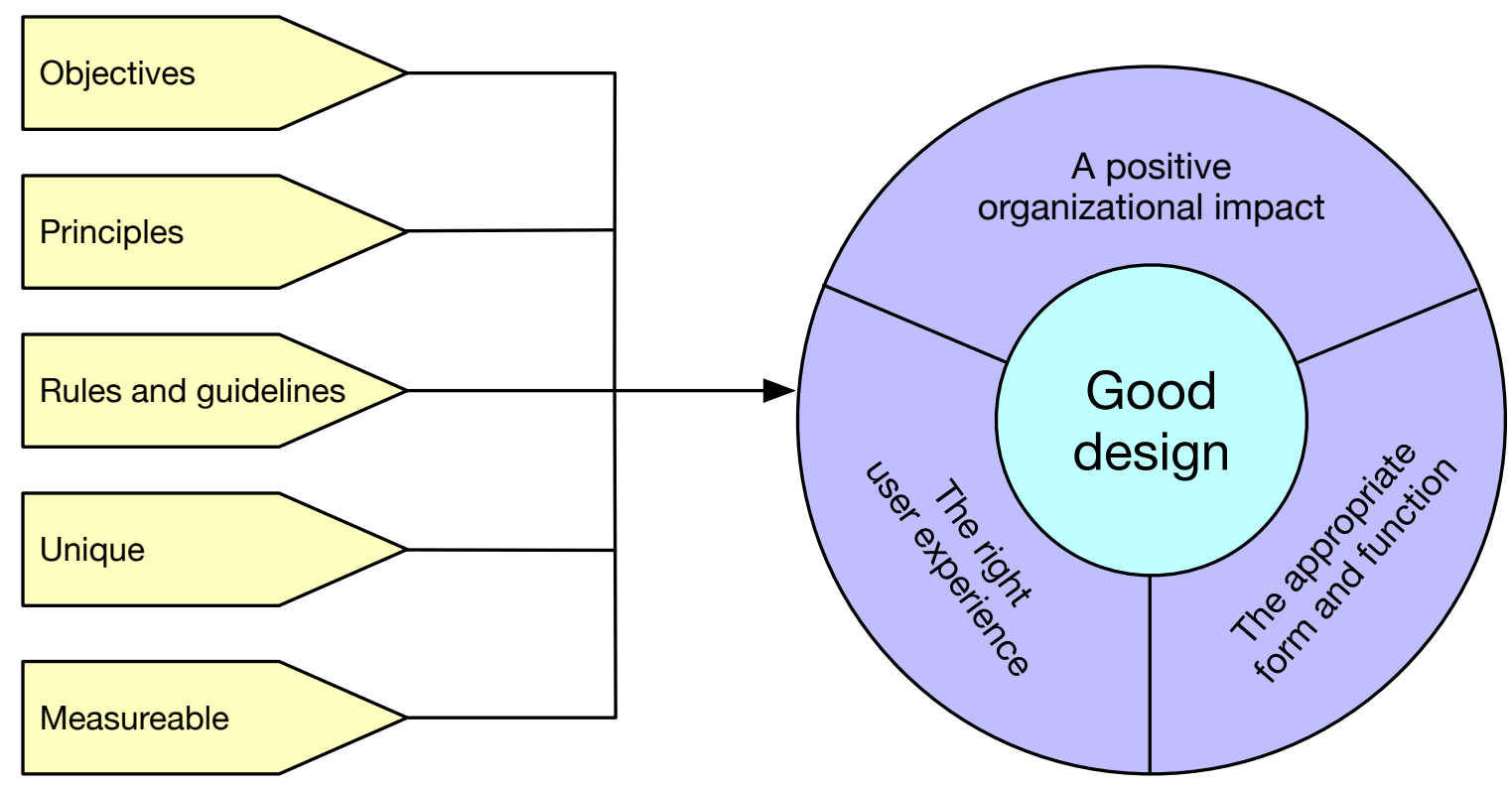

FIGURE 1. A PROPOSED MODEL OF 'GOOD DESIGN' BASED ON CHARACTERISTICS IDENTIFIED IN LITERATURE.

To generate benefit, 'good design' must also be something that is desirable, viable and feasible (Brown \& Katz, 2009) and the organization responsible for the creation of the design, must be able to transform it from a great idea or concept into a great product, system, or concept. Traditional, quantitative metrics such as 'return on investment' or client satisfaction values, and novel, qualitative metrics such as improved quality of life can be used to assess organizational benefit but are primarily validated once a design is in use (Hirsch, Fraser \& Beckman, 2003; Organization for Economic Co-operation and Development, 2016). As mentioned earlier, benefit in the public service is likely found in measures of credibility, reduction in uncertainty and risk, cost savings and efficiencies (Kershaw et al., 2016). These metrics also likely must be explored in the context of use in order to determine if they were actually beneficial to the organization the people serve. 
Despite a designer's or design team's best efforts, if a design cannot be validated in the context of use (Mackintosh, n.d.), it is uncertain if the outcome will produce the benefit the organization needs.

Similarly, if an ineffective design is made a reality, or a 'good design' is made a reality ineffectively, the costs can be high and there will likely be no benefit generated (Charette, 2005; Collins \& Chiaramonte, 2017; Anthopoulos, Reddick, Giannakidou \& Mavridis, 2015; Design Commission, 2013). Lewin (1946) identified a "lack of standards by which to measure progress" as a factor in "making the wrong conclusions" (p. 143-144) and not learning from efforts that may even result in additional hidden costs. A design that does not get implemented, or gets implemented incorrectly, not only has financial implications for an organization in misused resources, but also opportunity costs (Wu \& McMullin, 2006), as time is spent focusing on something that does not contribute to improving an organization's situation, the well-being of clients or society as a whole.

So, if we are to realize benefit from a 'good design', there must be a baseline, the design must be 'good', it must be desirable, viable and feasible and that design must also be made (as close to the design as possible) into something real that can be used.

So how do we make a 'good design' a reality?

\subsection{Balanced Consideration}

Designers are typically trained to explore problems and opportunity spaces, develop an understanding of the user or human side of experience, and the role of things like form and function in supporting experience (Norman, 2013). There are countless 
design-specific methods that support the identification of organizational and client needs through qualitative and quantitative measures (e.g. Kumar, 2013; Martin \& Hanington, 2012). The fields of human-factors and user experience design are based on a strong foundation of understanding people's characteristics and their context in order to plan for outcomes that are useful, usable and used (Kelly, 2018) and the practice of things such as form-making and design to support functionality have been taught in design schools for decades (Burdek, 2005; Cross, 2001).

But as we saw in Figure 1, user experience and form and function, are not likely to contribute to a 'good design' on their own (Norman, 2013). Apart from such qualities, McMullin (2003) also calls for a balanced consideration of both the individual and organizational needs in order to support a successful project. In the article he goes on to note that "extreme user focus" can have unintended consequences of not meeting client and stakeholder needs and expectations in terms of the delivery of a design; In addition, it can alienate the designer and place other disciplines into disconnected siloes, which can lead to miscommunication and potentially overlooking stakeholder needs all together. The importance of focusing on organizational needs continues to be a topic of discussion across design and business literature (e.g., Bushore, 2012; Hall, 2013; Hertenstein al., 2013; Wu \& McMullin, 2006; Vassallo, 2017). Related to organizational considerations, the literature also highlights the importance of understanding business strategy in the practice of design, including understanding product objectives, brand identity, success metrics, competitive advantage, business models, value chain and business requirements (Garrett, 2011; Levy, 2015; Unger \& Chandler, 2009). However, the focus here seems to be on aligning design with existing organizational strategy, 
rather than understanding the effect the organization itself may have on the potential of a design being successful as it progresses towards something real.

There are, however, exceptions. In Erika Hall's book on design research, Hall (2013) identifies essential information that should be looked into in order to support the "success of a product or service" (p. 57). In her chapter Organizational Research (p. 5775), Hall (2013) illustrates areas that should be considered such as "the structure of the organization, how your work fits into the organization as a whole, and the approval process for various aspects of your project" (p. 61). Hall (2013) also goes on to illuminate various "opportunities [that may] influence your project's chances of success" (p. 61) that can be generated through doing organizational research. These opportunities include: understanding and potentially "neutralizing organizational politics" (p. 61); collecting a realistic and useful set of requirements for the thing being designed; understanding the organizational priorities and where the project fits within them; building a customized design process for the specific context you are designing for; "empowering" stakeholders through consultation (p. 63); "anticipate changes to workflow" (p. 64); and understanding where the work you are working on fits into the existing workflow. By Hall's exploration of a deeper need for organizational understanding, we can see that form and function and user experience alone are not enough to generate a design that can be made into something real.

This discussion is also found in The Design of Everyday Things (where Norman (2013) discusses first the "Ideal" (p. 236) Human Centred Design Process (a critical tool of design thinking process), but then shifts the conversation dramatically in the section titled What I just told You? It Doesn't Really Work That Way (p.236-239) where he talks 
about the "mess" (p. 238) of product development. In this section he identifies some of the complexities of turning a design for a product into an actual product, including such things as time, "clash of disciplines" and "everyone [speaking] a different technical language" (p. 239). He proposes tips for overcoming many of these challenges and continues to reflect that "Producing a good product requires a lot more than good technical skills: it requires a harmonious, smooth functioning, cooperative and respectful organization." (p. 240)

Despite this link between product development and organizational context and recent interest in the business of design from the design leadership community (Casey, 2019; Mackintosh, n.d.; Sheppard, Sarrazin, Kouyoumjian \& Dore, 2018; Kolko, 2015), there still appears to be little discussion in design literature and thought leadership about intersection between design and business and the complexities of design implementation (like those mentioned by Norman in 2013) within the context of design implementation.

Even with the trend of integrating 'design thinking' into traditional business strategy, the focus remains on the process of design (Brown, 2009; Fiell \& Fiell, 2019) and using design thinking as a "device" (Spool, 2017) and does not necessarily dig into the hands-on exploration of how design becomes real life or the implementation of design.

Jen (2018) points to the "false promise" of innovation through design thinking, arguing that this new focus on design thinking serves to help people come up with ideas or "invent", but that in order to innovate, something must be invented and brought to market where it achieves "mass adoption". The outcomes of design thinking processes, Jen argues, just results in post-its of ideas, and inventions. Walters (2011) also wrote 
about the need to focus on design overall and not specifically on design thinking as a "quick fix" too difficult problems in her talk about what design thinking isn't - an approach to help executives understand how they could use design thinking in the future. Although there are conversations about what may help to push design thinking into the realm of "design doing" (Banfield, 2017; Fajardo, Rehm \& Joffres, 2012; Norman, 2013; Malbon, 2016), I was not able to find a bigger, more formalized conversation about what happens when the dot voting is wrapped up, the prototypes are built, and the pitch is made; about how to transition a design from research and ideation into the creation of something that gets into the hands of real people.

\subsection{Design is Change}

As discussed in section 3.3 The Potential for Design in Government, design may have an impact in public service; increasing efficiencies, effectiveness, innovation and security, reducing costs, and supporting novel solutions to complex problems (Bushore, 2012; Clarke \& Craft, 2018; Collins \& Chiaramonte, 2017; Dunne, 2018; Deserti \& Rizzo, 2015; Junginger, 2018; The Design Commission, 2013). But to achieve these positive outcomes, an organization is likely to have to change or modify how it currently operates in some way (Buchanan, 2007; Buchanan, 2015; Domingo, Buckingham, Dekonick \& Cornwell, 2015; Hall, 2013; The Design Commission, 2013).

To increase the likelihood of understanding what the outcomes of a proposed design will be, Dorst (2011) proposes that it is not enough to only consider the "what", we must also consider the "how" (p. 522-523) or what needs to happen in order to ensure that a design is implemented effectively. To do this, researchers argue that we need to 
start learning about how a design fits into the organization as part of the context of design in order to learn how the organization may need to change to make a design a reality and improve our understanding of the factors may affect the success of the design (Cinite, 2006; Hall, 2013; Hetenstein, Platt \& Veryzer, 2013; The Design Commission, 2013).

\subsection{Is the Organization Ready for Change?}

Various researchers (e.g., Armenakis \& Harris, 1993; Beckhard \& Harris, 1977;

Weiner, 2009) have proposed that there is an ideal state or an organizational context that needs to be made available in order for an organization to be able to successfully change, or a transition between current and future states. This ideal state is often referred to in change management literature as "change readiness" or the "beliefs, attitudes and intentions regarding the extent to which changes are needed and the organization's capacity to successfully undertake those changes " and accounting for it may "[increase] the potential for change efforts to be more effective" (Armenakis, Harris \& Mossholder, 1993, p. 681-682).

If successful design implementation is likely to require that the organization change in some way, and we want to increase our potential for successful design implementation, then 'change readiness' and consideration for an organization's ability to change may be important considerations when trying to increase the effectiveness of change efforts in support of design implementation.

But change and 'change readiness' are complex, multifaceted, multilevel concept that must consider many factors across many levels (Rafferty, Jimmieson \& Armenakis, 
2013). Despite the importance of including such concepts in an effort to explore whether an organization will be able to change, expecting people working in design in the Canadian Federal Public Service to have the ability and willingness (Weiner, 2009) to understand such concepts within their work may be overwhelming.

In my experience, people working in design in the public service design already have a lot to contend with. They are likely to be part of a very small team, if they have a team at all. If they are being used effectively, they are probably at capacity and stretched thin across many different types of projects, all at different stages of completion. They are probably waiting for stakeholders to get back to them, while balancing the needs of new projects, ministerial taskings, and perhaps an Access to Information and Privacy (ATIP) request. All the while still working on a computer using windows 10, with limited access to many online services and modern tools, in a cubicle-style environment, likely designed in the 1980 's. They are probably struggling every day to get stakeholders to understand what they do and why it matters and within the past 24 hours they have likely come across at least one web service managed by their institution that has a multitude of usability errors in it, but somehow, was still released.

If they are not in the public Service, but still working for the public service, they were very likely told exactly what to do by a statement of work (SOW) that was written by a procurement advisor who may have limited understanding about the problem being explored or what work needs to be done. There is not likely a lot of time to get the work done and even if there was, there is probably little interest on the client's end to go outside of the SOW. They also probably have many projects on the go right now, are 
waiting for their clients and stakeholders to get back to them with feedback or approvals and are behind schedule.

To try and then ask designers working on design projects in the Canadian Federal Public Service to understand the concepts of change and change readiness, know all the models and to be aware of all of their intricacies, let alone be able to apply the concepts, seems fruitless. Even if they were willing, would they be able?

Beckhard \& Harris (1977) adopted a formula summarizing a change process proposed by their colleague David Gleicher that proposed 4 factors that signify an organization's potential ability to change and simplified them into 4 factors that reflect the cost of change or "a way of looking at readiness for change and the attitudes and motivation toward implementing change" (p. 25). This formula, the Change Formula was:

$$
\mathrm{C}=(\mathrm{ABD})>\mathrm{X}
$$

Where $\mathrm{C}=$ change, $\mathrm{A}=$ level of dissatisfaction with the status quo, $\mathrm{B}=$ clear desired state, $\mathrm{D}=$ Practical first steps toward the desired state, and $X=$ cost of change. (Beckhard \& Harris, 1977, p. 25)

In other words, the Change Formula proposed that the motivation and ability to change must be greater than the cost of change for that change to be successful.

The formula was concise, easy to recall and easy to make sense of. It seemed to me like it could be the right type of tool to share with people working on design projects within the Canadian Federal Public Service to help increase the possibility of design implementation. It seemed like it might be able to act as a framework for exploring organizational context and perhaps a useful tool to have in the public service design tool 
kit. But it turned out this wasn't the only change formula, nor was it the only formula that may be able to be used to assess organizational ability to change.

Over the years, a multitude of formulas to understand change readiness and ability to change have been proposed and extended in change management literature (see Appendix 1 for a more detailed review of the formulas from change management literature that I explored). Beckhard \& Harris' Change Formula, for example, has been through several iterations over the years, by a collection of authors (Cady et al., 2018). Formulas are created for different industries and practices (Kitson \& McCormak, 1998; Lehman et al., 2002) and different authors propose different lenses with which to explore the organizational change context (Cinite, 2006; Harris, 2017; Holt, Armenakis, Field \& Harris, 2007; Shea, Jacobs, Esserman, Bruce \& Wiener, 2014; Wiener, 2009). Some of the formulas have elements in common and many have significant differences, making it potentially difficult to know which formula to use, when and have confidence in the results when determining if the organization will be able to change.

The 12 formulas I explored (see Tables 1, 2 and 3) were selected specifically because I felt they could be used as a type of heuristic check list or tool that design practitioners working on Canadian Federal Public Service design projects could adopt and add to their design research toolkit when trying to explore their unique organizational context.

When I selected the formulas for review, I used the following criteria: they had to relate to determining an organization's ability to change and did not reflect factors for the actual implementation of change (which, if it also follows the criteria for 'good design' set out in 3.5 Realizing the Potential of Design would not be able to follow any 
check list as it should likely be unique to the particular context of the change it is undertaking); they included factors that could apply at the organizational level (not just the individual level); and they came from an original publication.

Through the exploration of formulas, one mythological formula did surface - The Delores Ambrose Model for Managing Complex Change. Despite many attempts, the original attribution could never be found and so it was excluded.

Despite differences in the formulas, many of the formulas reviewed did contain similar factors to the original Change Formula proposed by Gleicher, containing some variation on the need to have elements of "dissatisfaction with the status quo", "clear desired state" and "first steps towards the desired state" (Beckhard \& Harris, 1977). Further discussion about the limitations of still including these similar formulas in the study can be found in 6.5.8 Limitations of the review of formulas. However, not all the formulas contained the same factors, and each provided a different level of granularity to support an understanding of the context of change, what factors contribute to what outcomes and how (Dorst, 2011). Each tool had a different level of complexity and effort required to use it.

Despite this, all of formulas did strive to accomplish the same goal: highlight and explore a set of distinct factors that are likely to be essential to ensure an organization's successful ability change. 


\begin{tabular}{|c|c|c|c|}
\hline \multicolumn{4}{|l|}{$\begin{array}{l}\text { Table } 1 \\
\text { An inven }\end{array}$} \\
\hline $\begin{array}{l}\text { Formula } \\
\text { Title }\end{array}$ & Description & Formula & Factors from formula \\
\hline $\begin{array}{l}\text { Beckhard \& } \\
\text { Harris' Change } \\
\text { formula } \\
\text { (Beckhard \& } \\
\text { Harris, 1977) }\end{array}$ & $\begin{array}{l}\text { Using this formula, } \\
\text { Beckhard \& Harris (1977) } \\
\text { explore change readiness in } \\
\text { terms of "the cost of change" } \\
\text { (p. 25). }\end{array}$ & $\mathrm{C}=(\mathrm{ABD})>\mathrm{X}$ & $\begin{array}{l}\text { Where, } \\
\mathrm{C}=\text { Change } \\
\mathrm{A}=\text { Level of dissatisfaction with } \\
\text { the status quo } \\
\mathrm{B}=\text { Clear desired end state } \\
\mathrm{D}=\text { Practical first steps toward } \\
\text { the desired state } \\
\mathrm{X}=\text { Cost of change }\end{array}$ \\
\hline $\begin{array}{l}\text { Dannemiller's } \\
\text { Change Formula } \\
\text { evolution } \\
\text { (Dannemiller \& } \\
\text { Jacobs, 1992) }\end{array}$ & $\begin{array}{l}\text { In the } 1990 \text { 's, Dannemiller \& } \\
\text { Jacob's adapted Beckhard \& } \\
\text { Harris' Change Formula so } \\
\text { that it was "more usable and, } \\
\text { therefore, more accessible to } \\
\text { the worlds" (Cady et al., } \\
\text { 2014). }\end{array}$ & $\mathrm{D} \times \mathrm{V} \times \mathrm{F}>\mathrm{R}$ & $\begin{array}{l}\text { Where, } \\
D=\text { Dissatisfaction with the } \\
\text { current state of affairs } \\
V=\text { An ennobling vision of what } \\
\text { we yearn to be } \\
F=\text { Concrete first steps } \\
R=\text { Resistance to change }\end{array}$ \\
\hline $\begin{array}{l}\text { Cady et al.'s } \\
\text { Change Formula } \\
\text { extension } \\
\text { (Cady et al., } \\
\text { 2014) }\end{array}$ & $\begin{array}{l}\text { Cady et al. (2014) extended } \\
\text { Dannemiller \& Jacob's } \\
\text { formula so that it also took } \\
\text { into consideration the factor } \\
\text { of an organization's ability } \\
\text { to maintain change overtime } \\
\text { or "sustainability" }\end{array}$ & $\begin{array}{c}\mathrm{D} \times \mathrm{V} \times \mathrm{F} \times \mathrm{S}> \\
\mathrm{R}\end{array}$ & $\begin{array}{l}\text { Where, } \\
D=\text { Dissatisfaction with the } \\
\text { current state of affairs } \\
V=\text { An ennobling vision of what } \\
\text { we yearn to be } \\
F=\text { Concrete first steps } \\
S=\text { Sustainability } \\
R=\text { Resistance to change }\end{array}$ \\
\hline $\begin{array}{l}\text { The Elephant } \\
\text { and the Rider } \\
\text { (Heath \& Heath, } \\
\text { 2010) }\end{array}$ & $\begin{array}{l}\text { Heath \& Heath }(2010) \\
\text { explored the experience of } \\
\text { change and use the metaphor } \\
\text { of a rider and an elephant } \\
\text { trying to get somewhere by } \\
\text { following a path. }\end{array}$ & $\begin{array}{l}\text { Clear direction } \\
\text { x Emotional } \\
\text { commitment } \\
\frac{\text { x A situation }}{\text { that is ready }} \\
\frac{\text { Change }}{}\end{array}$ & $\begin{array}{l}\text { Where all of the factors must be } \\
\text { in place in order to achieve a } \\
\text { successful change result. }\end{array}$ \\
\hline $\begin{array}{l}\text { Pain and } \\
\text { Remedy } \\
\text { (Conner, 1994) }\end{array}$ & $\begin{array}{l}\text { Conner (1994) proposed a } \\
\text { very simple model that } \\
\text { looked at only two factors: } \\
\text { there is enough } \\
\text { dissatisfaction to justify the } \\
\text { change and there is a } \\
\text { solution that is realistic and } \\
\text { something people want. }\end{array}$ & $\begin{array}{l}\text { Pain } x \text { Remedy } \\
\quad=\text { Change }\end{array}$ & $\begin{array}{l}\text { Where, } \\
\text { Pain = "a critical mass of } \\
\text { information that justifies } \\
\text { breaking with the status quo" } \\
\text { Remedy = "desirable, accessible } \\
\text { actions that would solve the } \\
\text { problem or take advantage of the } \\
\text { opportunity afforded by the } \\
\text { current situation", } \\
\text { and both "Pain" and "Remedy" } \\
\text { must be present for the change to } \\
\text { be a success. }\end{array}$ \\
\hline
\end{tabular}

TABLE 1. THE FIRST 5 FORMULAS FROM LITERATURE THAT WERE INCLUDED IN THE INVENTORY OF 12 FORMULAS FROM CHANGE MANAGEMENT LITERATURE EXPLORED IN THIS THESIS. 


\begin{tabular}{|c|c|c|c|}
\hline \multicolumn{4}{|c|}{$\begin{array}{l}\text { Table } 2 \\
\text { An inventory of formulas collected and explored during the literature review } \\
\text { (continued). }\end{array}$} \\
\hline $\begin{array}{l}\text { Formula } \\
\text { Title }\end{array}$ & Description & Formula & Factors from formula \\
\hline $\begin{array}{l}\text { ADKAR } \\
\text { (Hiatt, 2006) }\end{array}$ & $\begin{array}{l}\text { In 2006, Hiatt proposed the } \\
\text { ADKAR Model, yet another } \\
\text { framework including similar } \\
\text { factors as found in the } \\
\text { original Change Formulas, } \\
\text { but with its own unique lens. } \\
\text { In this model the factors } \\
\text { have to be in place in the } \\
\text { order that they appear in the } \\
\text { framework. }\end{array}$ & $\begin{array}{c}((((\mathrm{A}+\mathrm{D})+\mathrm{K}) \\
+\mathrm{A})+\mathrm{R})= \\
\text { Change }\end{array}$ & $\begin{array}{l}\text { Where, } \\
A=\text { Awareness of the need for } \\
\text { change } \\
D=\text { Desire to support the change } \\
K=\text { knowledge of how to change } \\
A=\text { Ability to demonstrate skills } \\
\text { and behaviours (required for the } \\
\text { change) } \\
R=\text { Reinforcement to make the } \\
\text { change stick }\end{array}$ \\
\hline $\begin{array}{l}\text { The DICE } \\
\text { Factors } \\
\text { (Sirkin et al., } \\
\text { 2005) }\end{array}$ & $\begin{array}{l}\text { Through a study of } 225 \\
\text { companies, Sirkin et al. } \\
\text { (2005) uncovered a } \\
\text { framework that incorporates } \\
\text { four factors that contribute } \\
\text { to the success of a change } \\
\text { initiative. This framework } \\
\text { was thought by the authors } \\
\text { to be "hard factors" (p. 3) or } \\
\text { factors that are measurable, } \\
\text { their importance can be } \\
\text { easily communicated, and } \\
\text { they can be quickly } \\
\text { influenced. }\end{array}$ & $\begin{array}{l}\mathrm{D}+(2 \times \mathrm{I})+(2 \\
\mathrm{x} \mathrm{C} 1)+\mathrm{C} 2+\mathrm{E} \\
=\text { Dice Score }\end{array}$ & $\begin{array}{l}\text { Where, } \\
\mathrm{D}=\text { Duration between reviews } \\
\mathrm{I}=\text { Performance integrity } \\
\mathrm{C} 1=\text { Commitment of senior } \\
\text { management } \\
\mathrm{C} 2 \text { = Commitment of employees } \\
\text { or "local level" commitment } \\
\mathrm{E}=\text { Effort }\end{array}$ \\
\hline $\begin{array}{l}\text { PARiHS } \\
\text { (Kitson et al., } \\
\text { 1998) }\end{array}$ & $\begin{array}{l}\text { The PARiHS framework } \\
\text { comes from the health } \\
\text { sciences field looks at three } \\
\text { factors that may support the } \\
\text { successful implementation } \\
\text { of "research evidence into } \\
\text { practice" (Kitson et al., } \\
\text { 1998, p. 149). }\end{array}$ & $\mathrm{SI}=\mathrm{f}(\mathrm{E}, \mathrm{C}, \mathrm{F})$ & $\begin{array}{l}\text { Where, } \\
\mathrm{SI}=\text { Successful Implementation } \\
\text { is a function of: } \\
\mathrm{E}=\text { Evidence } \\
\mathrm{C}=\text { Context } \\
\mathrm{F}=\text { Facilitation }\end{array}$ \\
\hline $\begin{array}{l}\text { ORC } \\
\text { (Lehman et al., } \\
\text { 2002) }\end{array}$ & $\begin{array}{l}\text { The Organizational } \\
\text { Readiness for Change } \\
\text { Instrument (or OCR) was } \\
\text { also found in literature } \\
\text { relating to change in health } \\
\text { care, specifically technology } \\
\text { implementation. }\end{array}$ & $\begin{array}{c}\mathrm{M} \times \mathrm{I} \times \mathrm{S} \times \mathrm{O}= \\
\text { Change }\end{array}$ & $\begin{array}{l}\text { Where, } \\
\mathrm{M}=\text { Motivational readiness } \\
\text { (people want to change) } \\
\mathrm{I}=\text { Institutional readiness (the } \\
\text { environment to support the } \\
\text { change is available) } \\
\mathrm{S}=\text { Staff attributes (people can } \\
\text { change and help others change) } \\
\mathrm{O}=\text { Organizational climate (is } \\
\text { open and adaptable) }\end{array}$ \\
\hline
\end{tabular}

TABLE 2. THE NEXT 4 FORMULAS FROM LITERATURE THAT WERE INCLUDED IN THE INVENTORY OF 12 FORMULAS FROM CHANGE MANAGEMENT LITERATURE EXPLORED IN THIS THESIS. 


\begin{tabular}{|c|c|c|c|}
\hline \multicolumn{4}{|c|}{$\begin{array}{l}\text { Table } 3 \\
\text { An inventory of formulas collected and explored during the literature review } \\
\text { (continued). }\end{array}$} \\
\hline $\begin{array}{l}\text { Formula } \\
\text { Title }\end{array}$ & Description & Formula & Factors from formula \\
\hline $\begin{array}{l}\text { Readiness } \\
\text { Factors } \\
\text { (Holt et al., } \\
\text { 2007) }\end{array}$ & $\begin{array}{l}\text { The Readiness Factors } \\
\text { proposed by Holt et al. } \\
\text { (2007) are factors that are } \\
\text { intended to explore change } \\
\text { readiness within an } \\
\text { organization at an individual } \\
\text { level. Their point of view is } \\
\text { that readiness is a result of } \\
\text { the collective beliefs of } \\
\text { employees and that the tool } \\
\text { explores employees' beliefs } \\
\text { that the organization can } \\
\text { change. }\end{array}$ & $\begin{array}{c}\mathrm{A} \times \mathrm{S} \times \mathrm{C} \times \mathrm{B}= \\
\text { Change }\end{array}$ & $\begin{array}{l}\text { Where people believe that, } \\
\mathrm{A}=\text { The change is appropriate } \\
\mathrm{S}=\text { Management supports the } \\
\text { change } \\
\mathrm{C}=\text { They can make change } \\
\text { successful } \\
\mathrm{B}=\text { The change will benefit them }\end{array}$ \\
\hline $\begin{array}{l}\text { Multilevel } \\
\text { Framework } \\
\text { (Rafferty et al., } \\
\text { 2013) }\end{array}$ & $\begin{array}{l}\text { The Multilevel Framework } \\
\text { proposes a way of looking at } \\
\text { change readiness across } \\
\text { different levels of an } \\
\text { organization (namely, } \\
\text { individual, workgroup and } \\
\text { organizational). This } \\
\text { framework is similar to the } \\
\text { readiness factors as it } \\
\text { explores the beliefs of } \\
\text { people, although the factors } \\
\text { vary slightly. }\end{array}$ & $\begin{array}{c}\text { N x I x S x B }= \\
\text { Change }\end{array}$ & $\begin{array}{l}\text { Where people believe that, } \\
\mathrm{N}=\text { The change is needed and } \\
\text { appropriate } \\
\mathrm{I}=\text { Can be implemented } \\
\mathrm{S}=\text { will be supported } \\
\mathrm{B}=\text { Will benefit them }\end{array}$ \\
\hline $\begin{array}{l}\text { Determinants } \\
\text { and Outcomes } \\
\text { of } \\
\text { Organizational } \\
\text { Readiness for } \\
\text { Change } \\
\text { (Weiner, 2009) }\end{array}$ & $\begin{array}{l}\text { Weiner's (2009) framework } \\
\text { for organizational readiness } \\
\text { proposes that change } \\
\text { readiness is a factor of } \\
\text { employees shared } \\
\text { willingness to commit to a } \\
\text { change and their ability to } \\
\text { make that change real but } \\
\text { extends this theory to } \\
\text { propose that an individual's } \\
\text { readiness is a result of } \\
\text { organizational factors } \\
\text { relating to the effort required } \\
\text { for the change, resources } \\
\text { needed and context. }\end{array}$ & $\begin{array}{c}\mathrm{EI}=\mathrm{V} \times \mathrm{fE}(\mathrm{T}+ \\
\mathrm{R}+\mathrm{S})\end{array}$ & $\begin{array}{l}\text { Where, } \\
\mathrm{EI}=\text { Effective implementation } \\
\mathrm{V}=\text { Change Valence or that the } \\
\text { change is desired } \\
\mathrm{fE}=\text { Change efficacy as a } \\
\text { function of: } \\
\mathrm{T}=\text { Task demands } \\
\mathrm{R}=\text { Resource availability } \\
\mathrm{S}=\text { Situational factors }\end{array}$ \\
\hline
\end{tabular}

TABLE 3. THE LAST 3 FORMULAS FROM LITERATURE THAT WERE INCLUDED IN THE INVENTORY OF 12 FORMULAS FROM CHANGE MANAGEMENT LITERATURE EXPLORED IN THIS THESIS. 


\subsection{Is One Formula Best?}

At this time, it does not seem that there is one authoritative formula to explore an organization's ability to change, and particularly, an organization's ability to change in support the implementation of design projects. I did not find in this selective review of formulas or my literature review, one authoritative source comparing and contrasting the content of the formulas or a review of the factors that may help people determine a best fit within their specific organizational context; let alone the specific context of design implementation, and even more specifically, the context of design implementation within government. Although I did find one such article listing and reviewing different collections of formulas (Calder, 2013), this list was not all inclusive based on my personal exploration of the formulas available in change management literature.

As mentioned earlier in section 3.6 Design is Change, it is likely necessary for people working in design in the Canadian Federal Public Service to understand the current state of an organization in relation to its ability to change in order to implement their designs and generate benefit within this system. So how can we improve our understanding of organizational factors that may influence design processes and implementation of services within government to increase opportunities for successful design implementation?

\subsubsection{Point of view}

Just as design is complex, so it appears, is the practice of change management. Given the lack of agreement between experts in the field in terms of what factors ultimately have the greatest effect on the success of a change initiative (Sirkin, Keenan \& Jackson, 2005), it would be difficult for a designer or design researcher working in the 
public service to find the formula that could best support them in exploring and contributing to an organization's ability to change through their design process and practice. To add to the difficulties of selection, it is also not clear from the literature explored for this thesis if any of these 12 formulas could support successful design implementation within the context of the Canadian Federal Public Service.

It is worth noting at this point, that change readiness in the Canadian Federal Public Service has been explored (Cinite, 2006), however, the author looked specifically at the perceived change readiness of employees, rather than the organization as a whole. This framing is similar to perspectives from Hanapachern (1997) and even Armenakis (Armenakis \& Harris, 1993) that focus on the individual's readiness for change rather than the organization's (or system's) ability to change. Like Holt et al. (2007) and Weiner (2009), for the purposes of this study, I opted to look at factors of an organization's ability to change from a contextual perspective rather than an individual perspective.

I believed this point of view allowed for a focused exploration of the potential organizational factors impacting ability to change thereby shifting the cause of resistance to change from the individual to the context in which the individual exists. In my view, this allowed more opportunity to manage change outcomes as contexts can be designed, but individuals cannot.

\subsubsection{Developing an understanding of organizational ability to change in context - establishing a methodology}

In an effort to understand what factors the authors reviewed in this thesis believed were important considerations in an organization's ability to change and 
explore how this can be considered within a specific context of design within public service, I conducted a literature review to establish appropriate methods to: compare and find patterns in literature (secondary research), learn about real people's experiences in public service design (primary research) and compare the secondary and primary research findings. Three qualitative methods were selected to clarify which factors from the change management formulas discussed in this thesis may be related to the success or failure of implementing public service design projects. These methods included:

- Method 1: content analysis (coding and themeing) of factors in the formulas found in change management literature (Martin \& Harrington, 2012; Saldaña, 2016);

- Method 2: participant inquiry through multiple-method storytelling techniques (storytelling exercise kit and semi-structured interview with participants) (Gaver, Dunne and Pacieti, 1999; Kalbach, 2016; Martin \& Harrington, 2012; Sanders \& Stappers, 2014; Visser, Stappers, van der Lugt \& Stappers, 2005; Wherton, Sugrahood, Procter, Rouncefield, Dewsbury, Hinder \& Greenhalgh, 2012) followed by content analysis coding and themeing of factors of relevance to participants, (Martin \& Harrington, 2012; Saldaña, 2016); and

- Method 3: a comparative analysis of the identified factors and themes from Methods 1 and 2 (Boschken, 1988).

In order to execute Method 1, I focused specifically on formulas in change management literature that looked at factors related to ability to change (see Tables 1, 2 and 3 for a summary and Appendix 1 for a more detailed review of these formulas), looking at what each author thought contributed to the ability of organizations to change. In order to find patterns and themes in the various formulas, hoping to find commonalities and outliers, I took a systematic coding approach to explore the literature. 
Saldaña (2016) suggests that "coding is analysis" (p.9) and helps to interpret the data. Through three cycles of coding, I felt that using a qualitative coding approach in my content analysis of the literature would be an effective approach to uncover a collection of themes related to factors that could contribute to an organization's ability to change.

For Method 2, I decided I would talk with people who worked on design projects for the Canadian Federal Public Service to hear stories about their projects and learn about their perceptions of their projects' success and/or failure and uncover some organizational factors they thought may have contributed to their project outcomes. In Storytelling for User Experience, Whitney Quesenbery and Kevin Brooks (Quesenbery \& Brooks, 2010) note that "the stories you collect compliment other data" and "illuminate" additional data collected through other means (p. 62). A multiple-method storytelling approach was chosen to compliment and add richness to the systematic study of factors explored during the first part of the exploration (Method 1). First, participants were provided with research kits that contained cultural probes (Gaver, Dunne and Pacenti, 1999; Sanders and Stappers, 2014) that intended to support them in personal reflection regarding two projects they had worked on. Probes may help participants to think about their personal experiences (Sleeswijk Visser, Stappers, van der Lugt \& Stappers, 2005) and explore them more deeply, than with conversation alone. Sleeswijk Visser et al. (2005) have proposed that this type of sensitizing approach may enhance the quality and quantity of contributions to further research exercises. The probes were intended to add more depth to the next part of the research exercise, an in-person directed storytelling exercise (semi-structured interview) in which participants told me stories about their experiences working on successful and unsuccessful projects. As the 
analysis of the data I collected from the formulas led to the emergence of themes in the change management literature I reviewed, I applied a similar content analysis approach to the participants' data, using coding methods to explore, find patterns and generate themes within this data.

To situate their perspectives in relation to existing formulas, Method 3 was developed. Here I decided to collate all of the factors from the literature and the stories I collected from my participants in order to identify similarities and differences between factors from the literature and those identified in participant stories.

As Method 1 served to support a more comprehensive analysis of the formulas found in the change management literature, it is discussed further in section 3.10 Method 1: Content analysis of Formulas in Change Management Literature, along with the results of the coding and theming of the formulas. Methods 2 and 3 which consist of field work are then discussed in Chapter 4: Field Work Methods.

\subsection{Method 1: Content Analysis of Formulas in Change Management Literature}

During the literature review, an exploratory coding exercise was undertaken to find commonalities and differences between the factors in various formulas taken from the literature that may indicate ability to change in order to support design implementation (Harris, 2017; Martin \& Harrington, 2012). As noted previously, many of the formulas discussed were based on or extended pre-existing formulas or contained similar factors. As such, it was important to understand when certain characteristics or factors across these formulas were similar or different, and which seemed to hold the 
most importance for the potential ability to change, based on their prevalence in the literature.

\subsubsection{Rationale for coding strategy}

As this exercise was exploratory, to extract and assess potential factors related to design implementation found in the formulas from literature, NVivo was used to identify a set of Provisional Codes (Saldaña, 2016) using a process of In Vivo Coding, Pattern Coding and Focused Coding. The In Vivo Coding method supports the extraction of the factors from the literature using the language of the authors to ensure that their meaning is captured in the coding (Saldaña, 2016). Each formula was re-reviewed and when specific terms or phrases that were felt to represent a factor related to an organization's ability to change appeared in the context of the description used in the literature, it was captured exactly as written in an In Vivo Code, using the "Code In Vivo" function in the software program. Examples of In Vivo Codes found in literature included "clear and desired end state", taken from Beckhard \& Harris' (1977) Change Formula, "common ground" taken from Dannemiller \& Jacobs' (1992) version of the Change Formula, "nature and strength of evidence" from Kitson \& McCormak's (1998) PARiHS and “change efficacy” from Weiner's (2009) Organizational Readiness for Change Framework. 


\section{First cycle coding (In Vivo Coding)}

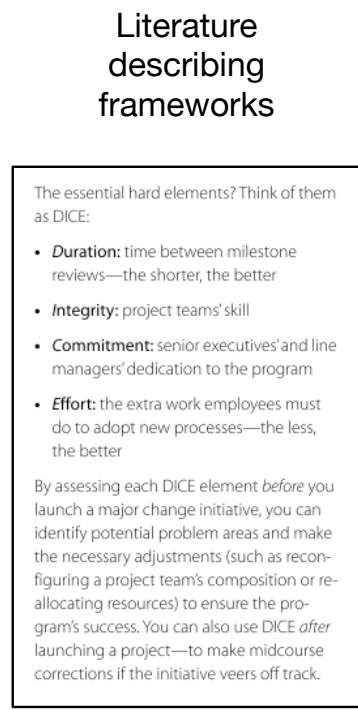

Literature

describing

rameworks
The essential hard elements? Think of them
as DICE:
- Duration: time between milestone
reviews - the shorter, the better
- Integrity: project teams'skill
- Commitment: senior executives'and line
managers' dedication to the program
- Effort: the extra work employees must
do to adopt new processes - the less,
the better
By assessing each DICE element before you
launch a major change initiative, you can
identify potential problem areas and make
the necessary adjustments (such as recon-
figuring a project team's composition or re-
allocating resources) to ensure the pro-
gram's success. You can also use DICE ofter
launching a project-to make midcourse
corrections if the inititive vers of track.

\begin{abstract}
A list of individual codes, reflecting the language of the authors
\end{abstract}

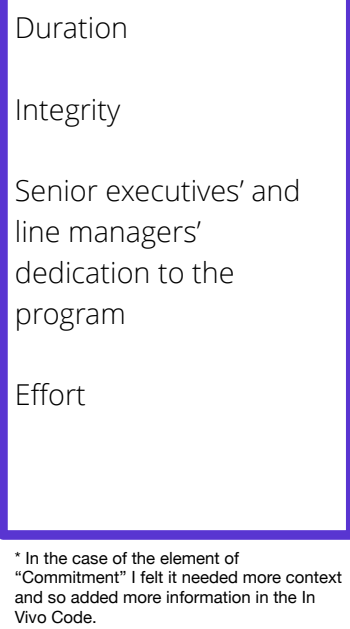

Duration

Integrity

Senior executives' and

line managers

dedication to the

program

Effort

and so added more information in the In

In Vivo Codes uncovered in the first cycle coding

FIGURE 2. AN EXAMPLE OF THE FIRST CYCLE CODING PROCESS USED WHILE EXPLORING FORMULAS FROM LITERATURE USING AN EXCERPT FROM SIRKIN, KEENAN \& JACKSON'S (2005) THE HARD SIDE OF CHANGE MANAGEMENT .

When each formula had been coded using the In Vivo Codes, I conducted a second cycle of coding to identify patterns in the codes (Saldaña, 2016) and to establish higher order categories which could contain similar factors. The In Vivo Codes from the first cycle of coding were organized into folders based on their topic or what they were referring to. Then, they were combined into new codes called Pattern Codes. These Pattern Codes were given a name or label to represent the group or category. For example, the In Vivo Code common ground was grouped with similar codes in a group or category called common understandings, beliefs and values. 


\section{Second cycle coding (Pattern Coding)}

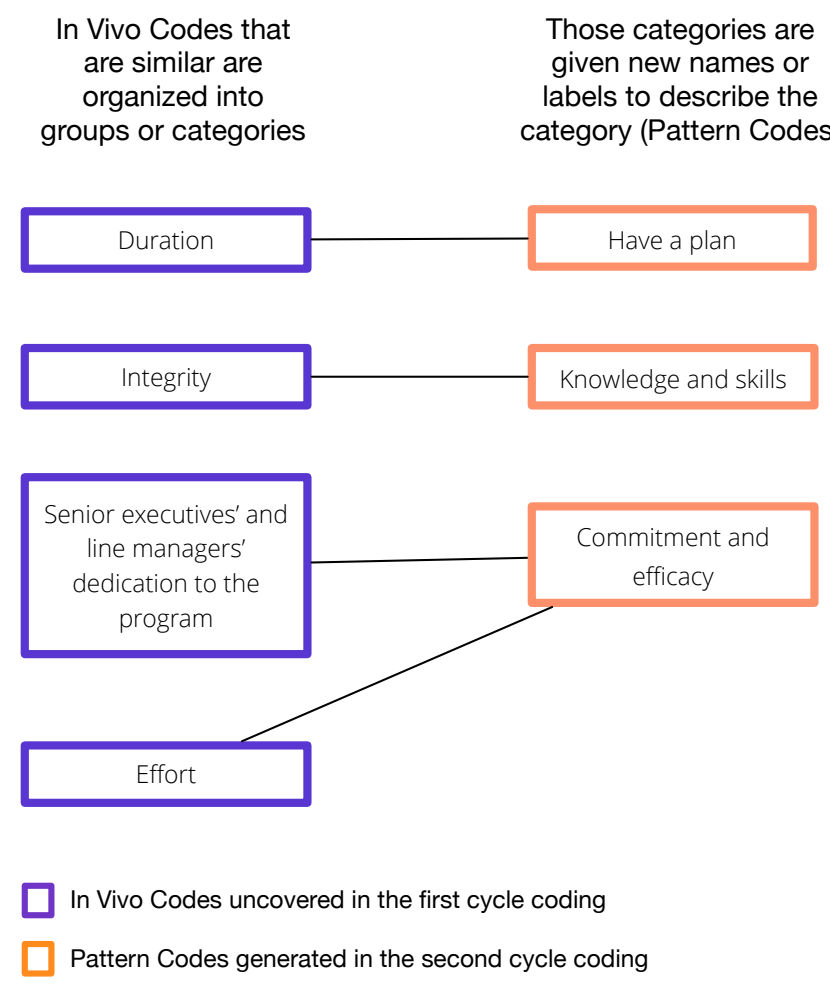

FIGURE 3. AN EXAMPLE OF THE SECOND CYCLE CODING PROCESS USED WHILE EXPLORING FORMULAS FROM LITERATURE USING AN EXCERPT FROM SIRKIN, KEENAN \& JACKSON'S (2005) THE HARD SIDE OF CHANGE MANAGEMENT .

Finally, Focused Coding was used to further refine the proposed categories and identify the most significant factors (Saldaña, 2016). First the Pattern Codes with the greatest number of references from literature (or the highest magnitude) were organized into categories. Then Pattern Codes with less magnitude were organized into those groups where possible, and where not possible, further categories were created. 


\section{Third cycle coding (Focus Coding)}

\author{
Pattern Codes are \\ organized into new \\ categories
}

Those categories are given new names or labels to describe the new category (themes)
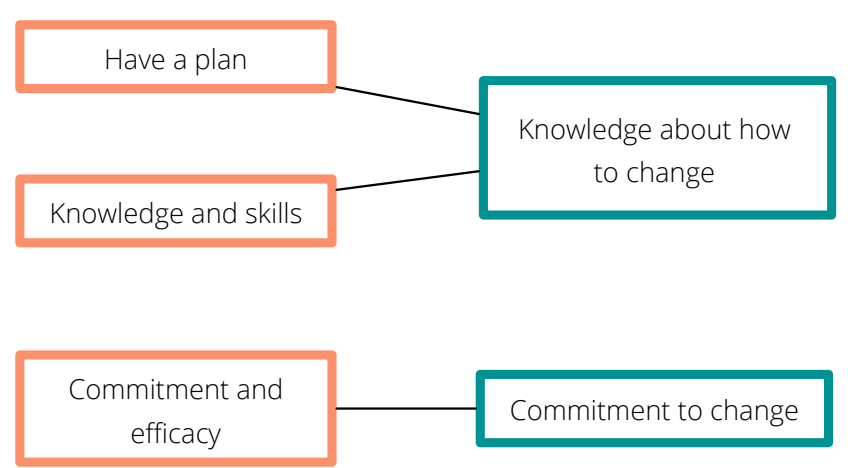

Pattern Codes generated in the second cycle coding

The themes that emerged out of the third cycle coding exercise

FIGURE 4. AN EXAMPLE OF THE THIRD CYCLE CODING PROCESS USED WHILE EXPLORING FORMULAS FROM LITERATURE USING AN EXCERPT FROM SIRKIN, KEENAN \& JACKSON'S (2005) THE HARD SIDE OF CHANGE MANAGEMENT .

When all of the Pattern Codes had been grouped into new categories (to be used as Provisional Codes for field work data analysis), the magnitude of these categories was reviewed. This number reflected how many formulas the category was related to, based on the lower level In Vivo Codes the category contained. The more formulas the category was related to, the higher the magnitude. This indicated how popular or relevant the category (representing a category of factors relating to an organization's ability to change) or 'theme' might be across the literature. 


\subsubsection{The Provisional Codes}

After coding the formulas from the literature (see Tables 1, 2 and 3), and working through the three cycles of coding, 6 themes emerged: capability to change, commitment to change, a need for change, low cost of change, situational readiness and a clear and desired end state (see Table 4.).

Each of the themes had sub-categories at the second and third levels of the information hierarchy generated through coding (see Figure 5). A collection of 18 subcategories (second level categories) were organized into the 6 themes and these subcategories had an additional 10 sub-sets (third level categories) organized below them (Figure 5). These second and third level categories indicated specific considerations related to each of the main categories including such things as the ability to change, knowledge about how to change, scope of change and facilitation in the case of capability to change. The only theme that did not have secondary or tertiary subcategories was the category of $a$ clear and desired end state. Interestingly, this was also the category with the least references in literature. 


\section{Table 4}

The 6 themes that emerged through a content analysis of a selection of 12 formulas found in change management literature. The table includes the description for each theme and the magnitude of that theme.

Name

Capability to change

Commitment to change

A need for change

Low cost of change

Situational readiness

A clear and desired end state

\section{Description}

The knowledge about how to change and the ability for the organization to make the change happen and the size of that change. Includes the organizations ability to change as well as the individual employees' abilities to change as well as what the first steps are required and how to sustain that change in the long run.

The support and positive emotional response to a change that employees and groups of employee's exhibit. Commitment is supported by a common understanding of the change and beliefs about the change.

There is a need for the change to happen. There is dissatisfaction with the status quo, an awareness of the need to change and there is a belief that the change is needed.

The things that are being given up for a change including start team members, money, time for other initiatives. The cost of change must be outweighed by the commitment to the change in order for the change to be successful.

In support of ensuring the situation (environment, climate or context) is ready for the change before the change can be successfully undertaken. Situation includes culture, the physical environment, how people are lead and work together, project management, measurement, and the level of stress. There is a clear sense of what the organizational, work and individual situation will be once the change has been undertaken. That end state is something people want and share an understanding about.

TABLE 4. 


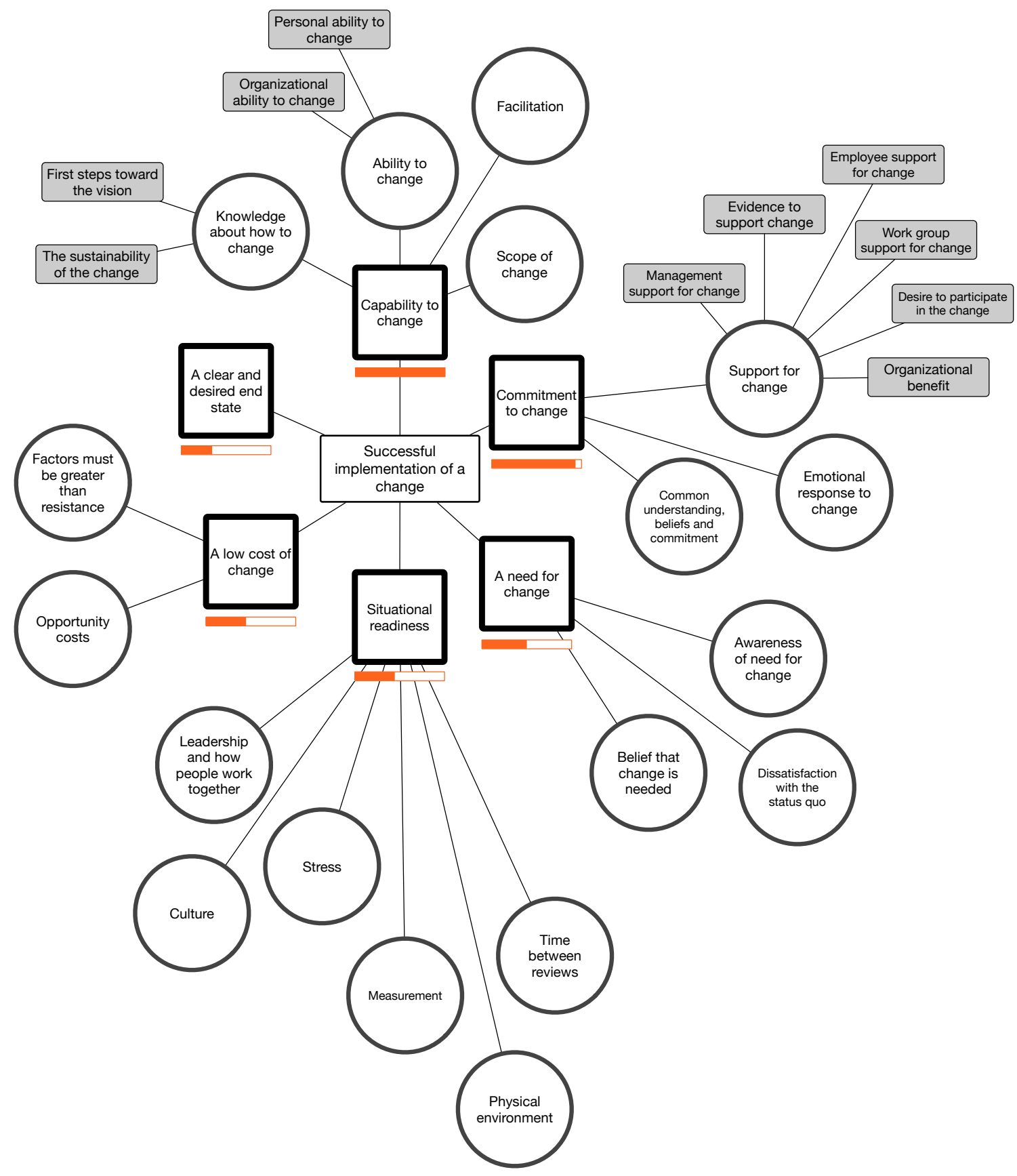

FIGURE 5. A MODEL OF THE CATEGORIES UNCOVERED THROUGH THE CODING OF THE FORMULAS IN LITERATURE AND THE MAGNITUDE OF THE TOP LEVEL CATEGORIES OR THEMES (REPRESENTED BY THE ORANGE BARS BELOW EACH BOX WHICH CONTAINS A THEME). 
The category capability to change had the greatest magnitude in the study and was identified in all 12 formulas analyzed. It is likely that the level of magnitude of any particular category of codes indicates the importance of that factor or those factors have in relation to an organization's ability to change.

A model of the themes and categories is shown in Figure 5, with the goal of Successful implementation of a change at the centre and the contributing factors radiating outward beginning with the main themes or first level categories from the literature followed by second and third level categories (more granular levels). Magnitude is identified by bars below each category in the map, where the greater the magnitude of the category, the fuller the bar. For example, the category of capability to change has a bar that is complete. This indicates that it was, as noted earlier, identified in all 12 formulas. The theme a clear and desired end state, on the contrary, only appeared in 4 of the 12 formulas reviewed, and its bar reflects this.

These themes, sub-categories and their descriptions were used to create a codebook to be used in the coding of the research data collected during the participant portion of the study (Method 2). As I was looking to determine if one of the formulas in literature would be best suited for use within the context of supporting the implementation of public service design, this new set of codes was created to uncover similarities and differences between the factors found in the formulas and those identified through primary research with designers in the public service. Saldaña (2016) states that "Provisional Coding is appropriate for qualitative studies that $[\ldots]$ corroborate previous research and investigations" (p. 168). Given that I was looking for similarities and dissimilarities across data sets, this approach was a natural fit and the codes 
generated in the third cycle of coding the content from the literature served as my Provisional Codes during content analysis of the field work (see Chapter 4: Field Work Methods and specifically section 4.3.6 First cycle coding: Provisional and In Vivo Coding).

\subsection{Design, The Public Service and Formulas from Change Management Literature}

At the beginning of this first part of my study I set out to uncover what might be making it difficult to make design in government something real that people could use. Design has potential to benefit the public service, and if we are truly intent on making things better for all people using government information and services, it is essential that the work designers do gets into the hands of people who need it. But this is no easy feat. If a design is made into something real, then something has to change to bring about this new state, this new thing, this new service - but change can be hard.

According to change management theory, change is more successful when the organization undertaking the change is ready for it. So if designers in the public service are to produce effective design solutions that can be realized, they likely need to know if the organization is ready for that change and more specifically, what factors may influence the ability to bring about change.

But where to start?

As I have shown here, there are a number of formulas available in change management literature, tools that could be used to determine if an organization might be able to change in support of a new design. But is there one formula that would be best for a designer in the Canadian Federal Public Service could use to determine if the 
organization they are working for might be able to change in order to implement proposed designs? There was no easy answer to that question in the literature, so an indepth assessment of the selected formulas was required to determine where the formulas were similar and where they weren't, before digging any deeper.

Based on the findings from the exploration of the formulas from a selection of change management literature, there appear to be 6 themes that represent categories of factors that may contribute to an organization's ability to change, with the most important themes being capability to change and commitment to change. I found that this finding aligned most closely with Weiner's (2009) Organizational Readiness for Change Framework and also very close to the condition's for change Conner (1994) proposes in the Pain $x$ Remedy formula. But, despite these 2 factors perhaps being important to ability for an organization's ability to change, they were not the only themes that appeared in my exploration of the formulas. I also wasn't entirely sure if this finding was reflective of what was actually hindering progress in the real-life context of public service design.

As I mentioned in 3.8.1 Point of view, Cinite (2006) did explore change readiness in the Canadian Federal Public Service in terms of the employee attitudes towards change, however, I had chosen to explore the context of the change in terms of the factors that could contribute to a successful design implementation, rather than employees' attitudes alone (which follows the formal definition of change readiness found in 3.7 Is the Organization Ready for Change?). Although employee attitude toward the change is an important consideration of readiness for change, following review of both Rafferty et al's (2013) Multilevel Framework of Change Readiness and 
Weiner's (2009) point of view on organizational readiness for change, I took the point of view that the factors that may indicate an organization's ability to change to implement a design would likely be a result of the context of the organization and so continued an exploration of factors that may contribute to an organization's ability to change that could be broadly applied to an organization, rather than the employee context alone. Limitations of this point of view are discussed in 6.5.4 Researcher Bias.

I believed that further analysis of the formulas I had found in literature would help me find a formula that would be a good fit for exploring organizational ability to change for design implementation in the Canadian Federal Public Service and support the next part of the study where I examine what may be influencing the success or failure of design projects in public service through the voices of participants working in this area. 


\section{Chapter 4: Field Work Methods}

\subsection{Overview}

Through my literature review and content analysis of 12 different formulas from a selection of change management literature, I uncovered 6 main factors related to an organization's ability to implement successful change. But could such factors be related to the success or failure of design projects in public service? Was there a specific formula that I or my colleagues working in design could begin using tomorrow that could help me explore an organization's ability to change as I considered my next design project?

After coding and themeing the literature review (3.9 Method 1: Content Analysis of Formulas in change management literature), I undertook an exercise to learn about peoples' experiences with design projects in the public service context through Method 2: Participant Inquiry followed by Method 3: Comparative Analysis. In Method 2: Participant Inquiry, organizational factors that may contribute to the success or failure of a design project and, by extension, the ability to affect change were explored using two 'storytelling' methods to support the qualitative inquiry: an unmoderated exercise that required participants to complete a workbook and a mind mapping activity followed by a semi-structured interview where the exercise was discussed in person. This data was then coded and themed, again using NVivo following a similar approach used for the content analysis of the literature (Method 1). Once the data was coded and themed, a new set of factors that may indicate the potential for successful design implementation that emerged from the participant research data was compared with the factors I found when exploring 
12 formulas from change management literature in Method 3: Comparative Thematic Analysis. The formula from the literature exhibiting the greatest volume of similar factors to the participant data (with the greatest magnitude) was identified and the findings were discussed.

Method 2: Participant Inquiry consisted of two parts: 1) individual participant reflection on personal experiences using the research kit (workbook) which contained probes and design tools (Gaver, Dunne and Pacenti, 1999; Sanders and Stappers, 2014) to support the storytelling exercise and mind mapping activity and 2) a follow up semistructured interview with the participant to explore the outcomes from completing the kit. Each research kit contained materials and two probes to elicit a type of 'directed storytelling' about projects that were successful and not successful (Martin and Hannington, 2012) for each project. The first probe was a workbook that contained a set of questions designed to direct the participant through a personal story. This probe was intended to sensitize the participant to the work they needed to do in the second part of the exercise and help them think deeper about past experiences. When the workbook was done, the storytelling activity was extended through the second probe, which involved the use of a mind mapping tool (Hanington \& Martin, 2012). Here, participants first identified the outcomes from their project that surfaced in the workbook and then suggested the main factors that they felt may have contributed to those outcomes. They were then asked to consider sub-factors that may have contributed to the main factors and then also include what may have contributed to the sub-factors. 


\subsection{Preparing for Methods 2 and 3}

Preparing for Methods 2 and 3 involved the development and piloting of prototypes of possible research tools (Figures $7,8 \& 9$ ) that might be used with participants to explore the intricacies of the proposed methods in advance of submitting the ethics protocol.

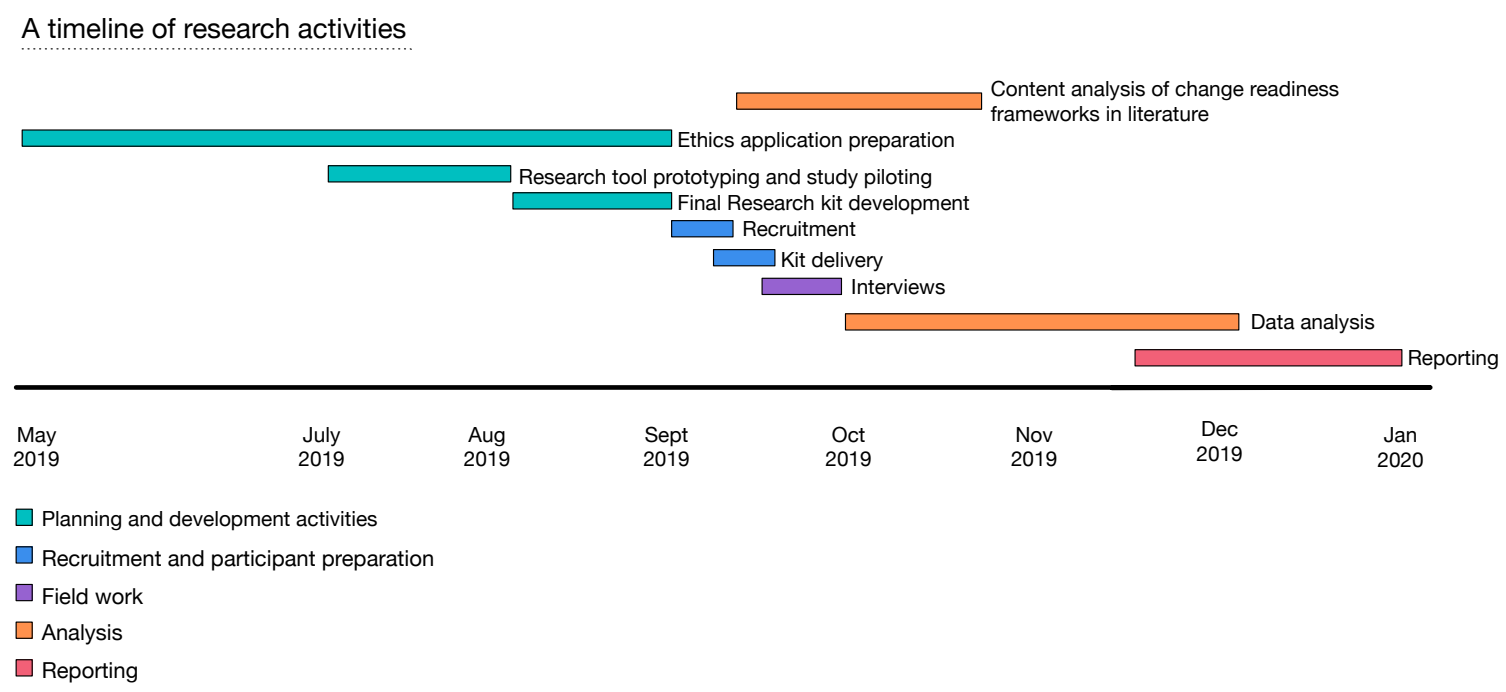

FIGURE 6. A TIMELINE OF RESEARCH ACTIVITIES BETWEEN MAY 2019 AND JANUARY 2020.

These prototypes (see Figures 7, $8 \& 9$ ) helped explore unknown details of the study, assess feasibility of the approach and share the participant inquiry methods with people in a way that was more tangible and could convey the intent of the research tools more readily. The pilot testing also brought up a very important ethical consideration for the project: the culture of trust within the government setting and learning about the fear of sharing information about how government works. This protocol (see Appendix 6 for more detail) was amended to provide even greater anonymity to participants to address this concern. 

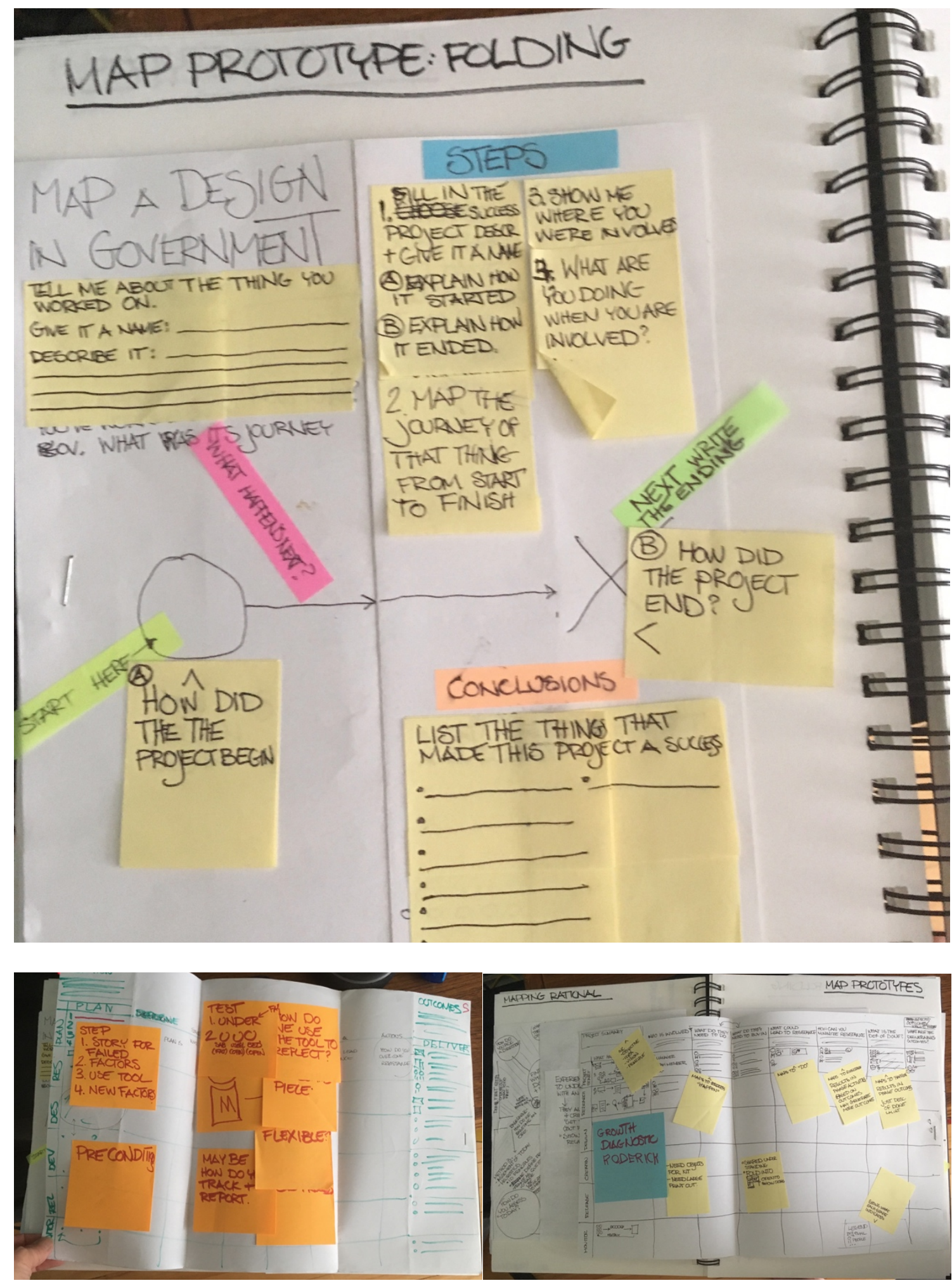

FIGURE 7. MAP CONCEPT PROTOTYPES THAT WERE USED TO EXPLORE VARIOUS MODERATED AND UNMODERATED MAPPING METHODS (KABLACH, 2016; MARTIN \& HANINGTON, 2012). 

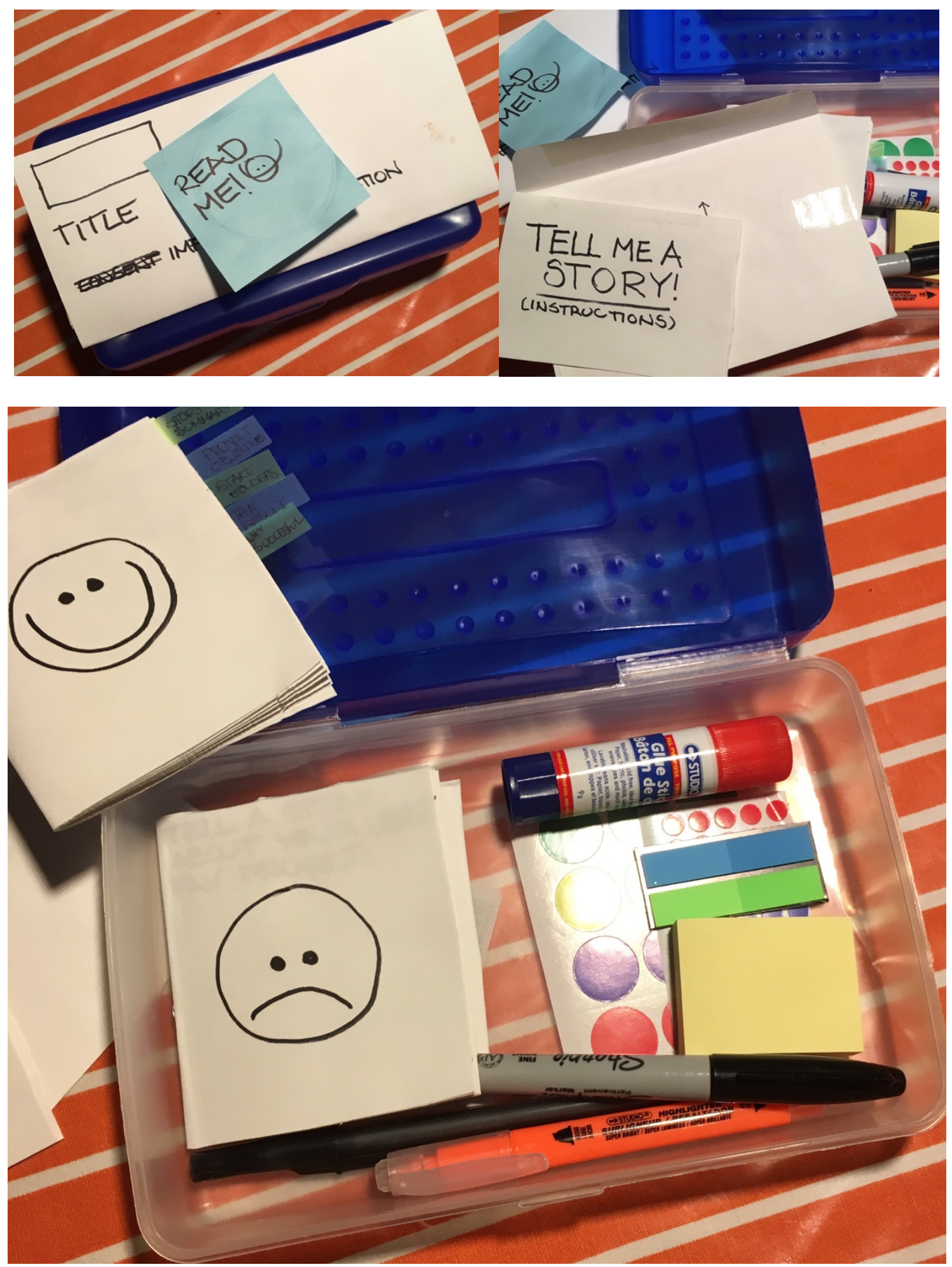

FIGURE 8. PRELIMINARY RESEARCH KIT CONCEPTS INCLUDING CONSENT FORMS, STUDY INFORMATION AND CULTURAL PROBES (WORKBOOKS TO HELP PARTICIPANTS THINK ABOUT SUCCESSFUL AND UNSUCCESSFUL PROJECTS. 


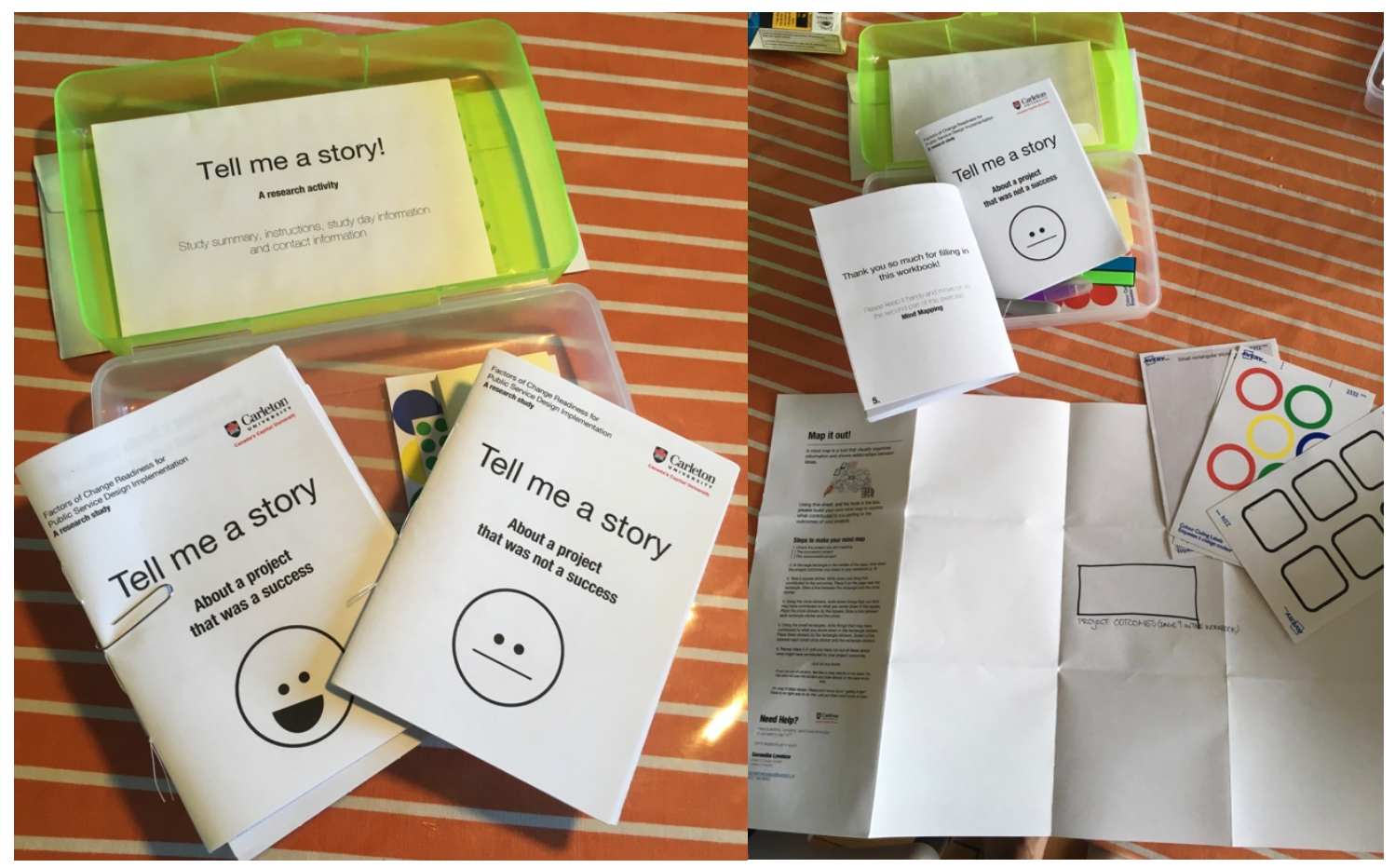

FIGURE 9. A REFINED PROTOTYPE RESEARCH KIT USED IN THE PILOTING OF THE STUDY TO TEST METHODS IN ADVANCE OF ETHICS APPLICATION.

\subsection{Method 2: Participant Inquiry}

\subsubsection{The research kit}

Each research kit was delivered to participants at least three days before the inperson portion of the study. The kits contained: the study information and consent form research, a study summary, kit instructions, in person interview information and contact information, a pen, highlighter, sharpie, small post-its, flags, and small and extra-small dot stickers and 2 envelopes containing probes to elicit storytelling.

The participants were prompted to start with the probes for a successful story as I believed that this story would be easier to reflect on and would give the participant practice with completing the probes before they got into describing the unsuccessful 
project. Each probe envelop contained: a workbook, a mind mapping tool, and stickers to be used with the tool.

\subsubsection{The workbook}

The workbook began with a request for the participant to first tell a successful story about a design project they worked on while working with the Government of Canada (Figure 10) followed by an unsuccessful story. There were no rules to how this story was told. The participant was allowed to use their own words and cover details they felt may be relevant to explain what the project experience was like. The participant was then prompted for further information with a series of follow up questions relating to the project including: What the project objectives were, who was involved in the project, what the project outcomes were, why the project was a success or not a success and if there were any other considerations they would like to include with their story. 


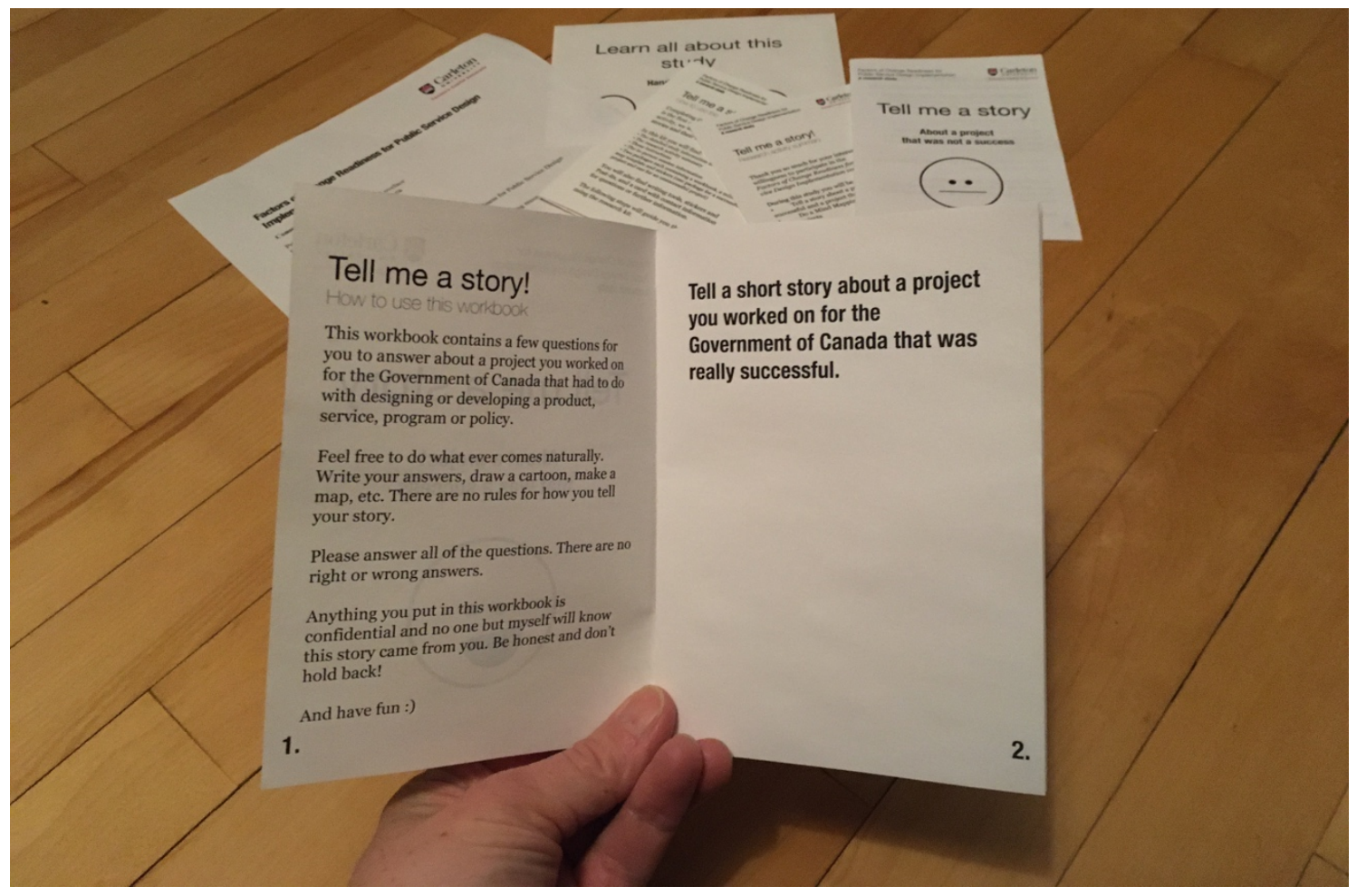

FIGURE 10. AN IMAGE OF THE FIRST TWO PAGES OF THE OF WORKBOOK FOR A SUCCESSFUL PROJECT.

\subsubsection{The mind mapping tool}

When participants opened up the mind mapping tool, they also found 5 sheets of stickers: 1 sheet of squares, 2 sheets of circles and 2 sheets of grey rectangles. To the left of the map, participants found instructions about how to make their mind map. In the centre of the tool, they found a rectangle in which they were instructed to enter the project outcomes from page 10 in the workbook that was found with the mind mapping tool when they opened their kit. Then they were asked to identify one factor that felt may have led to this outcome and write it down on a square sticker. Participants were not guided as to what type of factor this should be and were free enter whatever came to mind. 


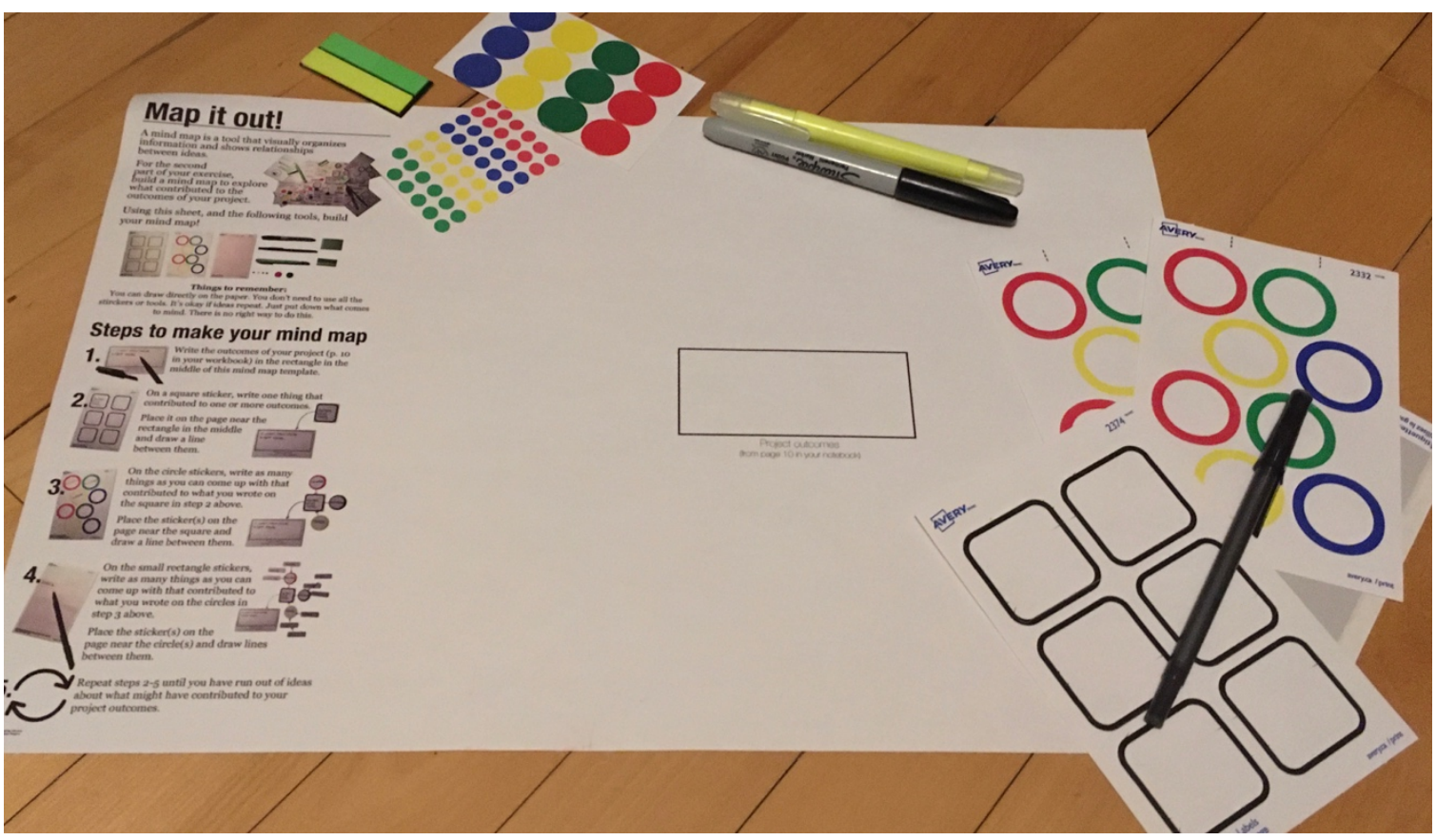

FIGURE 11. AN IMAGE OF THE MIND MAPPING TOOL, STICKERS THAT CAME WITH THE TOOL AND SOME ADDITIONAL DESIGN TOOLS FROM THE RESEARCH KIT.

Once participants had entered something on the square sticker, and placed it on the page, they were prompted to explore additional things that may have contributed to that factor on the circle stickers. They were prompted one more time to repeat the exercise and write things down on the small grey rectangles that may have contributed to the factors on the circle stickers. These three steps were repeated until participants ran out of ideas or space, based on the constraints of the paper mind mapping template they were using (Figure 11). 


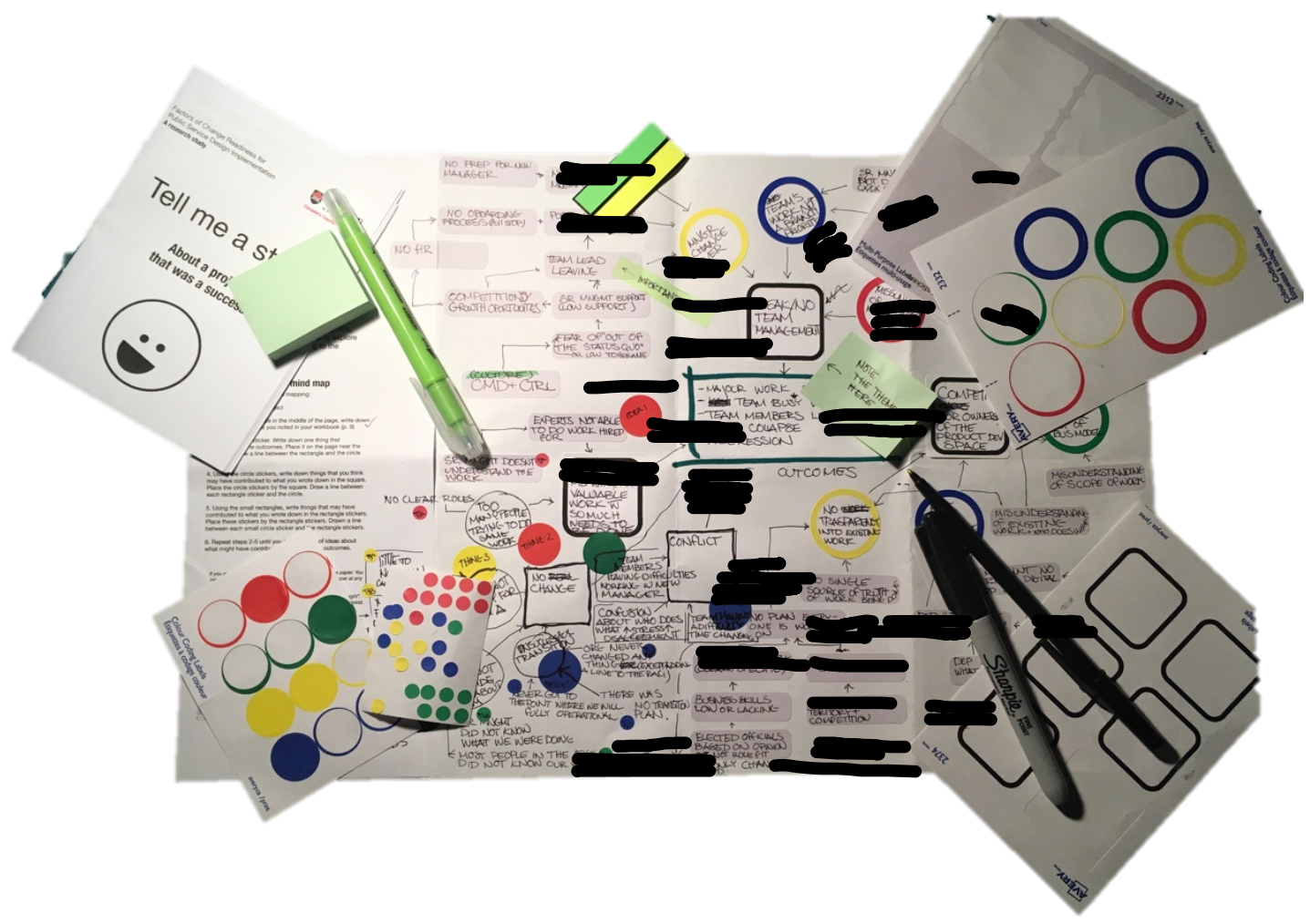

FIGURE 12. A PILOT MIND MAP COMPLETED USING A PROTOTYPED RESEARCH KIT.

\subsubsection{Semi-structured interviews}

Following the unmoderated, storytelling exercises, participants met with me in

person to tell me their stories. In this part of the study, I asked the participant to:

1. Summarize the unsuccessful project (participants were offered the option to also share their workbook and map and use them as storytelling tools).

2. Reflect on what they would do differently or would repeat in their next project and why.

3. Review the key points from the discussion with the researcher to ensure they didn't misinterpret or miss any vital information.

4. Repeat this discussion for the successful project. 
The interviews originally started with the successful project and then covered the unsuccessful project, but after a few conversations it was clear that the sessions needed to end on a high note as the stories of unsuccessful projects tended to be emotional and exhausting, not the way anyone (myself or the participants) wanted to wrap up the interview. The unsuccessful stories were also found to take more time to tell and the sessions were going over time.

After greeting the participants, going over the study information and signing or receiving a signed consent form, I asked them to tell me their story. They were not asked to tell their story in any way at the beginning but were asked to follow up questions after the story was done if they did not already cover the questions asked in the workbook. These questions included: What were the project objectives, who worked on the team, what the project outcomes were, why the project was or was not a success and if there was anything else to share. Once the participant was done telling the story, I recapped the information I collected, and the participant was asked to confirm if I had captured their story effectively in my notes.

\subsubsection{Participants, recruitment \& ethical considerations}

This study was approved by the Carleton University Research Ethics Board. A total of 18 participants (Guest, Bunce \& Johnson, 2006) were recruited which included people who identify as designers, design researchers, or analysts on program, policy, service or product development projects (referred to as 'design projects') and had worked or were working on Government of Canada projects. Participants were recruited directly by email and via a snowball sampling technique (Taylor, DeVault \& Bogdan, 2016). This approach ensured that a selection of peers outside of my immediate network 
were also represented in the study. Participants were also recruited via social media posts on Twitter and LinkedIn social networking platforms. Scheduling for the study was done directly with the participants using the Calendly scheduling application (www.calendly.com). Participants selected their preferred time for meeting based on a pre-selected date range and time frame.

Given the nature of the subject matter, all participant data was treated as completely confidential and any identifying information was redacted or removed from the data. So that participants had as much information as possible when considering participating in the study, a link to the study information was provided during recruiting. Participants also received printed study information and a consent form with their kit and the study details, objectives, benefits and risks were reviewed with the participant prior to beginning the in-person interview. The interview portion of the study was conducted at a location that was convenient for the participant, quiet enough to talk and had enough space to review the participant's map, while conversing comfortably. Locations included open public spaces such as coffee shops and cafeteria seating areas.

\subsubsection{Types of research data}

The research data included:

- The researcher's notes in a journal

- Audio recorded from the interview session

- The workbooks and maps created by the participants

- Photographs of the participant using the items from the research kit during the interview

- Any other artifacts generated in the study that the participant wanted to share including emails with follow up information 


\subsubsection{Redaction and information management}

Data collected from the exercise was first prepared for analysis by redacting identifying information relating to the participant's:

- Project name

- Project type

- Organization

- Industry

- Team member details

- Participant job title or role

- Years of employment

- Personal information

Each participant's data was then photographed and uploaded to NVivo for coding and themeing. The audio from the interview was set aside in case clarification was needed later. The photographed participant research objects were assigned values to identify which participant they belonged to, whether they were for a successful or unsuccessful project, what type of research object they were (notes, maps, or workbooks) and what question from the study they related to.

The photographs were all uploaded into NVivo and Attribute Coding was used to assign each file codes that classified them by participant ID, type of story (successful or unsuccessful) and type of photograph (notes, map or workbook pages). The Attribute Codes were used for data management so that I could quickly find related files within the system and explore the data by participant, story type and file type to find patterns and develop a better understanding of the data based on the context of its origin (Saldaña, 2016). To increase efficiency during the coding process, the files were organized by 
participant and analysis was undertaken 6 participants at a time. Similar file types were coded together (for example, all the maps from the first group of participants were coded together, the notes were coded together, etc.). This increased analysis efficiency as the steps required to code each research object type could be repeated and method shifting was minimized.

\subsubsection{First cycle coding: Provisional and In Vivo Coding}

\subsubsection{Provisional Coding}

In the first cycle of coding the participant data, each photographed research object was coded using Provisional Coding and In Vivo Coding (Saldaña, 2016). Provisional Coding was used to explore the participant data in relation to the set of Provisional Codes uncovered in Method 1 where factors from 12 formulas found in change management literature were explored. The purpose was to determine if the themes and patterns from literature would appear in real life. This was a validation exercise as well as a mapping exercise where any additional factors could be mapped to the categories identified in the literature. During Provisional Coding, the themes and subcategories generated in Method 1: Content Analysis of Formulas in Change Management Literature were set up in NVivo as starter codes that were then used to explore the data. As a potential factor of project success was identified in the participant data, that factor was coded with one of the existing Provisional Codes, if there was one that fit.

\subsubsection{In Vivo Coding}

In Vivo Codes were also used in the first cycle coding to explore the data deeply, to add context to the content coded with the Provisional Codes and to code factors from the participant data that could not be coded with an existing Provisional Code. The first 
cycle of coding was designed to build and in-depth familiarity with the data, to code the data for reporting and retrieval, and to understand how participant experiences might relate to the factors from literature. To code the data with In Vivo Codes, when a potential factor of project success was identified in the participant data, it was first coded with a Provisional Code, and if applicable, the exact wording of the data point was used to generate the In Vivo code. Depending on the type of data, this In Vivo Code may be one word or many.

\subsubsection{Simultaneous Coding}

The use of the Provisional Code and In Vivo Codes together is called “Simultaneous Coding” (Saldaña, 2016, p. 94). This approach was used so that I could find relationships between the participant data and the themes generated from the literature and also capture the content of the data point as my data was generated from digital photographs of research objects.

There were times during the coding process where I found that some of the Provisional Codes were not clear or meaningful enough to decide if one code was better suited to participant data than another. In this case, the data were coded with two or more Provisional Codes and a memo was created in NVivo noting observations about the issue and along with a recommendation for how to address it. For example, in a memo titled "Capability to change and situational readiness" I wrote:

"I think there is too much overlap between capability to change and situational readiness.

According to Beckhard and Harris, Chip and Dan Heath and Conner, to change, people must know what a change is, want to change, 
know how to change and have the environment in which they can change (amongst other things). Without the right environment, though, a person can have all the knowledge in the world and not be capable of change. As such, I think the label is incorrect and does not reflect the contents effectively."

Similarly, some data points from participants related to more than one Provisional Code. For example, a point in a map about a "lack of understanding about overall goals" could be about how people perceived what they were doing and whether or not there was a clear goal. In this case, the data point was coded with two Provisional Codes: common understanding, beliefs and commitment and a clear and desired end state. 

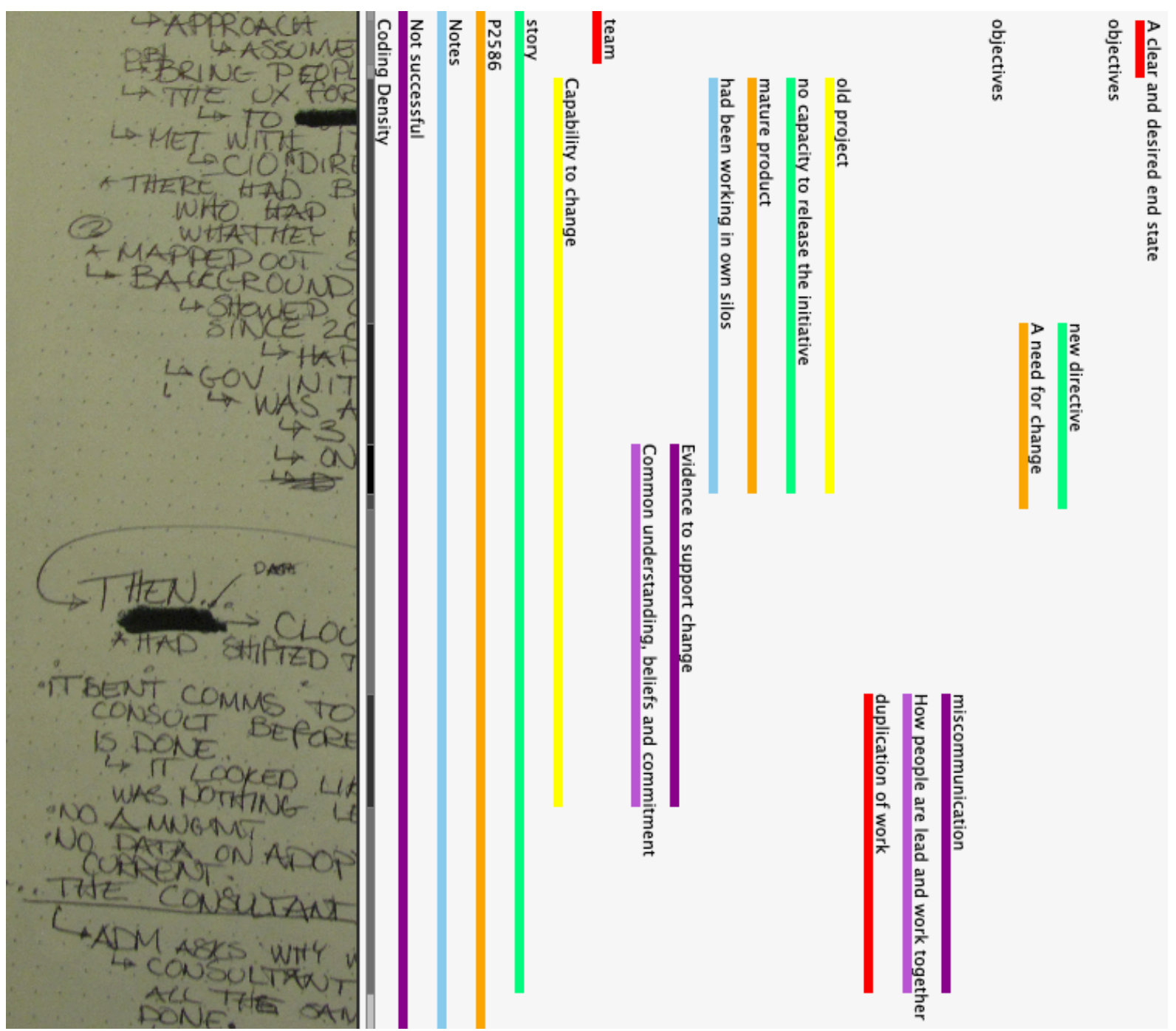

FIGURE 13. AN EXAMPLE OF A NOTE THAT IS SIMULTANEOUSLY CODED WITH MULTIPLE PROVISIONAL CODES AND IN VIVO CODES.

The Simultaneous Coding approach I used generated blocks of codes in NVivo (Figure 13) that could be used to visually explore the data. It also served to build a data set that would allow me to use NVivo queries and exploration tools to learn which Provisional Codes were most closely related and which In Vivo Codes fit themes developed from the Provisional Coding. By using the Simultaneous Coding method I was able to use the NVivo data generated to inform patterns in the second and third cycle 
coding activities that helped identify factors that did not fit in to the Provisional Codes.

For more detail on coding strategies for each research object, refer to Appendix 2: Approach to Coding Participant Data.

\subsubsection{Second cycle coding: Pattern Coding}

When the first cycle coding was complete, a second round of coding was undertaken to find patterns in the data and group the In Vivo Codes into categories based on findings from the first cycle coding (Lidwell, Holden \& Butler, 2003). This exercise also served to get rid of duplicate and redundant In Vivo Codes and organize the data into manageable, smaller "chunks" of data (Lidwell, Holden \& Butler, 2003) that were much easier to work with.

Folders were set up for each of the categories found in the first cycle coding and labeled with that proposed category. The In Vivo codes generated in the first cycle of coding were then organized into the folders and codes that were the same or similar in wording or nature were merged into new codes that merged the codes together under one new code. Within each folder, the In Vivo Codes were further organized into categories, generating Pattern Codes or as Saldaña (2016) explains "more meaningful [...] units of analysis" (p. 236). Once all of the In Vivo Codes had been organized by a Pattern Code (or it had been concluded that there was no existing category for an In Vivo Code), all of the codes (Pattern Codes and In Vivo Codes that did not seem to have a natural category) were moved out of the folders so that they could be explored together.

Similar Pattern Codes were merged, and new Pattern Codes emerged as the new codes were explored all together. 
This second review of the codes allowed for further reflection on the organization of the codes after the first cycle of coding and presented an opportunity to correct any mistakes made during the coding process. This review was also supported with a series of reports and exploratory artifacts, generated to explore the Pattern Codes uncovered in the second cycle of coding and confirm the final set of Pattern Codes.

The final set of Pattern Codes were identified and compared with the original categories identified in the first cycle of coding.

\subsubsection{Third cycle coding: Focused Coding}

In the third and final round of coding, the reports generated to search for patterns in the second cycle coding (such as the tree map and sunburst diagram of the hierarchy of codes used throughout participant data) were used to inform the final set of codes which were proposed as the themes that may indicate an organizations' ability to implement a design successfully found in the research with participants.

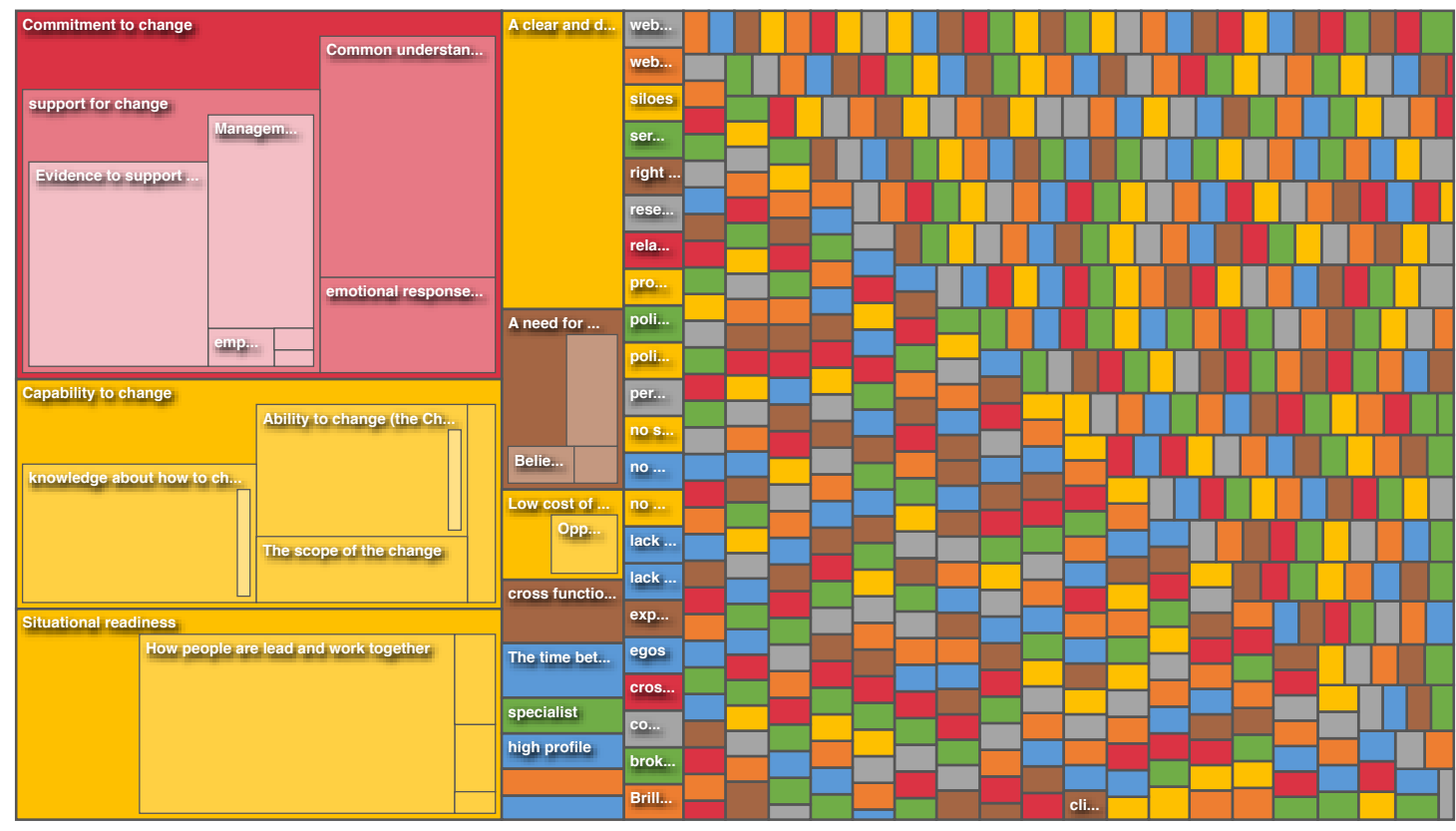

FIGURE 14. AN EXAMPLE OF A TREE MAP VIEW OF A HIERARCHY CHART IN NVIVO. 


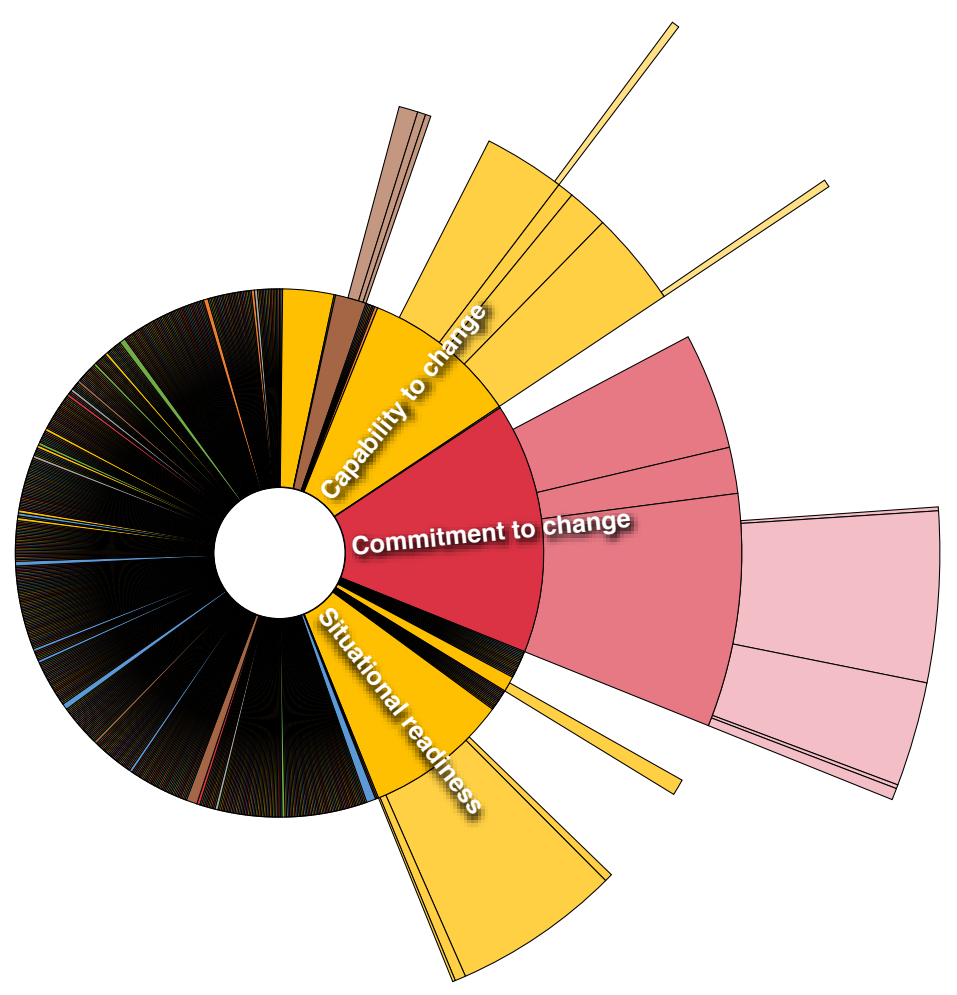

FIGURE 15. AN EXAMPLE OF A SUNBURST MAP VIEW OF A HIERARCHY CHART IN NVIVO.

The Pattern Codes from the second cycle of coding were explored in order of magnitude or the volume of aggregated references across the participant data. The Pattern Codes with the greatest number of aggregated references were organized first and subsequent Pattern Codes were organized into these new categories.

To support the Focus Coding exercise, a framing exercise was developed to help make further sense of the Pattern Codes and organize them quickly and effectively. The exercise asked the question "In order for change to happen, what has to be true?" This technique taken from a research question generation exercise proposed by Knapp et al. (2016), helped me reframe the Pattern Codes generated in the second cycle and make sure that I was comparing similar types of information (Knapp, Zeratsky \& Kowitz, 
2016). For example, I worked through the exercise as I reviewed and considered the Pattern Codes bring people along, expectations and reasons for doing the work. These three Pattern Codes were difficult to consider together, because they were so different. The code bring people along of course was an action, while expectations something people have and reasons for doing the work are things that people must understand. I could have organized the terms in the following categories:

\section{Table 5}

An example of 1 approach I could have taken when organizing a set of Pattern Codes in the third coding cycle.

\section{Pattern Codes}

Bring people along Expectations Reasons for doing the work
Examples of categories I could organize into

How to make change happen Things to consider when managing change What people must understand

TABLE 5. AN EXAMPLE OF GROUPS THREE PATTERN CODES COULD HAVE BEEN ORGANIZED INTO.

None of these categories seemed like they would reflect factors that may contribute to and organization's ability to change, so I reframed the Pattern Codes using a "what has to be true?" question (Table 6). 


\section{Table 6}

An example of the "what has to be true?" question framing process I used to generate Focus Codes in the third cycle of coding.

\begin{tabular}{|lcc|} 
Pattern Codes & $\begin{array}{c}\text { Answer to the question: "What } \\
\text { has to be true in order for } \\
\text { change to happen?" } \\
\text { Bring people along }\end{array}$ & $\begin{array}{c}\text { The resulting category } \\
\text { names or labels used in } \\
\text { the Focused Coding } \\
\text { exercise }\end{array}$ \\
$\begin{array}{l}\text { Everyone has to be on the same } \\
\text { page }\end{array}$ & $\begin{array}{c}\text { There is shared } \\
\text { understanding about the } \\
\text { work }\end{array}$ \\
$\begin{array}{l}\text { Everyone's expectations have to } \\
\text { be known }\end{array}$ & $\begin{array}{c}\text { There is shared } \\
\text { understanding about the } \\
\text { the work }\end{array}$ \\
$\begin{array}{l}\text { Everyone has to have a shared } \\
\text { understanding of why the work is } \\
\text { being done }\end{array}$ & $\begin{array}{c}\text { There is shared } \\
\text { understanding about the } \\
\text { work }\end{array}$ \\
\hline
\end{tabular}

TABLE 6. A TABLE ILLUSTRATING AN EXAMPLE OF HOW I ANSWERED THE QUESTION OF "WHAT HAS TO BE TRUE?” TO GENERATE FOCUS CODES.

This exercise was used to support the Focus Coding exercise and generate the final set of codes that would represent the factors that may support an organization's ability to change for design implementation. These factors were then merged into higher order, first level categories or 'themes' and the magnitude of the themes was identified to determine how important the factor may be in relation to participant experience. The higher the magnitude, the greater the importance.

\subsection{Method 3: Comparative Analysis}

In the final part of the study, the final set of factors explored in Method 2 Participant Inquiry to address the question What factors may be influencing design project success and failure in the federal public service? were mapped to each of the 12 formulas found in the literature review using a comparative matrix. 


\begin{tabular}{|c|c|c|c|}
\hline $\begin{array}{l}\text { Table } 7 \\
\text { A comparati } \\
\text { also found ir }\end{array}$ & $\begin{array}{l}\text { exploring } \\
\text { ulas from li }\end{array}$ & ot the mair & in research \\
\hline Factor & Formula 1 & Formula 2 & Formula n \\
\hline Factor 1 & $\mathrm{x}$ & & $\mathrm{x}$ \\
\hline Factor 2 & & $\mathrm{x}$ & \\
\hline Factor $\mathrm{n}$ & $\mathrm{X}$ & & $\mathrm{X}$ \\
\hline Total count & 2 & 1 & 2 \\
\hline
\end{tabular}

TABLE 7. AN EXAMPLE OF A COMPARATIVE MATRIX

This helped me to see which formula(s) incorporated the most factors found in the field work and how often the factors were found across these formulas.

Saturation and gaps in the literature were identified by totaling how often the factors were found in literature. If a factor was incorporated in all the formulas $(100 \%$ of the formulas), it was considered 'saturated' meaning that it was well covered in literature. If a factor was included in a few formulas (less than $20 \%$ ), it was considered a 'gap' meaning that the literature may not be exploring this factor well. The formula that was identified to have the greatest amount of factors from the field work with participants, with the highest level of magnitude, was considered to be the best suited to be used by designers exploring organizational readiness for change to better support design implementation within the Canadian Federal Public Service. 


\section{Chapter 5: Results}

\subsection{Overview}

After uncovering the themes related to an organization's potential ability to change from the selected review of change formulas found in the literature, which included themes of a commitment to change, the capability to change, a clear and desired end state, situational readiness, a need for change and the low cost of change (Figure 5), it was important for me to understand if these or any other factors may be uncovered in the real-life context of design implementation as experienced by individuals working in design for the Canadian Federal Public Service. If it turned out that the factors from the formulas found in the literature were reflected in the real-life experiences of participants, it was likely that one of these tools could be used by designers to explore organizational context during the design process and perhaps increase the potential for successful design implementation in the Canadian Federal Public Service.

The following results present an overview of 1) what I found in the exploration of the data collected from the participants and 2) what I found when comparing these findings to themes from existing change formulas found in the literature.

\subsection{Information About the Study}

During this study, 18 participants told a total of 34 project stories about successful and unsuccessful projects they worked on for the Government of Canada. 
Of the people who participated in the study, I knew:

- 5 very well (I had socialized with them outside of a work context more than once);

- 6 socially (I had worked with them or had socialized with them in a work context); and

- 7 not at all (The kit drop-off was the first time I had met the participant in person).

All participants in the study were provided with a research kit at least three days in advance of the in-person portion of the interview. They all attempted to complete all the exercises in the research kit, however, 3 participants were not able to complete or start the probes for one of their two stories. In 2 of the cases, the participants ran out of time to finish the probes before the interview. However, their stories were still explored in the interview.

Participants reflected on various types of projects when they shared their experiences. Stories included long-term, multi-facetted projects that included all the phases of the design process such as a program awareness campaign, and the development of large-scale enterprise applications that aimed to fully digitize operations for a government program:

- Project example 1: "...last year we were tasked with the creation of [the internal initiative] concept with internal comms"

- Project example 2: "...an experimental [...] initiative for the government of Canada. It is currently live. It is ongoing and it is changing every day."

Stories also included shorter, one-off projects that had only one objective and addressed only one phase of the design process. These projects were mostly projects related to usability improvements following usability testing or usability testing projects 
that resulted in a report that included study results and recommendations for improvement:

- Project example 3: “...we basically just wanted to make improvements to their website [...] the objective was to make interacting with the [...] website easier for Canadians."

- Project example 4: “...we were asked to [do] a usability test for a website ..."

- Project example 5: “...we were tasked with doing simple usability testing [...] on some design changes just to see if they worked."

Although all participants were asked to reflect on and share a successful and an unsuccessful project, they approached the task in different ways. Two participants told only one story and many participants identified that their stories had both successful and unsuccessful elements. I recall at least 5 of the participants remarked that it was not always that easy to say an experience was purely "successful" or purely "unsuccessful".

Depending on how the participant identified success, there were many instances where their stories contained outcomes that were both successful and unsuccessful. For example, in one story a participant reflected on the outcomes of their 'unsuccessful' story in both terms of success and lack thereof. The project was "put on pause" but "...it helped to inspire ideas for other projects from our side..." so it seemed it wasn't seen as a complete waste by the person recalling it.

In some stories the participants took the role of a specialist working on their own or with a specialist team to get the work done, while other stories focused more on the participant as a member of a cross-functional team of people getting work done or as the designer's role as a facilitator to help others to do the work. Close to half of the 
participants held different roles in their different stories (either facilitator, collaborator or lone specialist).

The research data consisted of the completed workbooks (containing the participant's written accounts of their stories), the completed mind maps, notes from the interviews (that contained my interpretations of the participants' verbal account of their stories), audio from the interviews and some photos of the participants with their mind maps. In two cases, the participants sent additional details about the stories in follow-up emails. The content of these emails was added to my notes.

Across the workbooks, maps and interview notes, a total of 322 images were taken and uploaded NVivo. Each image was assigned key terms or 'codes' to give them meaning and generate insights through, as Saldaña (2016) states "pattern detection, categorization, assertion or proposition development, theory building and other analytical purposes" (p. 4). Each image was assigned various codes at different stages of the coding process (see Chapter 4: Field Work Methods and Appendix 2: Approach to Coding Participant Data for more detail on this process).

\subsection{Preliminary Results Generated from the First and Second Cycles of Coding}

As discussed in the methods section, detailed description of the incremental results from the first and second cycles of coding can be found in Appendix 3: Coding the Notes for further reference. Some of those preliminary results are presented here to give the reader a sense of how the final themes or factors emerged across the coding cycles. However, this section focuses primarily on the final results of the study. 


\subsubsection{First cycle coding - Results from Provisional Coding, In Vivo Coding and Simultaneous Coding}

There was a large data set generated in the first cycle of coding of the participant data. All of the 34 Provisional Codes generated from the content analysis of the 12 formulas from the literature review were used during the first cycle coding exercises of the participant data and an additional 1457 In Vivo Codes capturing the voices of participants were generated during this first cycle of coding.

Some of the interesting patterns that emerged in the first cycle of coding are presented in the tables (Tables 8,9,10 and 11) and Figure 16 below.

The top 6 Provisional Codes from the codebook (by coverage) accounted for over $50 \%$ of the Provisional Code references in the participant data (see Table 8) whereas 13 of the 34 Provisional Codes accounted for only $0.99 \%$ of coded participant references or less (see Table 8) indicating they were less prevalent across participant stories.

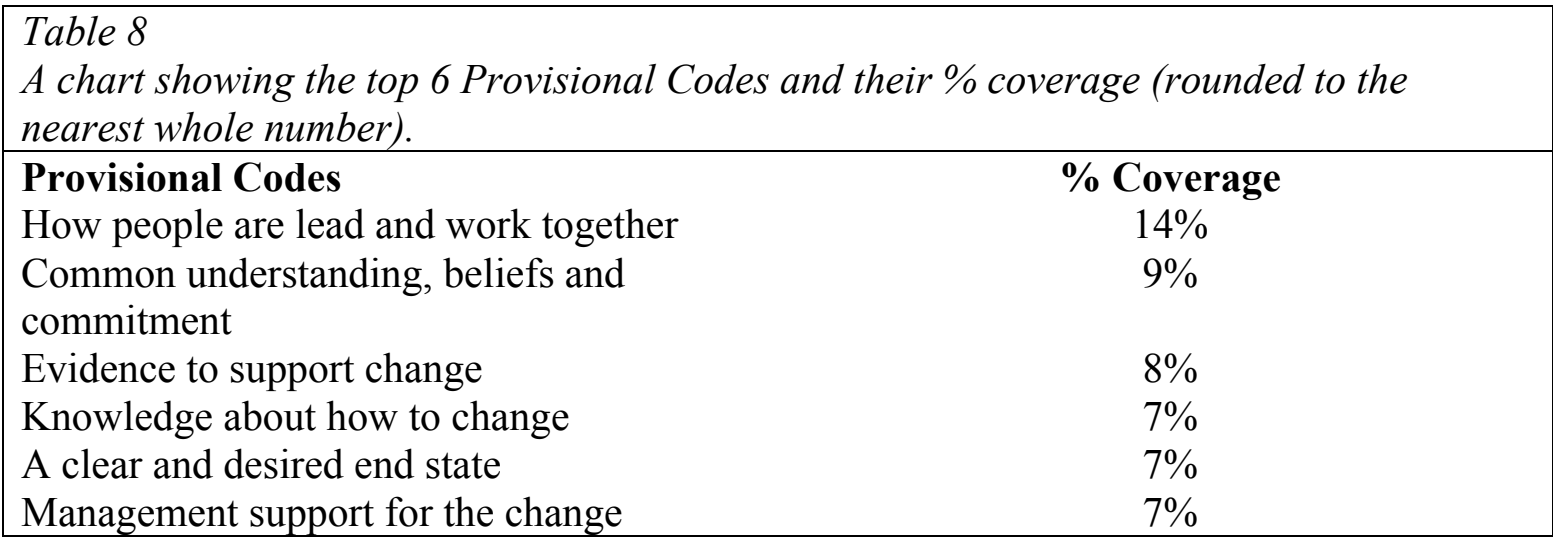

TABLE 8. THE TOP 6 PROVISIONAL CODES FOUND IN PARTICIPANT DATA.

Some examples of data that were coded with the most popular category How people are lead and work together include:

- "Communication was broken. No one knew what anyone else was doing" 
- “...the project team just keeping everyone on point. And the communications were fantastic and the stand-ups, like always efficient always on point and you knew what you had for the day. You had your tasks that you would need to get through and we did in in a way where it wasn't overwhelming. You know, some design element 'okay we need to crack this one today'. It's tested this way, here's a bit of a challenge, how can we approach it differently?

- “...losing our director who knew what they were doing, the onus fell on [colleague and I] to continue the second half. We had her up until the end of that piece, which was wonderful."

- “...[Sr. management] were a bit hands off, initially. It was also really unclear which of the Sr. Management was, like, involved and who's project it was, to be honest. [...] Now Sr Management is very actively involved, but it was only because when we were left to our own device, with kind of limited sr. management supervision, the ideas we proposed were completely not aligned to their vision..."

\section{Table 9}

A chart showing the 13 Provisional Codes that accounted for less than $1 \%$ of the references coded in participant data and their \% coverage (rounded to the nearest hundredth).

\section{Provisional Codes}

Dissatisfaction with the status quo

First steps toward the vision

Physical environment

The sustainability of the change

Stress

Personal ability to change

Employee support for change

Belief the change is needed

Factors must be greater than resistance

Low cost of change

Workgroup support for the change

Organizational benefit

Organizational ability to change

\section{\% Coverage} $0.009 \%$

$0.008 \%$

$0.007 \%$

$0.007 \%$

$0.006 \%$

$0.006 \%$

$0.006 \%$

$0.006 \%$

$0.006 \%$

$0.004 \%$

$0.003 \%$

$0.003 \%$

$0.002 \%$

TABLE 9. PROVISIONAL CODES THAT ACCOUNTED FOR LESS THAN $1 \%$ OF CODED FACTORS. 
In Vivo Codes reflected both the participant's voice directly (when the codes were taken from the maps and workbooks) and the interpretation of the participant's voice when the codes were pulled from the notes taken during the interviews.

The most common words that were reflected in the In Vivo Codes accounted for $11 \%$ of the terms used throughout this type of coding (Table 10 and Figure 16).

\begin{tabular}{|c|c|c|c|}
\hline \multicolumn{4}{|c|}{$\begin{array}{l}\text { Table } 10 \\
\text { A chart showing words that were used in In Vivo Coding most often. }\end{array}$} \\
\hline Word & Count & $\begin{array}{l}\text { Weighted } \\
\text { Percentage }\end{array}$ & Similar Words \\
\hline team & 118 & $2.73 \%$ & team, teams \\
\hline project & 74 & $1.71 \%$ & project, projects \\
\hline design & 74 & $1.71 \%$ & $\begin{array}{c}\text { design, designed, designer, } \\
\text { designers }\end{array}$ \\
\hline works & 66 & $1.52 \%$ & $\begin{array}{c}\text { work, worked, working, } \\
\text { works }\end{array}$ \\
\hline managers & 62 & $1.43 \%$ & $\begin{array}{l}\text { manageable, managed, } \\
\text { management, manager, } \\
\text { managers, managing }\end{array}$ \\
\hline client & 49 & $1.13 \%$ & client, clients \\
\hline time & 49 & $1.13 \%$ & time, times, timing \\
\hline
\end{tabular}

TABLE 10. WORDS THAT WERE USED IN IN VIVO CODING MOST OFTEN.

For example, participants often talked about "team", "project" and "design" in their projects:

- "team was really focused on making it work"

- "team worked well together"

- "reliable team"

- "great project management from both sides"

- "lack of clear project plan"

- "multiple projects all at once"

- "trust and confidence between designers and client team"

- "design team learned some hard lessons" 


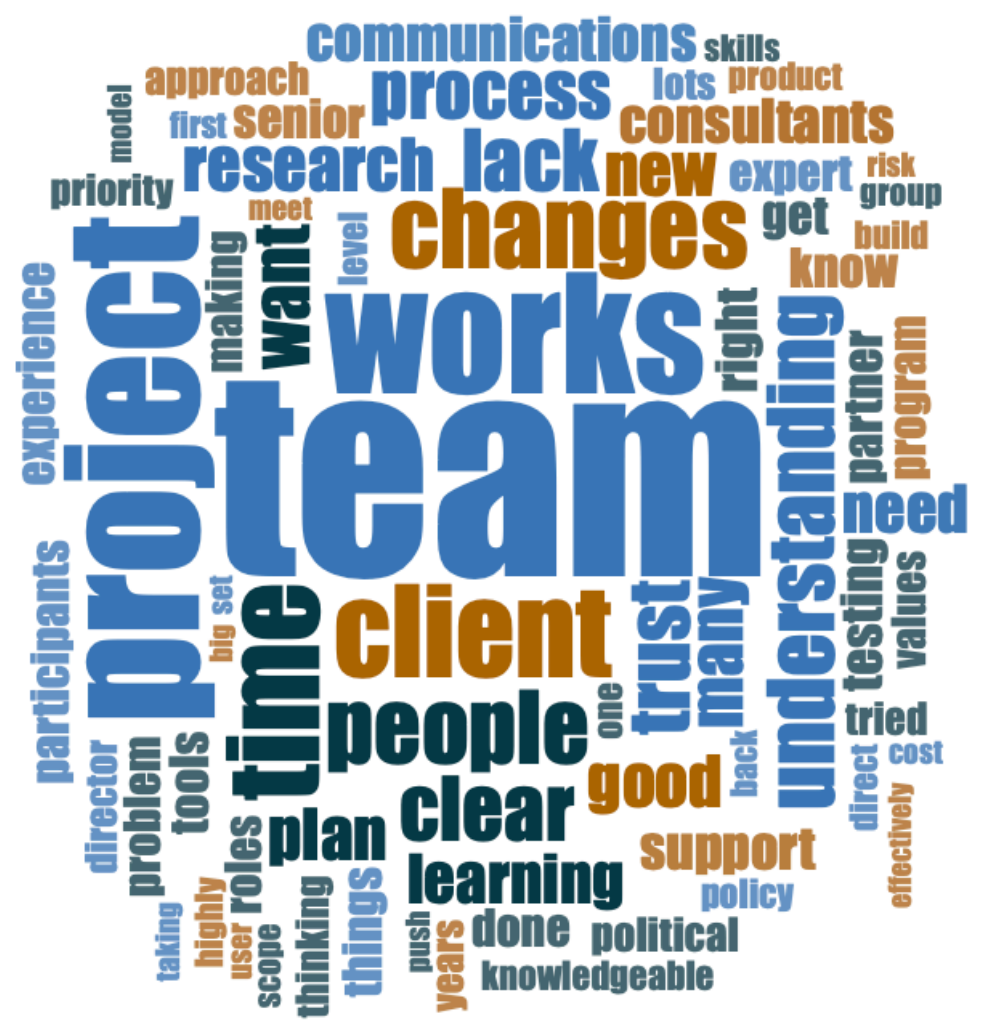

FIGURE 16. A WORD CLOUD ILLUSTRATING THE FREQUENCY OF IN VIVO CODES.

In Vivo Codes were generally coded to one, unique phrase, word or paragraph found in the research data. This was a result of their precise nature in reflecting the words of the participant. However, some participants did use the same language in their telling of their stories and there were many instances where similar language was used by different participants.

There were 6 In Vivo Codes in particular that appeared in 3-5 unique stories (Table 11). 
Table 11

The number of people that shared popular In Vivo Codes.

\begin{tabular}{lc|} 
Word & $\begin{array}{c}\text { Number of participants who used the } \\
\text { term }\end{array}$ \\
Trust & 5 \\
Leadership & 4 \\
Experts & 3 \\
High-profile & 3 \\
Right people & 3 \\
Teach teams how to work together & 3 \\
\hline
\end{tabular}

TABLE 11. A TABLE OF SHARED IN VIVO CODES.

For example, when participants talked about "Trust" they said things like:

- "I was very happy with how we were able to gain that trust with the team and that they really did believe in us and they were convinced that we were there to help and that's 'cause we were."

- “Trust: Participant's trust in designers and designers' trust in own abilities and the design thinking process" (extracted from a participant map)

- "A relationship building exercise that did not build relationships. Feelings and egos were injured, and trust was damaged"

The majority of terms used throughout the participant data were also

Simultaneously Coded with at least one Provisional Code from the codebook generated from the content analysis of the formulas from the literature and one In Vivo Code taken directly from the participant data. This Simultaneous Coding occurred $89 \%$ of the time. This means that out of the 1457 In Vivo Codes generated, there were only 162 In Vivo Codes that were not Simultaneously Coded with a Provisional Code. This was because either there was no related Provisional Code or a mistake in coding (i.e. there was a related Provisional Code, but it was not Simultaneously Coded due to oversight). Overall, 5 Provisional Codes accounted for $22 \%$ of the Simultaneously Coded references 
(see Table 12 and Figure 17). As we can see in Table 12 and the hierarchy chart in Figure 17, the categories How people are lead and work together, Common understanding, beliefs and commitment, Knowledge about how to change, Evidence to support the change and Ability to change (change efficacy) were all much larger than the rest, indicating a greater level of coverage throughout the data that was coded.

\begin{tabular}{|l|}
\hline Table 12 \\
A table showing the top 5 Provisional Codes, which accounted for $22 \%$ of all of the \\
data points coded with an In Vivo Code (1295 total In Vivo Codes or $89 \%$ of the \\
codes). \\
\hline Code
\end{tabular}

table 12. The top 5 Provisional Codes Simultaneously Coded with In Vivo Codes. 


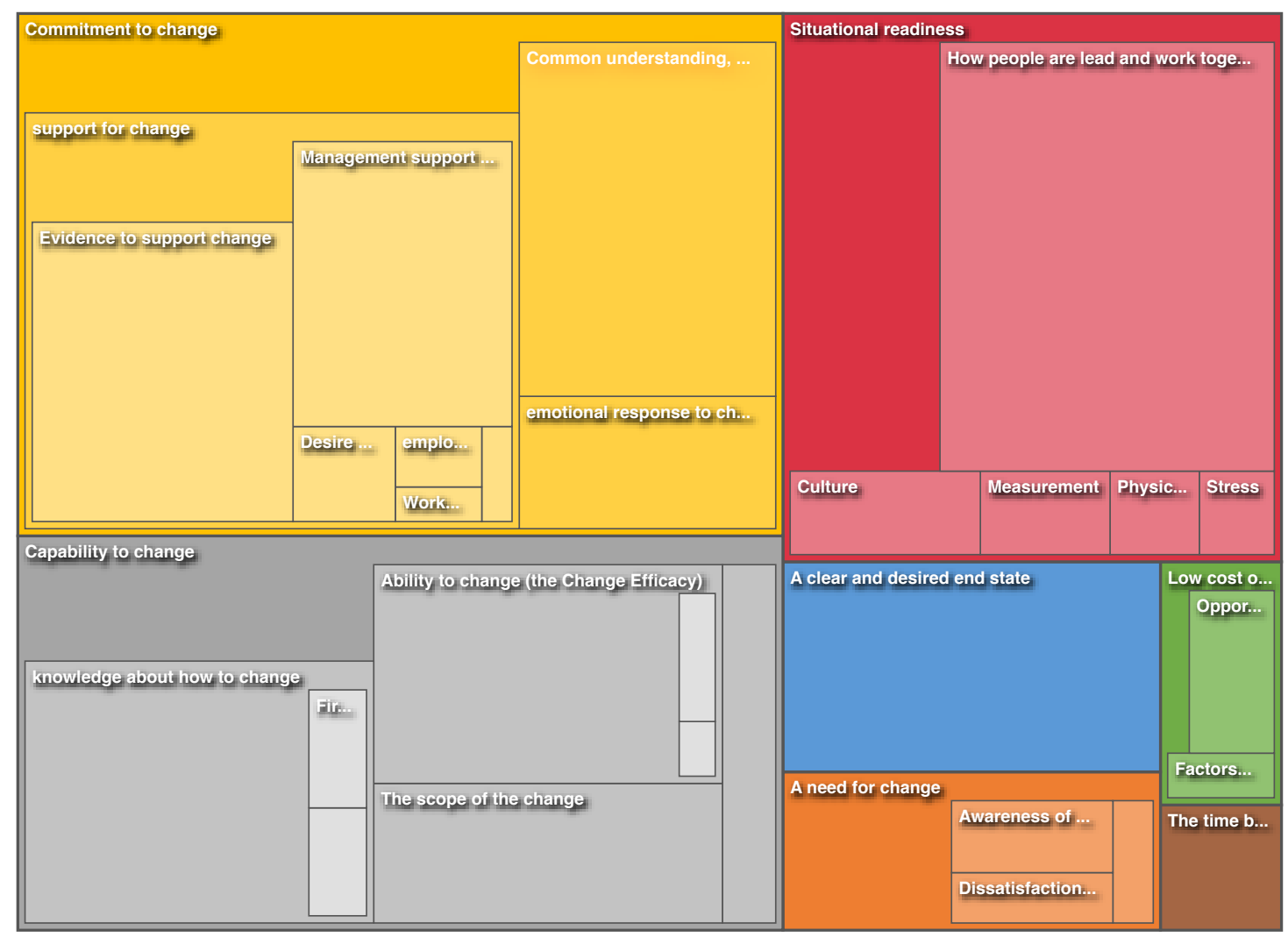

FIGURE 17. A HIERARCHY CHART ILLUSTRATING HOW OFTEN A PROVISIONAL CODE WAS USED (THE PROVISIONAL CODE'S MAGNITUDE) DURING THE FIRST CYCLE OF CODING.

A collection of categories emerged after consideration for the magnitude of

Provisional Codes found in participant data, the popularity of certain terms and themes uncovered in the In Vivo Codes and the frequency of Simultaneous Coding of In Vivo and Provisional Codes. These categories represent a preliminary attempt to develop a collection of factors that may have an impact on an organization's ability to change for design implementation (see Figure 18).

A review of these preliminary categories indicated that one of the categories was not framed in the same way as the others, and therefore, needed to be modified slightly. The theme of How people are lead and work together was framed in a neutral sense, not 
actually indicating a potential factor or factors that would contribute to an organization's ability to change for design implementation. The other categories, on the other hand, had more indicating what needed to be present in order to be ready for change such as Evidence to support the change and Expertise and time to do the work. Therefore, the How people are lead and work together category was renamed Leadership and teamwork. The sub-categories below it remained the same. 
Categories from first cycle coding

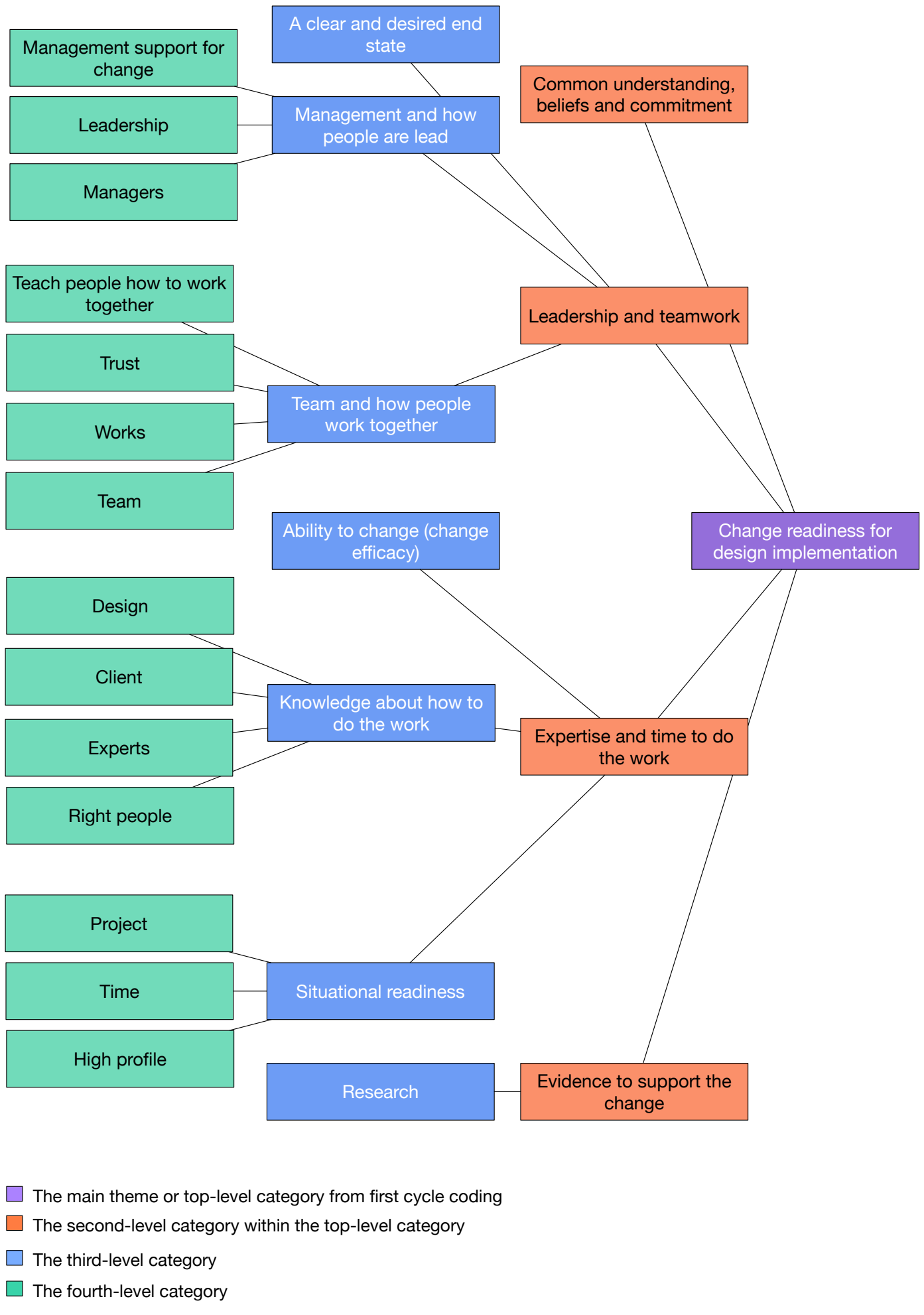

FIGURE 18. A MODEL OF THE CATEGORIES THAT EMERGED FROM THE FIRST CYCLE OF CODING. 
These categories were then used as buckets in which the In Vivo Codes could be organized to support the second cycle of coding - Pattern Coding.

\subsubsection{Second cycle coding - Results generated from Pattern Coding}

A total of 105 Pattern Codes (see Figure 19) were generated through Pattern Coding or, as Saldaña (2016) puts it the development of "the category label that identifies similarly coded data" (p. 235). Of these new codes, there were 8 In Vivo Codes that remained outliers and were therefore transferred into the collection of Pattern Codes as they could not be organized into a new category and did not have any related codes after the second cycle of coding. These 'outlier' codes included:

- Change fatigue

- Show next steps and how to make it work

- Simplified the rule

- Solutioning

- Leader and consultants are aligned which makes it difficult to raise concerns

- Program didn't know they could fight for it

- Committees

- Give people a sense of what they will be doing 


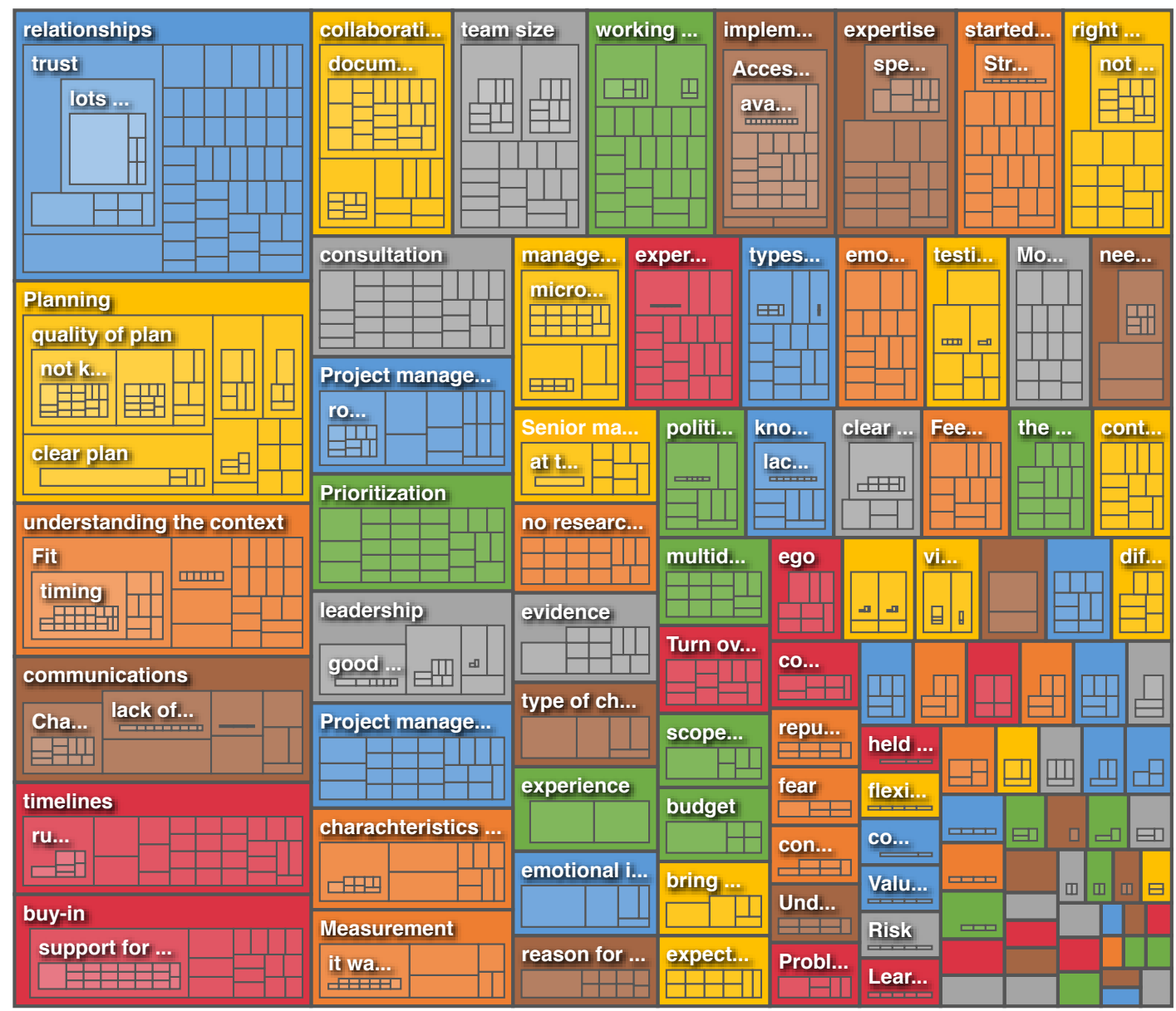

FIGURE 19. A tREe MAP OF THE PATTERn CODE HIERARCHY.

The top 17 Pattern Codes accounted for $50 \%$ of references that were aggregated from participant data (or 770 In Vivo references from the data). The top 6 Pattern Codes accounted for $25 \%$ of aggregate references (see Table 13). 
Running Header: AN EXPLORATION OF FACTORS RELATED TO DESIGN

IMPLEMENTATION IN THE CANADIAN FEDERAL PUBLIC SERVICE

\begin{tabular}{|c|c|c|}
\hline $\begin{array}{l}\text { Table } 13 \\
\text { A table showing } t \text { ) } \\
\text { references (round }\end{array}$ & $\begin{array}{l}\text { Pattern Codes refle } \\
\text { e nearest whole nun }\end{array}$ & otal number of In Vivo \\
\hline Word & $\begin{array}{c}\text { Number of In Vivo } \\
\text { references }\end{array}$ & Percent of total references \\
\hline Relationships & 106 & $7 \%$ \\
\hline Planning & 87 & $6 \%$ \\
\hline $\begin{array}{l}\text { Understanding } \\
\text { the context }\end{array}$ & 60 & $4 \%$ \\
\hline Communications & 49 & $3 \%$ \\
\hline Timelines & 44 & $3 \%$ \\
\hline Buy-in & 44 & $3 \%$ \\
\hline
\end{tabular}

TABLE 13. The TOP 6 PATtern CODES By AGgRegated In ViVo REFERENCES.

The Pattern Codes that emerged could be organized into the 4 top-level categories (or the main 'buckets') proposed at the end of the first cycle of coding (Figure 18). The category with the most In Vivo references was Expertise and time to do the work followed by Leadership and teamwork.

\begin{tabular}{|c|c|c|}
\hline $\begin{array}{l}\text { Table } 14 \\
\text { A table showing the categories } \\
\text { Vivo references (rounded to the }\end{array}$ & $\begin{array}{l}\text { the first cycle of con } \\
\text { rest whole number). }\end{array}$ & and the total number of In \\
\hline Category & $\begin{array}{c}\text { Number of In Vivo } \\
\text { references }\end{array}$ & Percent of total references \\
\hline $\begin{array}{l}\text { Expertise and time to do the } \\
\text { work }\end{array}$ & 606 & $40 \%$ \\
\hline Leadership and teamwork & 571 & $37 \%$ \\
\hline $\begin{array}{l}\text { Common understanding, } \\
\text { beliefs and commitment }\end{array}$ & 186 & $12 \%$ \\
\hline Evidence to support the change & 164 & $11 \%$ \\
\hline
\end{tabular}

TABLE 14. THE VOLUME OF IN VIVO CODED REFERENCES BY FIRST CYCLE CATEGORY. 


\section{Table 15}

A table showing the sub-categories from the Expertise and time to do the work category proposed following the first cycle of coding and the number of references that they contain based on the In Vivo Codes that were organized within them(rounded to the nearest whole number).

\section{Category}

Situational readiness

Knowledge about how to change

Ability to change (Change

efficacy)

\section{Number of aggregated In Vivo references}

Percent of total aggregated references within the category

TABLE 15 THE VOLUME OF IN VIVO CODED REFERENCES WITHIN THE EXPERTISE AND TIME TO DO THE WORK CATEGORY, PRESENTED BY SUB-CATEGORY.

Examples of some of the data points in the participant data relating to the situational readiness category included:

- "It was a complex program being piloted to begin with and it was hard to get into it midstream... [because of] not having had any input from the beginning was hard, not knowing sort of how this had been devised or why it was devised the way it was and then also not understanding the complexity of the relationships between the stakeholders and not having access to all the stakeholders [in a] concrete way... and sometimes we'd have a broken telephone situation where people didn't really understand our role...let alone bought into our approach."

- "No RACI" and "Every decision was always revisited" (taken from a workbook)

- “...It was near end of fiscal and so there was some extra room in the budget so therefore they thought 'what can we do to help spend this budget' and this is what came out of it. So therefore the [...] pacing was 'yeah okay, we just want to do essentially a "quick and dirty" and hopefully get as much as we can out of it'..." 


\begin{tabular}{|c|c|c|}
\hline \multicolumn{3}{|c|}{$\begin{array}{l}\text { Table } 16 \\
\text { A table showing the sub-categories from the Leadership and Teamwork category } \\
\text { proposed following the first cycle of coding and the number of references that they } \\
\text { contain based on the In Vivo Codes that were organized within them (rounded to the } \\
\text { nearest whole number). }\end{array}$} \\
\hline Category & $\begin{array}{l}\text { Number of aggregated } \\
\text { In Vivo references }\end{array}$ & $\begin{array}{l}\text { Percent of total aggregated } \\
\text { references within the } \\
\text { category }\end{array}$ \\
\hline Team & 420 & $74 \%$ \\
\hline Management & 151 & $26 \%$ \\
\hline
\end{tabular}

TABLE 16. THE VOLUME OF IN VIVO CODED REFERENCES WITHIN THE LEADERSHIP AND TEAMWORK CATEGORY, PRESENTED BY SUB-CATEGORY.

Some examples of participant date relating to the team category include:

- "...first time where there was a major IT project where the project manager was not part of the IT branch and that was 'cause [...] I earned their followship [...] and they got very comfortable saying 'no, no, we'll speak for the tech stuff, but certain things, we'll bump that over to [participant name]' because they had the understanding that I was willing to take on risks."

- "...we held the contract. Basically that means that we have the power to decide... to say 'hey, we don't want that ... we need something else'. So then [...] gradually we relied more on ourselves."

- "Too many players, ownership unclear" (extracted from a map)

- "...the way the team worked there was a definite respect for everybody's' different strengths and what they brought to the table. And I think every team has its frictions and stuff like that but as an overall, it worked really well together. There was good collaboration, challenges were constructive, and we pushed each other."

All of the In Vivo Codes generated in the first cycle of coding could be organized into the proposed categories and sub-categories proposed at the end of the first cycle of coding, without exception (Figure 18). But a refined organization of the original In Vivo Codes resulted in a substantial increase in the popularity or importance of the Expertise 
and time to do the work and Leadership and teamwork categories (see Table 15 and Table 10), which together accounted for $77 \%$ of the aggregated references across all of the In Vivo Codes. Within the two categories, Expertise and time to do the work and Leadership and teamwork, the sub-categories of Team (74\%) and Situational readiness $(62 \%)$ had the most aggregated references.

\subsubsection{Third cycle coding - Results generated from Focused Coding}

In the third and last cycle of coding, all of the Pattern Codes were reviewed, reorganized and combined to create the final proposed top-level categories (or themes) identifying the main factors which participants discussed in relevance to project success (see Figure 20). In total 6 themes or top-level categories of factors emerged from the research data. These categories reflect the potential importance of the following themes when participants discussed the success of their design projects for the Canadian Federal Public Service:

1. People can make the change happen.

2. People want to do the work.

3. People know why the work is being done.

4. People know how the work is being done.

5. The project fits within the existing context.

6. There is shared understanding about the work. 


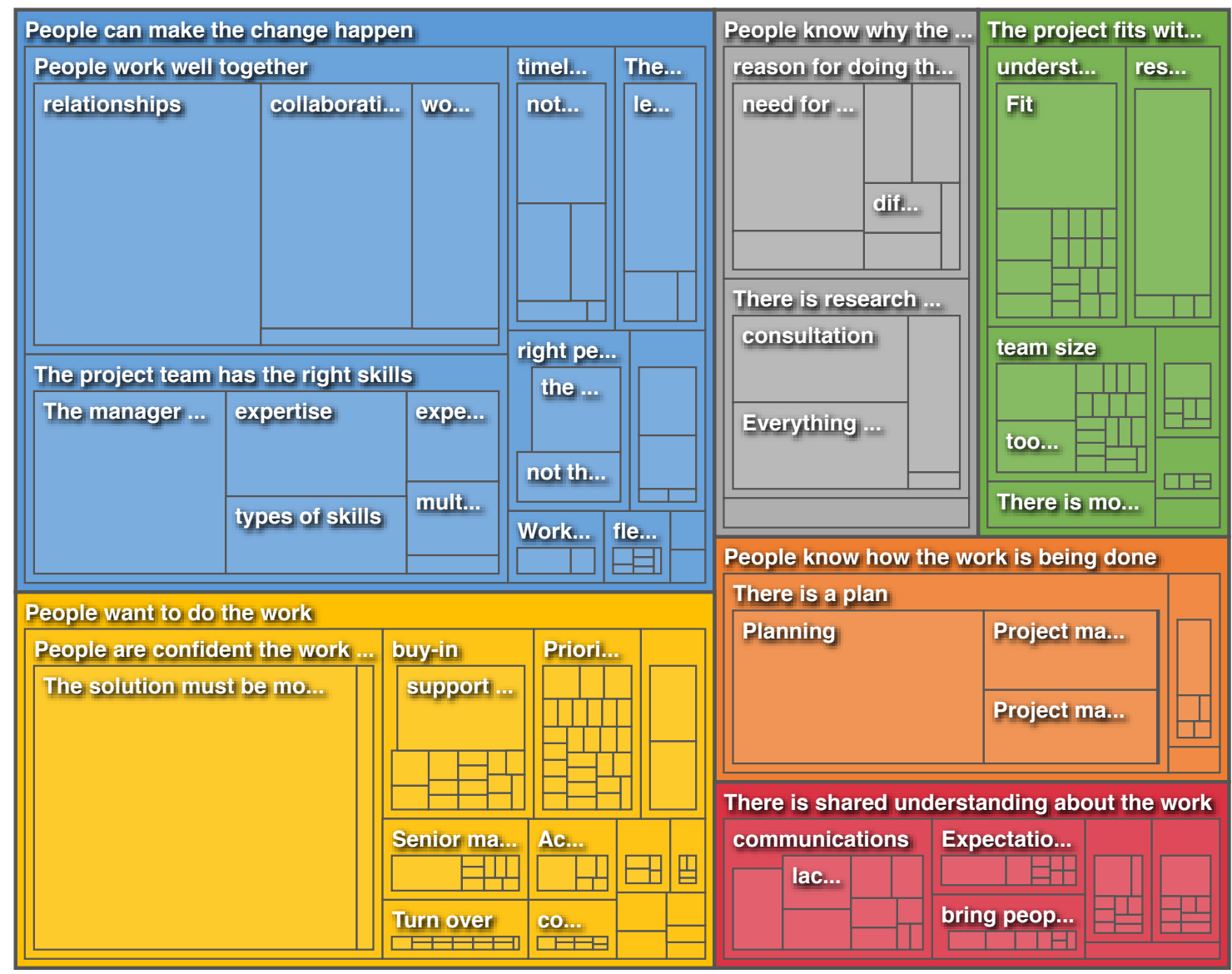

FIGURE 20. A TREE MAP OF THE NEW TOP-LEVEL CATEGORIES (THEMES) OF FACTORS THAT MAY CONTRIBUTE TO AN ORGANIZATION'S ABILITY TO CHANGE FOR DESIGN IMPLEMENTATION.

Each proposed category identified through Focused Coding was linked to the data coded from all 18 participants. As mentioned, in section 3.9 Method 1: Content Analysis of Formulas in Change Management Literature, it is likely that the level of magnitude of any particular category of codes indicates the importance of that factor or those factors in an organization's readiness to change. The category with the greatest magnitude based on references generated through the coding cycles was 1 . People can make the change happen (see Table 17). This category accounted for $35 \%$ of the coded references in the participant data. 
Table 17

The magnitude of each of theme uncovered in the research.

\section{Factors uncovered in participant data}

The people involved in the project can make the change happen

The people involved want to do the work

People know why the work is being done

The project fits within the existing context

People know how the work is being done

There is shared understanding about the work

\section{Percentage of the total aggregated references from the data (rounded to the closest whole number)}

TABLE 17. THE FINAL CATEGORIES UNCOVERED IN RESEARCH AND THEIR MAGNITUDE

These themes included Pattern Codes relating to the right people working on the project, there is enough time and people feel like they can do the work and contained In Vivo Codes related to relationships (including codes related to trust), collaboration (including codes about how people work together) and the manager is the right fit (see

Figures 21 and 22).

\section{Quotes relating to the category people can make the}

\section{change happen}

"Amazing colleagues who want to play"

"When objectives are clear, the design team is included early in the process and we get creative freedom, great

"[there was] time to do good work" work can be produced"

"Serendipity!

-Right people

-Respect of expertise

-Right vehicle"

"I liked it. Most in charge and control"

"The web is only as good as the director"

"To trust what I know to be true"

\section{"Design literacy"}

"Embedded in the system" 
FIGURE 21. A SELECTION OF QUOTES RELATING TO THE CATEGORY PEOPLE CAN MAKE THE CHANGE HAPPEN.

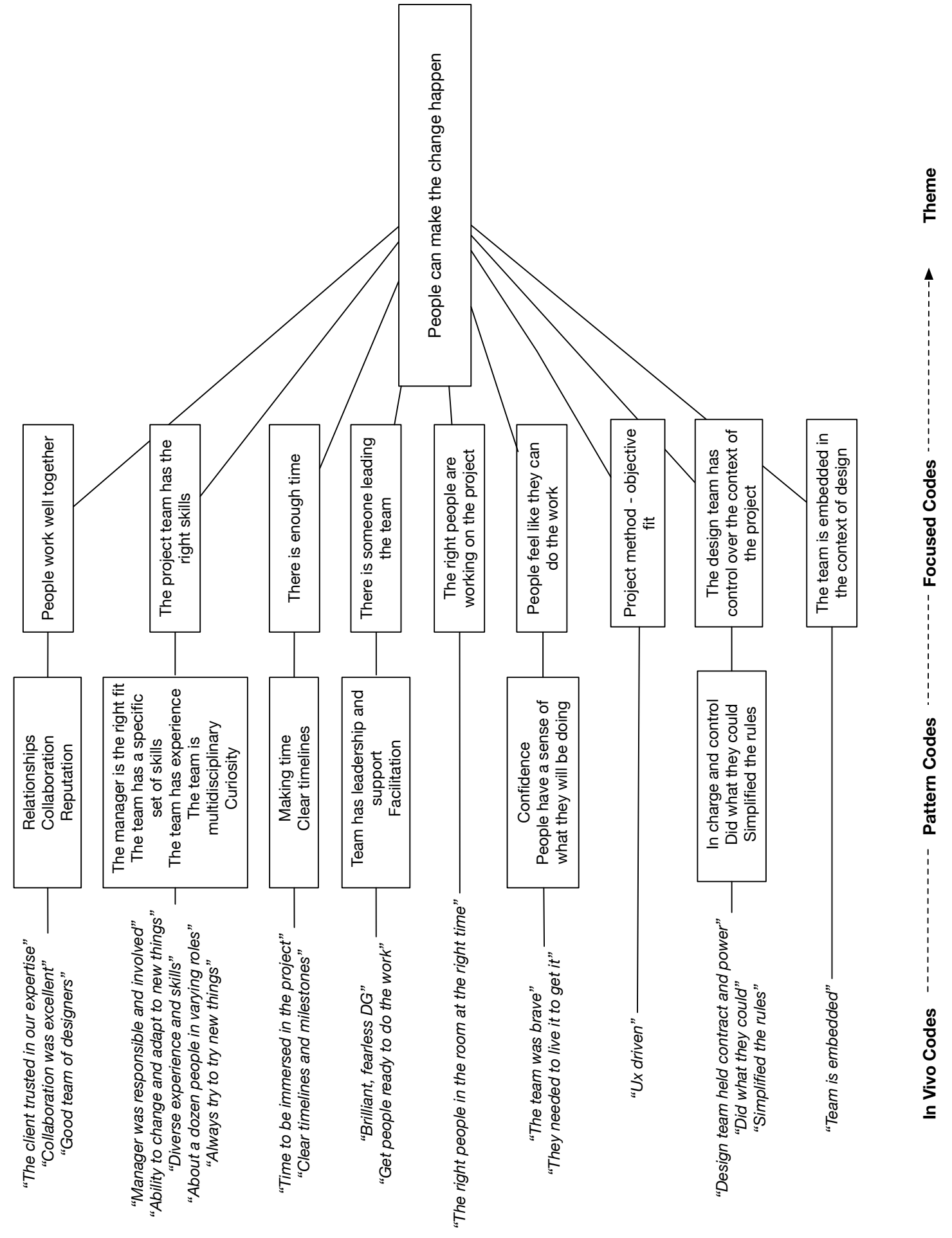

FIGURE 22. A TREE DIAGRAM EXPLORING THE THEME OF PEOPLE CAN MAKE THE CHANGE HAPPEN, FROM A SELECTION OF IN VIVO CODES OUT TO THE, SUB-CATEGORIES, PATTERN CODES AND THE THEME 
Following the theme people can make the change happen was the theme relating to factors about the desire to do the work called 2. People want to do the work, which accounted for $22 \%$ of the coded references in the research data. This category of factors included Pattern Codes relating to having the right people on the team, timelines and how the work is done and contained In Vivo Codes related to confidence that the work will deliver value (including codes related to modeling and sharing solutions, buy-in and vision), commitment and prioritization (see Figure 23 for some examples of quotes relating to the category).

\section{Quotes relating to the category people want to do the work}

"We had buy-in and direct involvement from the director level on the client side"

"You need the support from the top"

"The concept was fun and different from what we normally do"

"Have to prioritize funding on a system that works"

"Culture change!!!"

"Team was really focused on making it work"

"Passion to make change"

"Willing to invest in experts and time to do the study"

"Impassioned public servants"

"Shaping an environment for success"

"My project, my baby"

FIGURE 23. A SELECTION OF PARTICIPANT QUOTES RELATING TO THE CATEGORY PEOPLE WANT TO DO THE WORK.

The categories 1.People can make the change happen and 2. People want to do the work account for $57 \%$ of the references in the research, indicating the perceived importance of these two factors in the successful implementation of design. 
The other 4 categories identified in the third cycle of coding, related to people know why the work is being done, the project fits within the existing context, people know how the work is being done, and people have a shared understanding about the work.

\section{Quotes relating to the category people know why the}

\section{work is being done}

"There [was] a sense that it could change something"

"Surfaced issues and shifted culture!"

"Shed light on the need for user centred services with in gov internal services"

"We have to be advocates [and] help our

"The risk of doing nothing is worse than doing it" clients understand"

"Create an opportunity for public servants

"The client wanted to learn" to co-create solutions"

"Shift in workplace expectations"

"Need to connect to users"

FIGURE 24. A SELECTION OF PARTICIPANT QUOTES RELATING TO THE CATEGORY PEOPLE KNOW WHY THE WORK IS BEING DONE. 


\section{Quotes relating to the category the project fits within the existing context}

"No time for resistance"

"No shifting deadline"

"Right resources: tools, translation, people, right space, plan"

"Started with a good on boarding process...

"Serendipity. Timing." understanding constraints in time"

"Passion to make change"

"UX integrated in overall

development plan"

"Available technology"

"Quality resources"

"Existing capacity and mandate for UX"

"Scope controlled, excellent people

management with fair representation of

competing factors $[\ldots] "$

"Core team: small group of people with design experience"

FIGURE 25. A SELECTION OF PARTICIPANT QUOTES RELATING TO THE CATEGORY THE PROJECT FITS WITHIN THE EXISTING CONTEXT.

\section{Quotes relating to the category people know how the work}

\section{is being done}

"Great project management from both sides"

"A very rigorous test plan and protocol"

"Clear plan: comms working with team/working with stakeholders, working together.

Had realistic expectations.

Everyone was happy."

"People see design as a product, as tangible, but you have to get there"

"Knowledge that it looks simpler than it is"

$$
\text { "Explicit objectives" }
$$

"Clear roles and a reason for being there"

"Maintaining integrity of process"

FIGURE 26. A SELECTION OF PARTICIPANT QUOTES RELATING TO THE CATEGORY PEOPLE KNOW HOW THE WORK IS BEING DONE. 


\section{Quotes relating to the category there is shared understanding} about the work

"Explicit overview of approach with '101' understanding

of why "going to do it this way"'

"Good comms across teams"

"Frequent updates throughout"

"Ran a proper design led project. No

"Had a consession plan and tight knowledge transfer"

sacrifice [...] serving other projects now"

"Need to bridge lexicon"

"15 minute stand ups, everyone contributed"

"One voice external"

FIGURE 27. A SELECTION OF PARTICIPANT QUOTES RELATING TO THE CATEGORY THERE IS SHARED UNDERSTANDING ABOUT THE WORK.

These final 4 themes accounted for the final $43 \%$ of the coded references to the perceived factors of success for design projects within my case study and complete the picture of what factors could indicate an organization's ability to change for design implementation within the context of designing for the Canadian Federal Public Service.

\subsection{Finding the Best Fit Formula}

Once the Focused Coding was complete, the proposed themes that may contribute to improving our understanding of an organization's ability to change to support design implementation in the Canadian Federal Public Service were put into a matrix and compared with the formulas from literature (see Table 18). Each formula was assessed against the themes uncovered in this case study. 


\begin{tabular}{|l|c|c|c|c|c|c|c|}
\hline $\begin{array}{l}\text { Table 18 } \\
\text { A comparative matrix exploring the themes that emerged from the participant data in relation } \\
\text { to the factors found in the formulas from the literature. }\end{array}$ \\
\hline \\
\multicolumn{1}{|c|}{}
\end{tabular}

TABLE 18. A COMPARATIVE MATRIX EXPLORING THE RELATIONSHIP BETWEEN THE THEMES FOUND IN THE PARTICIPANT DATA AND THE FACTORS PROPOSED IN THE FORMULAS FROM THE LITERATURE.

Based on the review, none of the formulas accounted for all of the themes uncovered through the participant research. For example, although the perceived importance of 1.People can make the change happen and 2. People involved want to do the work aligns very closely with Weiner's (2009) Organizational Readiness for change model, which put extensive emphasis on people's willingness and ability to be part of a 
change, in the case of this particular case study, it was found that there were many other factors that needed to be considered as well.

In all cases, there were at least two themes not covered by the formulas from the literature, such as: There is a shared understanding about the work, People know how the work is being done, and The project fits within the existing context. The top three factors also found in literature were: The people involved want to do the work ( 8 matches), The people involved in the project can make the change happen (7 matches) and People know why the work is being done (7 matches).

The Prosci ADKAR ${ }^{\circledR}$ Model was the closest fit, based on the themes found in the content analysis of the 12 formulas from change management literature against those found from participant research, as well as consideration for the potential importance or magnitude of each of the themes. Of interest here, the two areas that were identified as important to participants but that appear to be missing in the existing Prosci ADKAR ${ }^{\circledR}$ Model were The project fits within the existing context and There is shared understanding about the work. Other formulas did reflect these themes but were missing other themes that were considered to be more important based on magnitude in the participant data. Specifically, Holt, et al's (2007) Readiness Factors and Rafferty, et al's (2013) Multilevel Framework (Table 18). 


\section{Chapter 6: Discussion}

\subsection{Factors that May Contribute to Successful Design Implementation in the Canadian Federal Public Service}

Research findings revealed 6 themes relating to the organizational factors that may have impacted the successful or unsuccessful implementation of the participants' design projects within the Canadian Federal Public Service, and ultimately, their ability to bring about change through the medium of design. The stories participants shared surfaced the following key factors that may have influenced the success of their design projects:

1. The people involved in the project could make the change happen.

2. The people involved in the project wanted to do the work.

3. People knew why the work was being done.

4. The project fit within the existing context.

5. People knew how the work was being done.

6. There was shared understanding about the work.

What this case study starts to suggest is that, if all of these factors are accounted for, it is possible that the organization will be able to bring about change in their systems and that a proposed design will have a better chance of being implemented.

\subsection{A Formula to Support Design Implementation in the Government of Canada}

In many cases (see Table 18), the themes which emerged from working with participants were similar to what was found in the selected 12 formulas discussed in the 
literature review. Although the 6 themes revealed in this study do not align perfectly with any one formula from the selective change management literature I explored, the Prosci ADKAR ${ }^{\circledR}$ Model (The PROSCI ADKAR Model, n.d.) proposed by Hiatt in 2006 (Figures 28 and 29) appears to be the closest fit; accounting for all but two of the categories of factors found to be perceived as important by participants to the success of design projects in the Canadian Federal Public Service. The two categories of factors not accounted for by the Prosci ADKAR ${ }^{\circledR}$ Model are:

- 4. The project fits within the existing context

- 6. There is a shared understanding about the work 
Running Header: AN EXPLORATION OF FACTORS RELATED TO DESIGN

IMPLEMENTATION IN THE CANADIAN FEDERAL PUBLIC SERVICE

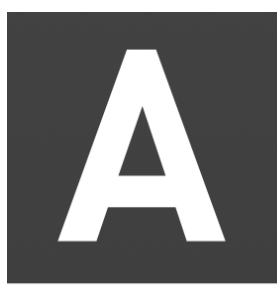

AWARENESS OF THE NEED FOR CHANGE

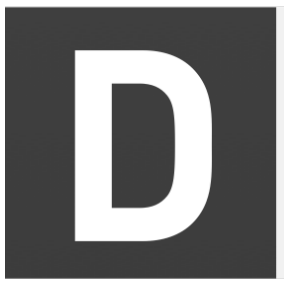

DESIRE TO SUPPORT THE CHANGE

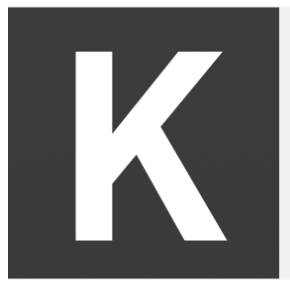

KNOWLEDGE OF HOW TO CHANGE

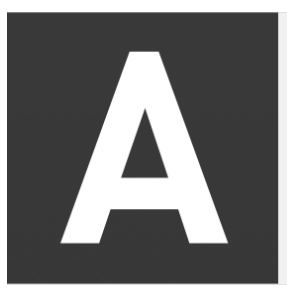

ABILITY TO DEMONSTRATE SKILLS \& BEHAVIORS

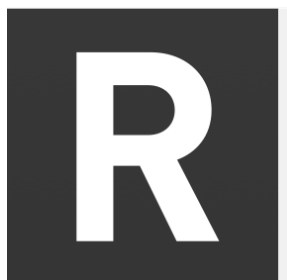

REINFORCEMENT TO MAKE THE CHANGE STICK

FIGURE 28. THE PROSCI ADKAR® MODEL TAKEN FROM WWW.PROSCI.COM. 

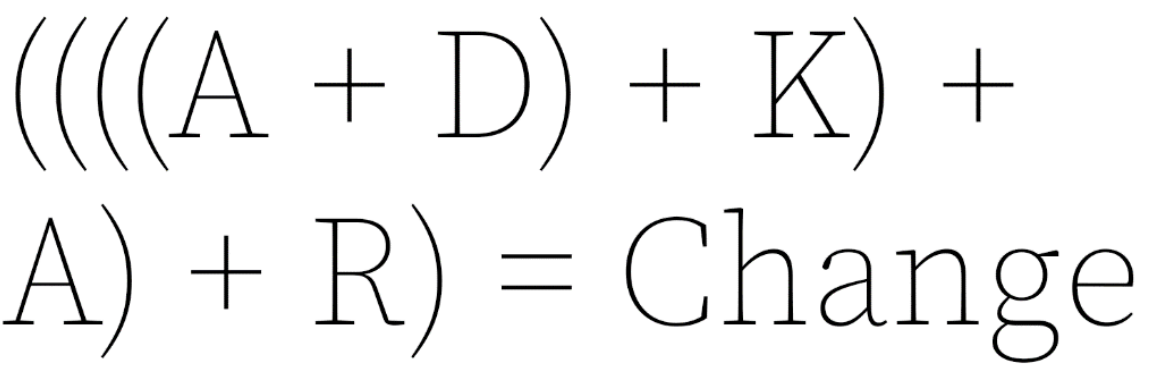

Where,

$A=$ Awareness of the need for change

$\mathrm{D}=$ Desire to support the change

$\mathrm{K}=$ Knowledge of how to change

A = Ability to demonstrate skills \& behaviours

$\mathrm{R}=$ Reinforcement to make the change stick

And where each factor is accounted for in the order it is displayed in the formula (e.g. Awareness for the need for change has to come bfore the Desire to support the change can be achieved).

FIGURE 29. AN INTERPRETED FORMULA OF THE PROSCI ADKAR® MODEL ILLUSTRATING THAT ALL OF THE FACTORS HAVE TO BE ACHIEVED IN ORDER.

Given the alignment between the models, it may be reasonable to propose that the Prosci ADKAR ${ }^{\circledR}$ Model be modified to include consideration for 4. The project fits within the existing context and 6. There is a shared understanding about the work. The ADKAR factor of "Reinforcement to make the change stick" is removed from the formula as it was not a factor that appeared explicitly in the research, and therefore, may not have a remarkable effect of successful design implementation within the context of public service design implementation. One of the factors descriptive titles has also been slightly modified to align more closely with findings from research. The "Ability to demonstrate skill and behaviours" from the Prosci ADKAR® Model has been modified 
to simply account for the broader factor of ability to change found in this study. It was found that the factors that surfaced in the participant data were less about having to "demonstrate" the necessary skills and behaviours, but rather being able to get the work done, which included consideration for skills, access to resources, time, etc. These factors do not seem to be explicitly considered in the original Prosci ADKAR® Model and so this modification increases the potential fit for the model in the Canadian Federal Public Service context.

To support the activity of understanding organizational factors relating to successful design implementation in the Canadian Federal Public Service, the following formula is proposed (Figure 30).

\section{The Public Service Design Implementation Framework (PSDIF)}
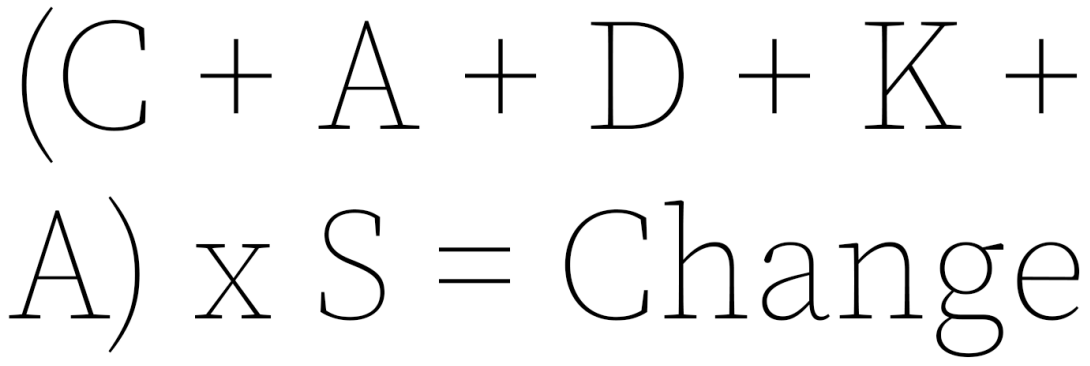

Where,

$C=$ Understanding of the context of the change to determine project fit

$A=$ Awareness for the need to change

$\mathrm{D}=$ Desire to support the change

$\mathrm{K}=$ Knowledge of how to change

A $=$ Ability to change

$S=$ Shared understanding

And the factors of C, A, D, K and A are modified by S.

FIGURE 30. A FORMULA TO EXPLORE READINESS TO IMPLEMENT DESIGN WITHIN THE CANADIAN Federal Public Service. 
In the modification of the Prosci ADKAR® Model, the factor of Understanding of the context of the change to determine project fit is added at the beginning of the formula and the entire formula is modified by There is a shared understanding about the work (which is reduced to 'shared understanding' in order to simplify the theme for the reader and is represented as an $S$ in the formula to emphasize the idea that 'understanding' has to be shared). The $S$ acts as a modifier, which means that if there is a low level of shared understanding regarding the other factors within the formula or no shared understanding, the outcome is likely to be unsuccessful (Figure 30).

Based on the results of this case study, this modified formula is proposed as a preliminary step to support exploration of organizational readiness for design implementation within the Canadian Federal Public Service. When an organization's readiness for change in relation to design implementation is better understood, designers and design teams may be able to use this information to identify tactics to support a suitable design process and generate outcomes that are more likely to lead to change.

It is recommended that, during the exploration phase, designers and design researchers working on projects for the Government of Canada take time to develop a better understanding of the organizational factors related to successful design implementation in order to support design implementation and that the modified Prosci ADKAR ${ }^{\circledR}$ Model is studied further within the context of design work for the Canadian Federal Public Service. 


\subsubsection{A name for the formula}

Given the specific nature of this proposed model, I would like to give it the name of the Public Service Design Implementation Formula (or PSDIF for short). It is a lens with which designers and design researchers can look at design projects to determine if they may end up being successfully implemented and if that likelihood is low, how they might change their tactics and approaches to increase their likelihood for success.

\subsubsection{An example of the formula in use}

I propose that this formula could be used in the context of design for any solution, be it a new feature on a website or a new policy relating the distribution of a minimum income to all Canadians. As a design research tool, it is not likely restricted to one particular type of design or another. However, for the purposes of exploring the application of the model in practice, let's look at a simple scenario that involves modification to a department's website in order to increase usability and reduce client support enquiries for general information.

\subsubsection{Reducing client enquiries with the right design, on time}

A manager of a popular government website has been tasked with improving the website to decrease client enquiries. The Director General (DG) of the manager's branch believes that the website just doesn't work for people and if it were improved, clients would call their client support centre less. The DG has tasked their e-communications team with improving the website content to decrease client support enquiries relating to general program information. 
The manager hires a web content specialist consultant to provide advice on the effectiveness of the website and bring their team together to get started. The team includes the manager, the consultant, a user experience designer, web developer, 2 web advisors, the division director and the branch DG. Other people included in the project are subject matter experts across the department, the digital transformation team at the Treasury Board Secretariat and the other web teams involved in maintaining the website.

The user experience designer on the team has heard about the PSDIF and decides this would be a great opportunity to try the formula out to develop a better understanding about whether or not the team will be successful in their initiative and, if not, what they need to consider in order for their design project to be successful.

She looks at the formula and begins to work through the formula:

$$
\text { Change }=(C+A+D+K+A) \times S
$$

Where,

$\mathrm{C}=$ Understanding of the context of the change to determine project fit

$A=$ Awareness for the need to change

$\mathrm{D}=$ Desire to support the change

$\mathrm{K}=$ Knowledge of how to change

A $=$ Ability to change

$\mathrm{S}=$ Shared understanding

To start, she considers the factors within the brackets. She begins with the factor of Understanding of the context of the change to determine project fit. She paused. Oh, dear! She recognizes that she understands little about 'the context of the change' and how it relates to her project. Right away she could pinpoint the first area she may need to explore with her colleagues to increase the likelihood of success of the project. She goes to her manager to share her thoughts. Specifically, she is concerned that they don't know 
enough about the problem and this could bring up issues down the road relating to feasibility of the solution, how much it will cost and who needs to be involved with the work. The manager thanks the user experience designer for the insight and asks her to pull another team member off a project to do some research. The two get to work!

One week later, the UX designer and design researcher come back to the manager with their findings. It turns out, people cannot find an important piece of information on the website and that's why they are calling. It's a findability issue! The manager thanks the UX designer and asks her to prepare a presentation of what she found with the team.

After the presentation, she goes back to the PSDIF and reassesses. She now has a better understanding of the context of the change to determine project fit; she moves on to awareness for the need to change. Since she shared the need for change in the presentation she had just done, she felt that her team understood the need, so she went to desire to support the change next. She noticed that the developer was a little argumentative about the recommendations the UX designer had put forward for change. They understood the need to change but had suggested that the team needed to focus on marketing the web content, instead of working on 'findability' of the content on the website. The designer noted that the developer might not support the change, although the rest of the team seemed onboard.

Next, she considered the factor of knowledge of how to change. To the UX designer, it seemed pretty straight forward. They needed to optimize the web content to support search engine optimization (SEO) both on Google and the Canada.ca search engine and increase the volume of links between the important information and related pages. She talked this approach through with the web content consultant to verify her 
hunch and she agreed that this would likely be an effective approach. The consultant also suggested that they could run some quick tests before they made the changes final to be sure that the approach would increase findability. The UX designer considered the factor of knowledge about how to change accounted for.

Finally, she considered the ability to change factor. Well, the developer could make changes to the website at any time and the consultant said she could recommend the required changes to support effective and validated changes. So yes! It looked like the ability was there.

Happy that it looked like the project would be a success so far, she moved out of the brackets to the 'S' for shared understanding. She stopped and frowned. Recalling her experience with the developer's reaction to her recommendations earlier, she knew that the understanding wasn't even shared on the team, let alone across all of the people involved in the project. She went back to her manager to talk about the issue. Together, they came up with a way to refine the recommendations with the team so that they had a shared belief about the best way to proceed. The manager also asked her to prepare a stakeholder map and communications plan to ensure that they could reach all project stakeholders as quickly as possible to ensure that everyone was on the same page and had been bought in to the project.

The upfront work the UX designer had done to understand the context for design implementation in the public service resulted in the successful implementation of changes to the web content that were done before the end of the fiscal year and turned out to decrease calls at the client support centre by $25 \%$ in the following quarter. 


\subsubsection{Consideration for complexity}

Although the scenario in section 6.2.2.1 explores a happy path scenario, life is rarely so straight forward. It would be wonderful if the formula could always be used effortlessly to make sense of a specific design context and guide next steps with respect to how to determine if a design could be successfully implemented. However, it is likely that, even with the development of a strong, effective tool that people working on design projects for the Canadian Federal Public Service might use, there will be issues that it misses or cannot work around. Consider the following two scenarios: 1 . The boulder and

\section{The gap.}

1. The boulder: In our happy path scenario, the UX Designer's manager is both invested and involved in this project, highly supportive of the designer's curiosity and not only encouraged her to explore her questions freely with other team members, and also allowed her access to another team member to work on the problem. But this scenario was not always the case as we saw through the participant stories. Some managers are not as supportive, and it may even feel to some employees that the manager is actively stopping the designer's work. In this circumstance, although someone may be able to use the formula to determine if the project will be a success or not, there is likely not anything that can be done to address the issues if they are found.

Similarly, if the person using the tool does not trust their manager or have a team member that they can turn to discuss the issues and take steps toward rectifying them, there may be no way forward.

2. The gap: In the case of the gap, lets imagine that the manager had not hired a web content specialist to work on this project and the UX designer did not know how to optimize web content for search engine optimization (for either Google or Canada.ca) and findability in general. Let's also imagine that there was no budget to hire someone to do that work and no time for the UX designer or another team member to learn how to do the work effectively. In 
this case the factor of ability to do the work would not have existed. But, the UX designer, paired with the developer, could find and address some content usability issues on the site that the UX designer found while exploring the context. Knowing that the issue causing the calls to the call centre isn't usability related, but that there are usability issues that they can address and would technically improve the site, should they focus on the usability issues? The formula will not help you make that decision. That is a much bigger conversation that must be had with the decision makers on the team. Although to the designer it may seem like a natural "yes" to simply by shifting the focus to fixing usability issues because it has the greatest likelihood of being successfully implemented, the fact that it will not address the reason for doing those changes in the first place, should likely still be shared so that others can benefit from additional insight into the context of design. The designer could even use the formula to show decision makers on the team the breakdown of the two approaches (focus on usability issues, but don't address calls or wait until there is budget to address the real issue for the calls) and let them use the information to make their own decision.

Although it is hoped that this formula may be a tool that can be used by designers working on public service design projects to explore design context, it is by no means a silver bullet that will make every project successful. It is only a guide that may help designers think differently about the context of their work and design solutions that could work within that context in support of successful design implementation. In some cases, however, the context of the work is so messy, that even the best solutions do not have a chance for being implemented effectively or there might just not be a clear path to implementing the best solution today. Either way, it is hoped that this tool might help frame the design context to help designers understand it better and provide the best recommendations they can in their unique context. 


\subsection{The Gap in Literature}

\subsubsection{A gap in design literature}

As discussed in section 3.3 The Potential for Design in Government, design can add rigour, principles and process to solution development (Lewin, 1946; the Design Commission, 2013), this thesis proposes one approach to add that rigour, principles and process to the solution development process by adding a repeatable set of steps that people can follow when exploring the context of design before they refine their solutions. This approach, as Lewin (1946) calls for, also may increase the possibility of measuring design (by asking the question "did we account for these areas of discovery when looking into our solution?") both before solution development in order to increase the chances of success and could potentially be used after the design project is complete to measure performance.

This exploration of factors potentially affecting the success of design projects within the Canadian Federal Public Service may also contribute to the practices and literature on building an understanding regarding how a design may impact an organization during the design process (Brown \& Katz, 2009; Hetenstein, Platt \& Veryzer, 2013; Junginger, 2018; McMullin \& Wu, 2006; The Design Commission, 2013). Given that this study focuses primarily on the organizational factors that may need to be considered during the design process, it begins to answer McMullin's (2003) call to consider organizational needs in order to produce benefit through design. It may also contribute to the discussion about understanding the business impact of design in support of good design (Hertenstein, Platt and Veryzer, 2013) and how to develop a 
better understanding of how a design may impact an organization during the design process.

Finally, this thesis may begin to contribute to the discussion about how to design well in the Canadian Federal Public Service and mitigate risks by adding a new step to the design process and reducing the chance of designing and implementing the wrong thing or designing the right thing but not implementing it.

\subsection{Future Work}

This study should be considered as a first step towards a much bigger and more mature exploration into the factors related to an organization's ability to change in order to support design implementation within the Canadian Federal Public Service and perhaps even public service in general. As will be seen in the sections on limitations in coding (sections 6.5.1-6.5.3 and 6.5.7) and in section 6.5.8 looking at the limitations of the review of the formulas, there is still much that could be done to increase the confidence in the findings and strengthen the categories and labeling of the factors and more understanding of change readiness and change management in general. Increasing the breadth of the literature review would serve to strengthen confidence in the content analysis and key factors drawn from literature and re-assessing the coding data using statistical methods would increase the validity of the findings.

\subsubsection{A larger study}

Increasing the size of the study, exploring more change readiness and change management literature and adding more researchers to code and explore the data (interrater reliability) would increase the confidence in the findings from this study. By 
increasing the size of the study, the risk of researcher bias and influence on participants responses would be reduced. Further confidence in the results could be achieved by conducting an assessment similar to Holt et al.'s (2007) quantitative study to revalidate the factors of change readiness across a broader inventory of literature, increasing the scope from formulas alone to any type of framework (considering including findings from Armenakis et al. (1993) and Kotter (1973) and Lewin (1946) would be a recommended first step).

To support the larger scale of the study, more researchers would need to be included in the study to increase the inter-rater reliability, add further insight and validation to the findings from the literature review and to undertake the coding of a larger dataset. Increasing the amount of researchers would also increase the coding reliability and speed of analysis and make this type of study more manageable.

\subsubsection{Statistically significant results}

Given the volume of data that can be generated by using electronic coding methods, this type of study is a candidate for a more rigorous, statistical analysis of the data. Not only would this quantitative approach to data analysis speed up the analysis process, but it would allow for richer exploration of relationships between codes and cases identified in coding.

Field (2013) talks about testing the fit of a model using statistical analysis which is applicable to this study since multiple formulas were coded, analyzed and compared with information from real life experiences. A statistical analysis would set out to understand the extent to which the model developed in this study accurately reflects the real world. Exploring the data collected in this study using statistics would help 
determine whether the conclusions drawn from this study are consistent and potentially identify new areas for consideration.

\subsubsection{A longitudinal study}

Further research should also be done to validate the findings from this study in terms of whether or not the factors uncovered do contribute to successful change in application. Specifically, a look at the existing potential organizational ability to change before a design project is initiated, how an understanding of this state may lead to tactics to improve the likelihood of the design being implemented and ensuring that the change occurs, looking at the organizational state after the intervention and over a period of time. This type of longitudinal study would further strengthen the findings and support a more definitive conclusion about which factors contributed to an organization's ability to change and successfully implement designs and with what magnitude.

\subsubsection{A tool to explore organizational ability to change in the federal public service}

In order for designers to be able to quickly and effectively assess an organizations ability to change, they likely require a tool that they can turn to quickly and with confidence.

Once additional research has been undertaken to increase the confidence in the findings from this study, further research should be done to explore options for developing this preliminary tool further so that people working on design projects for the Canadian Federal Public Service may be able to use it to better understand factors contributing to organizational ability to change for design implementation. Such a tool 
may help to increase the success of design implementation and generate benefit for the Canadian Government through design.

\subsection{Limitations and Considerations for Future Studies}

\subsubsection{Subjectivity of the coding}

Coding is subjective and it is reasonable that the organization and classifications and descriptions assigned to each of the concepts in the formulas found in literature may be contested by the authors. However, given that I could not evaluate the content analysis of the literature review with the authors, I hope that the analysis and recommendations to extend an existing formula proposed in this thesis will have the opportunity to be studied by others and adjusted over time. After two attempts at coding the formulas from the literature (with 3 cycles of coding in each attempt), I do believe that the selection of factors that emerged to develop the codebook for participant data analysis and comparison was relatively close to an optimal state of completion based on the approach taken, but further exploration using a different lens would likely shed light on new insights. Similarly, the coding of the research data was equally subjective and the results an outcome of the selected approach to analysis. It could be that participants may have disagreed with some of the coding and that interesting insights may be uncovered by taking a different approach to analysis of the data.

In future studies it is recommended that the time and ability to share coding of data with participants be included in the research plan to support a higher level of confidence with the coding approach and outcomes and that the data is explored using more than one data analysis approach. 


\subsubsection{Use of NVivo}

The use of any tool is subject to the user's ability to use that tool, perceived and actual. Although I have used NVivo electronic coding software for more than just this coding exercise, I am not an expert user. Despite my best efforts to optimize use of all the features and functions available in the tool, it is likely that I may have overlooked opportunities for discovery.

It is recommended that in future studies the methodology behind the use of the tool is as thoroughly explored and documented as the literature review and that extra attention is placed on what benefits could be realized from the coding technology available and how to realize those benefits prior to the analysis.

\subsubsection{Analysis of relationships between codes}

The relationships between the codes was not explored using statistically relevant methods. The approach to coding and theming the top-level categories was done manually using Pattern and Focused Coding methods (Saldaña, 2016) and the significance of specific relationships in the data was not explored (Field, 2013). As Field (2013) explains in an overview about "fit of the model" (p. 41), this means that my confidence that the results are true to real life is not as high as it may be, had I used statistical methods to explore the data. Given the volume of the codes generated, there was opportunity to take this lens, however, it did not align with the established methodology for the study and only became apparent as an option through analysis activities.

In future studies, it is recommended that, when determining the relationships between codes in large data sets uncovered in qualitative research, statistical methods are 
used to determine if the formulas from literature match participants' real-world experiences (Field, 2013). The findings from this type of analysis are very likely to reveal powerful relationships between the codes and increase confidence in the study results.

\subsubsection{Researcher bias}

I personally knew 11 of the 18 participants either very well or well. The recruitment methods relied on my personal networks to solicit interest from potential participants. Although my relationship with the participants may have introduced a bias into the study, this was mitigated with the use of multiple methods to explore successful and unsuccessful projects.

In the future it is recommended that researchers take note of their biases and mitigate the risk of bias through the use of mixed-methods research approaches.

There was also a bias in that I was in search of a tool, rather than exploring a context for insight. Although the study applied multiple-methods to both explore contexts and validated hypothesis, it did result in more of a validation exercise than exploratory study, where in I answered the question can formulas in change management literature be used to understanding a Canadian Federal Public Service organization's ability to change.

As a result, I may have overlooked important insights into how trust, teamwork and leadership effect and organization's ability to change and missed out on important findings relating to how individual attitudes affect and organization's ability to change. As the study was scoped so narrowly, there were many opportunities for exploration missed as when I uncovered both organizational and individual factors in my participant 
data and could have learned more about effect by exploring more formulas and frameworks relating the individual's readiness for change (including work by Cinite (2006), Armenakis et al. (1993) and Hanapachern (1997)) as an important factor in organizational ability to change.

\subsubsection{Participant reach}

I missed out on two critical opportunities to expand my participant reach: the use of an online social channel used specifically by Government of Canada employees and their partners and the option of running remote sessions. Despite a successful amendment to the research protocol, by the time approvals came in, research had completed.

In the future, it is recommended that, if possible, research protocols proposed for ethics review are not as tightly scoped to specific channels to allow for flexibility. Specifically, online recruitment channels should be kept relatively general (i.e. online social networks, rather than "Twitter" specifically), the ability for participants to participate remotely should be a possibility and participants should not be scoped any more specifically than required for the study (e.g., people who have worked on government projects, rather than public servants who have worked on government projects).

\subsubsection{Testing of recruitment methods}

Recruitment methods for the study were not tested in advance of recruitment. This meant that some messages used in recruitment did not convey the right information about the study eligibility or requirements for participation. 
In future studies it is recommended that recruitment methods (including channel, messaging, and systems) are tested before recruitment happens.

\subsection{7 "Lumping" the data vs "Splitting" the data}

Data coding and analysis took substantially longer than expected as I chose to "split" the codes rather than "lump" them (Saldaña, 2016, p. 23-25). This decision to use a "splitting" approach was made as I wanted to uncover similarities between the participant stories in the details of the stories. However, as the analysis progressed, the challenges of this approach for such a large data set began to outweigh the benefits of uncovering all of the details in the data. Given the volume of the codes generated and limitations of the NVivo software, the second and third cycles of coding took more than 3 times as long as expected. The volume of codes collected in the system also added a technical burden on the software and my computer systems, making NVivo slow and requiring emergency information management in my computer when I ran out of space on my hard drive.

In future studies it is recommended that, as Saldaña (2016) recommends, a "lumping" coding (p. 23-25) approach is taken in first cycle coding and the details are explored further in subsequent cycles.

\subsubsection{Limitations of the review of formulas}

As I was first introduced to the concept of a formula of change readiness, I likely held a bias toward not only articles relating to change readiness that had formulas or factors and considerations that could be arranged into a formula, but also exploring only factors that related to formulas. This may have resulted in an omission of important 
findings relating to change readiness and the factors that are considered to be foundational to change readiness.

This focus on formulas also lead me to pick literature that may not have been as effective for the study but contained a formula (such as Heath \& Heath, 2010) and omit findings from important texts such as Armenakis, Harris and Mossholder's (1993) article Creating Readiness for Organizational Change.

Similarly, the focus on a finding a solution to help designers rather than simply exploring the design implementation context within in the Canadian Federal Public Service, may have biased my research analysis methodology and study results, leading to potentially too much focus on getting to a set of themes of factors that contribute to ability for an organization to change rather than understanding what does or does not enable change within the Canadian Federal Public Service. For example, during my second cycle of coding of participant data, I was thrilled to uncover two findings that I thought were incredibly interesting. There was a noticeable pattern emerging relating to trust, teamwork and leadership. I talked about my discovery for days before completing my third cycle of coding to complete my research method that I had planned for the participant analysis. But in that third cycle of coding, the pattern that emerged in the second cycle almost completely disappeared, with the once strong themes of trust, teamwork and leadership falling now under the new themes of People can make the change happen: a theme that contains categories like People work well together, The project team has the right skills, There is enough time and There is someone leading the team. 
It is unclear what would have emerged if I had stopped to explore the second cycle findings further and was not as focused on finding a set of themes representing factors that could fit into a formula or even if the Provisional Codes generated in the literature content analysis had not been used in the first cycle of coding, but it is assumed that focusing specifically on the formulas found in change management literature did have an effect of my study overall and potentially hid important findings from discovery.

Change, like design, is also a complicated and rich subject that cannot be simply reduced down to check lists and formulas (Holt et al., 2007; Weiner, 2009). As such, the approach to explore formulas is likely a very narrow view of an organization's ability to change and further.

In future studies it is recommended that further exploration should be undertaken to understand the change and change readiness in the Canadian Federal Public Service better before the proposed PSDIF formula is turned into a tool and tested further. 


\section{Chapter 7: Conclusion}

This study set out to understand factors that might contribute to a Canadian Federal Public Service Organization's ability to change in support of design implementation. Further, I was interested in exploring if there was a formula from change management literature that could help designers working in public service develop a better understanding of how a design process may be impacted by organizational factors and whether or not that organization is ready to bring about change through the medium of design.

Through the exploration of successful and unsuccessful Canadian Federal Public Service design projects, I was able to identify 6 main factors that participants may have felt were important in discussing the success and/or lack of success in their project experiences.

The factors included:

1. The people involved in the project could make the change happen.

2. The people involved in the project wanted to do the work.

3. People knew why the work was being done.

4. People knew how the work was being done.

5. The project fit within the existing context.

6. There was shared understanding about the work.

These factors were mapped to the factors uncovered in a detailed review of formulas from change management literature and it was found that, although none of the formulas seemed to cover all of the factors that were revealed in the stories shared about 
projects in the Canadian Federal Public Service, the Prosci ADKAR ${ }^{\circledR}$ Model was the formula that was most likely closely aligned.

Despite being a good fit, the Prosci ADKAR ${ }^{\circledR}$ Model was found to not likely be a 'perfect fit' as a formula to explore a Canadian Federal Public Service organization's ability to change in support of design implementation. It was proposed that the Prosci ADKAR ${ }^{\circledR}$ Model could be modified and extended to include the additional factors of the project fits within the existing context and there is shared understanding about the work and that this extended version of the Prosci ADKAR ${ }^{\circledR}$ Model (The Prosci ADKAR Model, n.d.) could be given the name the Public Service Design Implementation Formula or PSDIF:

$$
\text { Change }=(\mathrm{C}+\mathrm{A}+\mathrm{D}+\mathrm{K}+\mathrm{A}) \times \mathrm{S}
$$

Where, $\mathrm{C}=$ Understanding of the context of the change to determine project fit $A=$ Awareness for the need to change $\mathrm{D}=$ Desire to support the change $\mathrm{K}=$ Knowledge of how to change A $=$ Ability to change $\mathrm{S}=$ Shared understanding

And the $S$ acts as a modifier, which means that if there is a low level of shared understanding regarding the other factors within the formula or no shared understanding, the outcome is likely to be unsuccessful (Figure 30).

Following change readiness theory, that in order to change, an organization must first be ready to change (Armenakis et al. 1993), coupled with what was revealed by participants in this study, it is proposed that if the factors proposed in the PSDIF (developed from this study) are considered early on in the design process, tactics to 
address weak factors in can be developed and used throughout the design process to increase the likelihood the project will be a success.

There are many opportunities to improve this study and continue to explore the topic of design implementation and organizational ability to change in the Canadian Federal Public Sector, including increasing the size, length and maturity of the study and developing a tool to explore organizational ability to change for design implementation in the public sector.

This thesis likely contributes to the fields of design and change management by bringing together the two areas to explore how we might increase our chances of successful design implementation in the Canadian Federal Public Service. Designers and design researchers may now have a preliminary formula by which they can begin to explore and organization's ability to change during the design process and hopefully uncover information that will increase their chances of a successful design implementation and improve the formula though use and documentation of its use.

The findings from this study may also begin new conversations about factors that contribute to design implementation, the impact design has on an organization, the relationship between organizational ability to change and design and design in the Canadian Federal Public Service. This study could also be the starting point to explore linkages between delivering benefit through design and topics of trust, teamwork, leadership, 'good design' in the Canadian Federal Public Service and measuring the success of design. 


\section{References}

$26^{\text {th }}$ Annual Report to the Prime Minister on the Public Service of Canada (2019).

Retrieved January 23, 2020, from https://www.canada.ca/en/privycouncil/corporate/clerk/publications/26-annual-report.html

The Prosci ADKAR Model (n.d.). Retrieved January 3, 2020, from https://www.prosci.com/adkar/adkar-model

Anthopoulos, L., Reddick, C. G., Giannakidou, I., \& Mavridis, N. (2016). Why e-government projects fail? an analysis of the healthcare.gov website. Government Information Quarterly, 33(1), 161-173. oi:10.1016/j.giq.2015.07.003

Armenakis, A. A., Harris, S. G., \& Mossholder, K. W. (1993). Creating readiness for organizational change. Human Relations, 46(6), 681-703. doi:10.1177/001872679304600601

Banfield, R. (2017). How To Make Design Thinking Deliver on Its Promise of Creating Better Product. Retrieved January 27, 2020 from https:/uxdesign.cc/how-tomake-design-thinking-deliver-on-its-promise-of-creating-better-productb87b7b408971

Brewer, J. (n.d.). The Sky Ain't the Limit. Retrieved March 28, 2019, from https://themanual.org/read/issues/2/josh-brewer/article

Beckhard, R., \& Harris, R. T. (1977). Organizational transitions: Managing complex change. Reading, Mass: Addison-Wesley Pub. Co.

Boschken, H. L., (1988). Strategic design and organizational change: Pacific Rim seaports in transition. Tuscaloosa, AL: University of Alabama Press.

Brown, T., \& Katz, B. (2011). Change by design. Journal of Product Innovation Management, 28(3), 381-383. doi:10.1111/j.1540-5885.2011.00806.x

Buchanan, R. (1992). Wicked problems in design thinking. Design Issues, 8(2), 5-21. doi: $10.2307 / 1511637$

Buchanan, R. (2008). Introduction: Design and organizational change. Design Issues, 24(1), 2-9. doi:10.1162/desi.2008.24.1.2

Buchanan, R. (2015). Worlds in the making: Design, management, and the reform of organizational culture. She Ji: The Journal of Design, Economics and Innovation, 1(1), 5-21. doi:10.1016/j.sheji.2015.09.003 
Bürdek, B. E. (2005). Design: History, theory, and practice of product design (1st English ed.). Boston, MA: Birkhauser-Publishers for Architecture.

Bushore, D. (2012). Evaluating design: Creating a quantitative value measurement tool to encourage a design policy in Canada.

Cady, S. H., Jacobs, R., Koller, R., \& Spalding, J. (2018). The Change Formula Myth, Legend, or Lore?. OD Practitioner, 46(3), 32-39.

Calder, A. M. (2013). Organizational Change: Models for Successfully Implementing Change. Undergraduate Honors Capstone Projects. 144. https://digitalcommons.usu.edu/honors/144

Charette, R. N. (2005). Why software fails [software failure. IEEE Spectrum, 42(9), 4249. doi:10.1109/MSPEC.2005.1502528

Cinite, I. (2006). Measurement of perceived organizational readiness for change and employees' attitudes toward change in the public sector

Clarke, A., \& Craft, J. (2019). The twin faces of public sector design. Governance, 32(1), 5-21. doi:10.1111/gove. 12342

Clarke, V., \& Braun, V. (2017). Thematic analysis. The Journal of Positive Psychology, 12(3), 297-298. doi:10.1080/17439760.2016.1262613

Collins, J. A., \& Chiaramonte, M. W. (2017). Project-Based Learning and Design Thinking: Fomenting Agility and Innovation in Government. IEEE International Professional Communication Conference (ProComm), Madison, WI. 1-8.

Conner, D. (1994). Managing at the speed of change: How resilient managers succeed and prosper where others fail (1st ed.). New York: Villard Books.

Cross, N. (2001). Designerly ways of knowing: design discipline versus design science. Design Issues, 17(3). 49-55.

Dannemiller, K. D., \& Jacobs, R. W. (1992). Changing the way organizations change: A revolution of common sense. The Journal of Applied Behavioral Science, 28(4), 480-498. doi:10.1177/0021886392284003

Deserti, A., \& Rizzo, F. (2014). Design and organizational change in the public sector. Design Management Journal, 9(1), 85-97. doi:10.1111/dmj.12013

Domingo, L., Buckingham, M., Dekoninck, E., \& Cornwell, H. (2015). The importance of understanding the business context when planning eco-design activities. Journal of Industrial and Production Engineering, 32(1), 3-11. doi:10.1080/21681015.2014.1000398 
Dorst, K. (2011). The core of 'design thinking' and its application. Design Studies, 32(6), 521-532. doi:10.1016/j.destud.2011.07.006

Dunne, D. (2018). Implementing design thinking in organizations: An exploratory study. Journal of Organization Design, 7(1), 1-16. doi:10.1186/s41469-018-0040-7

dmi: design management institute. (n.d.). The Value of Design. Retrieved March 4, 2018, from https://www.dmi.org/page/DesignValue/The-Value-of-Design-.htm

Edelman. (2020). Edelman Trust Barometer 2020. Retrieved January 24, 2020, from https://www.edelman.com/trustbarometer

Fajardo, G., Rehm, J., \& Joffres, K. (2012). Turning Design Thinking to Design Doing. Retrieved January 27, 2020 from https://ssir.org/articles/entry/turning_design_thinking_to_design_doing\#

Field, A. P. (2013). Discovering statistics using SPSS: And sex drugs and rock ' $n$ ' roll (4th ed.). Los Angeles, London, New Delhi, Singapore, Washington, DC: SAGE Publications.

Fiell, C. \& Fiell, P. (2019). "We have lost sight of what design thinking actually is". Retrieved July 17, 2019, from https://www.dezeen.com/2019/05/10/designthinking-opinion-charlotte-fiell-peter-fiell/

Garrett, J. J. (2011). The elements of user experience: User-centered design for the web (2nd ed.). Ne Berkeley, CA: New Riders.

Gaver, B., Dunne, T., \& Pacenti, E. (1999). Design: Cultural probes. Interactions, 6(1), 21-29. doi:10.1145/291224.291235

Government of Canada Digital Standards (2019). Retrieved December 14, 2019, from https://www.canada.ca/en/government/system/digital-government/governmentcanada-digital-standards.html

Guest, G., Bunce, A., \& Johnson, L. (2006). How many interviews are enough? an experiment with data saturation and variability. Field Methods, 18(1), 59-82. doi: $10.1177 / 1525822 X 05279903$

Harris, R. (2017). An exploratory study of the relationship among organizational readiness for change, project management, and ERP success

Hall, E. (2013). Just enough research (1st ed.). New York, New York: A Book Apart. 
Heath, C., \& Heath, D., (2010). Switch: How to change things when change is hard. Toronto: Random House Canada.

Hertenstein, J. H., Platt, M. B., \& Veryzer, R. W. (2016). What is "good design"? an investigation of the complexity and structure of design. IEEE Engineering Management Review, 44(3), 64-75. doi:10.1109/EMR.2016.7559062

Heskett, J. (2002). Design: A Very Short Introduction. New York: Oxford University Press Inc.

Hiatt, J. M. (2006). ADKAR: A Model for Change in Business, Government and our Community. Loveland, CO: Prosci Research

Hirsch, S., Fraser, J., \& Beckman, S. (2003). Leveraging Business Value: How ROI Changes User Experience. Adaptive path LLC.

Holt, D. T., Armenakis, A. A., Field, H. S., \& Harris, S. G. (2007). Readiness for organizational change: The systematic development of a scale. The Journal of Applied Behavioral Science, 43(2), 232-255. doi:10.1177/0021886306295295

Hum, R. \& Thibaudeau, P. (2019). Taking the Culture out of the Lab and Into the Office: A "Non-Lab" Approach to Public Service Transformation. In proceedings from DRS Learn X Design 2019: 5th International Conference for Design Education Researchers. METU, Ankara.

Jen, N. (2018). Design Thinking Is B.S. Retrieved July 15, 2019, https://www.fastcompany.com/90166804/design-thinking-is-b-s

Junginger, S. (2018). Inquiring, inventing and integrating: Applying human-centered design to the challenges of future government. JeDEM - eJournal of eDemocracy and Open Government, 10(2), 23-32. doi:10.29379/jedem.v10i2.520

Kalbach, J. (2016). Mapping Experiences: A Complete Guide to Creating Value through Journeys, Blueprints, and Diagrams. Sebastopol, CA: O'Reilly Media.

Kelly, S. (2018). Useful, Usable, and Used: Why They Matter to Designers. Retrieved May 2, 2018, from https://www.interaction-design.org/literature/article/usefulusable-and-used-why-they-matter-to-designers

Kershaw, A., Dahl, S., \& Roberts, I. (2016). Designing for Public Services. Retrieved January 24, 2020, from https://www.nesta.org.uk/toolkit/designing-for-publicservices-a-practical-guide/ 
Kitson, A., Harvey, G., \& McCormack, B. (1998). Enabling the implementation of evidence based practice: A conceptual framework. Quality in Health Care, 7(3), 149-158. doi:10.1136/qshc.7.3.149

Knapp, J., Zeratsky, J., \& Kowitz, B. (2016). Sprint: How to solve big problems and test new ideas in just five days. New York, NY: Simon \& Schuster.

Kolko, J. (2015). Design thinking comes of age. Harvard Business Review, 93(9), 66. Kumar (2013).

Kotter, J. P. (1973). The Psychological Contract: Managing the Joining-up Process. California Management Review 15.3: 91-99.

Kotter, J. P. (2012). Leading Change. Boston, MA: Harvard Business Review Press.

Kumar, V. (2013). 101 design methods: A structured approach for driving innovation in your organization. Hoboken, N.J: Wiley.

Lehman, W. E., Greener, J. M., \& Simpson, D. D. (2002). Assessing organizational readiness for change. Journal of Substance Abuse Treatment, 22(4), 197-209. doi:10.1016/S0740-5472(02)00233

Levy, J. (2015). UX Strategy: How to Devise Innovative Digital Products that People Want. Sebastopol, CA: O'Reilly Media.

Lewin, K. (1946). Action research and minority problems. Journal of Social Issues, 2(4), 34-46. doi:10.1111/j.1540-4560.1946.tb02295.x

Lidwell, W., Holden, K., \& Butler, J. (2003). Universal principles of design. Gloucester, Mass: Rockport.

Mackintosh (n.d.). The New Enterprise Designer. Retrieved March 28, 2019, from https://www.frogdesign.com/designmind/the-new-enterprise-designer

Malbon, T. (2016). The Solution To Design Thinking. Retrieved on January 27, 2020 from https://medium.com/the-many/the-solution-to-design-thinking42e8f1b59022\#.xxyhdv4kt

Martin, B., \& Hanington, B. (2012). Universal Methods of Design: 100 Ways to Research Complex Problems, Develop Innovative Ideas and Design Effective Solutions. Beverly, MA: Rockport Publishers.

McGann, M., Blomkamp, E., \& Lewis, J. M. (2018). The rise of public sector innovation labs: experiments in design thinking for policy. Policy Sciences, Springer; Society of Policy Sciences, vol. 51(3), pages 249-267, September. 
McMullin (2003). Searching for the center of design. Retrieved April 25, 2019, from http://boxesandarrows.com/searching-for-the-center-of-design/

Wu, R. \& McMullin, J. (2006). Investing in design: To build business buy-in, designers need to buy in to business. Ambidextrous. Winter 2006.

Norman, D. A. (2004). Emotional design: Why we love (or hate) everyday things. New York, NY: Basic Books.

Norman, D. A. (2013). The Design of Everyday Things. New York, NY: Basic Books.

OED Online. (2018). "design, n." Oxford University Press. Retrieved January 20, 2019, from http://www.oed.com

OED Online. (2018). "design, v." Oxford University Press. Retrieved January 20, 2019, from http://www.oed.com

Organization for Economic Co-operation and Development (OECD). (2016). Digital Government Strategies for Transforming Public Services in the Welfare Areas.

Peters, T. J. (2005). design. London: Dorling Kindersley.

Quesenbery, W., Brooks, K., \& O'Reilly for Higher Education (Firm). (2010).

Storytelling for user experience (1st ed.) Rosenfeld Media.

Rae, J. (2013). What is the real value of design? Design Management Review, 24(4), 3037. doi:10.1111/drev.10261

Rafferty, A. E., Jimmieson, N. L., \& Armenakis, A. A. (2013). Change readiness: A multilevel review. Journal of Management, 39(1), 110-135.

doi:10.1177/0149206312457417

Saldaña, J. (2016). The coding manual for qualitative researchers (Third ed.). London; Los Angeles, CA: SAGE.

Sanders, E. B., \& Stappers, P. J. (2014). Probes, toolkits and prototypes: Three approaches to making in codesigning. Codesign, 10(1), 5-14. doi:10.1080/15710882.2014.888183

Shea, C. M., Jacobs, S. R., Esserman, D. A., Bruce, K., \& Weiner, B. J. (2014). Organizational readiness for implementing change: a psychometric assessment of a new measure. Implementation Sci 9, 7 (2014) doi:10.1186/1748-5908-9-7

Sheppard, B., Sarrazin, H., Kouyoumjian, G., \& Dore, F. (2018). The Business Value of Design. McKinsey Quarterly. 
Sirkin, H. L., Keenan, P., \& Jackson, A. (2005). The Hard Side of Change Management. Harvard Business School Publishing. October, 2005.

Spool, J. (2017). Shh! Don't Tell Them There's No Magic In Design Thinking. Retrieved on January 27, 2020 from https://medium.com/user-interface-22/sshdont-tell-them-there-s-no-magic-in-design-thinking-b95f33867656\#.4u465crhh

Visser, F. S., Stappers, P. J., van der Lugt, R., \& Sanders, E. B-N. (2005) Context mapping: experiences from practice. CoDesign, 1:2, 119-149, DOI: $10.1080 / 15710880500135987$

Taylor, S. J., Bogdan, R., \& DeVault, M. (2016). Introduction to qualitative research methods: A guidebook and resource. New York: Wiley.

The Design Commission. (2013). Restarting Britain 2: Design and public services. Retrieved April 19, 2019, from https://www.designcouncil.org.uk/resources/report/restarting-britain-design-andpublic-services.

Unger, R., \& Chandler, C. (2009). A Project Guide to UX Design: For user experience designers in the field or in the making. Berkley, CA: New Riders.

Vassallo, S. (2017). Design Thinking Needs To Think Bigger. Retrieved July 5, 2019, from https://www.fastcompany.com/90112320/design-thinking-needs-to-thinkbigger

Vizard, L. (2018). The Material of Outcomes. https://noti.st/linnviz/kVZorP (retrieved on: December 14, 2019)

Walters, H. (2011). Design Thinking Won't Save You. Retrieved, July 15, 2019, from https://helenwalters.com/2011/03/21/design-thinking-wont-save-you/.

Weiner, B. J. (2009). A theory of organizational readiness for change. Implementation Sci 4, 67 doi:10.1186/1748-5908-4-67

Wherton, J., Sugarhood, P., Procter, R., Rouncefield, M., Dewsbury, G., Hinder, S., \& Greenhalgh, T. (2012). Designing assisted living technologies 'in the wild': Preliminary experiences with cultural probe methodology. BMC Medical Research Methodology, 12(1), 188-188. doi:10.1186/1471-2288-12-188

Williams, G. (2015). Design: An essential introduction. London: Goodman-Fiell.

Young, R. A. (2007). An integrated model of designing to aid understanding of the complexity paradigm in design practice. Futures 40, 6, August 2008. 562-576. 


\section{Appendices}

\section{Appendix 1: Formulas from Change Management Literature}

\section{A1.1 A Review of the 12 Formulas from Change Management Literature Reviewed for this Thesis}

The following sections discuss the 12 formulas included in this thesis. Each section

briefly reviews the formula, the factors that make up the formula and the similarities and differences between some of the formulas.

\section{A1.1.1 Formula 1a: The Change Formula}

The Change Formula (Figure A1) is an equation that was first attributed to David Gleicher in an article by Richard Beckhard (1975) in Sloan Management Review; a formula that was designed to assist "in determining readiness for change" (as cited in Cady, Jackobs, Koller \& Spalding, 2014). A similar description of Gleicher's formula was reused by Beckhard \& Harris (1997) to define a relationship of factors that could change or transition an organization from the current state to a new state. 

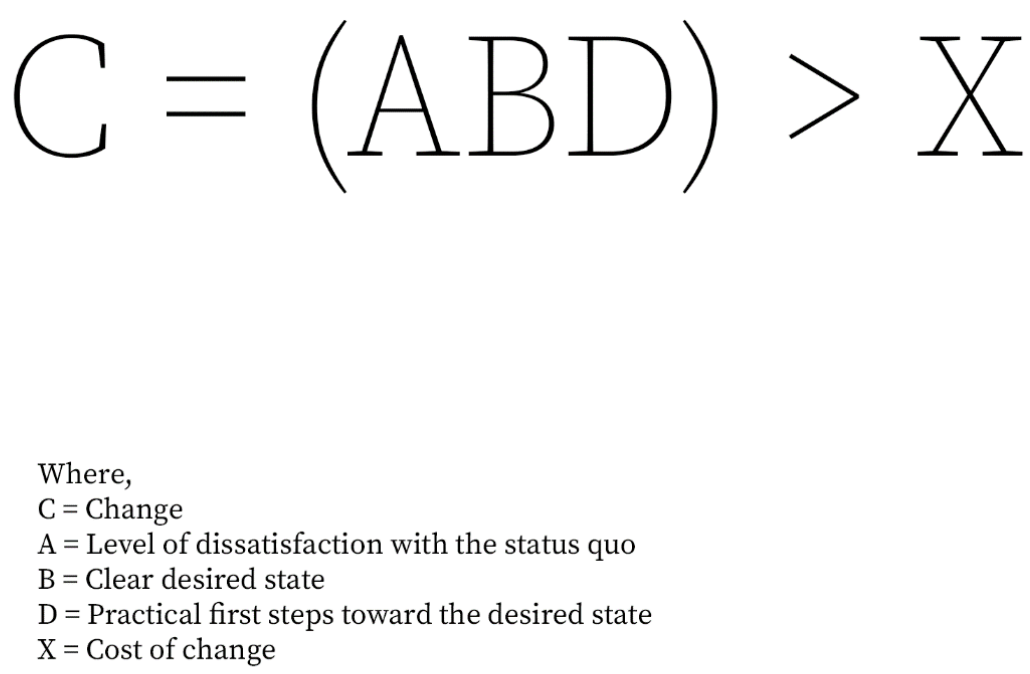

FIGURE A1. BECKHARD AND HARRIS' ADAPTATION OF GLEICHER'S ORIGINAL CHANGE FORMULA (BECKHARD \& HARRIS, 1977,)

Beckhard \& Harris (1977) proposed that in order for a change to be successful, there had to be:

- enough dissatisfaction with the status quo to get people "mobilized for the change";

- "clear goals" to offset the cost; and

- a sense of what the first steps of the transition needed to be to get started

There also had to be substantial representation of these factors to offset the cost of the change in order for the change to be successful. 


\section{A1.1.2 Formula 1b: Dannemiller's version of the Change Formula}

This formula was further adapted in the 1990's to make it more accessible to the people using it. In 1992, Dannemiller \& Jacobs redefined the Change Formula by reframing it "for ease of recognition and application" (p. 483) for use in an intervention at Ford Motor Company. The adapted formula proposed by Dannemiller \& Jacobs (1992) in the case study, identified change as the "product of dissatisfaction (D) with the present situation, a vision (V) of what is possible, and first steps (F) toward reaching the vision must be greater than resistance to change (R)" to transition to a future state (Dannemiller \& Jacobs, 1992).

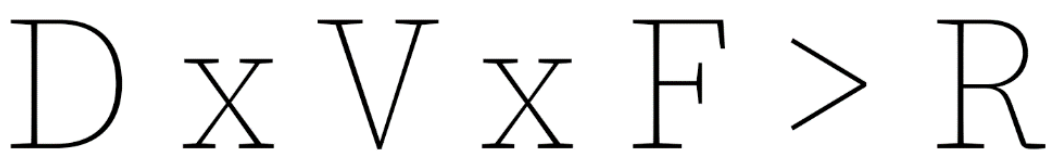

\footnotetext{
Where,

$\mathrm{D}=$ Dissatisfaction with the current state of affairs

$\mathrm{V}=$ An enobnobling vision of what we yearn to be

$\mathrm{F}=$ Concrete first steps

$\mathrm{R}=$ Resistance to change
}

FIGURE A2. DANNEMILLER'S ADAPTATION OF BECKHARD AND HARRIS' CHANGE FormUlA (DANNEMILLER \& JACKOBS, 1992). 
Like Gleicher's original equation, this revised formula employed a multiplier effect wherein if the value on the left-hand side of the formula was low or any of the values was 0 , this value would not be greater than the cost or resistance to change.

\section{A1.1.3 Formula 1c: Cady et al.'s version of the Change Formula}

As a response to the changing priorities of business leaders through the 2000's, a third iteration on the Change Formula was proposed which included a new factor contributing to the success of change. This additional consideration was sustainability (S) or the ability or an organization to maintain progress towards a change over time . This resulted in a new Change Formula that relied not only on considerations of the present, but the future effect of a change (Cady et al., 2014).
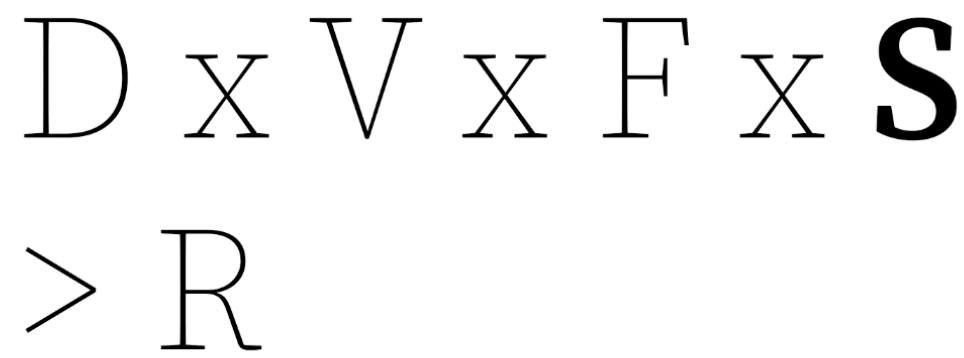

Where,

$\mathrm{D}=$ Dissatisfaction with the current state of affairs

$\mathrm{V}=$ An enobnobling vision of what we yearn to be

$\mathrm{F}=$ Concrete first steps

$\mathrm{S}=$ Sustainability

$\mathrm{R}=$ Resistance to change 


\section{A1.1.4 Formula 2: The Elephant and the Rider}

In 2010, Heath \& Heath explored three distinct factors they argued must be considered all of which are required to make a successful change.

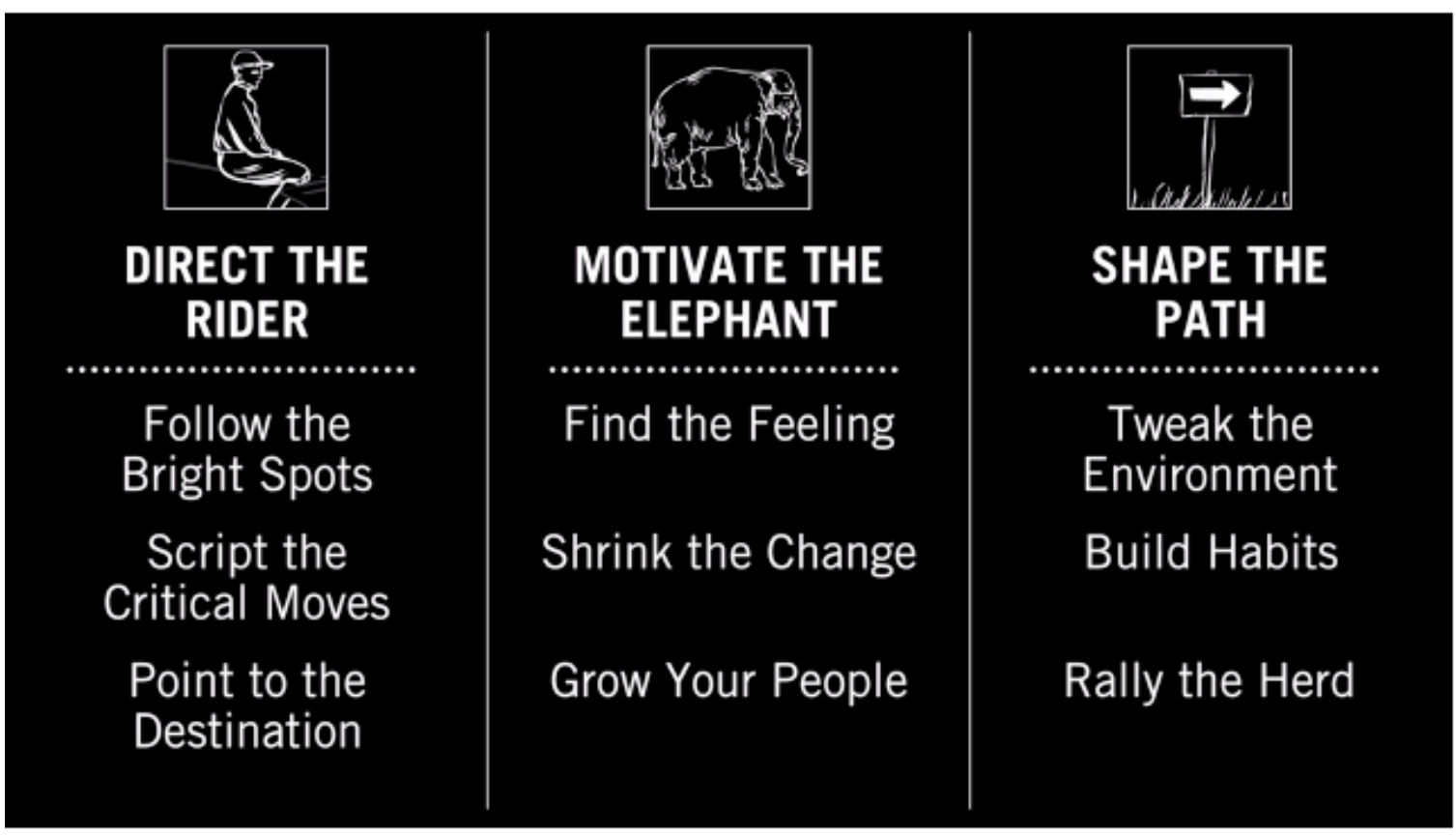

Figure A4. Change formula by Heath \& Heath (2010)

The authors use a metaphor of an elephant and a rider trying to get somewhere.

To do so, the rider must have direction (the logical side of the brain must have clear focus), the elephant must have motivation (the emotional side of the brain must be triggered) and there must be an environment or situation that can be changed to support the change.

Based on the descriptions taken for the formula illustrated in the book, this roughly translates to the need for the following factors to result in successful change: 


\section{Clear direction \\ $\mathbf{x}$ Emotional commitment \\ $\mathbf{x}$ A situation that is ready \\ Change}

Where not having all of the factors considered will result in unsuccessful change.

FIGURE A5. TRANSLATED VERSION OF CHIP AND DAN HEATH'S CHANGE FORMULA BASED ON THE DESCRIPTIONS OF EACH FACTOR (HEATH \& HEATH, 2010.)

Like Dannemiller and Jacobs (1992), the Heath \& Heath (2010) proposed that existing change formulas were difficult to use and that this formula, was "simple enough to be practical" (p. 18), but also warned that it was incomplete and that despite a person's best efforts, sometimes people simply do not want to change, for many, very good reasons.

The main difference between this formula and the other formulas proposed by Beckhard \& Harris (1977), Dannemiller \& Jacobs (1992) and Cady et al. (2018), is interestingly, the absence of explicit consideration for resistance to change and the focus on an environment to support the change. Although resistance is discussed through the book as a factor that can result from experiences like exhaustion, lack of direction or an 
inability to relate to a proposed plan, it does not surface as a key factor of the formula, but rather an ongoing theme across all the elements of the formula. Situational readiness, or having an environment to support a change, was not a consideration in any of the other change formulas. Although it may be argued that in order to have a condition of situational readiness, you would first need clear, concrete first steps toward change (thus another contributing factor), none of the other formulas covered this factor explicitly.

\section{A1.1.5 Formula 3: Pain and Remedy}

Yet another similar change formula was proposed by Conner (1994) where "pain and remedy" are two "prerequisites for major organizational change" (p. 96).

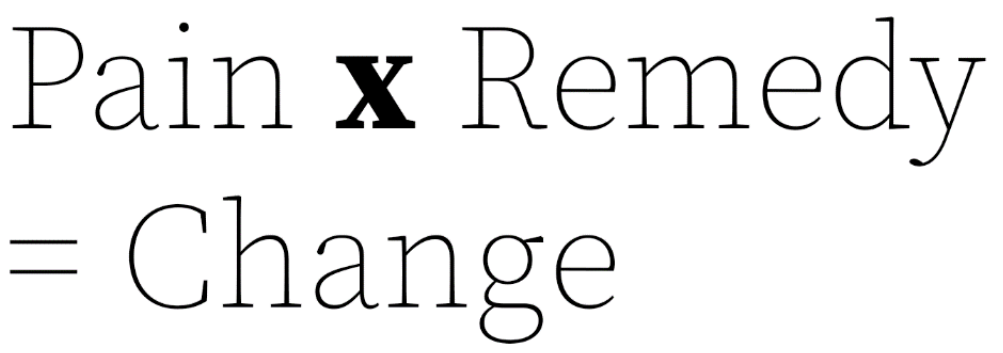

Where,

Pain = "a critical mass of information that justifies breaking with the status quo"

Remedy = "desirable, accessible actions that would solve the problem or take advantage of the opportunity afforded by the current situation."

And both pain and remedy must be present for the change to be a success.

FIGURE A6. A FORMULA REPRESENTING CONNER'S “PREREQUISITES FOR MAJOR ORGANIZATIONAL CHANGE"' (CONNER, 1994). 
In describing each prerequisite, the author identifies similar factors to those found in other change formulas. For example, the prerequisite of 'pain' aligns very well with Beckhard \& Harris' (1977) factor of A level of dissatisfaction. Similarly, the 'remedy' prerequisite, seems to reflect Beckhard \& Harris' factor of practical first steps. Like Heath \& Heath's (2010) formula, the formula proposed by Conner (1994) doesn't include a factor of resistance, nor does it include any specifics around vision, cost or sustainability. Instead, the author suggests that these elements are implied through the "timing" of the change or when the problem that needs to be addressed, appears. He proposes that, if the pain is "current" (or happening right now) and high enough (p. 96), then there will not be resistance as the cost of the problem isn't sustainable. In this case, the type of response to address it is tactical. I believe that this means, the vision of that remedy doesn't have much bearing on whether people need to do it. It simply has to be done.

However, when a change is oriented to an opportunity rather than a problem, the 'pain' is much more difficult to communicate as it is not grounded in people's current experiences. In this case, the vision of the 'remedy' is likely to take a larger role in ability to get people interested in a change. 


\section{A1.1.6 Formula 4: The Prosci ADKAR® Model}

In 2006, Hiatt proposed a formula that includes "five elements or objectives" that need to be "in place in order for a change to be realized" (The Prosci ADKAR Model, n.d.).

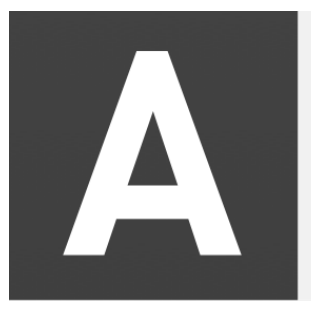

AWARENESS OF THE NEED FOR CHANGE

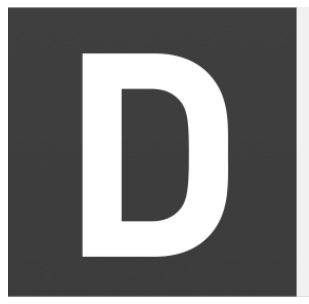

DESIRE TO SUPPORT THE CHANGE

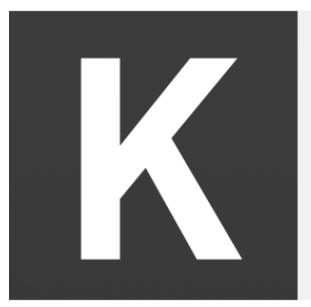

KNOWLEDGE OF HOW TO CHANGE

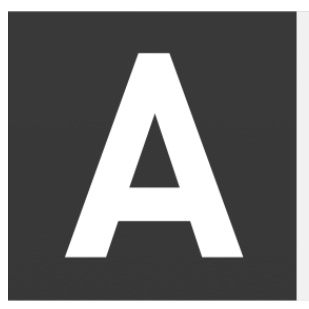

ABILITY TO DEMONSTRATE SKILLS \& BEHAVIORS

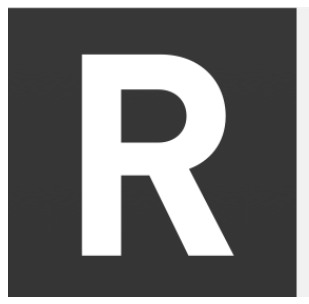

REINFORCEMENT TO MAKE THE CHANGE STICK

FIGURE A7. The Prosci ADKAR® MOdEL TAKEN From Prosci.com. 
In the Prosci ADKAR ${ }^{\circledR}$ Model (n.d.) the formula focuses specifically on "understanding change at an individual level" (p. 1) but proposes that it can be extended to the organization overall. For this reason, the formula was included in the inventory of formulas explored and continues to contribute to the theory that ability to change, like change readiness, is a multilevel phenomenon and cannot be achieved by looking at the individual alone, but rather must be explored across many facets, supporting theories proposed by both Weiner (2009) and Rafferty et al. (2013).

Like the other change formulas mentioned previously, the PROSCI ADKAR Model also includes factors that align with the original Change Formula. Specifically factors of Awareness of the need to change, Desire to support the change and Knowledge of how to change can be mapped to the Beckhard \& Harris Change formula factors of Dissatisfaction with the status quo, Clear desired end state and Practical first steps towards the end state.

\section{ADKAR}

Change $=((((A+D)+K)+A)+R)$
Change Formula

$\mathrm{C}=(\mathrm{ABD})>\mathrm{X}$

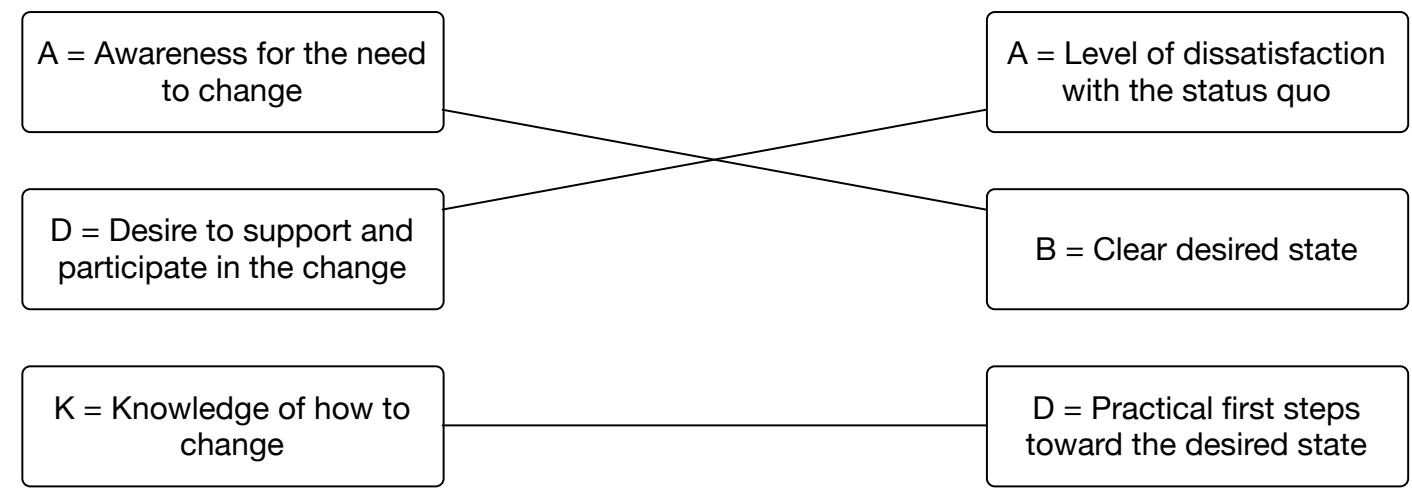

FIGURE A8. THE FIRST THREE FACTORS OF PROSCI ADKAR® MODEL (THE PROSCI ADKAR MODEL, N.D.) MAPPED TO THE THREE MAIN FACTORS PROPOSED IN GLEICHER'S ORIGINAL CHANGE FORMULA (BECKHARD \& HARRIS, 1977). 
Prosci ADKAR ${ }^{\circledR}$ Model also includes Cady et al's. (2014) idea of 'Sustainability' in the factor called Reinforcement to make the change stick. Cady et al. (2014) thought "Sustainability" was missing in Dannemiller \& Jacob's (1992) version of the Change Formula . As such, Prosci ADKAR® Model would appear to extend the Change Formula in the way proposed by Cady et al. Prosci ADKAR® Model also extends the Change Formula by including the importance of 'skills \& behaviors' in the factor called Ability to demonstrate skills \& behaviours. This is the first instance of a formula proposed in the literature reviewed that follows closely to the original and extended versions of the Change Formula that introduces the idea of whether or not the organization has the capability to implement a change when it is ready. However, this factor does come up in other formulas explained later. Prosci ADKAR ${ }^{\circledR}$ Model was the only formula that required that the factors of readiness were attained in order from the top ("A") to the bottom ("R") as well as requiring all factors to be accounted for in order for the change to be successful.

In summary, the Change Formula is the most common and frequently extended formula of those surveyed in this thesis. Six of the twelve formulas reviewed either actively extended the Change Formula or contained many of the same or similar factors. 
The Level of dissatisfaction with the status quo $\mathbf{x}$ Clear desired state

$\mathbf{x}$ Practical first steps toward the desired state

$>$ Cost of change

Change

Dissatisfaction with the current state of affairs

$\mathbf{x}$ An enobnobling vision of what we yearn to be

$\mathbf{x}$ Concrete first steps

x Sustainability

> Resistance to change

Change

Clear direction

$\mathbf{x}$ Emotional commitment $\mathbf{x}$ A situation that is ready

Change
Dissatisfaction with the current state of affairs

$\mathbf{x}$ An enobnobling vision of

what we yearn to be

$\mathbf{x}$ Concrete first steps

> Resistance to change

Change
Pain

$\mathbf{x}$ Remedy

Change
((((Awareness of the need to change

+ Desire to support the change)

+ Knowledge of how to change)

+ Ability to demonstrate skills and behvaiours)

+ Reinforcement to make the change stick) Change

FIGURE A9. ALL THE FORMULAS THAT EXTEND OR REFLECT SIMILAR FACTORS TO THOSE FOUND IN THE ORIGINAL CHANGE FORMULA PROPOSED BY GLEICHER (BECKHARD \& HARRIS, 1977). 


\section{A1.1.7 Formula 5: The Dice Factors}

Sirkin, Keenan \& Jackson (2005) propose a formula that will "determine the outcome of any transformation initiative" (p. 4). Through a study of 225 companies, the authors concluded that there are four factors that contribute to the success of a change initiative:

- (D) the duration between project reviews;

- (I) the capabilities of the project team(s) referred to as performance integrity;

- (C) the commitment of the people whom the change will affect the most; and

- (E) the additional effort employees must undertake to facilitate the change.

This collection of factors is referred to as the DICE Factors because they "could load them in the favor of projects' success" (Sirkin et al., 2005, p. 3). Unlike the Change Formula, the DICE Factors do not explicitly include the previously identified core factors of vision, dissatisfaction, clear first steps or resistance. Instead they focus mainly on the "hard factors" (p. 3) that contribute to a change effort. The authors propose this approach because these factors are measurable, their importance can be easily communicated, and they can be quickly influenced (Sirkin et al., 2005). Although the DICE Factors do not share many of the factors outlined in the Change Formula, they do contain the "Ability" factor from ADKAR which considers skills and behaviours (seen in the DICE Factors under "Integrity (I)") a necessary factor for change.

The formula also includes an evaluation tool to assess if an organization is ready to change which consists of a set of questions probing each factor which is then tied to a scoring rubric. When the scoring is complete, a "DICE Score" (p. 6) can be calculated that the authors propose indicates the likelihood that a project will be successful. 


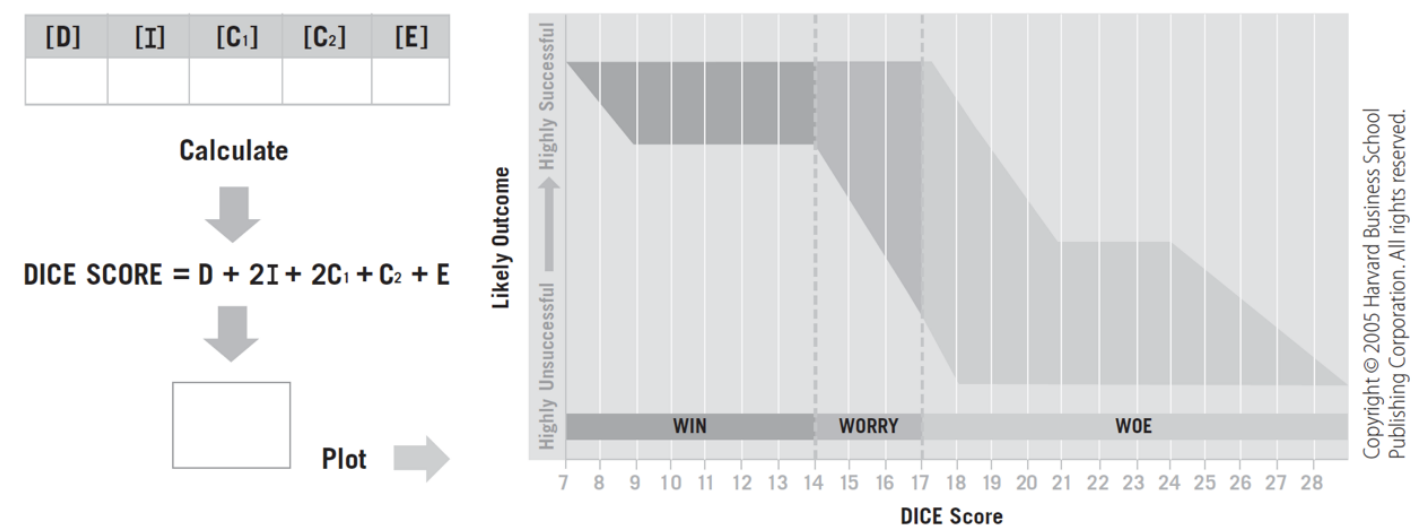

FIGURE A10. THE EXAMPLE OF THE SCORE “ZONES” THAT INDICATE PROJECT RISK LEVELS PROPOSED BY THE AUTHORS IN THE 2005 HARVARD BUSINESS REVIEW ARTICLE (SiRKIN AT AL., 2005, P. 7).

The score, not unlike the Change Formula generates a value that can be mapped against yet another scoring rubric which the authors argue can predict the potential for change success.

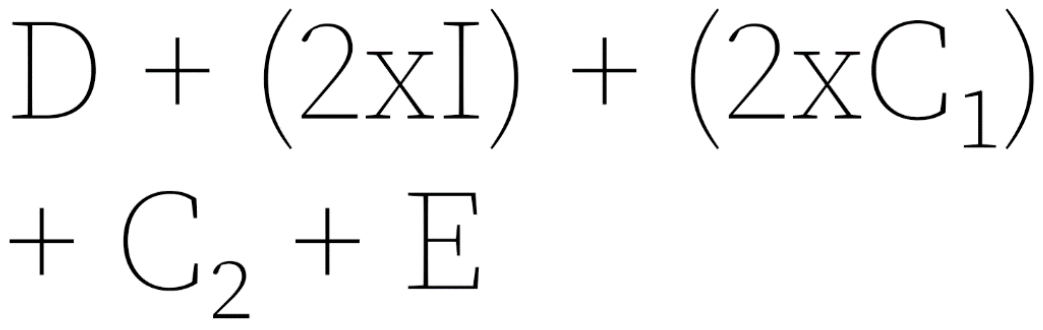

Where,

$\mathrm{D}=$ Duration between reviews

$\mathrm{I}=$ Performance integrity

$\mathrm{C} 1=$ Commitment of senior management

$\mathrm{C} 2=$ Commitment of employees or "local level" commitment

$\mathrm{E}=\mathrm{Effort}$

FIGURE A11. SirKin, KEENAN AND JACKSON's Dice SCORE FORMUla (SirKIN ET AL., 2005). 
As we can see from the formula, through an assessment of the authors' proprietary change effort data bases, they found that two of the contributing factors, performance integrity (I) and senior management commitment (C1) were found to weigh heavily (by a factor of 2) in their contribution to project success. With the exception of the weighting, however, the DICE formula was proposed as an additive formula that assumes that: 1. All factors can be accounted for and 2. The project context is made up of these 4 factors regardless of type.

The DICE formula continues to evolve an organization's understanding of the likelihood that a change initiative will be successful by focusing in-depth on the factors in question. The scoring approach and related insights may generate meaningful information as employees can use the tool quickly to identify low scores or areas that urgently need improvement. This has a prioritizing effect on organizational improvement tactics helping people make faster decisions backed by data, which may also help get buy in from stakeholders with strong analytical backgrounds.

\section{A1.1.8 Formula 6: PARiHS}

Another formula comes from the health sciences field of practice. Referred to as the PARiHS (Promoting Action on Research Implementation in Health Services) framework (Kitson, Harvey \& McCormack, 1998). The tool links the successful implementation (SI) of "research evidence into practice" (p. 149) to:

- (E) the "nature of the evidence;

- (C) the context in which the proposed change is to be implemented; and

- (F) the mechanisms by which the change is facilitated". 

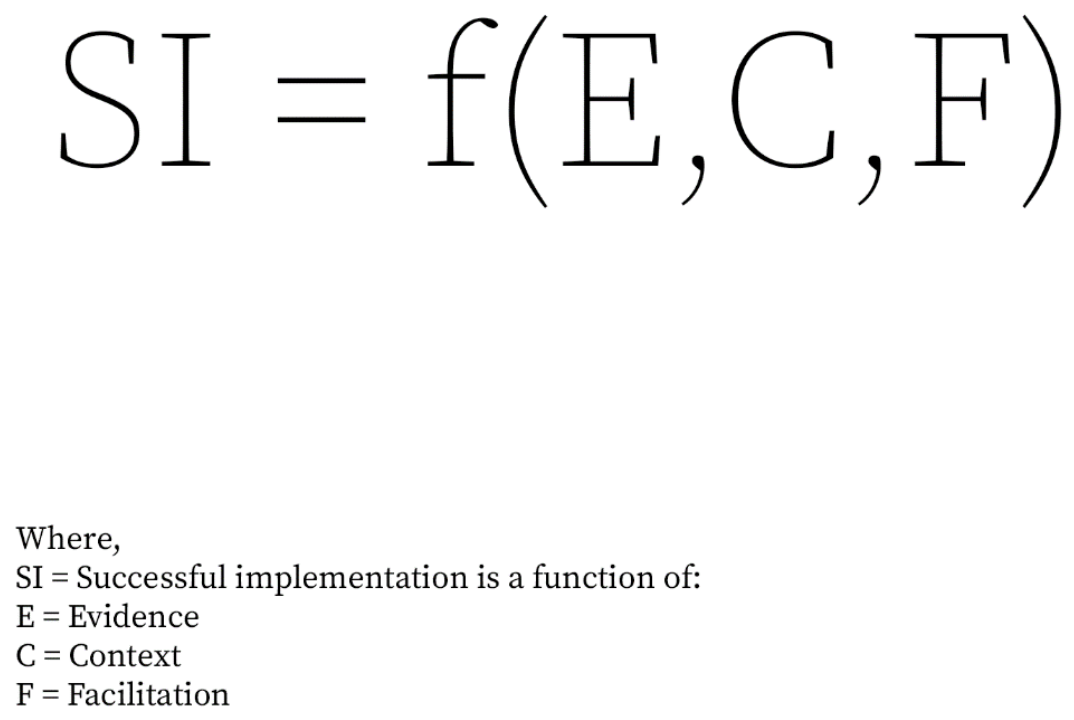

FIGURE A12. THE Formula PROPOSED In PARIHS (NATIONAL COLlaboration CENTRE FOR MeTHODS AND TOOLS, N.D.).

Like the DICE Factors, PARiHS proposes a set of mechanisms that contain factors which are graded based on a scoring rubric. In this case, scoring is based on a value of low to high, wherein the higher the rating, the greater the likelihood of implementation success. This approach is very similar to what we saw proposed in iterations on the Change Formula, and similar to the Change Formula, would result in an unsuccessful implementation of the proposed outcome if all the elements in the formula were low.

An interesting contribution of this particular formula is the focus on the subfactors within each mechanism. Although the DICE Factors incorporate more detail in 
the granularity of the composition of the core factors of assessment, the PARiHS explicitly identifies unique contributing factors that support successful implementation. In total, thirteen factors are proposed for assessment complete with related principles to support understanding of what has to be done, rather than what has been done or exists. Although the PARiHS formula supports a grading approach, the focus on factors of success combined with principles of design, frame this tool more as a set of heuristics that people can draw on in their change initiatives, rather than a quality assurance and performance measurement tool like the previous formulas discussed. This may make it a viable candidate for design research, exploration and ideation in the design process where an accurate understanding of the context of implementation can be fuzzier and thereby resistant to concrete measures.

\section{A1.1.9 Formula 7: The Organizational Readiness for Change Instrument (OCR)}

Another formula, The Organizational Readiness for Change Instrument (OCR)

was found in literature relating to change management in health care, in this case, specifically relating to change resulting from "technology transfer" within the context of substance abuse treatment (Lehman, Greener \& Simpson, 2002). The OCR focuses on four categories of factors that could contribute to the implementation of new technologies in a health care program. The four categories are:

- (M) motivational readiness;

- (I) institutional resources;

- (S) staff attributes; and

- (O) organizational climate. 
With the exception of the factor of Motivational readiness which includes factors relating to an awareness of or desire to change which we saw in the Change Formula, the OCR is more focused on whether or not the context of the change can support a change, rather than if that change is defined or if there is a plan to make it happen.
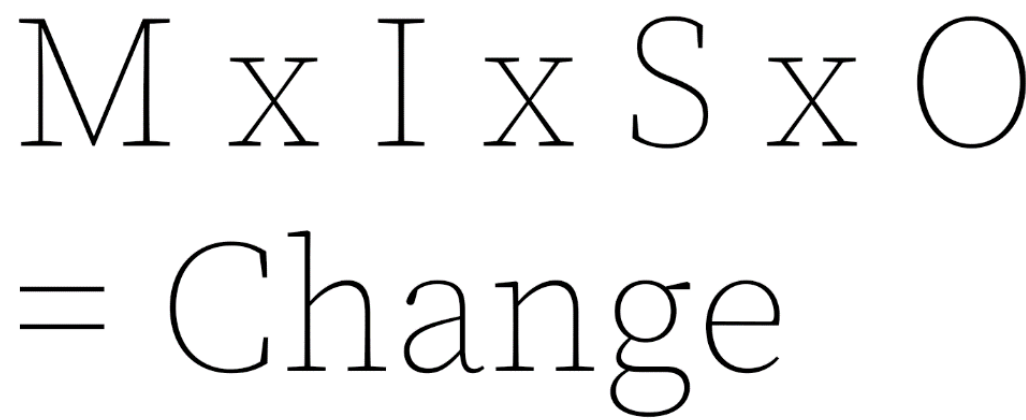

Where,

$\mathrm{M}=$ Motivational readines (people want to change)

$\mathrm{I}=$ Instituational readiness (the environment to support the change is available)

$\mathrm{S}=$ Staff attributes (people can change and help others change)

$\mathrm{O}=$ Organizational climate (is open and adaptable)

FIGURE A13. THE FACTORS CONTRIBUTING TO THE ORGANIZATIONAL CHANGE READINESS INSTRUMENT (OCR) (LEHMAN, ET AL., 2002).

The OCR examines if team members can change, if the right resources are available to support the change and if the culture of the organization will enable the change. These factors could be seen as similar to the Context factors in PARiHS and the factors of Integrity and Commitment found in the DICE Factors. Like both the DICE 
Factors and the PARiHS framework, the OCR does not explicitly require an understanding of the desired end state, nor first steps, or sustainability.

Each category of factor had between three and six sub-factors, similar to PARiHS and DICE Factors and the factors contained within OCR were meant to be graded on a scale of low to high. Findings from the OCR testing identified that "Staff attributes" and "Organizational climate" were of particular importance in change readiness and that the "Organizational climate" specifically may be able to make or break a change initiative (Lehman et al., 2002, p. 197).

\section{A1.1.10 Formula 8: The Readiness Factors}

Holt, Armenakis, Field \& Harris (2007) explored an instrument that was intended to "gauge readiness for organizational change" (p. 232) at an individual level. This instrument identified that "readiness for change is a multidimensional construct influenced by beliefs among employees" (p. 232). The tool explores the individual's perception of the organization's change readiness, not the readiness of the individual persay. Holt et al. (2007), take the point of view that change readiness can be organizational attitude that is influenced by many elements of the proposed change including the proposed change itself, how the change will be undertaken, the context in which the change will take place who is involved in the change and if the people involved in the change want to change. 


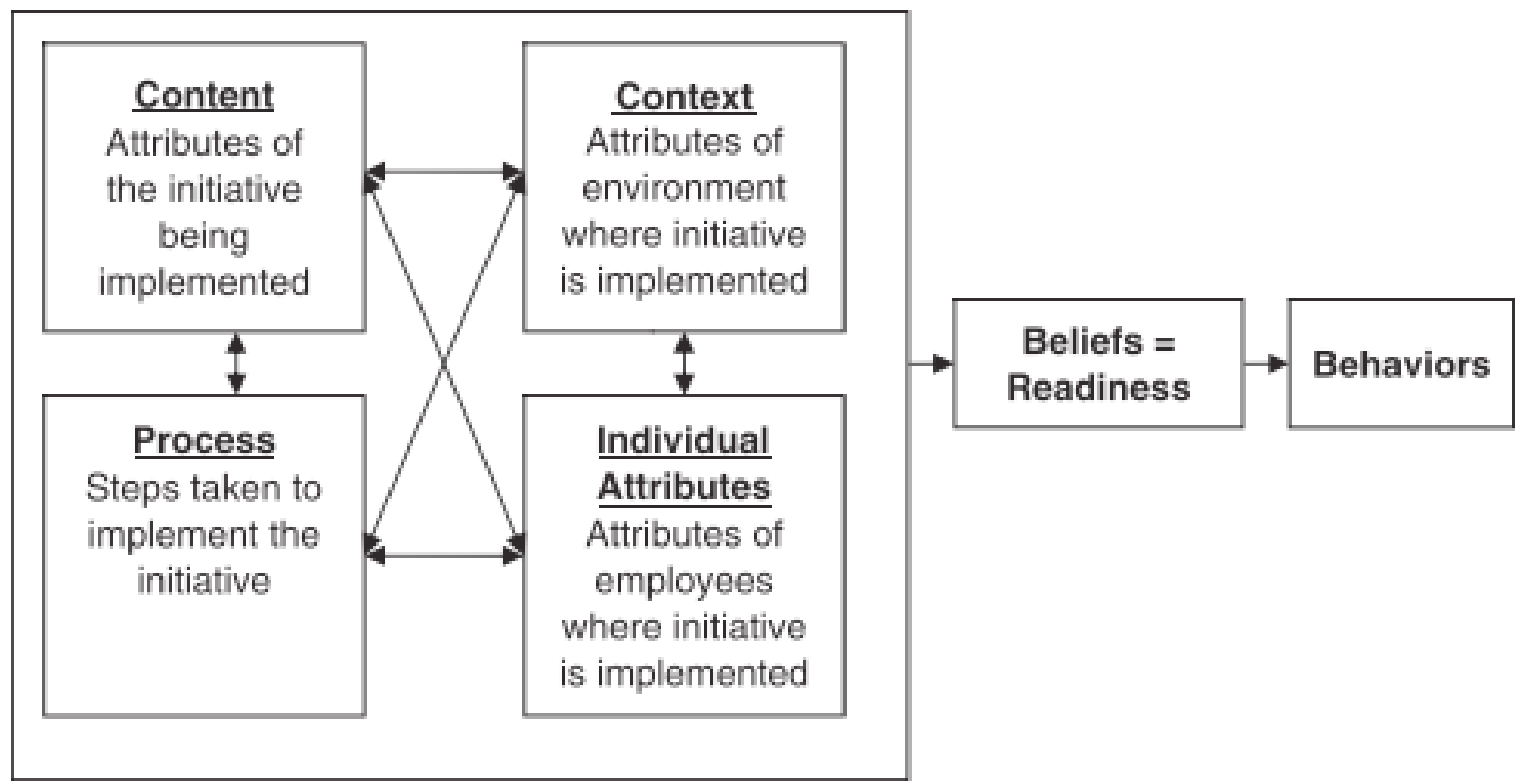

FIGURE A14. A MODEL TAKEN FROM HOLT ET AL.'S (2007) ARTICLE TITLED THE RELATIONSHIP BETWEEN CONTENT, PROCESS, CONTEXT, AND INDIVIDUAL ATTRIBUTES WITH READINESS FROM MEASURING READINESS FOR CHANGE (P. 235).

The authors focus heavily on the individual and their own or their team's perspective of the change situation as being a determinant of adoption or of resistance to a change. This perception of the readiness for organizational change may be linked to similar, individual focused factors from other formulas including perceived Cost of change or Resistance in the Change Formula, Commitment to the change from the DICE formula, and Motivational readiness from the OCR. Further, after a rigorous study using quantitative methods to assess the validity of proposed readiness factors, the authors developed four beliefs they argue contributes to organizational change. 

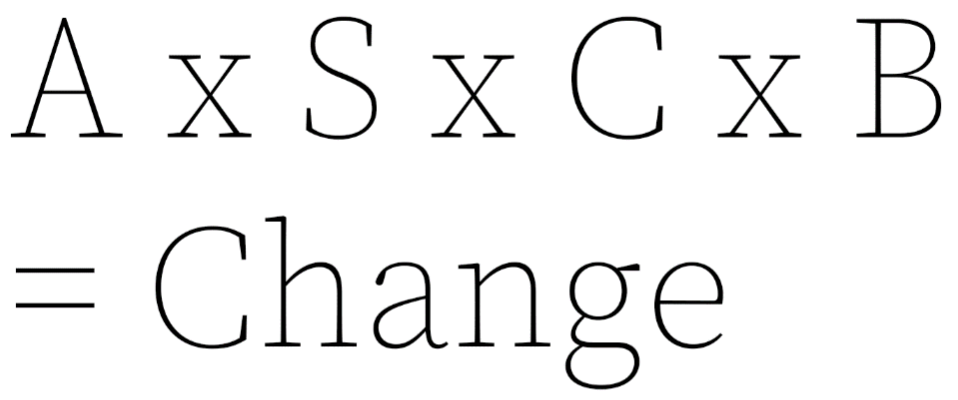

Where people beleive that,

$\mathrm{A}=$ The change is appropriate

$\mathrm{S}=$ Managament supports the change

C = They can make the change successful

$\mathrm{B}=$ The change will benefit them

FIGURE A15. THE FOUR BELIEFS THAT INDICATE WHETHER AN ORGANIZATION MAY BE READY TO CHANGE (HOLT ET AL., 2007).

Like the DICE Factors, the Readiness Factors include management support, efficacy (seen in the DICE Factors as Integrity) and look at not only the management support, but also the employee level support. Also similar to the DICE Factors, PARiHS Framework and OCR formulas, the Readiness Factors were explored through an instrument that sub-factors on a scale.

\section{A1.1.11 Formula 9: Multilevel Framework of the Antecedents and Consequences of Readiness for Change}

The Multilevel Framework proposes that change readiness should be explored across the individual, work group and organizational levels and that readiness will be 
exhibited in different manners, depending on the level being explored. Unlike the other formulas explored so far; this framework looks specifically at the outcomes of readiness instead of the factors contributing to readiness but takes time to explore what contributes to these outcomes.

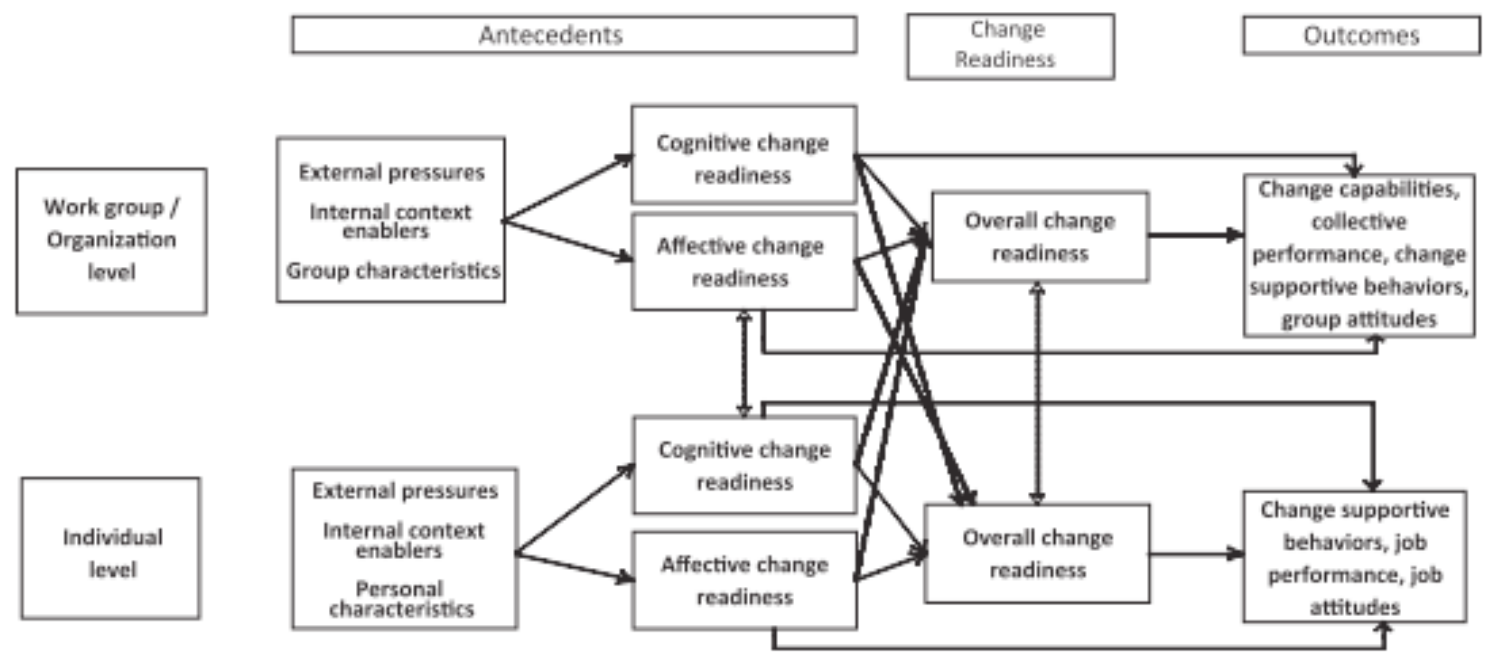

FigURE A16. The MultileVel Framework of the ANTECEDENTS AND CONSEQUenCES OF READINESS FOR CHANGE (RAFFERTY, JIMMIESON \& ARMENAKIS, 2013).

In The Multilevel Framework, the authors propose that there are two categories of contributing factors across the individual, group and organizational levels of analysis: cognitive factors and affective factors. The cognitive factors have to do more with a person's believe in the change, whereas the antecedent factors have to deal with how people feel about a change. 


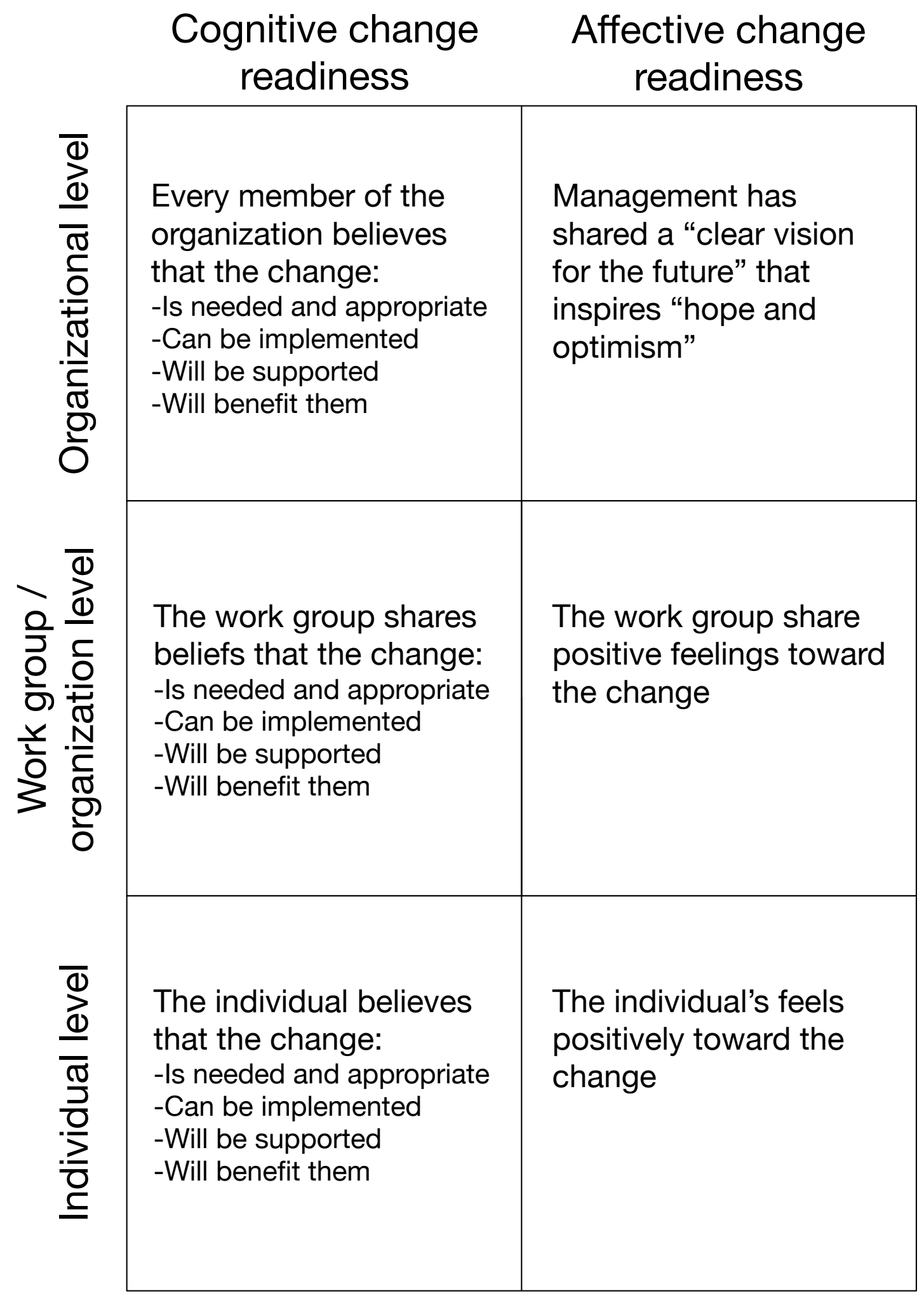

FIGURE A17. THE ANTECEDENTS OF CHANGE READINESS PROPOSED By RAFFERTy, JiMMIESON \& ARMENAKIS IN 2013. 
The article echoes most of the factors cited in Holt et al. (2007) at the cognitive and group level, with the exception of the affective readiness factor which has more to do with clear vision or, like in the Change Formula, a clear desired state. Like Heath \& Heath's (2010) formula, The Multilevel Framework leans heavily on the factor of emotion and accounting for emotional and non-emotional factors in determining readiness at many levels.

\section{A1.1.12 Formula 10: Organizational Readiness for Change}

Weiner's (2009) framework for organizational readiness illustrates change readiness as an organizational members':

- Interest and ability to commit to a change (Willingness); and

- Ability to make the change something that works in real life (Ability).

Weiner (2009) proposes a collection of factors (or "determinants") that may promote organizational readiness for change and contribute to the ability of employees to implement a change (or their "change efficacy". The determinants of change efficacy are: "Task demands, resource availability and situational factors" (p. 4). 


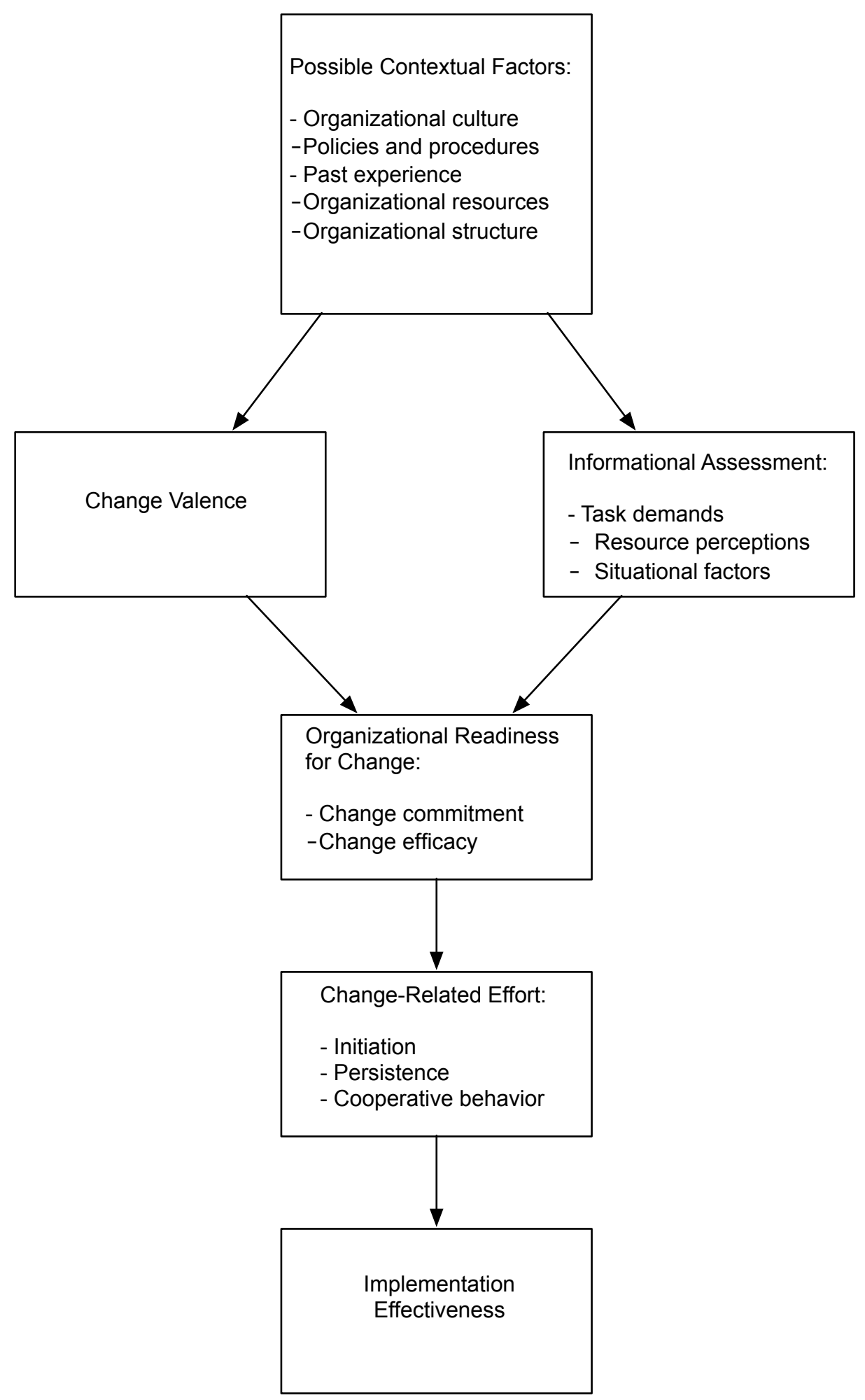

FIGURE A18. A SLIGHTLY MODIFIED VERSION OF THE PROPOSED FRAMEWORK TO SUPPORT ORGANIZATIONAL READINESS FOR CHANGE AS PROPOSED BY WEINER (2009). 
Through discussion of the framework, the author illustrates how commitment to change is a function of how much the members of an organization value or are invested in a change. This belief that the change will benefit the organization or the organization's clients, or members may be a result of any number of things and may be a result of different reasons for different groups across an organization. However, it does not matter why people value the change as long as they value it. Weiner notes (2009), that beyond the determinants of organizational change, the ability to make a change real (change "efficacy") will tend to be higher when people share their "sense of confidence" (p. 2) that they can change together. Some factors that contribute to this shared belief include:

- Consistent messaging and actions between managers; and

- Sharing experiences with team members through "social interactions".

The author explores more specific contextual factors but notes that they can all be tied back to change valence and/or efficacy as they lead to change valence or confidence. 

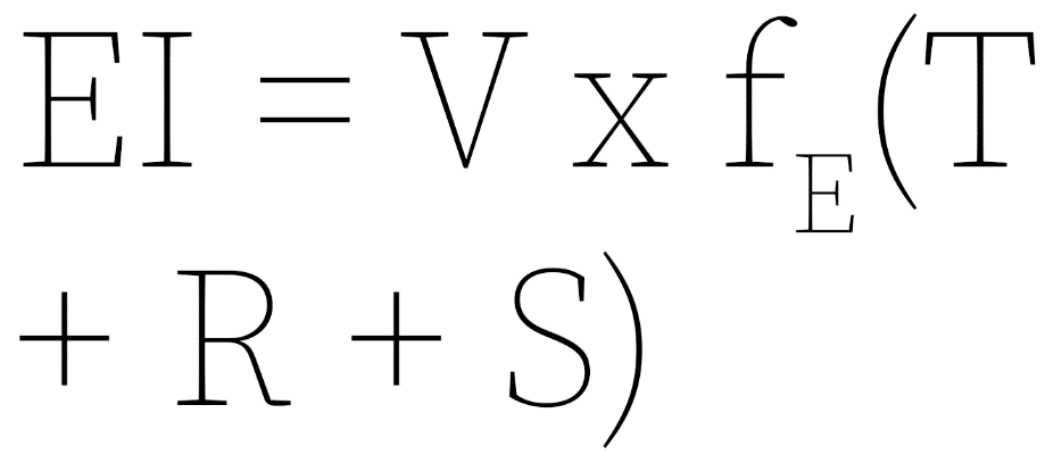

Where,

$\mathrm{EI}=$ Effective implimentation

$\mathrm{V}=$ Change Valence or that the change is desired

$\mathrm{f}_{\mathrm{E}}=$ Change efficacy as a function of,

$\mathrm{T}=$ Task demands

$\mathrm{R}=$ Resource availability

$\mathrm{S}=$ Situational factors

\section{FIGURE A19. A FORMULA ILLUSTRATING WEINER's (2009) FACTORS OF READINESS.}

The two factors of change readiness proposed in the Organizational Readiness

for Change Framework (that people are both willing and able to get the work done) can be found explicitly in all of the formulas reviewed. Even PARiHS, which focuses specifically on the efficacy and perceived ability of the facilitator of the change rather than the people involved in the change in general, could be seen to align with this framework. 


\section{Appendix 2: Approach to Coding Participant Data}

The following details cover the approach to coding the participant data. I used a rigorous data coding approach that was undertaken in 3 rounds to keep my interest in the research study data up, maintain a consistent and efficient coding process for the sake of time and to ensure that I had captured records of my work to date in case I suffered an issue with my technology. As my NVivo files got bigger, the software began to crash more often and at one point I ran out of space. Record keeping methods during the coding process reduced stress relating to the uncertainty of the stability of my tools.

\section{A2.1 Information Management and Attribute Coding}

When images were uploaded into the system they were given codes (or coded) with codes that reflected the type of file they were and what type of data the file contained. These codes, also referred to by Saldaña (2016) as “Attribute Codes" (p. 83), reflected important information about the files and data within in them which allowed me to quickly and efficiently find files when I needed them. The information provided in the Attribute Codes also let me take a multi-dimensional approach to data analysis that supported comparison of data across various different lenses, including where the data came from, who it came from, in what context, in relation to what type of story and in relation to what type of project. The Attribute Codes used reflected the following descriptive categories (or type of Attribute Code) and Attribute Codes:

- Research object (if the image was a picture of a workbook page, a map, or); 
- A unique identifier to keep all of the pictures from the same files together;

- The question(s) from the workbook and semi-structure interview that the image related to (if the image contained information about the story in general, project objectives, the team, the outcomes, why it was (or was not) a success, what the participant would do differently next time and if there were more to add);

- The story type (successful or unsuccessful); and

- Project characteristics (how the designers worked with others in the project, if the work was a long term or a one-off project and what type of project it was (i.e. a research project, strategy design, a larger scale campaign, etc.).

\section{A2.2 Provisional and In Vivo Coding}

Following the Attribute Coding, each file was explored and factors that either I determined could contribute to the outcome(s) of the project, or that participant identified as a factor that contributed to the outcome(s) of the project were Coded with:

- Either one or more Provisional Codes from the Codebook generated from the literature review;

- An In Vivo Code or In Vivo Codes if there was no Provisional Code to suit from the Codebook; or

- Both Provisional Codes and one or multiple In Vivo Code(s).

This Simultaneous Coding method was applied given that preliminary coding identified that the Provisional Codes identified in the literature review were not specific enough or meaningful enough to capture the essence of the participant data. Provisional Codes and In Vivo Codes were used together specifically to add additional context and meaning to the Provisional Codes. Two Provisional Codes were used together when it was not clear which code the factor may belong to and multiple In Vivo Codes were 
occasionally codes with additional In Vivo Codes to identify when codes were grouped together in the context of the participants' stories. This approach was used specifically in the coding of the maps but was applied throughout the coding exercise when appropriate.

\section{Appendix 3: Coding the Notes}

Coding started with the notes as they were felt to be the richest data files. To code the notes, I:

- opened the file in NVivo so I could see everything well

- Set the view to include coding strips for "all coded nodes"

- Coded data points from the file with the question cases (i.e. a data point relating to objectives from the notes was coded with the "objectives" case)

- Coded data points with the Provisional Codes (the Provisional Codes generated in during the analysis of the literature) (Saldaña, 2016)

- Coded the data points with In Vivo Codes as well (Saldaña, 2016)

○ The In Vivo Codes had two purposes:

- They provided additional context to the Provisional Codes by adding context to the code

- They served as a record of what the participant said so that insights about the related Provisional Codes could be generated later without having to go back into each file excerpt

- In Vivo Codes were not used if the data coded contained similar words as the Provisional Code (for example a data point that said "scope" which was coded as "a clear scope" was not also coded with an In Vivo Code.

When each set of participant notes (images of notes from the successful story and images of notes from the unsuccessful story) were coded, they were moved into a folder labelled with the participant's unique identifier. 


\section{A3.1.1 Coding the maps}

When the notes for the first group of participants was complete, the maps for that group was coded. Coding was often faster as the In Vivo Codes identified in the notes were often in the maps. However, there were many terms and concepts reflected in the maps that were missed in the in-person story telling notes. These data points were coded with their appropriate In Vivo Codes. Even if the difference was slight, I tried to maintain integrity by reflecting the actual words in the research data.

Maps were coded slightly differently than notes. The outcomes box was first coded with the "outcomes" case for data identification purposes. Once that administrative task was complete, each branch of data points extending from the outcomes box on the map was coded using 2 rounds of Simultaneous Coding:

- Round 1:

- The whole branch was coded with an In Vivo Code reflecting the data in the square (Figure A20)

- The second level branch was coded with an In Vivo Code reflecting the data in the circle (Figure A2l)

- Each third level point was individually coded with an In Vivo Code reflecting the data in the little grey rectangle (Figure A22)

- Round 2:

- Branches were coded with Provisional Codes where applicable 

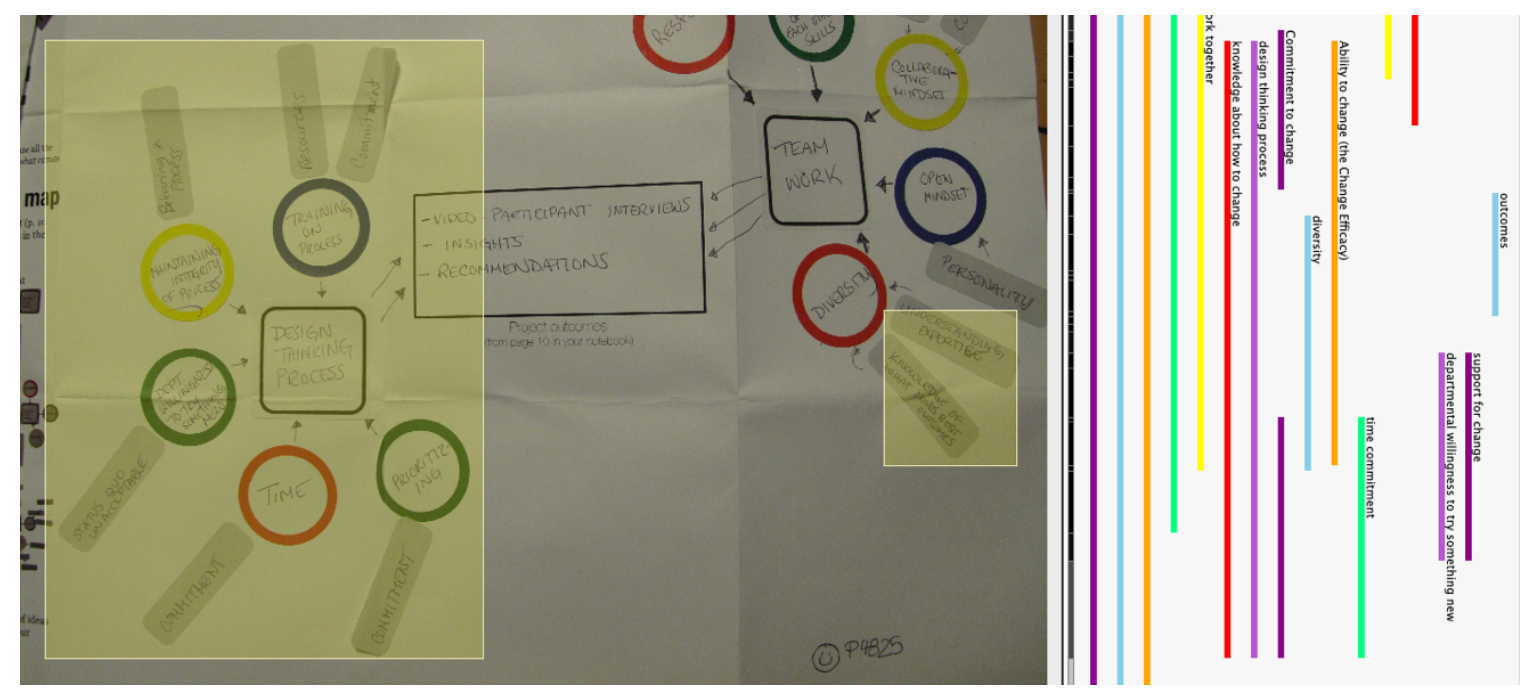

FIGURE A20. AN EXAMPLE OF A TOP LEVEL BRANCH ON A MAP CODED IN NVIVO WITH CODING STRIPS $\mathrm{ON}$
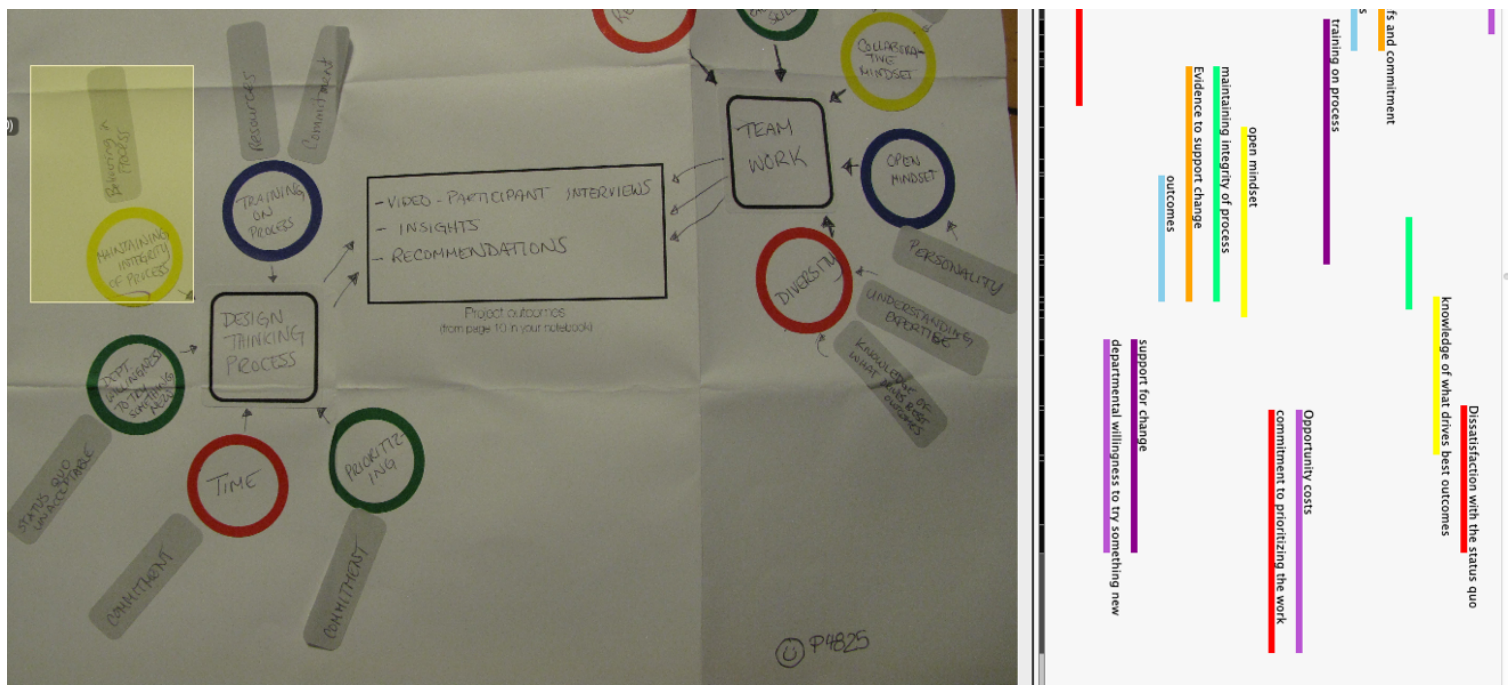

FIGURE A21. AN EXAMPLE OF A SECOND LEVEL BRANCH ON A MAP CODED IN NVIVO WITH CODING STRIPES ON 


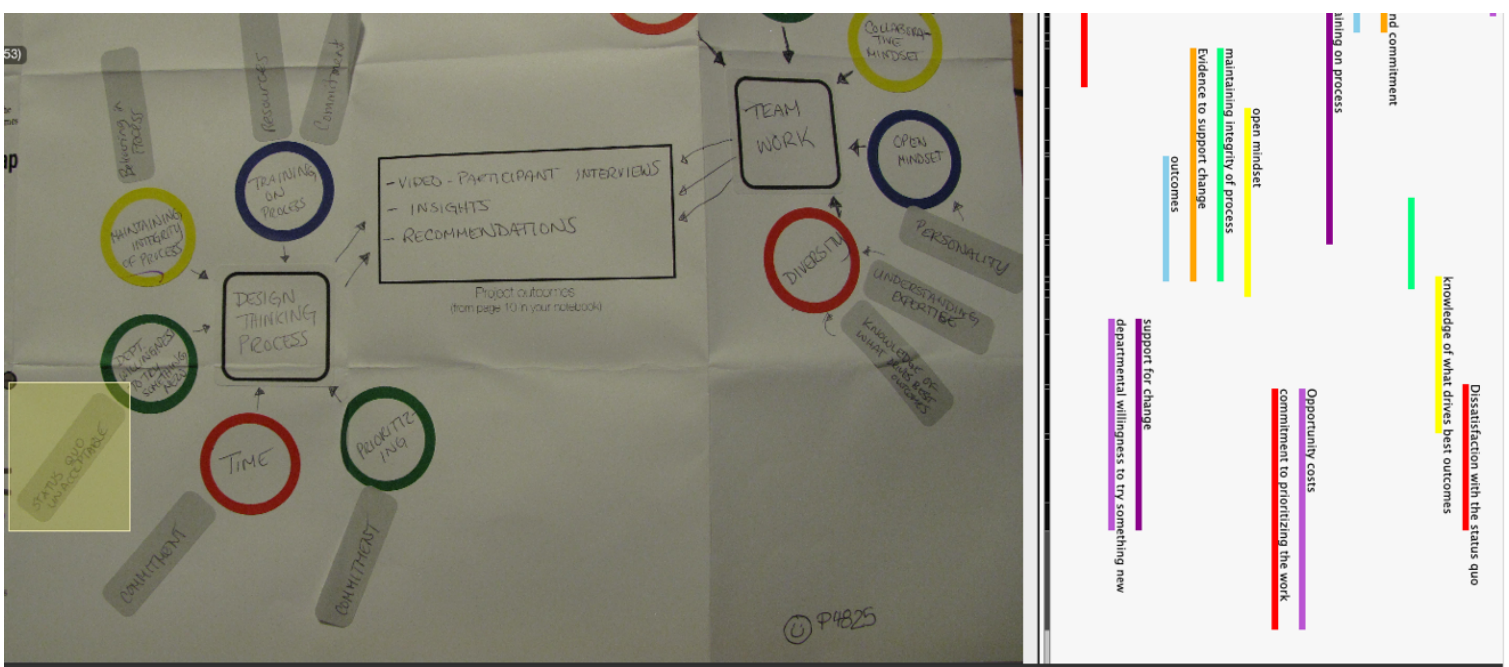

FIGURE A22. AN EXAMPLE OF A THIRD LEVEL BRANCH ON A MAP CODED IN NVIVO WITH CODING STRIPES ON

When each participant's maps were coded, they were moved into the folder with the participant's ID.

\section{A3.1.2 Coding the workbooks}

Once the maps were done for the group of participants, the workbooks were coded. For this exercise, each photographed page of the workbooks was reviewed and coded.

Coding the workbooks was done in a very similar approach as the notebooks:

- The workbooks page files were opened in NVivo

- The view was set to include coding strips for "all coded nodes"

- Data points from the file were coded with the question cases (i.e. Page 6 in the workbook contained the question "what were the project objectives? What were you and/or your team trying to do?" this file was coded with the “objectives" case)

- In some cases, stories and notes would continue on to pages 5, 7, 9, 11. In this case, the file was simultaneously coded with the 2 related 
cases (i.e. for a notebook page file that covered pages 11 and 12 might be coded with cases "outcomes" and "why a success")

- Data points were coded with the Provisional Codes

- Data points with In Vivo Codes “

When each page was coded, it was moved into the folder with the related participant ID.

\section{A3.1.3 Record keeping and generating preliminary insights}

When the first round of participant files was complete, I took a break from coding and ran some reports for record keeping purposes. These reports served as:

- a point-in-time record in case anything happened to NVivo during coding

- a snapshot of what information may be uncovered when the coding was complete

- A method of refining the data analysis approach early on in the process so that less time was spent fixing things at the end

Five reports were run at the end of each round of coding. They were all matrix reports which enabled the research to explore relationships between the codes (In Vivo and Provisional Codes) and both the cases and the Provisional Codes. The reports included:

- Codes compared with "All cases"

- Codes compared with "Participant ID"

- Codes compared with "Document type"

- Codes compared with "Story type"

- Codes compared with "Question from workbook"

- Codes compared with Provisional Codes 
A codebook containing the In Vivo Codes was also exported for record keeping purposes. This file was also used to generate a word cloud which showed how often terms appeared in the individual In Vivo Codes that had been collected up until the end of the round of coding (Figure A23).

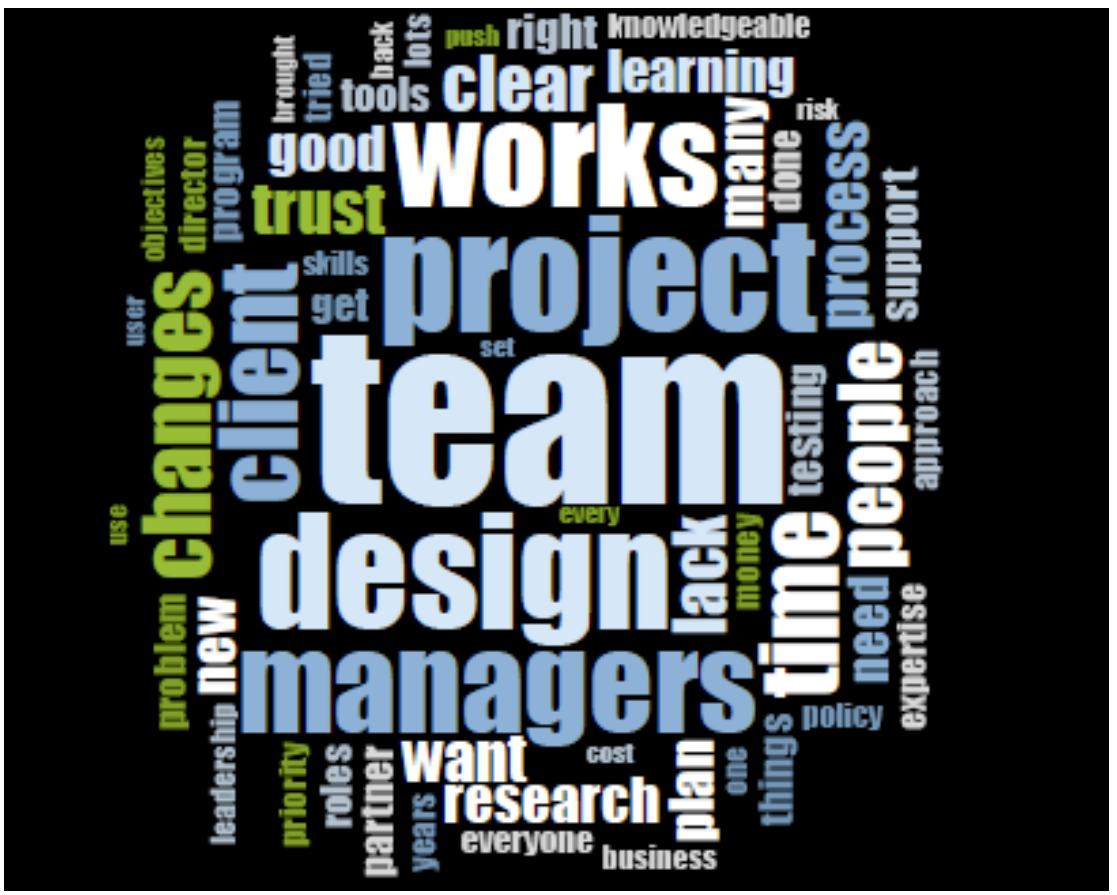

FIGURE A23. AN EXAMPLE OF A WORD CLOUD GENERATED FROM A CODEBOOK CONTAINING THE IN VIVO CODES FROM THAT ROUND OF CODING ACTIVITIES.

Unfortunately, this analysis method was not uncovered until the end of the second round of coding and so there was no word cloud generated for the preliminary codes. However, these Figures were only used for record keeping purposes until all of the codes had been generated. It was not possible to compare them, so the missing visualization is not an issue for data analysis.

The last record generated was a hierarchy chart. Each hierarchy chart had a tree map view, a sub burst view and a summary report view. Each view was exported and 
saved for record keeping purposes. The hierarchy charts explored the designed hierarchy from the Provisional Codes and showed magnitude for the In Vivo Codes. These In Vivo Codes were seen by the system as level 1 codes since no organization of the codes happened in the first cycle of coding. Their magnitude was indicated by size and they were all considered to be at the same level (Figures A24 and A25).

When the reports were taken for each group of participants, a preliminary assessment of the data was undertaken to model what insights could be drawn from the data and make any necessary adjustments. Notes were taken at the end of each round.

Once all the files were coded, a final round of reporting was done using data from all of the participant files. This final data set was used to generate results for the first cycle of coding and inform the second cycle coding where Pattern Coding was undertaken. 


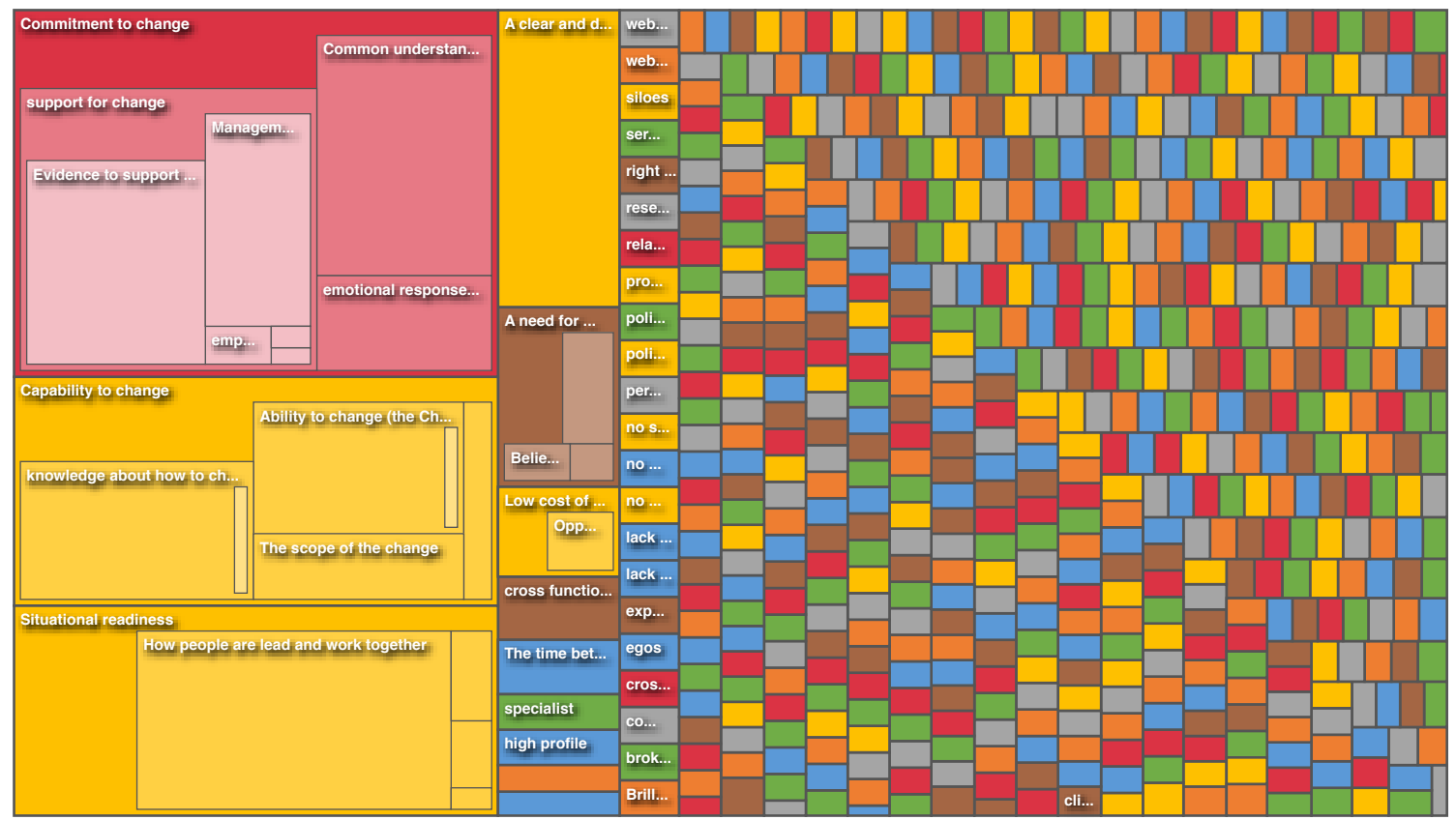

FIGURE A24. AN EXAMPLE OF A TREE MAP VIEW OF A HIERARCHY CHART IN NVIVO. THIS CHART WAS TAKEN AT THE END OF THE CODING ACTIVITIES FOR THE SECOND GROUP OF PARTICIPANTS.

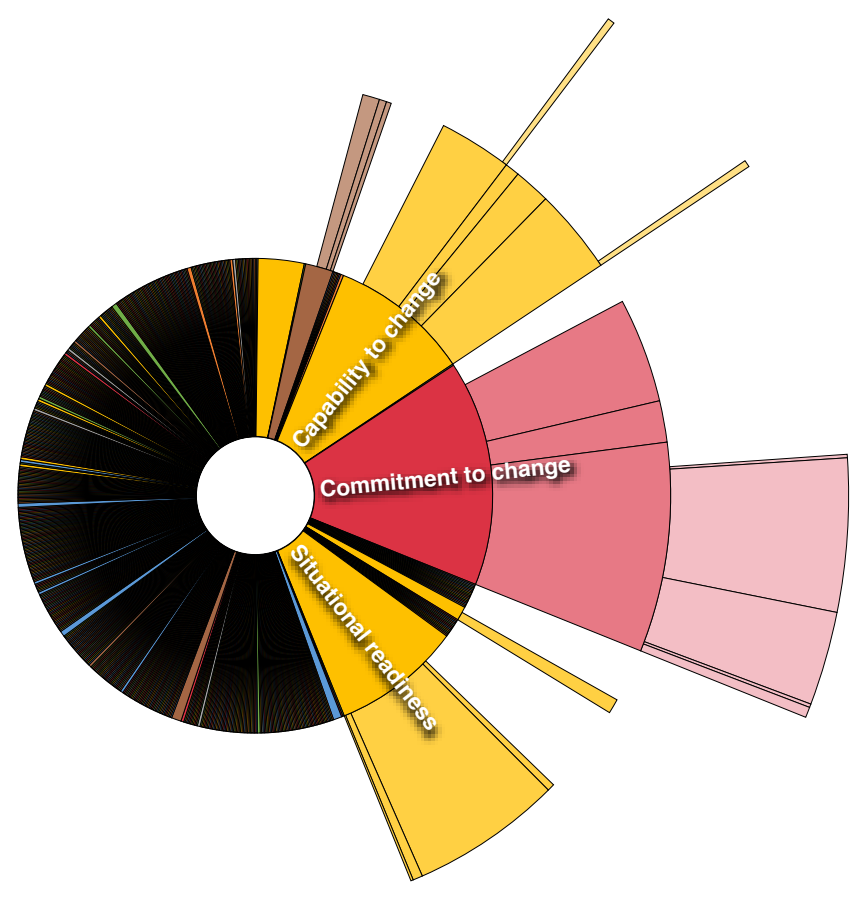

FIGURE A25. AN EXAMPLE OF A SUNBURST MAP VIEW OF A HIERARCHY CHART IN NVIVO. 


\section{Appendix 4: Incremental Results}

\section{A4.1 First Cycle Results}

Two interesting patterns that emerged from the first cycle of coding included the common reference to the term trust across the stories from 5 different participants and the volume of data that was either coded or simultaneously coded with the Provisional Code, How people are lead and work together.

\section{A4.1.1 Occurrence of Provisional Codes from literature within the participant data}

There were 34 Provisional Codes introduced through use of the codebook generated following the detailed review of the formulas found in literature. The 34 codes were coded to a total of 1258 references. The Provisional Code used to code project factors most often was the code How people are lead and work together, a code related to the Situational readiness Provisional Code found in literature. This Provisional code was used to indicate factors relating to how people worked together and included the coding of datum like "The collaboration was excellent", "No clear leadership", "Too many people", "Want to maintain good relationships with partners" and "Good communication across teams". 


\section{Table Al}

A chart showing the top 6 Provisional Codes and their \% coverage (rounded to the nearest whole number).

\section{Provisional Codes}

How people are lead and work together

Common understanding, beliefs

and commitment

Evidence to support change

Knowledge about how to change

A clear and desired end state

Management support for the

change

\section{$\%$ Coverage}

$14 \%$

$9 \%$

$8 \%$

$7 \%$

$7 \%$

$7 \%$

TABLE A1. The top 6 Provisional Codes.

All Provisional Codes were coded to at least one factor that may identify an organization's ability to change in literature, but there were 13 of the 34 Provisional

Codes that only accounted for $0.99 \%$ or less of the coded references.

\section{Table A2}

A chart showing the 13 Provisional Codes that accounted for less than $1 \%$ of the references coded and their \% coverage (rounded to the nearest hundredth).

\section{Provisional Codes}

Dissatisfaction with the status quo

First steps toward the vision

Physical environment

The sustainability of the change

Stress

Personal ability to change

Employee support for change

Belief the change is needed

Factors must be greater than resistance

Low cost of change

Workgroup support for the change

Organizational benefit

Organizational ability to change
$\%$ Coverage

$0.009 \%$

$0.008 \%$

$0.007 \%$

$0.007 \%$

$0.006 \%$

$0.006 \%$

$0.006 \%$

$0.006 \%$

$0.006 \%$

$0.004 \%$

$0.003 \%$

$0.003 \%$

$0.002 \%$

TABLE A2. PROVISIONAL CODES THAT ACCOUNTED FOR LESS THAN $1 \%$ OF CODDED FACTORS. 
Since How people are lead and work together was the most popular Provisional Code by a factor of 1.5 , it was compared against the other Provisional Codes to determine how much overlap there was. There were 4 Provisional Codes that were not Simultaneously Coded with the Provisional Code How people are lead and work together. They included the Provisional Codes of Stress, Factors must be greater than resistance, Organizational Ability to change, and Belief that change is needed. All 4 of these codes accounted for less than $1 \%$ of the coded factors. There were 7 Provisional Codes that were coded to a data point with How people are lead and work together simultaneously over $50 \%$ of the time. None of these codes appeared in the top 6 list. Those codes which were found in the list were Simultaneously Coded with How people are lead and work together in $20 \%$ and $49 \%$ of the instances of Simultaneous Coding.

\section{A4.1.2 In Vivo Codes generated from participant data}

A total of 1457 In Vivo Codes were generated by exploring participant data in the first round of coding. In Vivo Codes reflected both the participants voice directly (when the codes were taken from the maps and workbooks) and the interpretation of the participant's voice when the codes were pulled from the notes taken during the interviews.

The most common words that were reflected in the In Vivo Codes accounted for $11 \%$ of the terms used in coding (Table A3). 
Running Header: AN EXPLORATION OF FACTORS RELATED TO DESIGN IMPLEMENTATION IN THE CANADIAN FEDERAL PUBLIC SERVICE

\begin{tabular}{|c|c|c|c|}
\hline \multicolumn{4}{|l|}{$\begin{array}{l}\text { Table A3 } \\
\text { A chart sh }\end{array}$} \\
\hline Word & Count & $\begin{array}{l}\text { Weighted } \\
\text { Percentage }\end{array}$ & Similar Words \\
\hline team & 118 & $2.73 \%$ & team, teams \\
\hline project & 74 & $1.71 \%$ & project, projects \\
\hline design & 74 & $1.71 \%$ & $\begin{array}{c}\text { design, designed, designer, } \\
\text { designers }\end{array}$ \\
\hline works & 66 & $1.52 \%$ & work, worked, working, works \\
\hline managers & 62 & $1.43 \%$ & $\begin{array}{c}\text { manageable, managed, } \\
\text { management, manager, } \\
\text { managers, managing }\end{array}$ \\
\hline client & 49 & $1.13 \%$ & client, clients \\
\hline time & 49 & $1.13 \%$ & time, times, timing \\
\hline
\end{tabular}

TABLE A3. WORDS THAT WERE USED IN IN VIVO CODING MOST OFTEN.

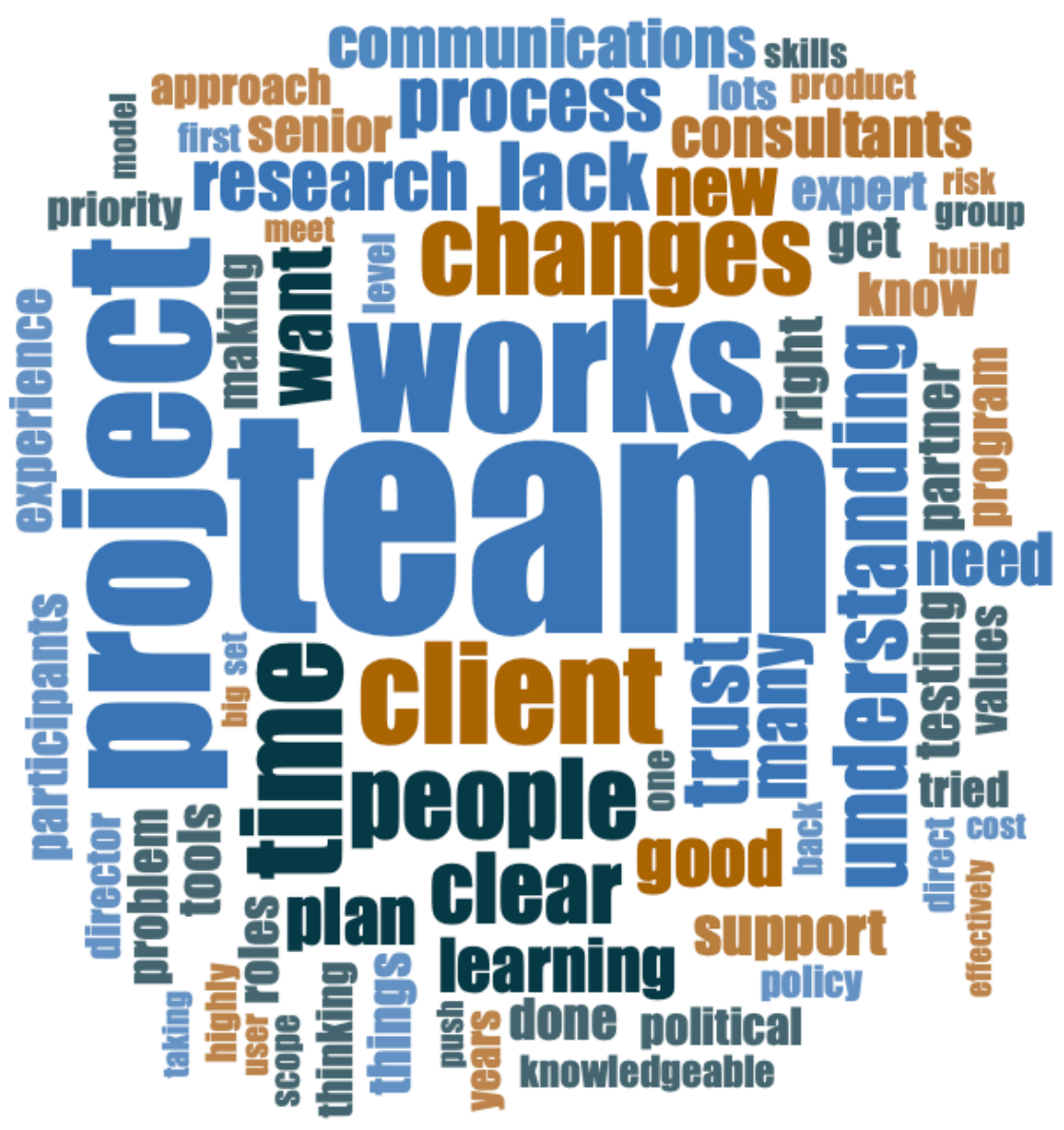

FIGURE A26. A WORD CLOUD ILLUSTRATING THE FREQUENCY OF IN VIVO CODES. 
In Vivo Codes were generally coded to one, unique phrase, word or paragraph found in the research data. This was a result of their precise nature in reflecting the words of the participant. However, some participants did use the same language in their telling of their stories and there were many instances where similar language was used by different participants.

There were 6 In Vivo Codes in particular that appeared in 3-5 unique stories. Specifically the words, trust, leadership, experts, high profile, right people, and teach teams how to work together.

The trust code occurred in the data of 5 participants. This involved the direct use of the word "trust" in discussion or in the map or workbook or interview. Apart from this term, there were other In Vivo Codes that contained the word "trust". These instances were assessed and merged in the second cycle of coding.

\begin{tabular}{|lc|}
\hline Table A4 & \\
The number of people that shared popular In Vivo Codes. \\
\hline Word & Number of participants who used the \\
& term \\
Trust & 5 \\
Leadership & 4 \\
Experts & 3 \\
High-profile & 3 \\
Right people & 3 \\
Teach teams how to work together & 3 \\
\hline
\end{tabular}

TABLE A4. A TABLE OF SHARED IN VIVO CODES.

\section{A4.1.3 Relationships between the Provisional and In Vivo Codes found through Simultaneous Coding}

The majority of terms used throughout the participant data were coded with at least one Provisional Code and on In Vivo Code. This approach to coding called CoCoding or Simultaneous Coding, occurred $89 \%$ of the time. This means that out of the 
1457 In Vivo Codes generated, there were 162 codes that were not Simultaneously

Coded with a Provisional Code. This was because either there was no related Provisional

Code or mistake in coding (i.e. there was a related Provisional Code, but it was not

Simultaneously Coded due to oversight).

The Provisional Code with the greatest number of related In Vivo Codes was

How people are lead and work together accounting for $7 \%$ of all of the coded data.

Overall, 6 Provisional Codes accounted for $22 \%$ of all the coded references (Table A5).

\section{Table A5}

A table showing the top 5 Provisional Codes, which accounted for $22 \%$ of all of the data points coded with a Provisional Code (1295 total codes or $89 \%$ of the codes)

\section{Code}

How people are lead and work together

Common understanding, beliefs and commitment

Knowledge about how to change

Evidence to support the change

Ability to change (the Change Efficacy)

\section{$\%$ Coverage}

$$
\begin{gathered}
7 \% \\
4 \% \\
\\
4 \% \\
3.5 \% \\
3.5 \%
\end{gathered}
$$

TABLE A5. THE TOP 6 PROVISIONAL CODES.

Each of the Provisional Codes within the top 6 codes by volume of coverage were lower level Provisional Codes, meaning that they belonged to a greater overall category identified in literature. These codes contributed to the popularity of the following categories identified in literature:

- Commitment to the change

- Capability to change

- Situational readiness 


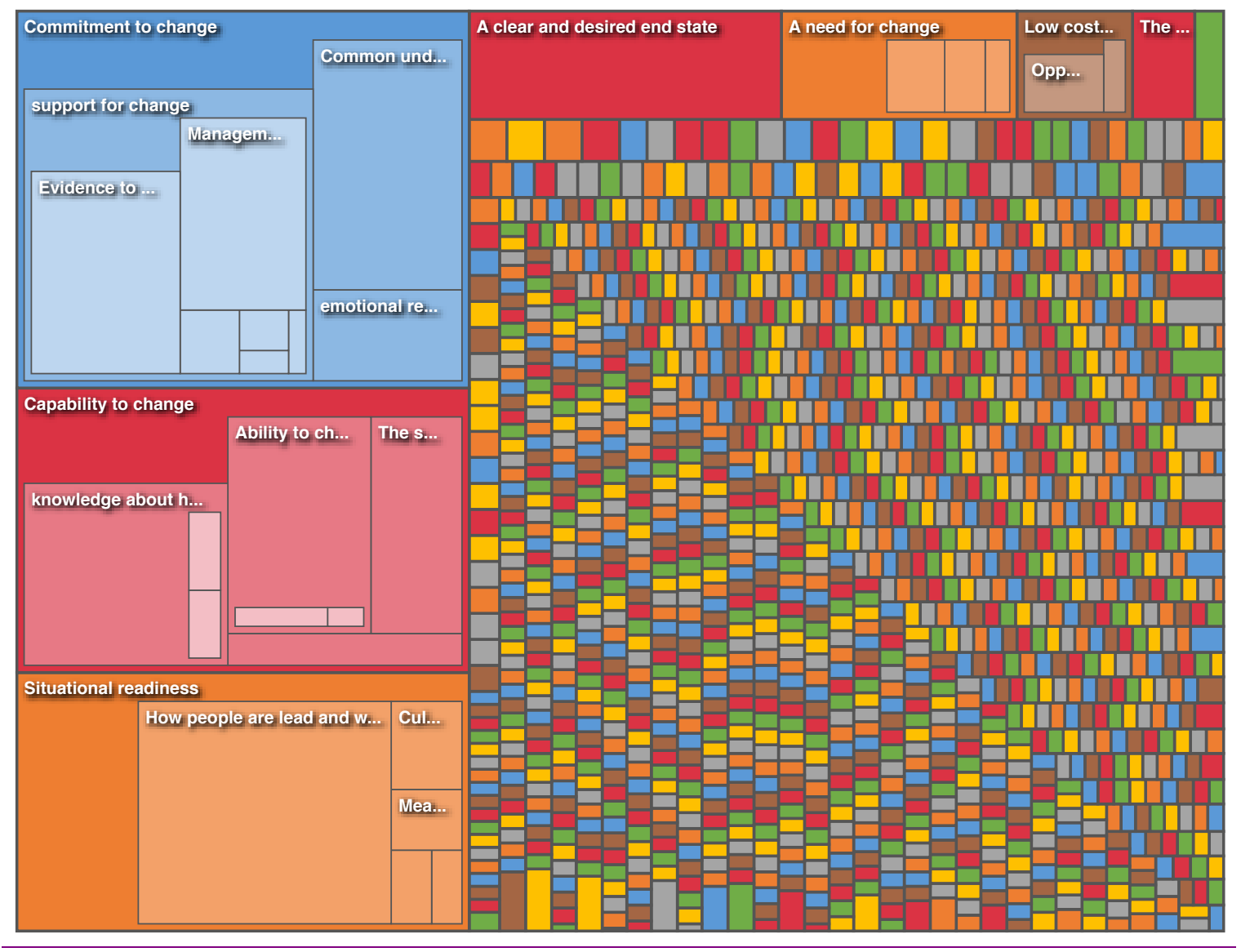

FIGURE A27. A HIERARCHY CHART ILLUSTRATING THE MAGNITUDE OF THE THEMES FROM THE FIRST CYCLE OF CODING

As we can see in the hierarchy chart in Figure A27, the boxes containing the phrases How people are lead and work together, Common understanding, beliefs and commitment, Knowledge about how to change, Evidence to support the change and Ability to change (change efficacy) were all much larger than the rest, indicating a greater level of coverage throughout the data that was coded.

There were 162 codes that were not Simultaneously Coded with a Provisional Code. Following frequency analysis of terms used in these codes, 7 words appeared to have greater popularity across all participant's data. 


\begin{tabular}{|lccc|}
\hline \multicolumn{4}{|l|}{$\begin{array}{l}\text { Table A6 } \\
\text { A table showing the top } 7 \text { words appearing most often in codes } \\
\text { coded with a Provisional Code. }\end{array}$} \\
\hline Word & Count & Weighted Percentage & Similar Words \\
team & 16 & $3.22 \%$ & team, teams \\
client & 10 & $2.01 \%$ & client, clients \\
project & 9 & $1.81 \%$ & project, projects \\
work & 9 & $1.81 \%$ & work, worked, working \\
learn & 8 & $1.61 \%$ & learn, learned, learning \\
time & 8 & $1.61 \%$ & time, times \\
many & 6 & $1.21 \%$ & many \\
change & 6 & $1.21 \%$ & change, changed, changes \\
design & 6 & $1.21 \%$ & design, designer, designers \\
trust & 5 & $1.01 \%$ & trust \\
problem & 5 & $1.01 \%$ & problem, problems \\
management & 5 & $1.01 \%$ & management, manager \\
value & 5 & $1.01 \%$ & value, valued \\
\hline
\end{tabular}

TABLE A6. The TOP 7 WORdS NOT CODED WITH A PROVISIONAL CODE.

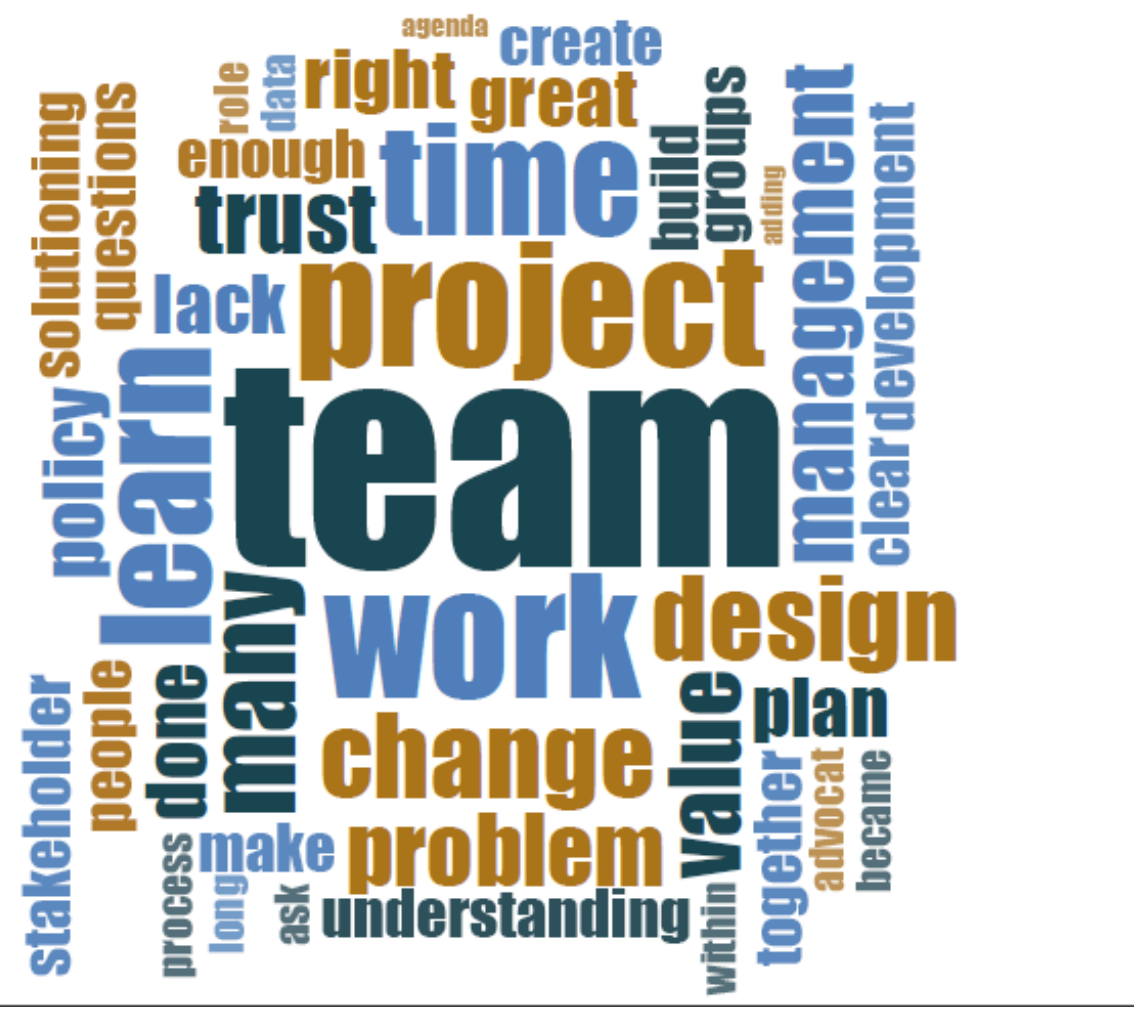

FIGURE A28. A WORD CLOUd REFLECTING THE TOP 7 WORDS NOT CODED WITH A PROVISIONAL CODE. 
The term team had the greatest level of coverage in the exploration of In Vivo terms that were not simultaneously coded with a Provisional Code.

\section{A4.1.4 Categories generated in the first cycle coding}

In the first cycle of coding, the Provisional Codes and In Vivo Codes were explored to determine magnitude (or how often a code occurred or how often terms within a code occurred) across all the coded references. These first cycle codes were also compared and explored from a similarity perspective or how often a code would be Simultaneously coded with another code.

The Provisional Codes that were used most often on their own or with an In Vivo Code through Simultaneous Coding were:

Table A7

A table showing the top 8 Provisional Codes by aggregated In Vivo references (rounded to the nearest whole number).

\section{Provisional Code}

How people are lead and work together

Knowledge about how to change Common understanding, beliefs and commitment

Evidence to support the change Situational readiness Ability to change (change efficacy) A clear and desired end state Management support for the change
Number of aggregated In Vivo Code references

655

345

339

270

277

273

253

238
Percent of total aggregated references $17 \%$

$9 \%$ $9 \%$ $7 \%$ $7 \%$ $7 \%$ $6 \%$ $6 \%$

TABLE A7. THE TOP PROVISIONAL CODES BY NUMBER OF AGGREGATED REFERENCES WITHIN THE DATA. 
A review of all of the In Vivo Codes used across all of the participant stories indicated that the top three codes or those that were used across 4 or 5 stories (on their own or with a Provisional Code) were trust, leadership and research.

Codes that were not coded with Provisional Codes but were common across participant stories included codes for trust, leadership, experts, high profile, right people, and teach people how to work together. This insight was uncovered from a review of how often a code was used across participant data.

The most prevalent terms that emerged from an exploration of all of the terms used in all of the In Vivo Codes included terms such as team, project, design, works, managers, client, and time (all terms that were frequently used across all codes (both the Provisional and In Vivo Codes)).

An assessment of codes generated and used in this first cycle of coding supported the development of an initial collection of what Saldaña (2016) calls "Hypothesis Codes" or codes that "are developed from a theory/prediction about what will be found in data" (p. 171). In this case, the theory was that all of the In Vivo Codes could be organized into the following categories (in no particular order), based on early insights from the first round of coding. Each category represented a collection of factors that may have an impact on organizational ability to change for design implementation.

The categories were organized based on their relationships uncovered when comparing prevalence of codes Simultaneously Coded together and their popularity across stories. 
The categories found after consideration for the popularity of codes and how often they were Simultaneously Coded were:

- Common understanding, beliefs and commitment;

- How people are lead and work together, including three different subcategories:

- A clear and desired end state;

- Management and how people are lead which also contains a sub-category for:
- Management support for the change
○ Leadership; and
○ Managers;

- Team and how people work together which also included sub-categories for:

○ Teach people how to work together;

○ Trust;

○ Works; and

○ Team.

- Expertise and time to do the work including sub-categories of:

- Ability to change (change efficacy)

- Knowledge about how to change with sub-categories for:

○ Design

○ Client;

○ Experts; and

○ Right people.

- Situational readiness with sub-categories for:

- Project;

- Time; and

- High profile.

- Evidence to support the change which included the sub-category of Research. 
A review of the new categories indicated that one of the categories was not framed in the same way as the others and needed to be modified slightly. The theme of How people are lead and work together was framed in a neutral sense, not actually indicating a potential factor or factors that would contribute to an organization's ability to change for design implementation. The other categories, on the other hand, were much more conclusive indicating what needed to be present in order to be ready for change such as Evidence to support the change and Expertise and time to do the work. The How people are lead and work together category was renamed Leadership and teamwork. The sub-categories below it remained the same. 


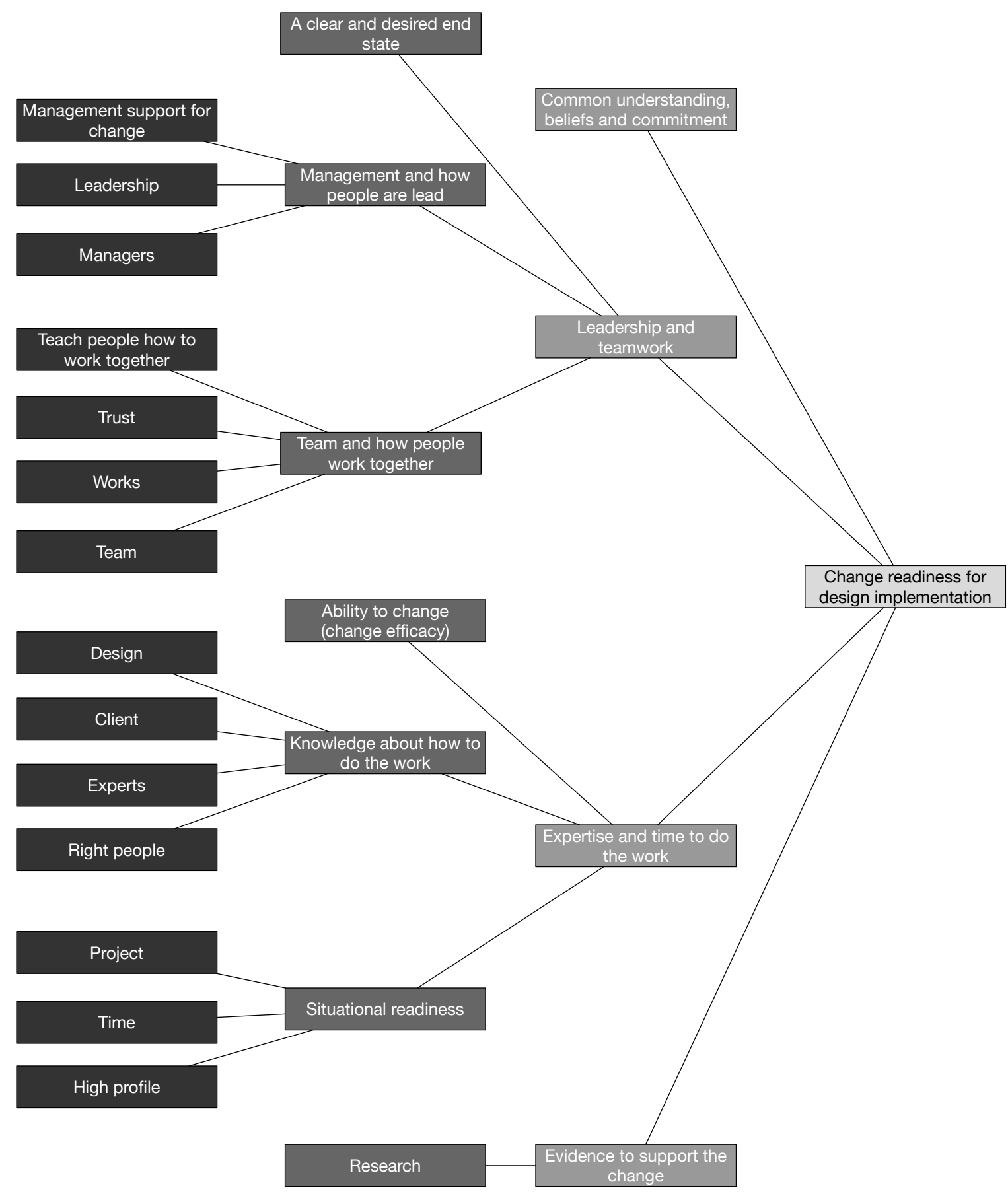

FIGURE A29. A MODEL OF THE STRUCTURE OF THE NEWLY PROPOSED HYPOTHESIS CODES. 
These Hypothesis Codes were used as preliminary categories or buckets in which the In Vivo Codes could be organized into to support the Second Cycle of coding Pattern Coding.

\section{A4.2 Results Generated from the Second Cycle of Coding}

Almost all of the In Vivo Codes generated in the First Cycle of coding were organized into the preliminary categories identified in the First Cycle of coding. One additional Provisional Code, Ability to change (change efficacy), was brought back into the collection of categories to support In Vivo Codes that did not have a logical home in the categories proposed in the first cycle of coding. Only In Vivo Codes were assessed in the second cycle of coding.

\section{A4.2.1 The Pattern Codes generated in the second cycle coding}

A total of 105 Pattern Codes were generated through Pattern Coding. Saldaña (2016) notes that pattern codes are "explanatory or inferential codes [...]that identify an emergent theme, configuration or explanation." And that Pattern Codes "pull together a lot of material from first cycle coding into more meaningful and parsimonious units of analysis" (p. 236). These new codes began to give structure to the data generated in the first cycle of coding that contained similar themes that were uncovered through the content analysis of the literature, but reflected different importance in certain categories, specifically the new themes of Experience and time to do the work and Leadership and teamwork. 
Of these new codes, there were 8 In Vivo Codes that were transferred into the collection of Pattern Codes as they were not organized into another group during Pattern Coding and did not have any related codes after the Second Cycle of coding. These codes included the following In Vivo Codes:

- "Change fatigue"

- "Show next steps and how to make it work"

- "Simplified the rules"

- "Solutioning"

- "Leader and consultants are aligned which makes it difficult to raise concerns"

- "Program didn't know they could fight for it"

- "Committees"

- "Give people a sense of what they will be doing" 


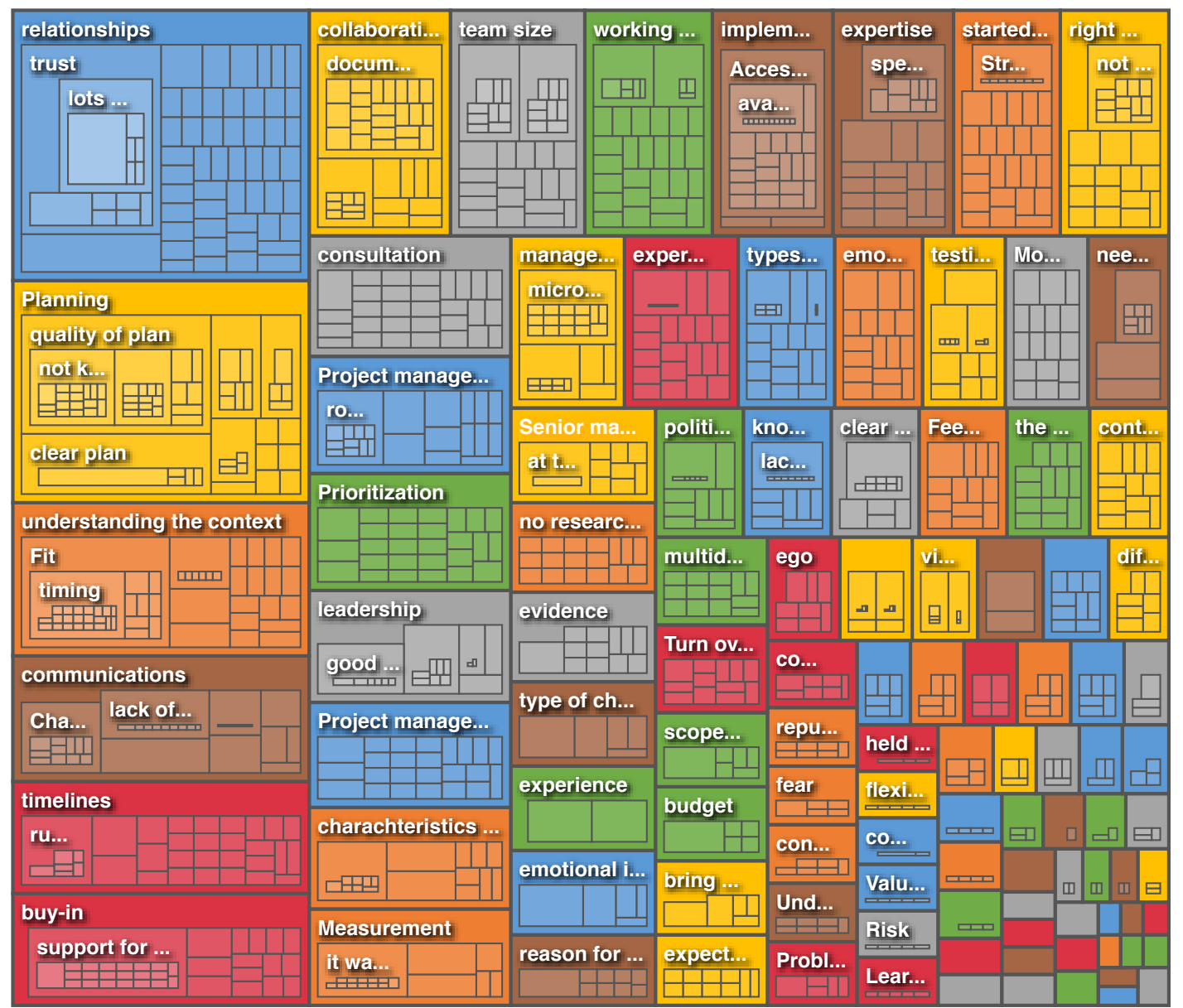

FIGURE A30. A TREE MAP OF THE PATTERN CODE HIERARCHY.

After a review of the aggregate references for all of the Pattern Codes, the top 17

Pattern Codes accounted for 50\% of the aggregated references (or 770 In Vivo

references from the data). The top 6 Pattern Codes accounted for $25 \%$ of aggregate

references (Table A8). 


\begin{tabular}{|c|c|c|}
\hline Word & $\begin{array}{c}\text { Number of aggregated In } \\
\text { Vivo references }\end{array}$ & $\begin{array}{c}\text { Percent of total aggregated } \\
\text { references }\end{array}$ \\
\hline Relationships & 106 & $7 \%$ \\
\hline Planning & 87 & $6 \%$ \\
\hline $\begin{array}{l}\text { Understanding } \\
\text { the context }\end{array}$ & 60 & $4 \%$ \\
\hline Communications & 49 & $3 \%$ \\
\hline Timelines & 44 & $3 \%$ \\
\hline Buy-in & 44 & $3 \%$ \\
\hline
\end{tabular}

TABLE A8. The top 6 Pattern Codes by aggregated In Vivo References.

These Pattern Codes included codes relating to Trust, Quality of plan, Access to resources, Fit and Documentation and information sharing.

\section{A4.2.2 Relationships between the Pattern Codes and the categories generated in the first cycle of coding}

The Pattern Codes could be organized into the 4 categories proposed at the end of the first cycle of coding (Table A9). The category with the most In Vivo references was Expertise and time to do the work followed by Leadership and teamwork.

Within the Expertise and time to do the work category, the sub-category of Situational readiness accounted for the majority of the references within the category and included Pattern Codes such as Understanding the context, Buy-in and Timelines, all Pattern Codes found in the top 6 Pattern Codes (Table A8). The Knowledge about how to change sub-category also contained the Planning Pattern Code which was also found within the top 6 Pattern Codes (Table A8). 


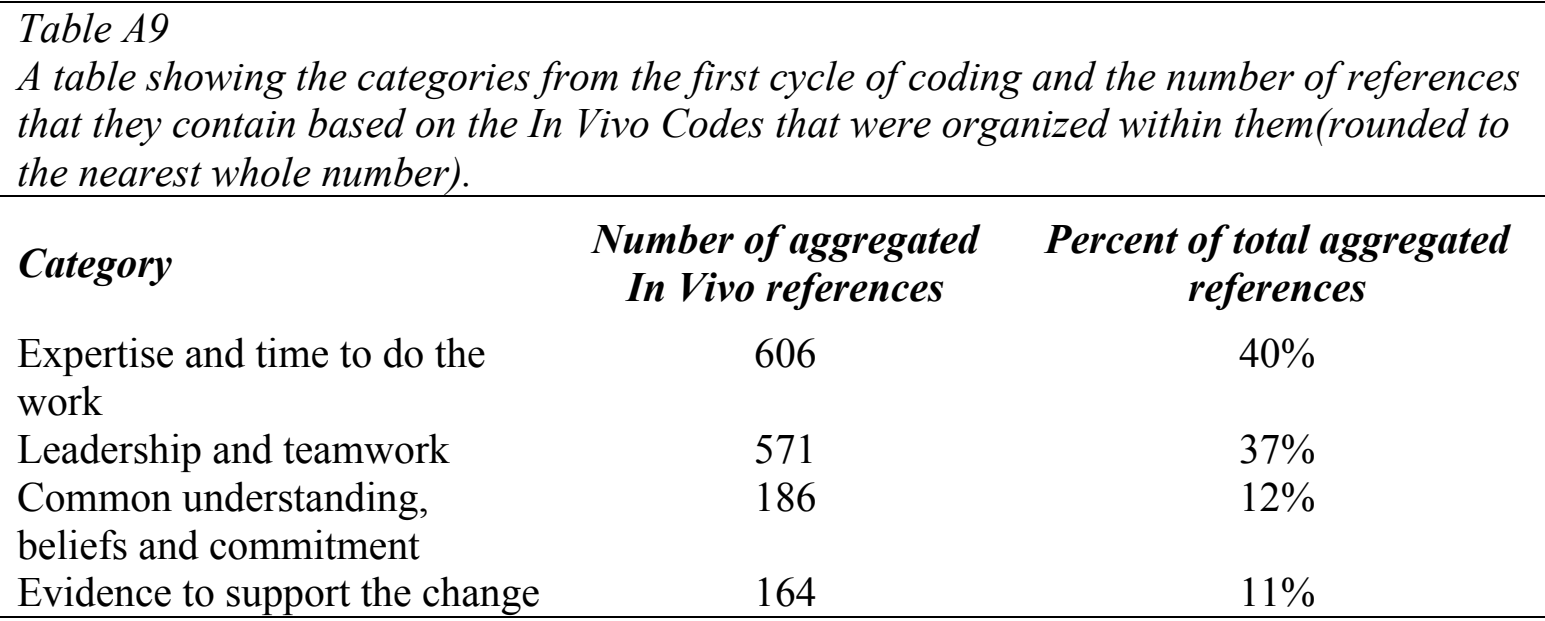

TABLE A9. THE VOLUME OF IN VIVO CODED REFERENCES BY FIRST CYCLE CATEGORY.

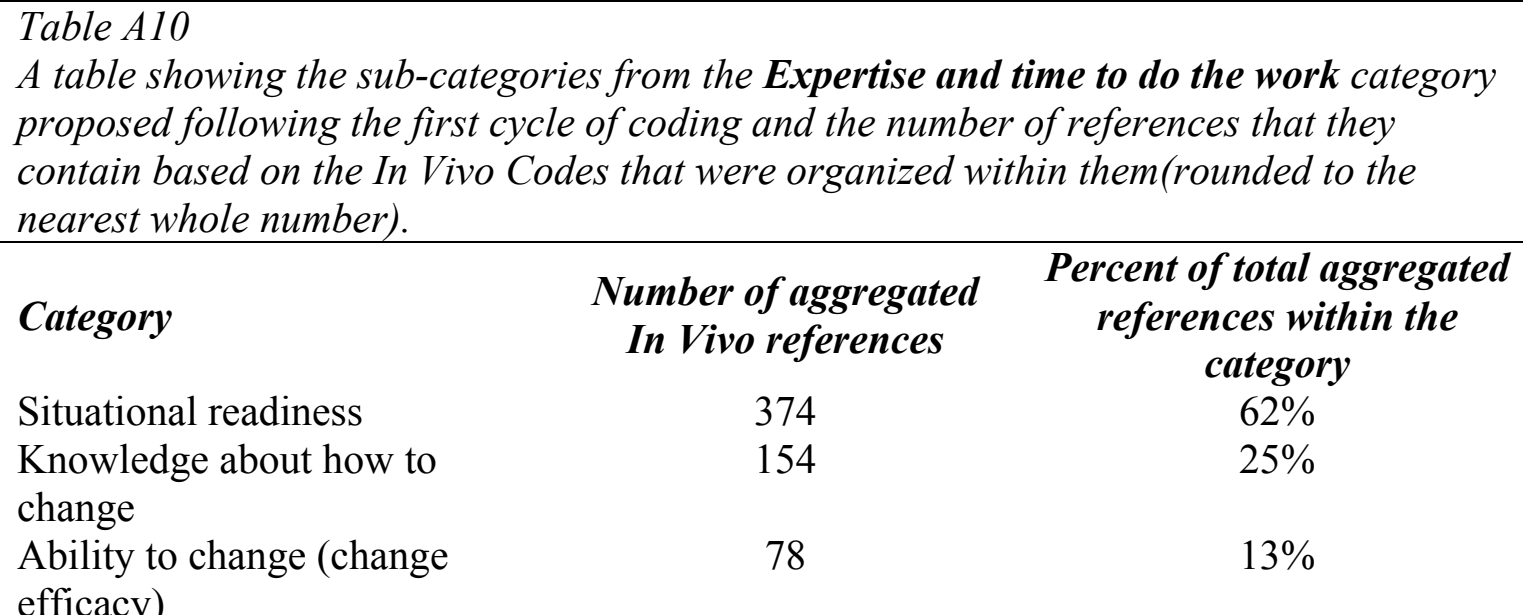
efficacy)

TABLE A10. THE VOLUME OF IN VIVO CODED REFERENCES WITHIN THE "EXPERTISE AND TIME TO DO THE WORK” CATEGORY, PRESENTED BY SUB-CATEGORY.

Within the Leadership and teamwork category, the sub-category Team accounted for the majority of the references within the category and included the Relationships Pattern Code, which contained the most aggregate references across all Pattern Codes (Table A11). 


\begin{tabular}{|c|c|c|}
\hline \multicolumn{3}{|c|}{$\begin{array}{l}\text { Table A11 } \\
\text { A table showing the sub-categories from the Leadership and Teamwork category } \\
\text { proposed following the first cycle of coding and the number of references that they } \\
\text { contain based on the In Vivo Codes that were organized within them (rounded to the } \\
\text { nearest whole number). }\end{array}$} \\
\hline Category & $\begin{array}{l}\text { Number of aggregated } \\
\text { In Vivo references }\end{array}$ & $\begin{array}{c}\text { Percent of total aggregated } \\
\text { references within the } \\
\text { category }\end{array}$ \\
\hline Team & 420 & $74 \%$ \\
\hline Management & 151 & $26 \%$ \\
\hline
\end{tabular}

TABLE A11. THE VOLUME OF IN VIVO CODED REFERENCES WITHIN THE "LEADERSHIP AND TEAMWORK" CATEGORY, PRESENTED BY SUB-CATEGORY.

\section{A4.2.3 Relationships between the Pattern Codes and Provisional Codes}

When the new categories were compared with the original Provisional Codes, similar patterns emerged as we saw in the first cycle of coding. The top Provisional Codes (Table A12) were all accounted for in the Pattern Coding. In addition to the top Provisional Codes illustrated in Table A12, additional Provisional Codes Ability to change and Situational readiness were included in the Second Cycle coding and Pattern Codes were generated within these sub-categories. In fact, the Situational readiness subcategory accounted for a large percentage of the In Vivo Codes generated once Pattern Coding was complete. 


\begin{tabular}{|c|c|c|c|}
\hline $\begin{array}{l}\text { Table A12 } \\
\text { A table compa } \\
\text { second cycles }\end{array}$ & $\begin{array}{l}\text { the magnitude of coding refere } \\
\text { ding. }\end{array}$ & by Category be & the first and \\
\hline $\begin{array}{l}\text { Provisional } \\
\text { Code }\end{array}$ & Category used in Second Cycle & $\begin{array}{l}\text { Percentage of } \\
\text { references in the } \\
\text { First Cycle }\end{array}$ & $\begin{array}{l}\text { Number of } \\
\text { references in } \\
\text { the Second } \\
\text { Cycle }\end{array}$ \\
\hline $\begin{array}{l}\text { How people } \\
\text { are lead and } \\
\text { work together }\end{array}$ & Leadership and teamwork & $17 \%$ & $35 \%$ \\
\hline $\begin{array}{l}\text { Common } \\
\text { understanding, } \\
\text { beliefs and } \\
\text { commitment }\end{array}$ & $\begin{array}{l}\text { Common understanding, beliefs } \\
\text { and commitment }\end{array}$ & $9 \%$ & $12 \%$ \\
\hline $\begin{array}{l}\text { Knowledge } \\
\text { about how to } \\
\text { change }\end{array}$ & $\begin{array}{l}\text { Expertise and time to do the } \\
\text { work-Knowledge about how to } \\
\text { change }\end{array}$ & $9 \%$ & $10 \%$ \\
\hline $\begin{array}{l}\text { Evidence to } \\
\text { support change }\end{array}$ & Evidence to support the change & $7 \%$ & $11 \%$ \\
\hline $\begin{array}{l}\text { Ability to } \\
\text { Change } \\
\text { (change } \\
\text { efficacy) }\end{array}$ & $\begin{array}{l}\text { Expertise and time to do the } \\
\text { work-Ability to change (change } \\
\text { efficacy) }\end{array}$ & $7 \%$ & $5 \%$ \\
\hline $\begin{array}{l}\text { Situational } \\
\text { readiness }\end{array}$ & $\begin{array}{l}\text { Expertise and time to do the } \\
\text { work-Situational readiness }\end{array}$ & $7 \%$ & $25 \%$ \\
\hline $\begin{array}{l}\text { A clear and } \\
\text { desired end } \\
\text { state }\end{array}$ & $\begin{array}{l}\text { Leadership and teamwork - A } \\
\text { clear and desired end state }\end{array}$ & $6 \%$ & $2 \%$ \\
\hline $\begin{array}{l}\text { Management } \\
\text { support for the } \\
\text { change }\end{array}$ & $\begin{array}{l}\text { NA } * * \text { the sub-category did not } \\
\text { remain through coding activities }\end{array}$ & $6 \%$ & 0 \\
\hline
\end{tabular}

TABLE A12. A COMPARISON OF MAGNITUDE OF REFERENCES FOR POPULAR PROVISIONAL CODES BETWEEN THE FIRST AND SECOND CYCLE OF CODING.

Since all of the In Vivo Codes could be organized into the proposed categories and sub-categories, the magnitude of references naturally increased between the first and second cycles of codes. The most remarkable change in the magnitude of the Provisional Codes compared with the categories and sub-categories most closely related to the Provisional Codes, was the substantial change in the number of aggregated references for 
the Situational readiness Provisional Code from $7 \%$ of total references to $25 \%$ references and the How people are lead and work together Provisional Code which was transformed into the Leadership and teamwork category. The shift in number of references from the First to Second Cycle of coding was $17 \%$ to $35 \%$ or over double the original magnitude.

There was also a notable decrease in aggregated references for the $A$ clear and desired end state Provisional Code from $6 \%$ of references to $2 \%$ of references.

Although the names and organization of the Provisional Codes changed slightly between the First and Second Cycles of coding, the only Provisional Code from the list of the top 6 Provisional Codes that was not carried over into the categories or subcategories used for the Second Cycle of coding was the Management support for the change Provisional Code. Although this Provisional Code was originally proposed as one of the original sub-categories, it did not remain when the second cycle of coding was done.

\section{A4.2.4 Summary of the second cycle coding}

All of the In Vivo Codes generated in the first cycle of coding could be organized into the proposed categories and sub-categories proposed at the end of the First Cycle of coding, without exception. This refined organization of the original In Vivo Codes resulted in a substantial increase in the popularity of the Expertise and time to do the work and Leadership and teamwork categories, which accounted for $77 \%$ of the aggregated references across all of the In Vivo Codes. 
Within the two categories, Expertise and time to do the work and Leadership and teamwork, the sub-categories of Team (74\%) and Situational readiness $(62 \%)$ had the most aggregated references.

\section{A4.3 Results Generated from the Third Cycle of Coding}

In the third and last cycle of coding, all of the Pattern Codes were reviewed, reorganized and combined to create the final proposed categories of factors of an organization's ability to change for design implementation identified through the research.

In total there were 6 Focus Codes or categories of factors that emerged from the research data. These categories were:

1. The people involved in the project can make the change happen

2. The people involved want to do the work

3. People know why the work is being done

4. The project fits within the existing context

5. People know how the work is being done

6. There is shared understanding about the work

Each proposed category identified through Focused Coding was linked to the data coded from all 18 participants.

It is likely that the level of magnitude of any particular category of codes indicates the importance of that factor or those factors have in an organization's readiness to change. The code with the greatest magnitude based on references in generated through the coding exercises was The people involved in the project can make the change happen. 


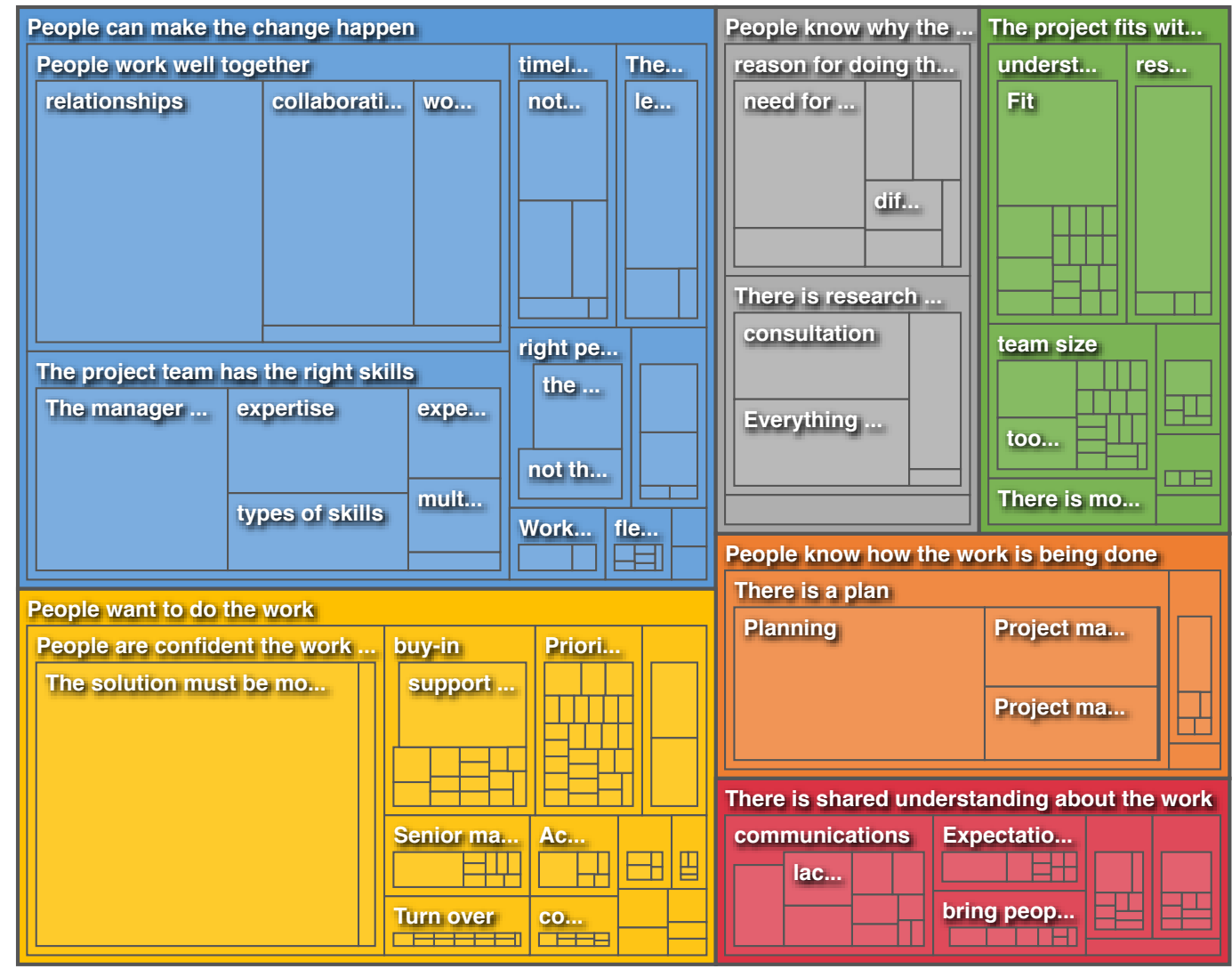

FIGURE A31. A TREE MAP OF THE NEW CATEGORIES OF FACTORS THAT MAY CONTRIBUTE TO AN ORGANIZATION'S ABILITY TO CHANGE FOR DESIGN IMPLEMENTATION.

Table A13

The magnitude of each of the proposed categories of factors uncovered in the research.

\section{Factors uncovered in participant data}

The people involved in the project can make the change happen

The people involved want to do the work

People know why the work is being done

People know how the work is being done

The project fits within the existing context

There is shared understanding about the work
Percentage of the total aggregated references from the data (rounded to the closest whole number)

TABLE A13. THE FINAL CATEGORIES UNCOVERED IN RESEARCH AND THEIR MAGNITUDE 


\section{Appendix 5: The Themes Generated from the Third Cycle of Coding}

The following diagrams illustrate how the themes found in the third cycle of coding were organized; from excerpts of the In Vivo Codes generated in the first cycle of coding participant data, through the Pattern Codes generated, Focused Codes and finally the themes. The diagrams represent the structure of the themes and indicate what kind of perceived factors of design project success might be contained within each of the themes. 


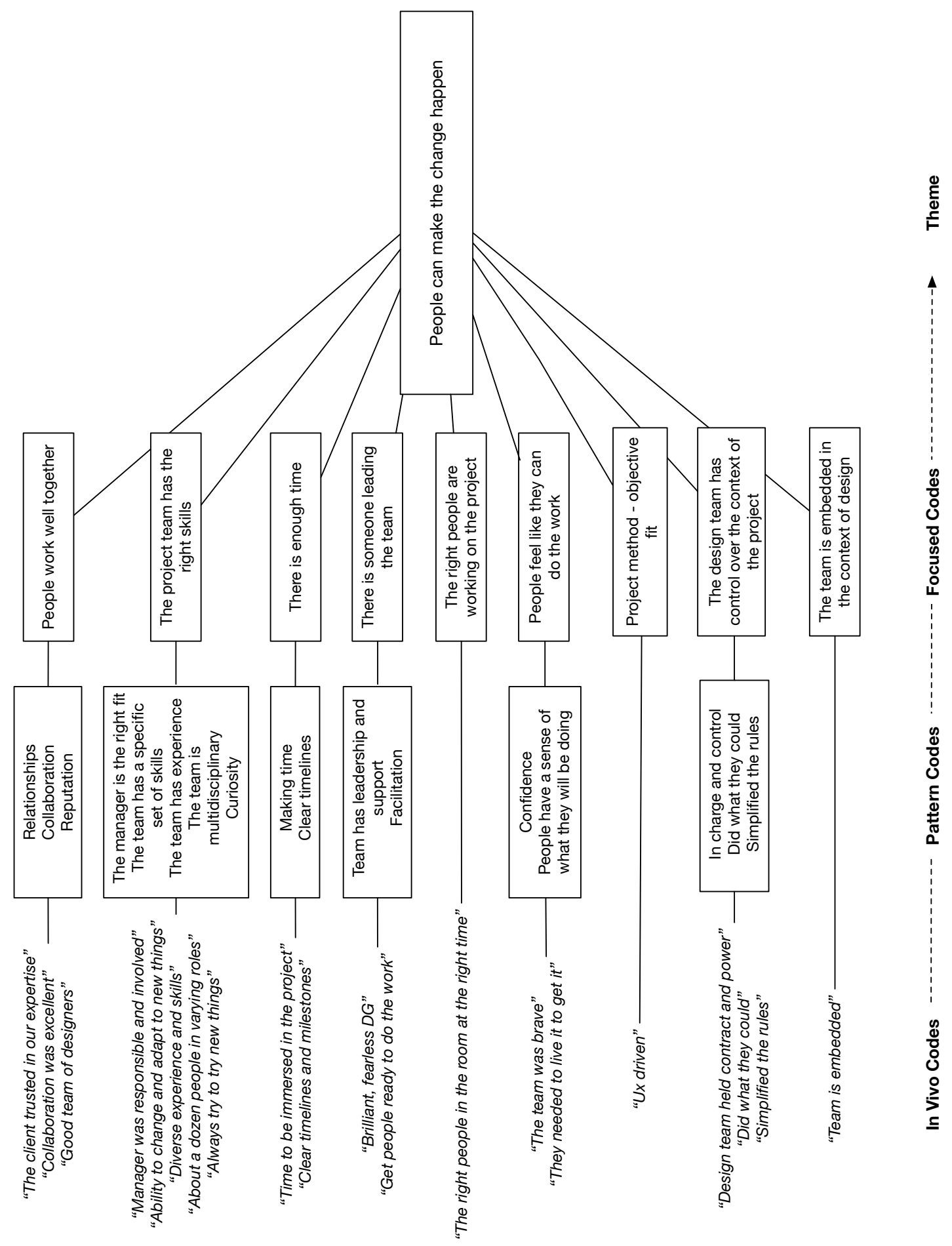

FIGURE A32. A Diagram REPRESENTING THE STRUCTURE OF THE PEOPLE CAN MAKE THE CHANGE HAPPEN THEME. 


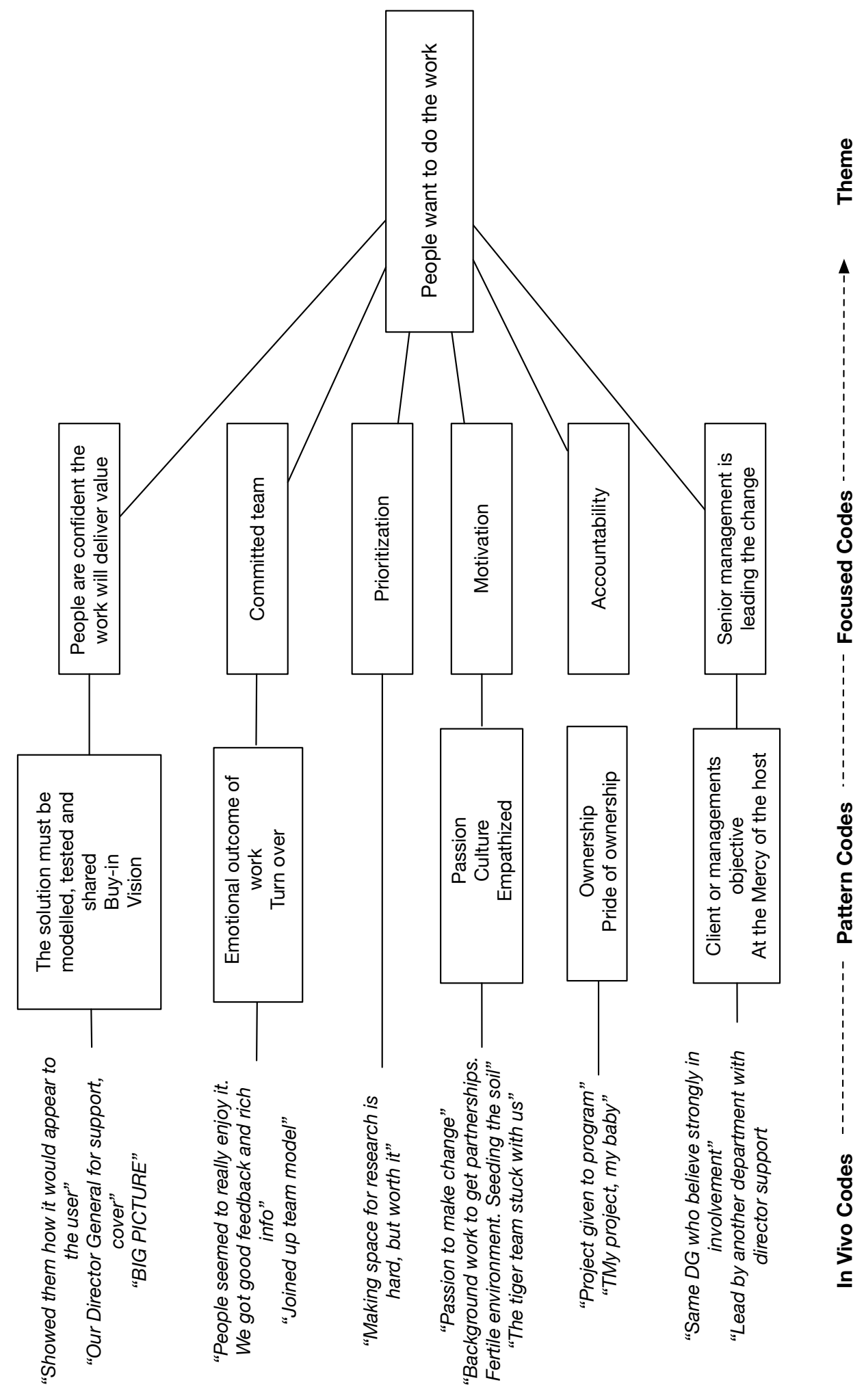

FIGURE A33. A DiAgRAM REPRESENTING THE STRUCTURE OF THE PEOPLE WANT TO DO THE WORK THEME. 


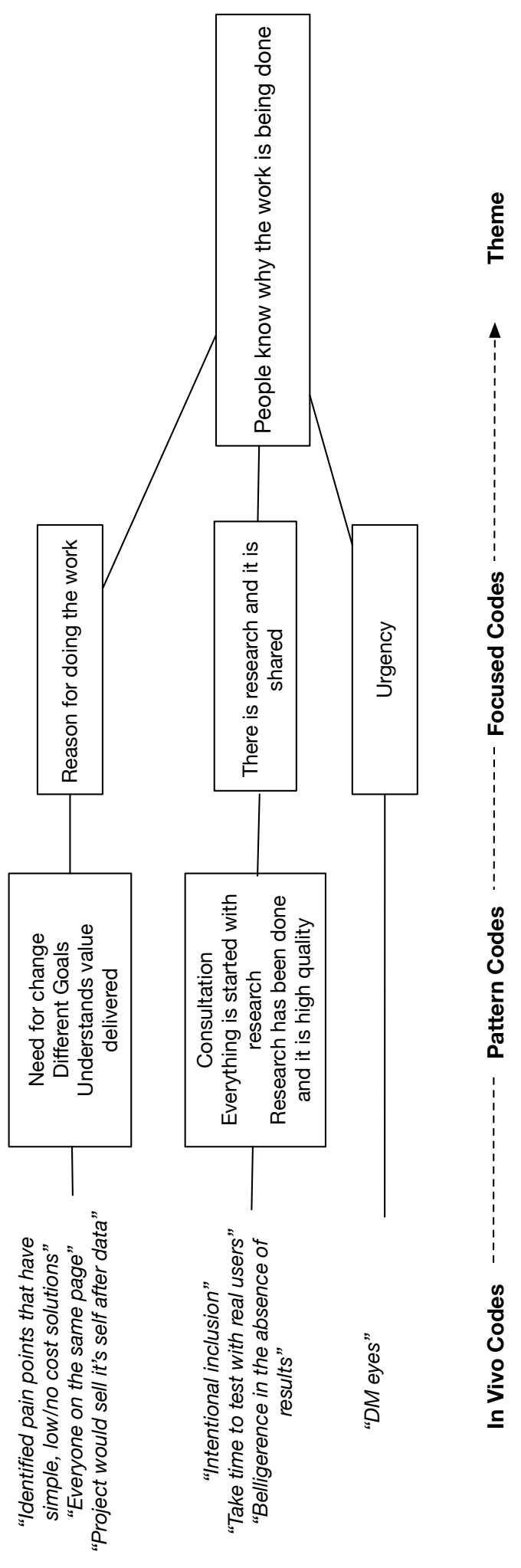

FIGURE A34. A DiAgRAM REPRESENTING THE STRUCTURE OF THE PEOPLE KNOW WHY THE WORK IS BEING DONE THEME. 


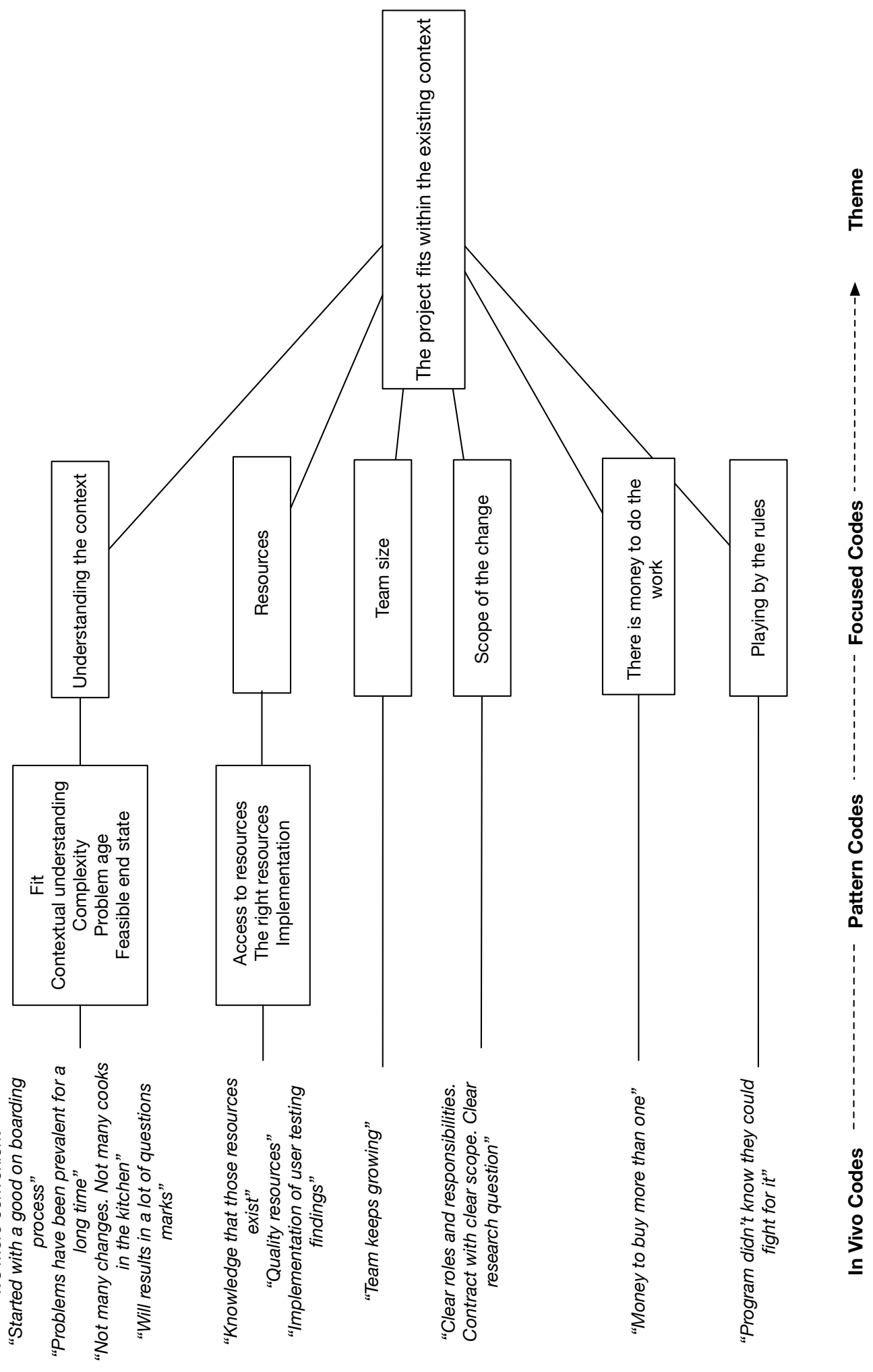

FIGURE A35. A DIAGRAM REPRESENTING THE STRUCTURE OF THE PROJECT FITS WITHIN THE EXISTING CONTEXT THEME. 


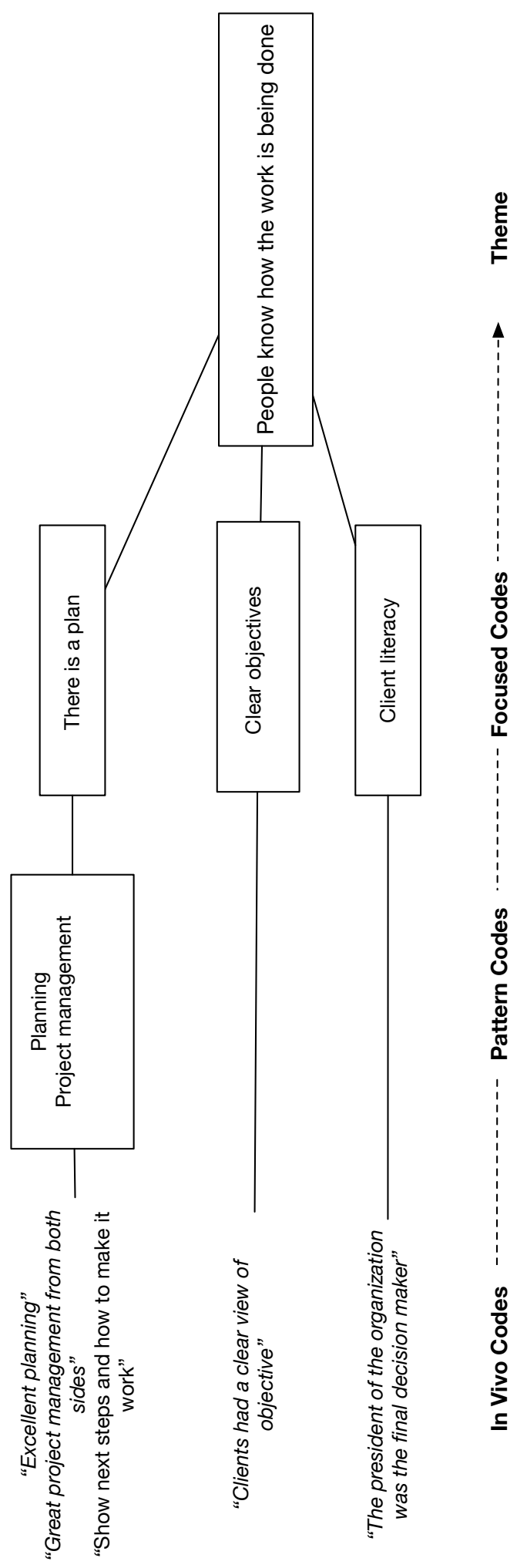

FIGURE A36. A Diagram RePRESENTING THE STRUCtURE OF THE PEOPLE KNOW HOW THE WORK IS BEING DONE THEME. 


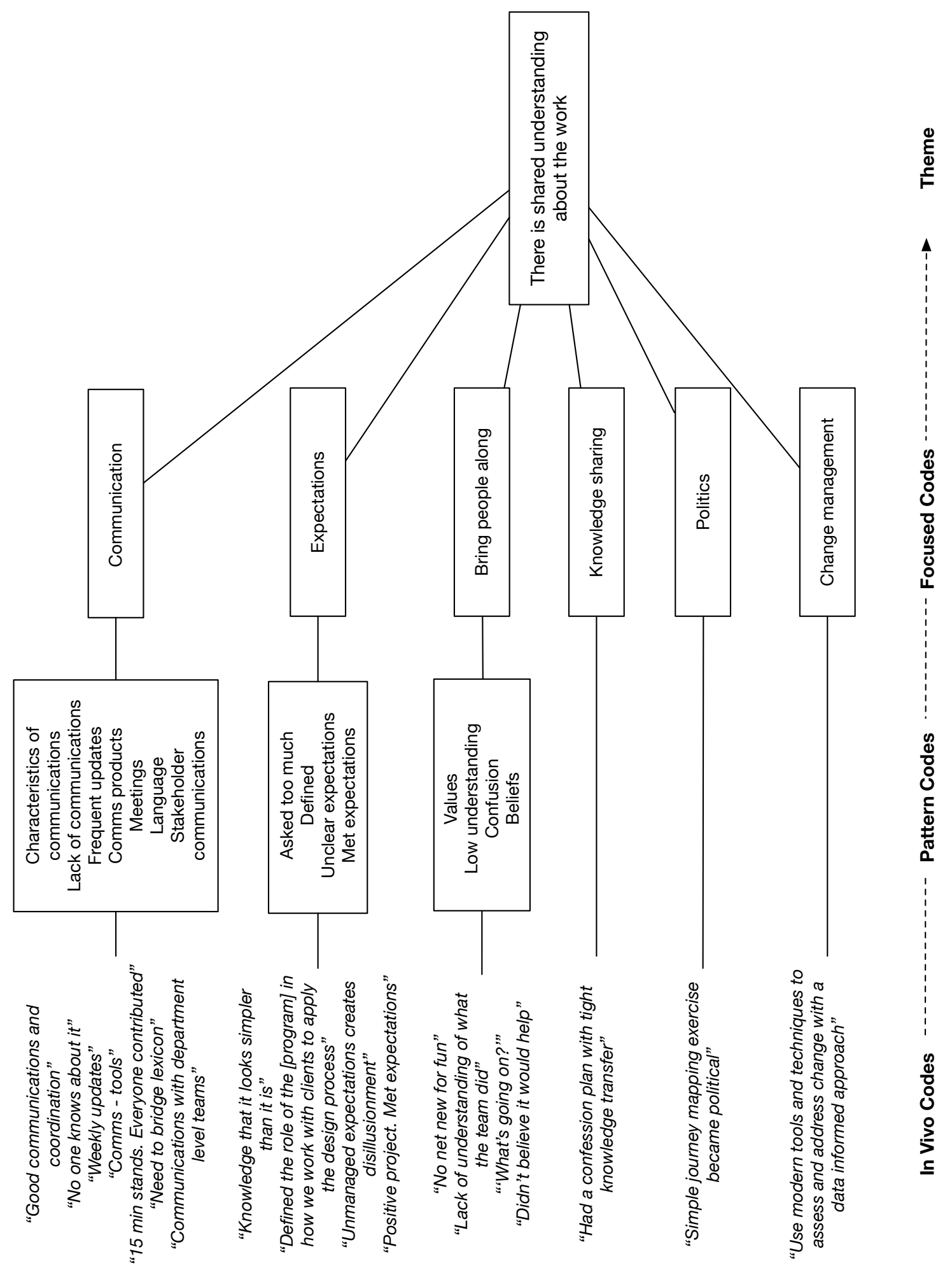

FIGURE A37. A DIAGRAM REPRESENTING THE STRUCTURE OF THE THERE IS SHARED UNDERSTANDING ABOUT THE WORK THEME. 


\section{Appendix 6: Research Protocol}

The following Application for REB Ethics Clearance contains the details of the research protocol as well as examples of the materials used in the research such as consent forms, recruitment messages, images of the research kit contents and the participant information tracking table. 
AUGUST 30, 2019

\title{
APPLICATION FOR REB ETHICS CLEARANCE - RESEARCH INVOLVING VERY LOW RISK
}

\author{
MASTER OF DESIGN RESEARCH STUDY \\ FActors of ChANGE READINESS FOR PUBLIC SERVICE DESIGN \\ IMPLEMENTATION
}




\section{RESEARCH INVOLVING VERY LOW RISK}

\section{Research Ethics Protocol Checklist}

\begin{tabular}{|c|c|}
\hline$\infty$ & $\begin{array}{l}\text { Include all information requested in CUREB Submission form (ensure track } \\
\text { changes have been removed and spelling/grammar has been checked. Please combine } \\
\text { the protocol and all attachments in a single PDF). }\end{array}$ \\
\hline$=-$ N.A. & $\begin{array}{l}\text { For student researchers: ensure supervisor provides approval in one of the } \\
\text { following ways: } \\
\text { - The Supervisor Signature Form is signed and attached with the application. } \\
\text { - The faculty supervisor may send an email to ethics@carleton.ca and it will be } \\
\text { accepted as confirmation of supervisor approval. }\end{array}$ \\
\hline- & $\begin{array}{l}\text { TCPS } 2 \text { Training Complete and Certificate attached? } \\
\text { The TCPS-2 Course on Research Ethics (CORE) is now required of all researchers } \\
\text { seeking ethics clearance from CUREB A/B: https://tcps } 2 \text { core.ca/welcome. }\end{array}$ \\
\hline$-\quad=$ N.A. & $\begin{array}{l}\text { Copies of all written communications (e.g. recruitment materials, information forms, } \\
\text { informed consent forms, debriefing form) to participants must be on } \\
\text { Department/Faculty letterhead }\end{array}$ \\
\hline $\begin{array}{l}=\text { N.A. } \\
=\quad \text { N.A. } \\
=\quad \text { N.A. } \\
=\text { N.A. }\end{array}$ & $\begin{array}{l}\text { Recruitment Materials } \\
\text { Script(s) - in-person, telephone, } 3 \text { rd party, email, etc. } \\
\text { Invitation to participate } \\
\text { Advertisement, poster, flyer } \\
\text { None required - explanation provided }\end{array}$ \\
\hline $\begin{array}{l}=\text { N.A. } \\
=\quad \text { N.A. } \\
=\quad \text { N.A. } \\
=\text { N.A. }\end{array}$ & $\begin{array}{l}\text { Data Collection Methods Checklist } \\
\text { Standardized Instrument(s) } \\
\text { Survey(s), Questionnaire(s) } \\
\text { Interview and/or Focus Group Questions } \\
\text { Confidentiality Agreement } \\
\text { Other (e.g. describe biomedical or prototype materials used in the experiment in } \\
\text { detail and/or include a photo of these materials). }\end{array}$ \\
\hline $\begin{array}{l}=\quad \text { N.A. } \\
=\quad \text { N.A. } \\
=\quad \text { N.A. }\end{array}$ & $\begin{array}{l}\text { Free and Informed Consent (instructions here) } \\
\text { Consent and Assent Form(s) - include forms for all participant groups and data } \\
\text { gathering methods. } \\
\text { Letter(s) of Information for Implied Consent } \\
\text { Verbal Consent and Assent Scripts }\end{array}$ \\
\hline N.A. & Debriefing Materials \\
\hline $\begin{array}{l}- \text { N.A. } \\
=- \text { N.A. }\end{array}$ & $\begin{array}{l}\text { Are all recordings (videos, audio, photo) used in the study adequately explained in } \\
\text { the protocol? } \\
\text { Permission obtained for each recording? }\end{array}$ \\
\hline$=\quad$ N.A. & Permission obtained to access confidential documents or materials? \\
\hline$=\quad-$ N.A. & $\begin{array}{l}\text { If using deception, participants must be debriefed. They must also have the } \\
\text { opportunity to withdraw their data (a follow-up consent form should be given so } \\
\text { participants may consent to the use of data in cases of deception). }\end{array}$ \\
\hline$=\quad-$ N.A. & $\begin{array}{l}\text { Other Approvals } \\
\text { (e.g. Biosafety committee approval, site permissions to recruit/conduct research on } \\
\text { properties, at organizations, and at institutions, etc.). }\end{array}$ \\
\hline
\end{tabular}




\section{Research Ethics Protocol Submission Form}

This Form is for research projects meeting all the following criteria. If you have any doubt about whether your study may use this form, or questions about its completion, please contact the Research Ethics Office at ethics@carleton.ca or by phone to 6135202600 ext. 2517 (CUREB A) or ext. 4085 (CUREB B).

1. The risks to participants are very low;

2. No research procedures involve any physically invasive intervention;

3. Participants are legally capable of consenting on their own behalf, and are free from coercion or undue influence;

4. Any accidental or intentional disclosure of the participants' responses would not reasonably place participants at risk of criminal or civil liability, harmful retaliation, or be damaging to the participants' emotional or financial well-being, employability, or reputation;

5. The study does not involve recruitment by a third party; and

6. The study does not involve deception or providing incomplete information to participants.

By submitting the Form, the Lead Researcher and academic supervisor, if any, attests that the Project meets all of the above requirements and to the Declarations in Section 6 of this Form.

\section{Project Title and Team}

\subsection{Submission Date: 8/26/2019}

1.2 Project Title: Factors of Change Readiness for Public Service Design Implementation

1.3 Lead Researcher (name, email, department, institution)

Samantha Lovelace, Samantha.lovelace@carleton.ca, School of Industrial Design, Carleton University

\subsection{Academic Supervisor $\quad$ Not Applicable}

Chantal Trudel, Carleton University

\subsection{Project Team Members}

Dr. Paul Thibaudeau (co-supervisor)

1.6 TCPS CORE Tutorial: TCPS training is required for all researchers. Attach Completion Certificates or justify any cases in which researchers have not completed the TCPS tutorial.

See Appendix B - TCPS certificate p. 9

\section{Project Description}

2.1 Is this Project Funded? — Yes — No If Yes, by whom?

2.2 Study Goal: briefly explain the primary objective(s) of the current study.

This case study aims to improve our understanding of factors that may influence design processes and implementation of services within government and how we might increase opportunities for successful design implementation. 


\section{RESEARCH INVOLVING VERY LOW RISK}

Findings from this study will be used to develop a framework to support change and design implementation within the context of government organizations.

\subsection{Study Rationale and Expected Benefits: Why should the study be done? What are the benefits, and to whom?}

The costs associated with project failures are high. In complex work such as the design of policies, services and products in the public sector, poorly implemented solutions or unused development efforts can be costly and may reduce the potential value design can bring to government organizations. This study references change management frameworks and factors identified in such frameworks that can influence change within organizations and increase the likelihood that proposed designs be implemented effectively.

This study may benefit people working in public service design by providing insight on factors that are likely to increase the successful deployment of a project and may benefit public service organizations by increasing the value of the design activities they undertake.

This study may provide indirect benefits to the public by improving design development processes undertaken by government organizations.

\subsection{Overview of Methodology and Participant Interactions: Briefly describe the study methodology and what will be required of participants for this study.}

Participants will be invited to individually participate in a mixed-methods, directed story telling exercise held in-person with the principle investigator; this moderated, semi-structured interview which will be informed by the completion of sensitizing activities to be completed before the interview using probes.

During recruitment, participants will be asked to pick a date and a time to meet the principle investigator for their interview (referred to from here on as the "in-person session") using an online tool called Calendly (Calendly.com).

Once the in-person session is scheduled, the principle investigator will use email to arrange to meet the participant and provide them with a research kit in which they will find a collection of probes that will be used to collect stories from the participants.

The probes come in two packages. One package to encourage reflection on a design project the participant worked on the was a success and one that was not successful. Each package contains a workbook with a series of questions within that aim to support storytelling and reflect the questions that will be asked during the in-person session. When the workbook is complete, the participant is required to complete a Mind Mapping exercise using information they uncovered from the workbook exercise.

The participant must complete the workbook and map exercises for both the successful and unsuccessful projects before the in-person session with the principle investigator.

During the in-person session, each participant will be asked to:

- Briefly describe the successful project they worked on and: 


\section{RESEARCH INVOLVING VERY LOW RISK}

O Indicate what the objectives of the project were

- Identify the stakeholders for the project

○ Talk about the outcome of the project, and specifically, if they thought the project was or was not a success and why they felt this way

- Discuss the Mind Map they created

- Reflect on what they would do differently or would repeat in their next project and why to influence the outcome, and adding this information as another category to the Map if appropriate

- Listen to the principle investigator reiterate what they heard and correct anything the principle investigator missed or made a mistake on

- Repeat the exercise for the unsuccessful project

The in-person session will be undertaken in a location unique to the participant's location of work or home or online using Zoom video conferencing software (zoom.us).

Participants will be offered the opportunity to choose a preferred location. If the participant does not have a preferred location, the principle investigator will suggest the closest publicly accessible location to the participant's place of work or home (depending on the day of study and where the participant is on that day).

Location identification will be coordinated by email with the participant when a study day and time is selected.

Pilots will be run before the launch of the study to address any issues of:

- Clarity or confusion regarding how to use the research kit

- Length of session

- Quality of research materials

Please see Appendix E-Kit materials and Appendix F-Study Session Materials (p. 22-42) for relevant materials including the information hand out, kit instructions and Study Day agenda, contact card, workbook questions, verbal consent form, and sample script and interview guide.

\section{Participants and Informed Consent}

\subsection{Description of the participants and any inclusion/exclusion criteria:}

Participants will include Government of Canada employees or people who work or have worked as designers, researchers or analysts on program, policy, service or product development projects (referred to as "design projects") for the federal public service.

Participants must be 18 years old or older to participate.

\subsection{How many participants do you plan to recruit?}

The participation goal is 12 participants based on Guest, Bunce and Johnson's study on qualitative sample size, 


\section{RESEARCH INVOLVING VERY LOW RISK}

Canada's Capital University

saturation and variability (Guest, Bunce \& Johnson, 2006).

To achieve this number, a minimum of 17 participants will be recruited (assuming that approximately $30 \%$ of participants will not be able to attend).

3.3 Describe how participants will be recruited including how contact information will be obtained. How will participants be made aware of the study, where will recruitment materials be located, and how may participants express their interest? Attach a copy of any recruitment materials including oral scripts, recruitment posters, emails and social media postings, etc.

Participants will be recruited primarily from the researchers personal contact list using direct email and a snowball sampling technique (Taylor, DeVault \& Bogdan, 2016) in which participants directly contacted by the researcher will be prompted with a call to action in the email to share the study with anyone they may think is interested. Additional participants will be recruited through word of mouth and using the researcher's existing personal social media networks on Twitter, LinkedIn, facebook and various online collaboration and community platforms (such as gccollab.ca).

This approach aims to capture a selection of peers outside of the researcher's immediate network and reduce the potential for researcher and research participant bias.

A link to the consent form and a summary of the study will be made available in the recruitment email and via social media links so that participants can explore the details of the study in advance and register to participate online.

Scheduling for the study will be done directly with the participants using their preferred email and the researcher's Carleton University email.

Please see Appendix D-Recruitment materials (p. 17-21) for the sample email, social media posts and proposed website content containing link to sign up to participate, information about the study and contact information for the researcher.

3.4 Describe any compensation or remuneration for participants and indicate when participants will receive the compensation. What happens to compensation if a participant withdraws early?

When the study location is a coffee shop, food court or other location where beverages are provided, participants will be offered a coffee, tea or hot chocolate.

All participants will be offered a bottle of water and a small snack during the session.

If the participant chooses to withdraw from the study before attending the in-person portion of the study, coffee, water and snacks will not be provided. If the participant decides to withdraw during the in-person portion of the study, they will be allowed to keep the beverages and snacks they were offered.

\subsection{Describe the process for a participant to withdraw their data after collection, and the time limits,} if any.

Participants will be able to withdraw their research data up to two weeks following the completion of the in- 


\section{RESEARCH INVOLVING VERY LOW RISK}

Canada's Capital University

person exercise, at which point all research data collected will be anonymized. During the anonymization process, the principle researcher will ensure that any personally identifying data will be removed or redacted and any specific details about the context of the projects will not be reported on including:

- Project name

- Project type

- Organization

- Industry

- Team member details

- Participant job title or role

- Years of employment

- Personal information

Given the foundational nature of the work, details are not required for the purpose of the study.

\subsection{Describe the process of obtaining informed consent from participants and include a copy of the} consent form(s) and materials. If signed consent is not to be used, justify the alternative method chosen.

Participants will be made aware of the confidentiality and data protection policies of the study prior to agreeing to participate via reference to a link in the recruitment email or social media post. Participants will also be provided with the study information and a consent form with their research kit.

Before starting the in-person exercise, the researcher will go over the study information verbally and make printed copies available to the participant. Participants will be asked to provide a signed and dated consent form prior to beginning the in-person portion of the study. If the participant did not bring their consent form with them to the in-person study, they will be provided with a blank form to sign before beginning the in-person portion of the study.

Participants participating in an online in-person session will be asked to email a scanned or photographed copy of their signed consent form prior to the beginning of the session. The researcher will print, sign and show the final copy to the participant at the beginning of the session.

\section{Participants will be required to provide written consent in order to participate in the study.}

Written consent will be tracked using a journal entry which will also indicate the beginning of the session following guidance in the Tri-Council Policy Statement: Ethical Conduct for Research with Humans, Section 2 - Free and Informed Consent, Article 2.1 (b). So that participants can withdraw their data, each journal entry will be coded with a randomly generated participant number. This number will also be used to track consent and provided to the participant on their printed copy along with their withdrawal deadline.

The written consent form will be stored temporarily in an envelope that will be kept separate from the study data until it can be properly stored in the locked storage location. 


\section{RESEARCH INVOLVING VERY LOW RISK}

The researcher will suggest that the participant keep a copy of the Statement of Consent for review, reference and contact information.

Please see the Statement of Consent example (p. 41)

\section{Data Collection, Use, and Storage}

4.1 Describe how data will be collected and any instruments to be used. Provide a copy of any questionnaires, surveys, interview guides or other data collection materials.

Data will be collected using a dedicated journal for research notes, the workbook completed by the participant, the Mind Map created by the participant and any other artifacts created in the study that the participant would like to share.

Photos may be taken of the participant using their workbook or Mind Map during the in-person session. Photos will be taken of the workbooks and Mind Maps for digital storage and analysis purposes after the in-person session has completed.

Audio recordings will be taken of the in-person sessions. Online in-person sessions will use the built-in recorder to capture video and audio from the session.

Journal entries, workbooks, maps, artifacts provided to the researcher, photos taken during the in-person session, photos taken of the workbooks and maps and audio recordings of the sessions will be coded with a randomly generated participant number so that if a participant wishes to withdraw from the study with in the two weeks following completion of the session, they can.

Please see the code key example (p. 50).

\subsection{Aside from the PI, who will have access to research data?}

The thesis supervisor and co-supervisor (thesis team member).

4.3 Describe the identifiability of research data, including how codes or pseudonyms will be assigned.

Data will contain information that directly identifies participants.

Data will contain information that may indirectly identify participants.

Data will be coded with the code key stored securely and separate from identifying information.

$\bigotimes \quad$ Data will be de-identified (anonymized) with any identifiers destroyed.

Any identifiable information captured in the research data will be anonymized and all potentially identifying data will be removed from research data immediately upon identification.

As noted in section 3.5, the following information is not required for the study and details for the following attributes will be redacted from study data:

- Project name 


\section{RESEARCH INVOLVING VERY LOW RISK}

Canada's Capital University

- Project type

- Organization

- Industry

- Team member details

- Participant job title or role

- Years of employment

- Personal information

4.4 Describe the physical (e.g. locked filing cabinet) and/or technical safeguards (e.g. Encryption) that will be used to securely store the collected data. Where will data be stored?

Physical research data (such as the researchers journal, participant Mind Map and artifacts provided by participants) will be stored in a locked storage unit (filing cabinet) when not in use. Digital research data generated through digital documentation activities (such as photographs, audio recordings and transcription) will be stored on a password protected external hard drive and locked in the secure location.

The master list will be separated from the rest of the research data on an encrypted USB and locked in a secure location separate from the rest of the research data. Consent forms collected will also be stored with the master list in the secure location.

4.5 After project completion, describe whether and how the data will be stored for future use. If shared, with whom? If made public, how (e.g. online)? If archived, provide details. Describe any restrictions on access. Will personal identifiers be deleted and when? If data will be destroyed, when? Will participant contact information be kept for future recruitment? (Include data disposition plans in the consent materials).

The physical and digital data will be archived and stored for future use for 5 years following data collection period. Only the principle researcher, thesis advisors and research team member will have access to the data at any point.

Digital record of physical research artifacts may be used in the thesis publication, which will also be available online following publication. No artifacts in the thesis will contain any personally identifying information.

\section{Attachments}

\subsection{Please indicate any attached materials.}

TCPS 2 Tutorial Course on Research Ethics (CORE) tutorial certificate for each team member Sample letters of information, recruitment materials, consent forms and/or scripts, debriefing forms

$\bigotimes$ Sample of data collection instruments (survey questionnaires, test instruments, etc.)

$\bigotimes \quad$ Supervisor approval form (if applicable) 


\section{RESEARCH INVOLVING VERY LOW RISK}

Permission letters from partner organizations (if applicable)

5.2 Provide a brief rationale if an attachment(s) is not available at time of submission.

\section{Declarations}

1. The information in this Form is correct and accurately describes the research project.

2. No recruitment or data collection for this protocol will start before receiving ethics clearance.

3. I (we) will carry out this project in accordance with the information in this Form and the other submitted documents. No changes will be made to the research project as described in this protocol without clearance from the Research Ethics Board.

4. I will promptly notify the Research Ethics Board of any ethical breaches or concerns, adverse events, unanticipated problems or complaints that arise relating to this research project.

\section{Comments}

Do you have any comments or suggestions to improve this form? 


\section{RESEARCH INVOLVING VERY LOW RISK}

\section{Appendix A - Supervisor Form}

\section{Carleton U N I VER S I T Y \\ Canada's Capital University}

\section{SUPERVISOR/SPONSOR SIGNATURE FORM}

For consideration of submitted ethics protocols, the Carleton University Research Ethics Boards require evidence that all student protocol documents (i.e., undergraduate, graduate and post-doctoral fellows) have been reviewed and approved by a faculty supervisor or sponsor.

Instructions:

After filling out the details in the text below, faculty sponsor/supervisors should either

1) Print and scan this document, or

2) Email the text of the document (below; with signature optional) to the lead researcher

The form or email can then be uploaded (in PDF format) with the protocol, to the CUResearch.

As the faculty supervisor or sponsor, I confirm that I have reviewed and that I approve for submission for ethics review, the protocol entitled Factors of Change Readiness for Public Service Design Implementation from Samantha Lovelace on July 23, 2019.

Signature of Faculty

Supervisor/Sponsor:

Name of Faculty Supervisor/Sponsor:

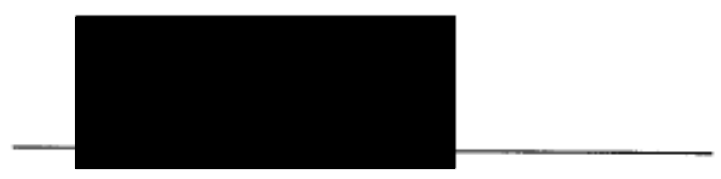
Citantal trudel

Date:

duvy $25 \quad 2019$ 


\section{RESEARCH INVOLVING VERY LOW RISK}

Canada's Capital University

$$
\text { Appendix B - TCPS certificates }
$$

A screen capture of Samantha Lovelace's TCPS 2 Core certificate.

\section{PANEL ON}

RESEARCH ETHICS

\section{TCPS 2: CORE}

\section{Certificate of Completion}

This document certifies that

\section{Samantha Lovelace}

has completed the Tri-Council Policy Statement:

Ethical Conduct for Research Involving Humans

Course on Research Ethics (TCPS 2: CORE)

Date of Issue: 12 May, 2019 


\section{RESEARCH INVOLVING VERY LOW RISK}

A screen capture of Paul Thibaudeau's TCPS 2 Core certificate.

\section{PANEL ON}

RESEARCH ETHICS

\section{TCPS 2: CORE}

Navigating the ethics of human research

\section{Certificate of Completion}

This document certifies that

Paul Thibaudeau

has completed the Tri-Council Policy Statement:

Ethical Conduct for Research Involving Humans

Course on Research Ethics (TCPS 2: CORE)

Date of Issue: $\quad 3$ July, 2019 


\section{RESEARCH INVOLVING VERY LOW RISK}

Canada's Capital University

\section{Appendix C - Research methodology map}

The following diagram represents the research process from clearance to study data disposition.

Factors of Change Readiness for Public Service Design Implementation Study Methodology

Prepared: August 2019
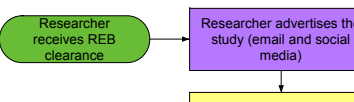

Participant is made aware of

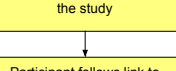

Participant follows link to
register for study or replies

to email

Participant opts to participate
in study

Legend

$\square$ Start of process

Rid

$\square$ Researcher process poil

$<$ condition
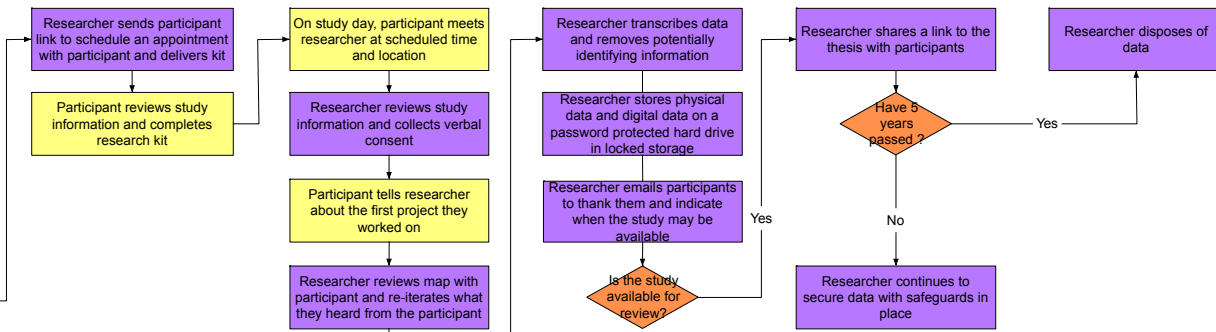

End study

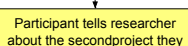
Participant tells researcher
about the secondproject they worked on

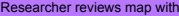
participant and re-iterates what
they heard from the participan

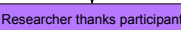
for their time and takes time 


\section{RESEARCH INVOLVING VERY LOW RISK}

\section{Appendix D - Recruitment materials}

The following attachments are samples of the recruitment materials to be used to find participants for the study.

Attachments include:

- Appendix D-1: Sample email

- Appendix D-2: Sample social media posts

- Appendix D-3: Wireframes for the web site containing:

$\circ$ The study summary

- Information to inform consent

- A link to register for the study

- Contact information 


\section{RESEARCH INVOLVING VERY LOW RISK}

\section{Appendix D-1: Sample email}

The following sample email will be distributed to a small selection of personal contacts who will hopefully forward the invitation to participate to other colleagues. This is the primary recruitment method.

\section{Email Invitation: Sample}

Subject: Factors of Change Readiness for Public Service Design Implementation - A research study

Dear [name],

I would like to invite you to participate in a study that aims to improve our understanding of factors that may influence design processes and implementation of services within government and how we might increase opportunities for successful design implementation.

Findings from this study will be used to develop a framework to support change and design implementation within the context of government organizations.

In order to be eligible for the study you must currently work for the federal public service as a designer or design researcher or have been involved in the development of a program, policy, service or product.

You must also be 18 years of age or older.

If you agree to take part in the study, you will be asked to:

- Choose a day and time to meet me in person to pick up a research kit in advance of our meeting

- Complete the research kit before we meet in person

- Meet with me in person to talk about your experiences

We will always meet at a location convenient to you.

The kit may take you two hours to complete depending on how much detail you provide.

When we meet in person to discuss your experiences, our conversation should not take longer than an hour.

Drinks and snacks will be provided during our meeting.

To participate in the study, please reply by [date] or go to [study link] before [date of recruitment end].

If you know of anyone else who may be interested in participating, please forward this email to them.

For more information about this study, please go to [URL].

If you have any questions, please do not hesitate to get in touch with me directly at Samantha.lovelace@carleton.ca.

All the best, 


\section{RESEARCH INVOLVING VERY LOW RISK}

Canada's Capital University

Samantha Lovelace

Master of Design Student

Carleton University

Samantha.lovelace@,carleton.ca

\section{Research Supervisors:}

Chantal Trudel, Carleton University, School of Industrial Design

Email: chantal.trudel@carleton.ca

Dr. Paul Thibaudeau, Carleton University, Department of Anthropology and Sociology

Email: paul.thibaudeau@carleton.ca 


\section{RESEARCH INVOLVING VERY LOW RISK}

\section{Appendix D-2: Sample social media posts}

The following are two sample social media posts that may be used to attract participants from the researcher's social network and the networks of their peers. Social media posts will be a secondary form of recruitment.

\section{Social media posts: Sample}

\section{Twitter post:}

Working for the government of Canada on the development of programs, policies, services or products? In the National Capital Region?

Over 18 ?

Join a study exploring factors influencing design implementation within the Government of Canada. [study link]

\#GCDesign

\section{LinkedIn post:}

Working for the government of Canada on the development of programs, policies, services or products?

Interested in contributing to research exploring factors that contribute to the success or failure of design projects within the federal public service?

I am conducting a study that aims improve our understanding of factors that may influence design processes and implementation of services within government and how we might increase opportunities for successful design implementation.

In order to be eligible for the study you must currently work for the federal public service as a designer or design researcher or have been involved in the development of a program, policy, service or product.

You must also be in the National Capital Region to participate and be 18 years of age or older.

If you agree to take part in the study, you will be asked to:

- Choose a day and time to meet me in person

Pick up a research kit one week in advance of our meeting

- Complete the research kit before we meet in person

- Meet with me in person to talk about your experiences

We will always meet at a location convenient to you.

The kit may take you two hours to complete depending on how much detail you provide.

When we meet in person to discuss your experiences, our conversation should not take longer than an hour.

Drinks and snacks will be provided during our meeting (with the exception of participants online). 


\section{RESEARCH INVOLVING VERY LOW RISK}

To participate in the study, please go to [study link] before [date of recruitment end].

Look forward to exploring with you! 


\section{RESEARCH INVOLVING VERY LOW RISK}

Canada's Capital University

\section{Appendix D-3: Wireframes for the web site containing participation sign up link and research information}

The following wireframes model the proposed website where interested participants may indicate their interest in participating in the study and learn more about the study and the research.

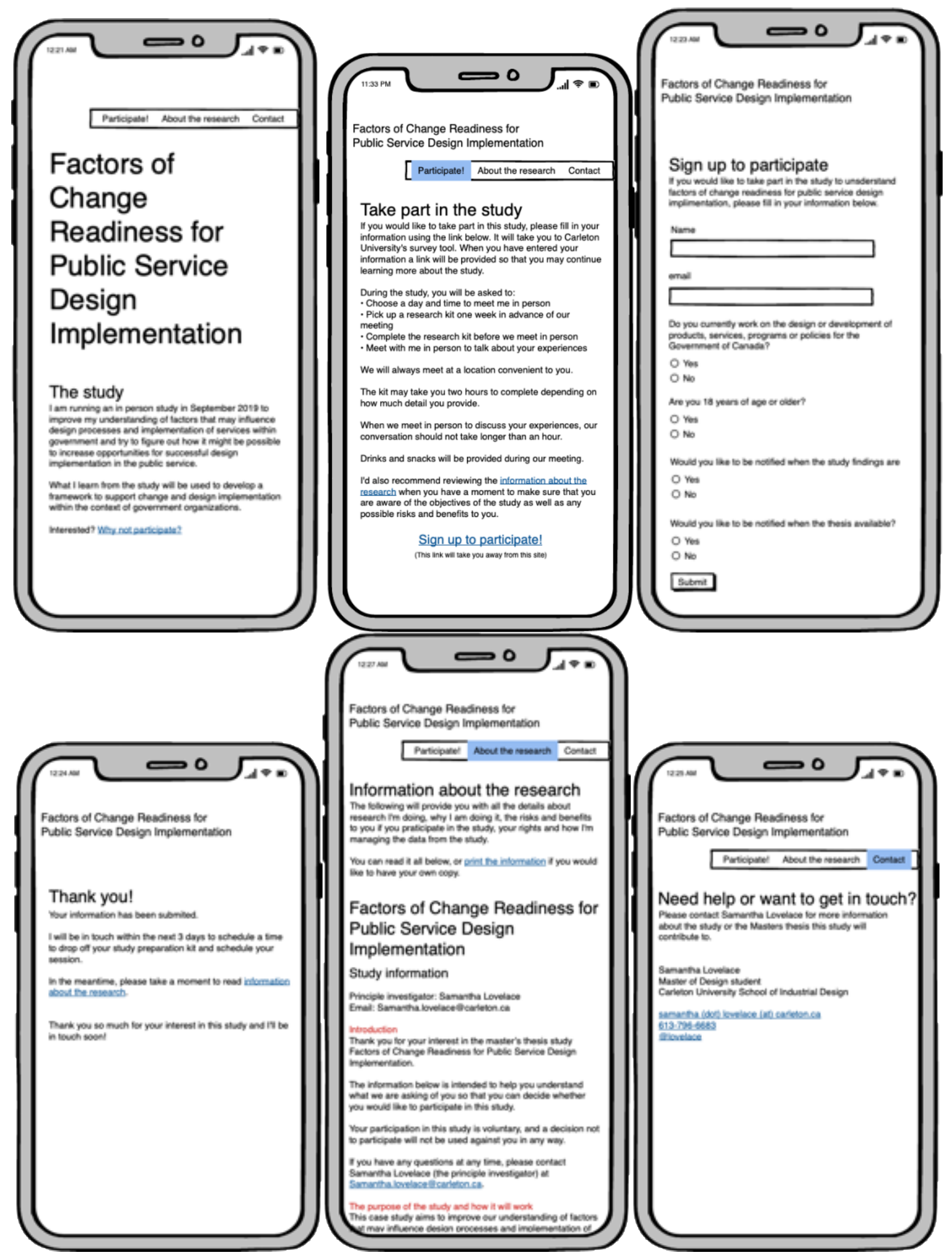




\section{RESEARCH INVOLVING VERY LOW RISK}

\section{Appendix E - Kit materials}

The following attachments are samples of the content to be provided in the kit that participants will receive in advance of the study.

Attachments include:

- Appendix E-1: Study information for consent

- Appendix E-2: Contact card

- Appendix E-3: Sample study summary, in-person session agenda and kit instructions

- Appendix E-4: Workbook content (for both successful and unsuccessful projects)

- Appendix E-5: Pictures of the kit prototype 


\section{RESEARCH INVOLVING VERY LOW RISK}

\section{Appendix E-1: Study information for consent}

The information that will be provided to participants in the kit about the study. This same information will be used for consent during the study. Please also see Appendix F-1: Consent form.

\section{Study information document: Sample}

\section{Factors of Change Readiness for Public Service Design Implementation}

Study information

Principle investigator: Samantha Lovelace

Email: Samantha.lovelace@carleton.ca

\section{Introduction}

Thank you for your interest in the master's thesis study Factors of Change Readiness for Public Service Design Implementation.

You have been invited to take part in this study because you work on or have worked on design projects (program, policy, service or product development projects) within the Canadian Federal Public Service, you are located in the National Capital Region and you are over 18 years of age.

The information below is intended to help you understand what will be asked of you so that you can decide whether you would like to participate in this study. Your participation in this study is voluntary, and a decision not to participate will not be used against you in any way.

If you have any questions at any time, please contact Samantha Lovelace (the principle investigator) at Samantha.lovelace@carleton.ca.

\section{The purpose of the study and how it will work}

This case study aims to improve our understanding of factors that may influence design processes and implementation within the Government of Canada and how we might increase opportunities for successful design implementation.

Findings from this study will be used to develop a framework to support change and design implementation within the context of federal government organizations.

If you agree to take part in the study, you will be asked to complete a research kit provided by the principle investigator (Samantha Lovelace) and participate in a one hour, in-person session where you will be asked to share your experiences working on design projects in the Government of Canada.

To complete this research kit, you will be asked to: 


\section{RESEARCH INVOLVING VERY LOW RISK}

- Pick a date and time for your in-person session

- Meet the principle investigator to pick up your research kit (participants who are not in the Ottawa area will receive a digital version of the kit)

- Use the tools provided in the kit to share your experiences with a successful and unsuccessful project you worked on

- Map the factors that contributed to the outcomes for each of your project experiences using a Mind Mapping template

To participate in the in-person session you will need to:

- Meet the principle investigator (Samantha Lovelace) on the scheduled day and time

- Have your consent form (signed and dated) and research kit (with both completed workbooks and maps) with you

During the in-person session:

- This study information will be reviewed with you

- You will be asked about your experiences and the Mind Maps you created

- You will be asked to reflect on what you would do differently or would repeat in your next project(s) and why

The completion of the research kit is required to participate in this study. If for whatever reason you don't feel like it is possible to complete the workbooks or maps in time for the in-person session, please contact Samantha Lovelace (the principle investigator) at Samantha.lovelace@carleton.ca as soon as possible to make alternate arrangements.

The principle investigator may ask to take photographs (or screen captures) during the session. Allowing the principle investigator to take photographs (or screen captures) during the session is voluntary and you may optout of having photos taken at any time.

The conversation during the session the session may be recorded for quality assurance purposes. Allowing the principle investigator to record the session is optional and you may ask that the session is not recorded at any time.

Physical workbooks and maps will be collected at the end of the session, however, if you would like to keep any of the completed tools, please let the principle investigator know. Images of the tools will be taken, and you can take the documents with you.

A few things to note:

- We will always meet at a location convenient to you. If you are participating online, please choose a place where you can comfortably sit during our conversation.

- The kit may take you two hours to complete depending on how much detail you provide.

- When we meet in person to discuss your experiences, our conversation should not take longer than an hour.

- Beverages and snacks will be available during the session (with the exception of online sessions). 


\section{RESEARCH INVOLVING VERY LOW RISK}

\section{Risks and possible benefits}

The Government of Canada has not been made aware of this study and it is not known what it's views on the subject matter might be. As such, all information in this study is anonymous and no information will be able to be tied back to you or your organization. As a member of the Canadian Public service, the protection of your identity is top priority.

You are not likely to receive any direct benefit from your participation in this study. However, your participation may allow researchers and designers to better understand what needs to be considered when they are exploring or working on solutions in the context of the public service and this study may provide indirect benefits to the public by improving design development processes undertaken by the Government of Canada.

\section{Compensation and your rights, withdrawing and data protection}

You will not be paid or otherwise financially compensated for your participation in this study, but your participation is highly valued.

By agreeing to participate in this study you are not waiving any rights or releasing the researchers from any liability. The principle investigator is accountable for the collection, storage and protection of any and all information you provide as well as the study results.

All research data collected as a result of this study will be treated as confidential.

You can withdraw from this study at any before the completion of the in-person session and your decision not to participate will not be used against you in any way.

You will be able to withdraw your research data up to two (2) weeks following the completion of the in-person session, at which point, all research data collected will be anonymized. During the anonymization process, any information provided during the study that could identify you, your organization, you team or your project will be removed or redacted. No specific details about the context of the projects will be reported on.

The principle investigator will provide you with a unique code the day of the study session as well as a withdrawal date. You may request that your data is withdrawn from the study up until and including this date. To withdraw from the study before the in-person session, please contact the principle investigator (Samantha Lovelace) at Samantha.lovelace@carleton.ca . To withdraw from the study after the in-person, please contact the principle investigator and reference your unique code.

The unique code referred to above will only be used by the principle investigator to find your specific data in the collection and note verbal consent to participate in this study for record keeping purposes. Codes and personally identifying data such as your name and email will be kept in a separate file and will only be accessed by the principle investigator. 


\section{RESEARCH INVOLVING VERY LOW RISK}

All research data collected as a result of this study will be treated as confidential.

All digital research data will be stored on a password protected hard drive stored in a secure location. Physical research data (including notes and anything taken away from the study) will be stored in a secure location when not in use. All research data will be deleted five (5) years after the study completes.

Images taken the day of the study may be included as examples in the thesis. You will not be able to be identified from the photographs, however, please let the principle investigator know if you do not want pictures of your Mind Maps to be used.

For in-person session run offline: The in-person session may be recorded using an audio recorder to ensure that the information shared in the session is accurately transcribed and nothing is missed. The audio files will be store on a password protected hard drive in a secure location and will only be used for quality assurance purposes. If you do not want the session to be recorded, please let the principle investigator know.

For in-person sessions run online: The remote in-person session may be recorded using the built in recording software supplied with the video conferencing software. This recording is being taken to ensure that the information shared in the session is accurately transcribed and nothing is missed. The video files will be downloaded and stored on a password protected hard drive in a secure location and will only be used for quality assurance purposes. If you do not want the session to be recorded, please let the principle investigator know.

The principle researcher will be using Zoom video conferencing software. According to Zoom's website (https://blog.zoom.us/wordpress/2018/01/04/zoom-opens-canadian-data-center/) the organization uses a Canadian data centre, unless there is a disruption of service (in which case they switch to American servers temporarily. This means that the video conference will be streamed using the Canadian data centre and that the meeting information will be stored within that Canadian data centre. Zoom does not, however, store the meeting. Video recordings are also not stored in the data centre. Instead they are automatically saved to the researcher's computer. If for whatever reason (due to disruption of service in Canada, data type or otherwise, the meeting data is stored on a US server, it is important to note that data transmitted and stored on American servers may be disclosed via a court order or data breach.

Research records may be accessed by the Carleton University Research Ethics Board (CUREB) in order to ensure continuing ethics compliance, however, as there is no personally identifying information linked to research data, no information that discloses your identity will be released or published. If there is any opportunity for you to be identifiable through your data, the principle researcher will ensure that that identifying information is removed from data in advance of analysis.

The results of this study may be published in publicly accessible publications or presented at conferences or meetings, but the data will be presented so that it will not be possible to identify any participants. 


\section{RESEARCH INVOLVING VERY LOW RISK}

\section{Ethics review}

This project was reviewed and cleared by the Carleton University Research Ethics Board B. Should you have any ethical concerns with the study, please contact the REB Chair, Carleton University Research Ethics Board-B (by phone: 613-520-2600 ext. 4085 or by email: ethics@carleton.ca). For all other questions about the study, please contact the researcher.

Clearance \#: $111330 \quad$ Date of Clearance: August 30, 2019

\section{Name and Contact Information of Researchers:}

\section{Principle investigator:}

Samantha Lovelace, Carleton University, School of Industrial Design

Tel.:

Email: samantha.lovelace@carleton.ca

\section{Supervisors:}

Chantal Trudel, Carleton University, School of Industrial Design

Email: chantal.trudel@carleton.ca

Dr. Paul Thibaudeau, Carleton University, Department of Anthropology and Sociology

Email:paul.thibaudeau@carleton.ca 


\section{RESEARCH INVOLVING VERY LOW RISK}

Canada's Capital University

\section{Appendix E-2: Contact card}

A card that will be available in the kit incase participants need to contact the principle investigator.

\section{Need Help?}

Have questions, concerns,

want more information or just want to say "Hi!"?

Don't hesitate to get in touch :)

Samantha Lovelace

Masters of Design Student

Carleton University

Samantha_lovelace@earleton.ca

613-796-6683

(i) lovelace

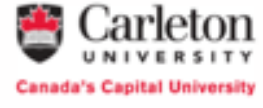

Canada's Capital University 


\section{RESEARCH INVOLVING VERY LOW RISK}

Canada's Capital University

\section{Appendix E-3: Sample study summary, in-person session agenda and kit instructions}

The following are samples of the study summary, in-person agenda and kit instructions. The summary, agenda and instructions will be printed and provided in an envelope in the kit for the participants reference.

\section{Study summary: Sample}

\section{Tell me a story!}

Activity summary

Thank you again for your interest in this study and your willingness to participate in the Factors of Change Readiness for Public Service Design Implementation research study.

During this study you will be asked to:

- Tell a story about a project that was successful and a project that was not successful

- Do a Mind Mapping exercise for each of your projects

This is a two-part study exploring factors that contribute to project success in the public service. Completing this kit is the first part of the study.

In the second part, we will meet in person to explore your stories in detail.

If you have questions or need more information, do not hesitate to get in touch with me, Samantha Lovelace, at Samantha.lovelace@carleton.ca or using the information on the contact card.

Thank you again and have fun!

Sincerely,

Samantha Lovelace

Master of Design Student

Carleton University

\section{Kit instructions: Sample}

Tell me a story!

How to use this kit.

Completing the workbooks and maps in this kit is the first part of the study. In the second part, we will meet in person to discuss your stories and their related maps to learn more about elements that impact project success and failure.

In this kit you will find all of the tools that you might need to complete the first part of this study. 


\section{RESEARCH INVOLVING VERY LOW RISK}

- The detailed study information and consent form

- The study summary

- These instructions

- Details for the in-person discussion

- Two packages containing a workbook, a Mind Map template and Mind Map stickers (one package for a successful project and one for an unsuccessful project)

You will also find writing tools, stickers and Post-its, and a card with contact information for questions or further information.

\section{Steps to use this kit}

1.Open and review the study information and sign and date the consent form

a. To begin, please take a moment to review the study information provided with this kit.

b. If you feel that you understand the research objectives, benefits and risks of the study, please sign and date the consent form and set it aside. You will need this form to complete the second part of the study.

c. If you have any questions or concerns about the study information, please contact Samantha Lovelace using the contact information provided.

2. Review the Activity Summary and these kit instructions and Prepare for the in-person discussion

a. You will find a card in this kit containing details for your in-person discussion

i. Please review the information and make sure you have an appointment for the session in your calendar

b. Put you signed and dated consent form, the workbooks and maps back in the kit so you can bring them to the in-person discussion

c. Come ready to tell some stories!

Thank you so much for your participation and contribution to this work. I look forward discussing your experiences soon!

Sincerely,

Samantha Lovelace

Master of Design Student

Carleton University

\section{In-person discussion agenda: Sample}

Let's talk!

\section{Details for your in-person discussion}

Study session date:

Study session time: 


\section{RESEARCH INVOLVING VERY LOW RISK}

Study session location:

\section{Agenda}

_._. : Meet Samantha at the session location

_ _ _ : Get settled and review the details of the study and the in-person discussion

____ : Exercise 1: Tell me a story about a successful project and the map

_ : _ : Exercise 2: Tell me a story about an unsuccessful project and the map

_ _ : Wrap up

If you have questions or need more information, get in touch with Samantha Lovelace using the information on the contact card. 


\section{RESEARCH INVOLVING VERY LOW RISK}

Canada's Capital University

\section{Appendix E-4: Workbook content (For both successful and unsuccessful projects)}

The following questions will be provided in workbooks found in the kit. The questions will be the same for the workbook for the successful project and the unsuccessful project.

\section{Sample Questions:}

- Tell me a short story about a project you worked on for the Government of Canada that was really successful/unsuccessful.

- What were the project objectives? What were you and/or your team trying to do?

- Who worked on the project with you and who was indirectly involved in the project?

- What happened at the end of the project? What were the project outcomes?

- Why was this project a success/unsuccessful?

- Is there anything else about this project that you would like to share? 


\section{RESEARCH INVOLVING VERY LOW RISK}

\section{Appendix E-5: Pictures of one kit prototype}

The following images show the preliminary prototype of the kit to be provided to participants to familiarize themselves with the study and prepare for participation in the in-person session. The type of packaging of the kit and supplies provided within may change slightly.

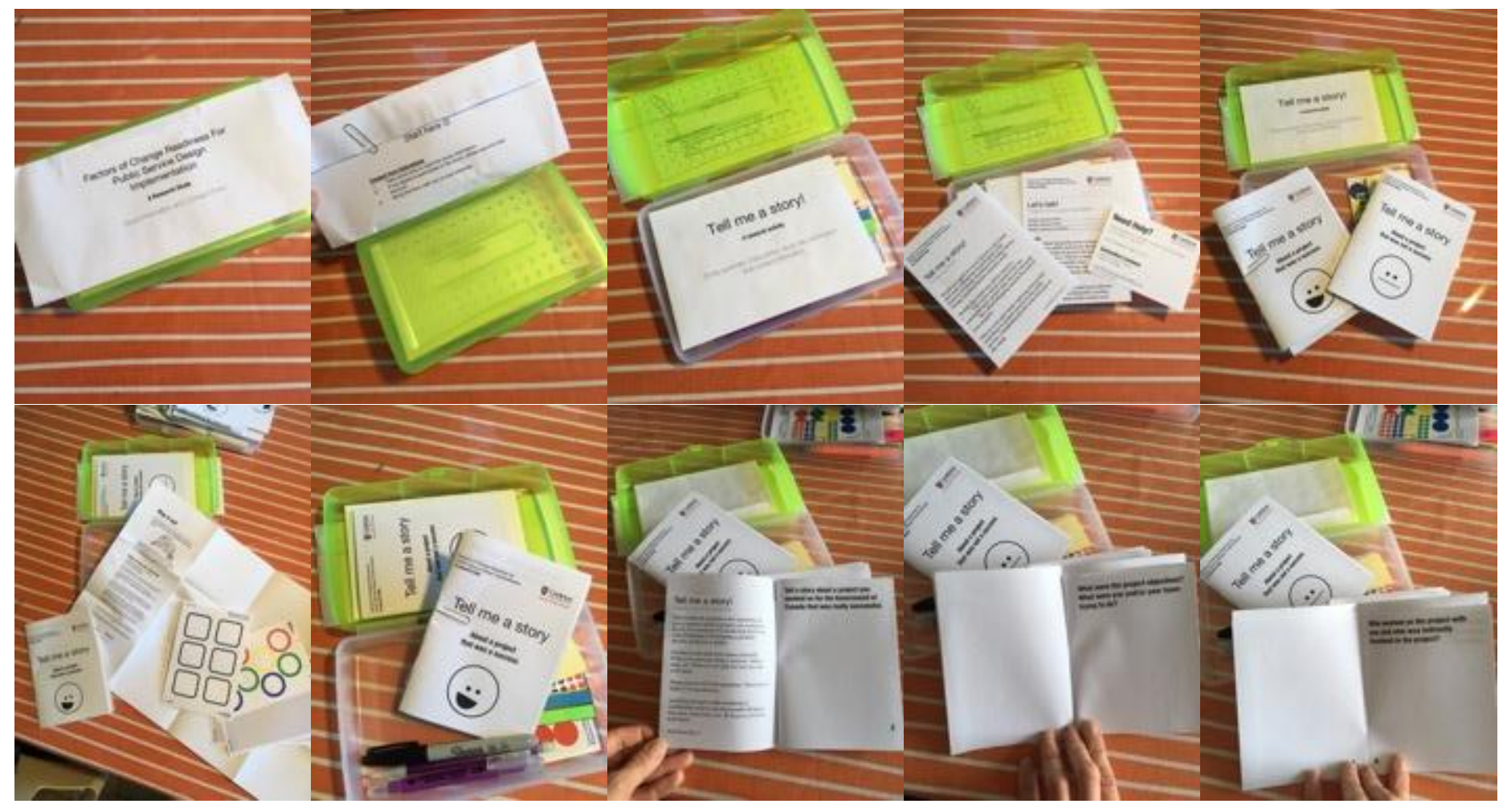




\section{RESEARCH INVOLVING VERY LOW RISK}

Canada's Capital University

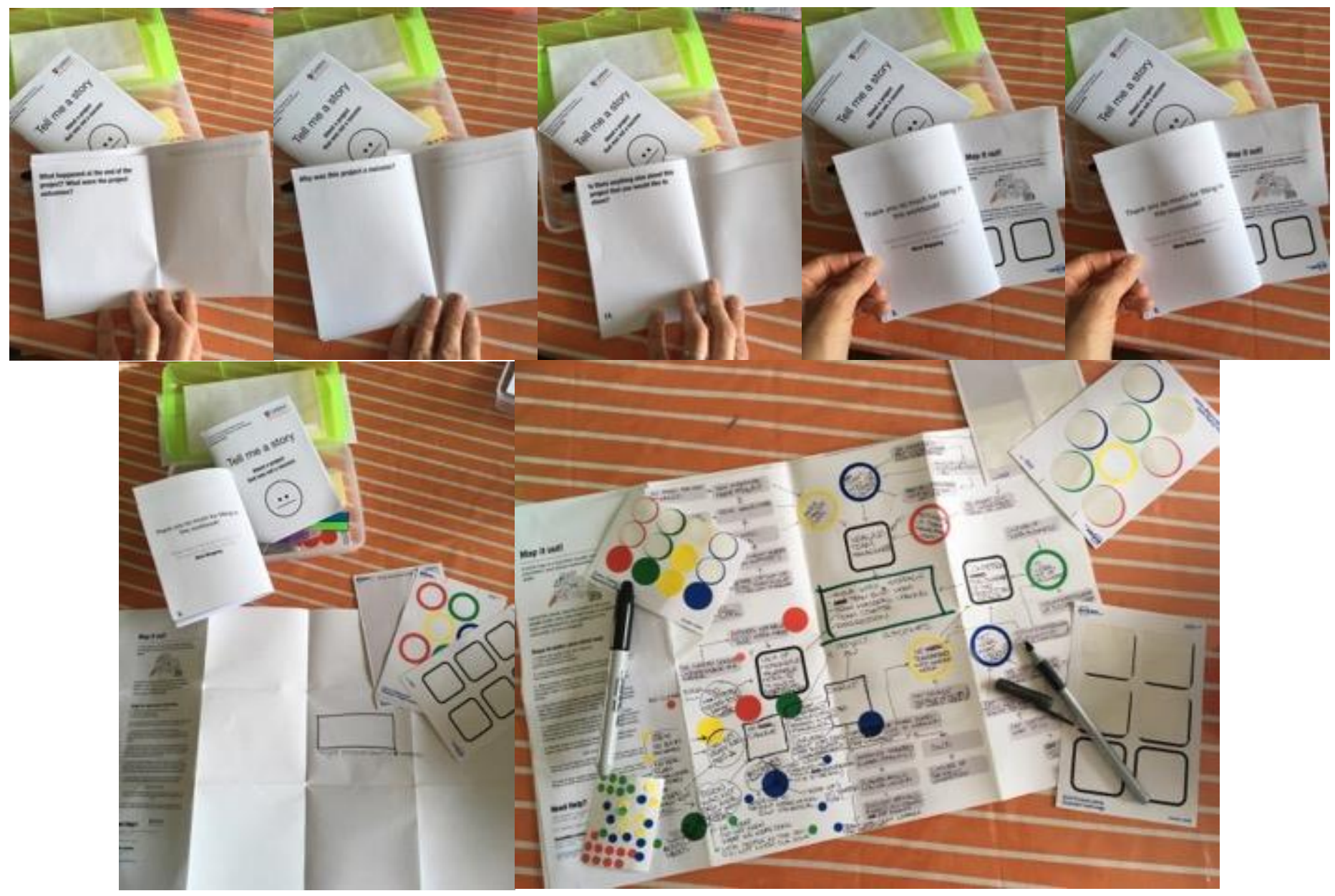




\section{RESEARCH INVOLVING VERY LOW RISK}

\section{Appendix F - Study Session Materials}

The following attachments are samples of the materials that will be used during the study session.

Attachments include:

- Appendix F-1: Study information, Consent Form and Statement of Consent

- Appendix F-2: Session script and interview questions

- Appendix F-3: Sample code key 


\section{RESEARCH INVOLVING VERY LOW RISK}

Canada's Capital University

Appendix F-1: Study information, Consent Form and Statement of Consent The following study information will be available on the participant intake website and summarized for participants prior to beginning the in-person session. Copies of the information will also be available at the session if participants would like to take a copy for their records. The study information will be followed by a consent form.

The Statement of Consent form will be given to participants as a record of their consent and as reference document containing their unique reference code, the date by which they can withdraw their data from the study and contact information for the principle investigator, research team and the Carleton University Research Ethics Board (CUREB).

Study information: Sample

\section{Factors of Change Readiness for Public Service Design Implementation}

Study information and statement of consent

Principle Investigator: Samantha Lovelace

Email: Samantha.lovelace@carleton.ca

\section{Introduction}

Thank you for your interest in the master's thesis study Factors of Change Readiness for Public Service Design Implementation.

You have been invited to take part in this study because you work on or have worked on design projects (program, policy, service or product development projects) within the Canadian Federal Public Service, you are located in the National Capital Region and you are over 18 years of age.

The information below is intended to help you understand what we are asking of you so that you can decide whether you would like to participate in this study. Your participation in this study is voluntary, and a decision not to participate will not be used against you in any way.

If you have any questions at any time, please contact Samantha Lovelace (the principle investigator) at Samantha.lovelace@carleton.ca.

\section{The purpose of the study and how it will work}

This case study aims to improve our understanding of factors that may influence design processes and implementation of services within government and how we might increase opportunities for successful design implementation. 


\section{RESEARCH INVOLVING VERY LOW RISK}

Findings from this study will be used to develop a framework to support change and design implementation within the context of government organizations.

If you agree to participate in this study, you will be asked to complete a research kit provided by the principle investigator (Samantha Lovelace) and participate in a one hour, in-person session where you will be asked to share your experiences working on design projects in the Government of Canada.

To complete the research kit you will be asked to:

- Pick a date and time for your in-person session

- Meet the principle investigator to pick up your research kit (participants who are not in the Ottawa area will receive a digital version of the kit)

- Use the tools provided in the kit to share your experiences with a successful and unsuccessful project you worked on

- Map the factors that contributed to the outcomes for each of your project experiences using a Mind Mapping template

To participate in the in-person session you will need to:

- Meet the principle investigator (Samantha Lovelace) on the scheduled day and time

- Bring your consent form (signed and dated) and research kit (with both completed workbooks and maps)

During the in-person session:

- This study information will be reviewed with you

- You will be asked about your experiences and the Mind Maps you created

- You will be asked to reflect on what you would do differently or would repeat in your next project(s) and why

The completion of the workbooks and maps are required to participate in this study. If for whatever reason you don't feel like it is possible to complete the workbooks or maps in time for the in-person session, please contact Samantha Lovelace (the principle investigator) at Samantha.lovelace@carleton.ca as soon as possible to make alternate arrangements.

The principle investigator may ask to take photographs during the session. Allowing the principle investigator to take photographs during the session is voluntary and you may opt-out of having photos taken at any time.

The workbooks and maps will be collected at the end of the session, however, if you would like to keep any of the completed tools, please let the principle investigator know. Images of the tools will be taken, and you can take the documents with you.

We will always meet at a location convenient to you.

The kit may take you two hours to complete depending on how much detail you provide.

When we meet in person to discuss your experiences, our conversation should not take longer than an hour. 


\section{RESEARCH INVOLVING VERY LOW RISK}

Beverages and snacks will be available during the session (with the exception of online sessions).

\section{Risks and possible benefits}

The Government of Canada has not been made aware of this study and it is not known what it's views on the subject matter might be. As such, all information in this study is anonymous and no information will be able to be tied back to you or your organization. As a member of the Canadian Public service, the protection of your identity is top priority.

You are not likely to receive any direct benefit from your participation in this study. However, your participation may allow researchers and designers to better understand what needs to be considered when they are exploring or working on solutions in the context of the public service and this study may provide indirect benefits to the public by improving design development processes undertaken by the Government of Canada.

\section{Compensation and your rights, withdrawing and data protection}

You will not be paid or compensated for your participation in this study, but your participation is highly valued.

By agreeing to participate in this study you are not waiving any rights or releasing the researchers from any liability. The principle investigator is accountable for the collection, storage and protection of any and all information you provide as well as the study results.

You can withdraw from this study at any time before we finish today and your decision not to participate will not be used against you in any way.

Once the study is done, you will be able to withdraw your data at any point up to and including

\section{Date}

If you wish to withdraw your data, please contact the principle investigator at Samantha.lovelace@carleton.ca and reference your personal code

\section{Code}

All research data collected as a result of this study will be treated as confidential.

You will be able to withdraw your research data up to two (2) weeks following the completion of the in-person session, at which point, all research data collected will be anonymized. During the anonymization process, any information provided during the study that could identify you, your organization, you team or your project will be removed or redacted. No specific details about the context of the projects will be reported on. 


\section{RESEARCH INVOLVING VERY LOW RISK}

All digital research data will be stored on a password protected hard drive stored in a secure location. Physical research data (including notes and anything taken away from the study will be stored in a secure location when not in use. All research data will be deleted five (5) years after the study completes.

Images taken the day of this study may be included as examples in the thesis. You will not be able to be identified from your photographs, however, please let the principle investigator know if you do not want pictures to be taken or used.

The in-person session may be recorded using an audio recorder to ensure that the information shared in the session is accurately transcribed and nothing is missed. The audio files will be store on a password protected hard drive in a secure location and will only be used for quality assurance purposes. If you do not want the session to be recorded, please let the principle investigator know.

For in-person sessions run online: The remote in-person session may be recorded using the built in recording software supplied with the video conferencing software. This recording is being taken to ensure that the information shared in the session is accurately transcribed and nothing is missed. The video files will be downloaded and stored on a password protected hard drive in a secure location and will only be used for quality assurance purposes. If you do not want the session to be recorded, please let the principle investigator know.

The principle researcher will be using Zoom video conferencing software. According to Zoom's website (https://blog.zoom.us/wordpress/2018/01/04/zoom-opens-canadian-data-center/) the organization uses a Canadian data centre, unless there is a disruption of service (in which case they switch to American servers temporarily. This means that the video conference will be streamed using the Canadian data centre and that the meeting information will be stored within that Canadian data centre. Zoom does not, however, store the meeting. Video recordings are also not stored in the data centre. Instead they are automatically saved to the researcher's computer. If for whatever reason (due to disruption of service in Canada, data type or otherwise, the meeting data is stored on a US server, it is important to note that data transmitted and stored on American servers may be disclosed via a court order or data breach.

Research records may be accessed by the Carleton University Research Ethics Board (CUREB) in order to ensure continuing ethics compliance, however, as there is no personally identifying information linked to research data, no information that discloses your identity will be released or published. If there is any opportunity for you to be identifiable through your data, the principle researcher will ensure that that identifying information is removed from data in advance of analysis.

The results of this study may be published in publicly accessible publications or presented at conferences or meetings, but the data will be presented so that it will not be possible to identify any participants.

\section{Ethics review}

This project was reviewed and cleared by the Carleton University Research Ethics Board B. Should you have any ethical concerns with the study, please contact the REB Chair, Carleton University Research Ethics 


\section{RESEARCH INVOLVING VERY LOW RISK}

Board-B (by phone: 613-520-2600 ext. 4085 or by email: ethics@carleton.ca). For all other questions about the study, please contact the researcher.

Clearance \#: $111330 \quad$ Date of Clearance: August 30, 2019

Name and Contact Information of Researchers:

Principle investigator:

Samantha Lovelace, Carleton University, School of Industrial Design

Tel.:

Email: samantha.lovelace@carleton.ca

\section{Supervisors:}

Chantal Trudel, Carleton University, School of Industrial Design

Email: chantal.trudel@carleton.ca

Dr. Paul Thibaudeau, Carleton University, Department of Anthropology and Sociology

Email:paul.thibaudeau@carleton.ca 


\section{Consent Form: Sample}

\section{Factors of Change Readiness for Public Service Design Implementation}

Study information and statement consent

Principle Investigator: Samantha Lovelace

Email: Samantha.lovelace@carleton.ca

\section{Consent Form}

If you agree to participate in Factors of Change Readiness for Public Service Design Implementation research project, please identify if photographs may be taken, if you are okay with the session being recorded, sign and then date this form.

Is it okay for photographs to be taken during the in-person session: $\quad$ Yes $\quad$ No

Is it okay for the session to be recorded using an audio/video recorder:

Yes

No 


\section{Consent Form: Sample}

\section{Factors of Change Readiness for Public Service Design Implementation}

Study information and statement consent for online participants

Principle Investigator: Samantha Lovelace

Email: Samantha.lovelace@carleton.ca

\section{Consent Form}

If you agree to participate in Factors of Change Readiness for Public Service Design Implementation research project, please identify that you agree to participate below. Please also note if photographs may be taken, if you are okay with the video and audio from the session being recorded. Once you have identified your consent, please sign and then date this form.

Do you agree to participate in this study: Yes No

Is it okay for photographs to be taken during the in-person session:

Yes

No

Is it okay for the session to be recorded using an audio/video recorder:

Yes

No

Is it okay for the session to be recorded using a video recorder:

Yes

No 


\title{
RESEARCH INVOLVING VERY LOW RISK
}

Canada's Capital University

\section{Statement of Consent Form: Sample}

\section{Factors of Change Readiness for Public Service Design Implementation}

\author{
Consent form
}

Principle Investigator: Samantha Lovelace

Email: Samantha.lovelace@carleton.ca

\section{Statement of Consent}

Factors of Change Readiness for Public Service Design Implementation is a research project to improve our understanding of factors that may influence design processes and implementation of services within government and how we might increase opportunities for successful design implementation.

The study you participated in required that you share two experiences you had working on Government of Canada design projects.

The study is anonymous and the information you shared will remain confidential.

You agreed to participate in the study on:

For reference, the code that has been assigned to your data is

\section{Code}

If you wish to withdraw from this study for any reason, please contact the principle investigator (Samantha Lovelace) before

\author{
Withdraw date
}

Please keep a copy of this Statement of Consent for your records and use the code noted above if you wish to withdraw from the study or discuss your data with the principle investigator.

Thank you for participating. 


\section{RESEARCH INVOLVING VERY LOW RISK}




\section{RESEARCH INVOLVING VERY LOW RISK}

Should you have any ethical concerns with the study, please contact the REB Chair, Carleton University Research Ethics Board-B (by phone: 613-520-2600 ext. 4085 or by email: ethics@carleton.ca). For all other questions about the study, please contact the researcher.

Clearance \#: $111330 \quad$ Date of Clearance: August 30, 2019

\section{Name and Contact Information of Researchers:}

\section{Principle investigator:}

Samantha Lovelace, Carleton University, School of Industrial Design

Tel.:

Email: samantha.lovelace@carleton.ca

\section{Supervisors:}

Chantal Trudel, Carleton University, School of Industrial Design

Email: chantal.trudel@carleton.ca

Dr. Paul Thibaudeau, Carleton University, Department of Anthropology and Sociology

Email:paul.thibaudeau@carleton.ca 


\section{RESEARCH INVOLVING VERY LOW RISK}

Canada's Capital University

\section{Appendix F-2: Session script and interview questions}

The following script and interview questions will be used to facilitate the in-person session. The script contains a slightly modified version of the information for consent and prompts the participant to provide their written consent form prior to beginning the study activities.

\section{Study script: Sample}

\section{Factors of Change Readiness for Public Service Design Implementation}

Session script and interview questions

Introduction and consent (15 mins)

Introduction

$(<5$ mins $)$

Hello!

Thank you for joining me today.

We're here today to talk about your experiences as a person who does design work on projects within the federal public service so I can learn more about what factors may influence the design process and implementation within the Government of Canada.

Before we get started, I'd like to go over a few things to make sure you understand why we are here today and to confirm that you are aware of your options as a participant.

This session should take one hour. If you need to take a break at any time, please don't hesitate to let me know. You may also withdraw at any time if you no longer wish to participate.

\section{Consent}

( 7 mins)

\section{The purpose of the study and how it will work}

This case study aims to improve our understanding of factors that may influence design processes and design implementation within the Government of Canada and how we might increase opportunities for successful design implementation.

Findings from this study will be used to develop a framework to support change and design implementation within the context of government organizations. 


\section{RESEARCH INVOLVING VERY LOW RISK}

In our session today, you will be asked about your experiences and the Mind Maps you created and then I will ask you to reflect on what you would do differently or would repeat in your next project(s) and why

I may ask to take photographs during the session. This is voluntary and you may opt-out of having photos taken at any time. I would also like to record our session today to make sure I don't make any mistakes or miss anything. If you do not wish to be recorded, that is completely fine! Please just let me know.

I will also collect the workbooks and maps at the end of the session, but if you would like to keep any of your tools, please let me know. I'll take pictures of them and you can take them with you.

\section{Risks and possible benefits}

As you know, the Government of Canada has not been made aware of this study and it is not known what it's views on the subject matter might be. As such, all information in this study is anonymous and no information will be able to be tied back to you or your organization. As a member of the Canadian Public service, the protection of your identity is my top priority.

You are not likely to receive any direct benefit from your participation in this study. However, your participation may allow researchers and designers to better understand what needs to be considered when they are exploring or working on solutions in the context of the public service and this study may provide indirect benefits to the public by improving design development processes undertaken by the Government of Canada.

\section{Compensation, withdrawing and data protection}

You will not be paid or compensated for your participation in this study, but your participation is highly valued.

You can withdraw from this study at any time before we finish today and your decision not to participate will not be used against you in any way.

Once the study is done, you will be able to withdraw your data at any point up to and including

\section{Date}

If you wish to withdraw your data, please get in touch with me by email and reference your personal code

\section{Code}

Finally, the results of this study may be published in publicly accessible publications or presented at conferences or meetings, but it will not be possible to identify you or any other participants.

That's it, do you have any questions?

Great! Before I go on, I'd just like to confirm that you: 


\section{RESEARCH INVOLVING VERY LOW RISK}

- Understand the study objectives

- Understand the risks

- Understand the benefits

Can you please confirm that you understand these three things?

I'll also take your signed consent form now. Do you have it with you?

[If the participant has not signed their consent form] Can you please take a moment to review sign this consent form?

Thank you. Here is a copy of the study information if you would like it for your records. I've also included a statement of consent form for you. It contains a short summary of what we did today, today's date, your unique code and the withdraw date. Please keep it handy in case you decide you'd like to withdraw from the study.

Once the withdraw date has passed, I'll no longer be able to separate your data from the study as the information will be anonymized, so it's important to keep this date in mind if you are unsure about participating.

Do you have any questions about consent, withdrawing or the study in general?

Okay, great! Let's get started.

Today I will be asking you to tell me about the two stories about projects you worked on while working for the Government of Canada that had to do with designing or developing a product, service, policy or program.

- First, I'll get you to tell me about your successful project and show me the map you created.

- Then we'll talk about anything that you would do again or differently

- When we're done, we'll repeat this exercise for your unsuccessful project

Do you have any questions before we get started?

[if the participant is okay with recording] Great. I'm now going to start recording.

\section{Study questions (50 mins)}

(25 minutes per project: 10 minutes for storytelling and 3015 minutes talking about the map and what would or would not do again)

○ Okay, we'll start with your successful project.

- Tell me a short story about it.

Okay, thank you. Now tell me a little more.

-What were the project objectives? What were you trying to do? 


\section{RESEARCH INVOLVING VERY LOW RISK}

- What happened at the end of the project? What was the outcome?

○ Who worked on the project with you and who was indirectly involved in the project?

○ Why do you feel like this project was a success/unsuccessful?

Okay, thanks again. This has been great. Next, I'll get you to show me your map for this project.

○ Tell me about what you came up with.

○ If you could do anything differently or repeat anything on your next project, what would it be? Why?

Okay, wow. What a story! Thank you so much for sharing it.

Before we move on, I just want to take a moment to go over what I heard to make sure I've captured your main points.

Did I miss anything?

Okay, great. Now we'll move on to your next project.

○ Okay, same as before, tell me a short story, about your unsuccessful project. about it.

Okay, thank you. Now tell me a little more.

○ What were the project objectives? What were you trying to do?

○ What happened at the end of the project? What was the outcome?

○ Who worked on the project with you and who was indirectly involved in the project?

○ Why do you feel like this project was a success/unsuccessful?

Okay, thanks again. This has been great. Next, I'll get you to show me your map for this project.

○ Tell me about what you came up with.

○ If you could do anything differently or repeat anything on your next project, what would it be? Why?

Thank you so much for sharing this story. It's incredible to hear about the work people do and how it turns out.

Same as last time, before we move on, I just want to take a moment to go over what I heard to make sure I've captured your main points.

Did I miss anything?

Great. This has been very insightful. Thank you so much for taking the time to talk to me today.

Is there anything else you'd like to share before we wrap up? 


\section{RESEARCH INVOLVING VERY LOW RISK}

\section{Thank you and wrap up ( $<5$ mins)}

Thank you so much for your interest in this study and your time today. I can't tell you how much I appreciate it.

If you have any questions at any time, please don't hesitate to get in touch. My contact information is on the consent form if you have questions, concerns or would just like to chat.

Thanks again and have a great day! 


\section{RESEARCH INVOLVING VERY LOW RISK}

Canada's Capital University

\section{Appendix F-3: Sample code key}

The following table is an example of the code key that will be used to generate a unique identifier for each participant in the study. This database will be stored separately from the research data.

\begin{tabular}{|c|c|c|c|c|c|c|c|}
\hline ID & $\begin{array}{l}\text { Participant } \\
\text { Name }\end{array}$ & Participant email & $\begin{array}{l}\text { Confirmation } \\
\text { of eligibility }\end{array}$ & $\begin{array}{l}\text { Reference } \\
\text { code } \\
\text { (="P"\& } \\
\text { randbetwe } \\
\text { en }(1000 \text {, } \\
5000)\end{array}$ & $\begin{array}{l}\text { Kit } \\
\text { delivery } \\
\text { date, } \\
\text { time \& } \\
\text { location }\end{array}$ & $\begin{array}{l}\text { Study } \\
\text { date, } \\
\text { time \& } \\
\text { location }\end{array}$ & $\begin{array}{l}\text { Verbal } \\
\text { consent } \\
\text { receive } \\
\text { d }\end{array}$ \\
\hline 1 & $\begin{array}{l}\text { Jane } \\
\text { Smith }\end{array}$ & Janesmith@canada.ca & $\mathrm{y}$ & P4278 & $\begin{array}{l}09 / 09 / 20 \\
19,1 \mathrm{pm}, \\
\text { Starbuck } \\
\text { s } \\
\text { Metcalfe } \\
\text { and } \\
\text { Slater }\end{array}$ & $\begin{array}{l}\text { 16/09/20 } \\
19,9 \mathrm{am}- \\
10: 30 \mathrm{am}, \\
\text { Hub } \\
\text { Ottawa }\end{array}$ & Y \\
\hline 2 & Joe Brown & Joe123456@BrownJoe.com & $\mathrm{y}$ & P7299 & $\begin{array}{l}07 / 09 / 20 \\
19,9 \mathrm{am}, \\
140 \\
\text { Laurier } \\
\text { AVE W }\end{array}$ & $\begin{array}{l}14 / 09 / 20 \\
19, \\
12 \mathrm{pm}- \\
1: 30 \mathrm{pm}, \\
140 \\
\text { Laurier - } \\
\text { meet in } \\
\text { the lobby }\end{array}$ & $\mathrm{y}$ \\
\hline 3 & $\begin{array}{l}\text { Sarah } \\
\text { Murphy }\end{array}$ & Meandmyself78@gmail.com & $\mathrm{n}$ & & & & \\
\hline$\ldots$ & $\ldots$ & $\ldots$ & $\ldots$ & & & .. & \\
\hline
\end{tabular}

